\title{
Car sharing in Wellington, New Zealand: benefits and barriers
}

\author{
Lucia Sobiecki
}

A thesis submitted to Victoria University of Wellington in partial fulfilment of the requirements for the degree of Master's in Environmental Studies

School of Geography, Environment and Earth Sciences

Victoria University of Wellington

June 2017 

Sprawling urban development and high levels of car dependency in New Zealand have resulted in a range of adverse impacts, including increased greenhouse gas emissions and air pollution. Car sharing can support compact development and sustainable transport patterns by providing a potential alternative to car ownership. Despite the increasing popularity of car sharing overseas, it is still in the early stages of development in New Zealand. There is a growing body of international literature about car sharing; however, very little has been written about car sharing in the New Zealand context. This thesis contributes to the literature by exploring car sharing in Wellington. This study has adopted a mixed method approach, surveying Wellington residents about car sharing and interviewing car share stakeholders. The findings from this research indicate that car sharing is a transport innovation which offers Wellington significant benefits. Perhaps most importantly, car sharing can reduce car ownership and usage, which in turn can help reduce congestion, demand for parking and greenhouse gas emissions. In addition, this study provides evidence that the people most interested in car sharing in Wellington have similar characteristics to car share members overseas. This includes younger people, apartment dwellers, households without children, and people who use a car occasionally but do not necessarily own one. This thesis also highlights that car sharing is complementary to alternative modes of transport, and underlines the close connection between car sharing and modern technologies such as automated booking. The findings from this research indicate that car share providers face a range of barriers, including access to public parking and financial assistance. Progress has already been made to remove barriers facing car sharing but more support for car sharing could allow Wellington to take full advantage of its benefits.

Key words: compact development; sustainable transport; car sharing; benefits; barriers; Wellington; New Zealand; mixed methods 

First of all, thank you to all the survey and interview participants for taking the time to contribute to my research. This research would not have been possible without your help.

My Master's thesis was funded through a scholarship from the New Zealand Centre for Sustainable Cities Resilient Urban Futures Programme, which is funded by the Ministry of Business, Innovation, and Employment. I am very grateful for this assistance.

I cannot thank my supervisor Ralph Chapman enough. I could not have written this thesis without your guidance. Your advice and support has been invaluable. I have come a long way since I started this Master's programme, and I am very grateful for the opportunities you have given me and the difficulties you have helped me overcome.

To all my friends and fellow postgrads, thank you for your constant encouragement and understanding. This year would have been much harder without your kindness and humour. Special thanks to Rebecca Nuttall for proofing my thesis and for being a wonderful friend and flatmate throughout the course of this study.

To my parents, you have always inspired me to work hard and educate myself. Thank you for trusting my decisions and never doubting my ability. I am blessed to be your daughter.

Finally, to my partner Andy. Every day you have supported me without fail, protecting both my sanity and happiness. Thank you for all your help and for making me feel like I was never on this journey alone. 



\section{Contents}

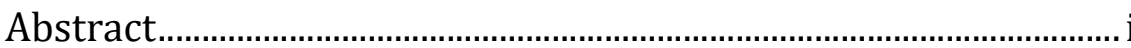

Acknowledgements .......................................................................... ii

List of figures ................................................................................. vii

List of tables ....................................................................................... ix

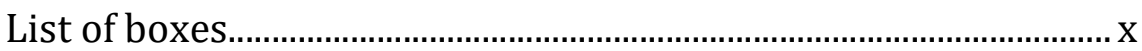

Chapter 1 Introduction ....................................................................... 1

Chapter 2 Literature review …....................................................... 5

2.1. What is car sharing? ........................................................ 5

2.2. Car sharing overview …………................................... 11

2.3. The benefits of car sharing ........................................... 13

2.4. Who uses car sharing? ................................................ 19

2.5. Car sharing and compact living................................... 20

2.6. Car sharing and sustainable transport...................... 22

2.7. Car sharing and modern technologies ...................... 25

2.8. The barriers facing car sharing ..................................... 26

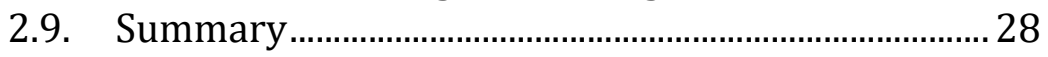

Chapter 3 Study context ................................................................ 29

3.1. Auckland and Wellington ............................................ 29

3.2. Car share policies in New Zealand .............................. 32

3.3. Car share providers in New Zealand.......................... 33

3.4. New Zealand car share research ............................... 35

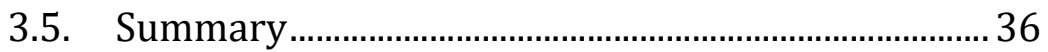

Chapter 4 Research gap and study framework ...............................37

Chapter 5 Research aim and questions ............................................ 40

Chapter 6 Methodology ......................................................................... 41

6.1. Research worldview......................................................... 41

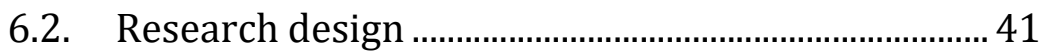

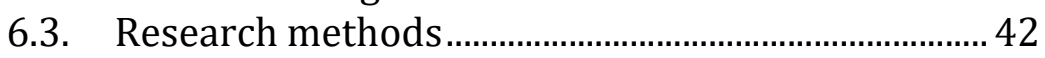

6.4. Data collection limitations ............................................ 51

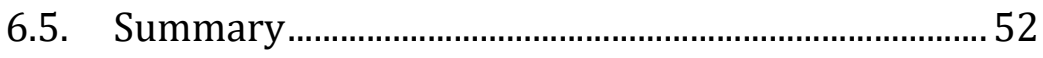

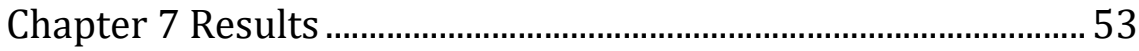

7.1. Survey sample characteristics..................................... 54

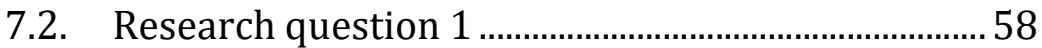

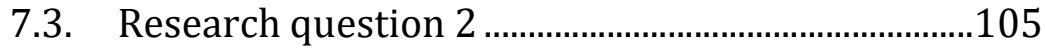

7.4. Summary .....................................................................122 
Chapter 8 Discussion and conclusion............................................ 125

8.1. Research question 1 .................................................. 125

8.2. Research question 2 ............................................ 135

8.3. Strengths, limitations and future research............. 138

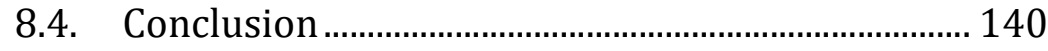

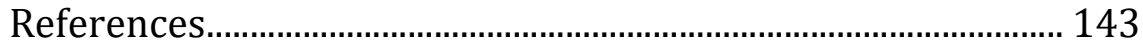

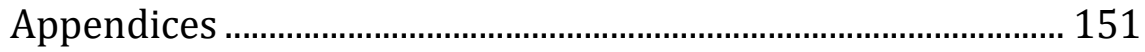

Appendix A Ethics approval letter .....................................151

Appendix B Online survey.................................................152

Appendix C Interview forms............................................... 163

Appendix D Thematic maps................................................ 167

Appendix E Multinomial regression analysis................. 169

Appendix F Full Metlink fare zone map............................. 175 


\section{List of figures}

Figure 2.1. Neighbourhood car sharing (adapted from Barth and Shaheen (2002), Figure 1, p. 106).

Figure 2.2. Station based car sharing (adapted from Barth and Shaheen (2002), Figure 2, p. 107).

Figure 2.3. Point-to-point car sharing (adapted from Barth and Shaheen (2002), Figure 3, p. 107)...

Figure 2.4. Car sharing's role in the transport system based on flexibility and distance (adapted from Britton (1999), Figure i, p. 9).

Figure 2.5. Car sharing's role in the transport network based on access and privacy values (adapted from Nawangpalupi and Demirbilek (2008), Figure 1, p. 3).

Figure 3.1. Number of vehicles per household on census day 2013.

Figure 3.2. Mode of transport for travel to work on census day 2013.

Figure 4.1. Study framework.

Figure 6.1. Phases of thematic analysis (adapted from Braun and Clark (2006), Table 1, p.35).

Figure 7.1. Place of Residence of the survey sample $(n=355)$ compared with 2013 census data for the Wellington Region

Figure 7.2. Gender of the survey sample $(n=355)$ compared with 2013 census data for the Wellington Region 55

Figure 7.3. Age Group of the survey sample $(n=355)$ compared with 2013 census data for the Wellington Region ........ 56

Figure 7.4. Personal Income Before Tax of the survey sample $(\mathrm{n}=356)$ compared with 2013 census data for the Wellington Region

Figure 7.5. Highest Qualification of the survey sample $(n=356)$ compared with 2013 census data for the Wellington Region

Figure 7.6. Benefits of car sharing …………………............................. 58

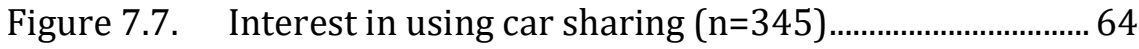

Figure 7.8. Interest in using car sharing by place of residence

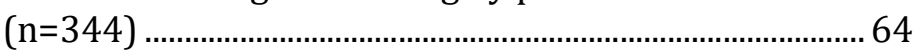

Figure 7.9. Interest in using car sharing by gender $(n=345) \ldots \ldots . . . . .65$ 
Figure 7.10. Interest in using car sharing by age group ( $n=344) \ldots . .66$

Figure 7.11. Interest in using car sharing by personal income before tax $(n=339)$

Figure 7.12. Interest in using car sharing by highest qualification $(n=342)$

Figure 7.13. Interest in using car sharing by employment $(n=345)$

Figure 7.14. Interest in using car sharing by household type $(n=345)$

Figure 7.15. Interest in using car sharing by dwelling type $(n=345)$

Figure 7.16. Interest in using car sharing by neighbourhood density ( $\mathrm{n}=345)$

Figure 7.17. Interest in using car sharing by access to a car $(n=345)$

Figure 7.18. Interest in using car sharing by car ownership $(n=345)$

Figure 7.19. Interest in using car sharing by car use $(n=345) \ldots \ldots . . . . .74$

Figure 7.20. Multinomial logistic regression model ............................. 75

Figure 7.21. Potential car share users .................................................... 78

Figure 7.22. Metlink fare zones 1-6, adapted from Greater Wellington Regional Council (2016)

Figure 7.23. Interest in using car sharing by Metlink fare zone $(n=345)$

Figure 7.24. Interest in using car sharing by access to parking at place of residence $(n=342)$ 84

Figure 7.25. Interest in using car sharing by access to parking at place of work or study $(n=303)$

Figure 7.26. Importance of high density for car sharing... .87

Figure 7.27. Interest in car sharing by main mode of transport to work or study $(n=317)$.

Figure 7.28. Interest in car sharing by main mode of transport to do grocery shopping $(n=337)$.

Figure 7.29. Interest in car sharing by main mode of transport to regular leisure activities $(n=341)$

Figure 7.30. Importance of public transport, walking and cycling for car sharing.

Figure 7.31. Interest in using car sharing by level of agreement with the statement 'if car sharing used electric 
vehicles, I would be more likely to use the service' $(\mathrm{N}=345)$

Figure 7.32. Interest in using car sharing by level of agreement with the statement 'if car sharing used smartphone technology for locating and booking vehicles, I would be more likely to use the service' $(\mathrm{N}=345)$......101

Figure 7.33. Importance of modern technologies for car sharing..102

Figure 7.34. The survey respondents' level of agreement with a range of statements regarding concerns with car sharing $(\mathrm{N}=346)$.

Figure 7.35. Concerns with using car sharing.......................................107

Figure 7.36. Encouragements for using car sharing ...........................112

Figure 7.37. The main barriers facing car sharing in Wellington...118

Figure C.1. Thematic map of the interview results 167

Figure C.2. Thematic map of the results from the open-ended survey questions

\section{List of tables}

Table 2.1. Guideline for where car sharing succeeds (MillardBall et al. (2005) Exhibit 3-15, p. 3-40)............................. 21

Table 2.2. $\quad$ Car sharing as a middle option between not owning a car and car ownership (adapted from Litman (2000), Figure 1, p. 32).

Table 6.1. Organisation and number of participants interviewed............................................................................... 49

Table 7.1. Model fitting information ………………………………..... 76

Table 7.2. Likelihood ratio tests............................................................. 77

Table 7.3. Spearman's rank-order correlation matrix: parking

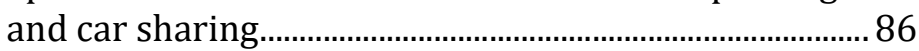

Table 7.4. Spearman's rank-order correlation matrix: car ownership, travel preferences and car sharing..............94

Table E.1. Multicollinearity including all variables ...........................170

Table E.2. Multicollinearity without location, highest qualification and access to a car ........................................170

Table E.3. Parameter Estimates .........................................................173 


\section{List of boxes}

Box 7.1. Reduces congestion and demand for parking ................. 59

Box 7.2. Reduces GHG emissions .................................................... 59

Box 7.3. Encourages the uptake of other transport modes.......... 60

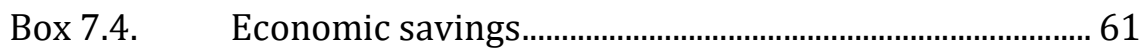

Box 7.5. Local economy benefits....................................................... 61

Box 7.6. Improves transport choices................................................. 62

Box 7.7. Sustainability and behaviour change................................. 62

Box 7.8. Young people ........................................................................ 79

Box 7.9. 'Smart' or with a 'millennial mind-set' ................................ 80

Box 7.10. Car ownership is expensive/inconvenient in higher-density areas............................................................... 88

Box 7.11. Higher-density areas provide better access to amenities and have more transport choices..................... 88

Box 7.12. It is easier to build a car share network in higher-

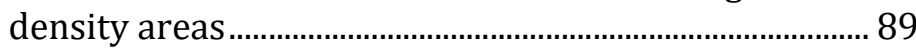

Box 7.13. There are more parking constraints in higherdensity areas 89

Box 7.14. Public transport, walking and cycling enable people to not own a car ....................................................................... 98

Box 7.15. Car share encourages the uptake of public transport, walking and cycling ............................................. 98

Box 7.16. Car share fills a gap in the transport network ................ 99

Box 7.17. Public transport, walking and cycling compete with car sharing ............................................................................ 99

Box 7.18. Benefits of car sharing stand on their own .....................102

Box 7.19. EVs are added risk/complication.....................................103

Box 7.20. EVs are exciting and the future ......................................104

Box 7.21. Difficult with children, installing car seats.....................108

Box 7.22. Availability and proximity of the car share vehicles..108

Box 7.23. Safety, maintenance and types of vehicles available..109

Box 7.24. Affordability of car sharing versus car ownership......109

Box 7.25. Being organised, emergencies ..........................................110

Box 7.26. Insurance, damage and theft............................................110 
Box 7.27. Sharing with other people, cleanliness of the vehicles.

Box 7.28. Operational concerns ……………………………………....111

Box 7.29. Environmental impact ........................................................112

Box 7.30. Affordability .....................................................................113

Box 7.31. Restrictions on car ownership..........................................113

Box 7.32. Availability, proximity and convenience .........................114

Box 7.33. Flexibility ...........................................................................114

Box 7.34. Electric vehicles, reduced emissions................................115

Box 7.35. Avoid car purchase............................................................115

Box 7.36. Different vehicle types, installed car seats ......................116

Box 7.37. Advertising, promotions and recommendations.........116

Box 7.38. Cost calculator ..................................................................117

Box 7.39. Community car share .......................................................117

Box 7.40. Access to parking …………………………………….......119

Box 7.41. Car culture, cost of car ownership .................................120

Box 7.42. Awareness .........................................................................121

Box 7.43. Small population.................................................................121 



\section{Chapter 1 Introduction}

Rapid mass urbanisation is a phenomenon transforming the way people live across the globe. More than half of the world's population live in urban areas, and this is expected to increase to over 60 percent by 2050 (IPCC, 2014). This unprecedented urban expansion is leading to enormous risks associated with locking in energy intense patterns of transportation and urban form for decades to come (Floater et al., 2014; Rode et al., 2014). The world's urban areas account for over 70 percent of energy-related carbon dioxide $\left(\mathrm{CO}_{2}\right)$ emissions (IPCC, 2014). Transport in cities is the largest single source of transport-related $\mathrm{CO}_{2}$ emissions in the world, and the largest source of local urban air pollution (Rode et al., 2014). The provision of sustainable transport systems is critical for tackling climate change and reducing local air pollution in the world's cities (Rode et al., 2014).

Transport and urban development are closely connected. There are two main development pathways that cities can follow - dispersed or compact development. Dispersed development is characterised by sprawling lower density urban form and high car dependence (Rode et al., 2014). This development pathway can adversely impact economic productivity by increasing transport costs and reducing accessibility (Floater et al., 2014; Rode et al., 2014). In addition, it can result in negative impacts on health, wellbeing and social inclusion, as well as increasing energy inefficiency, greenhouse gas (GHG) emissions, and air pollution (Floater et al., 2014; Racioppi, Dora, \& Rutter, 2005; Rode et al., 2014; The New Climate Economy, 2014). In contrast, compact development is characterised by higher density, mixed-use urban form and the promotion of alternative, more sustainable modes of transport, including public transport, walking and cycling (Floater et al., 2014; Rode et al., 2014). Compact urban development, alongside a sustainable transport system, can increase economic productivity, improve public health and wellbeing, increase social equity, increase energy efficiency, and reduce GHG emissions and air pollution (Floater et al., 2014; Rode et al., 2014; The New Climate Economy, 2014).

Car sharing is an emerging transport innovation which can support compact living and sustainable transport patterns by offering a potential alternative to private 
vehicle ownership. Car sharing refers to a system in which a fleet of vehicles are used throughout the day by different individuals. The basic premise is that vehicle costs and usage are shared amongst a group of people (Barth \& Shaheen, 2002). Car sharing can reduce car ownership and vehicle kilometres travelled (VKT) which in turn can help decrease congestion, demand for parking and GHG emissions (Martin \& Shaheen, 2010; Shaheen \& Cohen, 2013). Car sharing can also facilitate the uptake of alternative transport modes and improve people's transport choices (Litman, 2000; Martin \& Shaheen, 2011b). Individuals and businesses can make significant savings by forgoing car ownership in favour of car sharing (Litman, 2000). Due to these benefits, car sharing has been adopted extensively around the world. As of 2014, car sharing was operating in 33 countries, five continents, and an estimated 1,531 cities with approximately 4.8 million users sharing over 104,000 vehicles (Shaheen \& Cohen, 2016).

Despite the benefits of car sharing and its popularity overseas, it is still in the early stages of development in New Zealand. Car sharing is not well known or widely used, especially outside Auckland and Wellington. New Zealand is highly urbanised, with 86 percent of New Zealanders living in cities and towns (Early, HowdenChapman, \& Russell, 2015). The development of New Zealand's main cities has been characterised by urban sprawl and high levels of car dependency, driven in part by preferences for standalone housing with private backyards (Early et al., 2015). New Zealand has one of the highest rates of car ownership per capita of countries in the Organisation for Economic Co-operation and Development (OECD) (OECD, 2013). In 2013, 76 percent of households had one or two vehicles, and over 16 percent had three or more vehicles (Statistics New Zealand, 2013). This dispersed development and high level of car dependency has resulted in a range of adverse impacts for the country, including increased GHG emissions and air pollution. In 2013, road transport contributed over 40 percent of total emissions from the energy sector in New Zealand (Ministry for the Environment, 2017).

Many of New Zealand's main urban centres have pursued, with varying levels of success, the concept of developing more compact, resilient urban forms (Early et al., 2015). Car sharing has the potential to support this transition towards compact living and sustainable transport patterns. There is a growing body of international 
literature on car sharing, especially outlining the benefits that have resulted from the service in cities overseas. In contrast, very little has been written about car sharing in the New Zealand context. This study aims to contribute to the literature by exploring car sharing in New Zealand, specifically in Wellington. It aims to identify potential benefits of car sharing in Wellington, especially whether car sharing can support compact living and sustainable transport patterns in the central city. This includes examining the importance of high density, alternative transport modes and modern technologies for the success of car sharing in Wellington. This study also contributes to the literature by examining the barriers facing car sharing in Wellington, and how these barriers might be overcome.

The remainder of this thesis is structured as follows. Chapter 2 reviews the international literature on car sharing. Chapter 3 examines car sharing in the New Zealand context, including the country's car share policies, car share providers, and the available research on car sharing in the New Zealand context. Chapter 4 describes the research gap and the study framework for this thesis. This is followed by the research aim for this study and research questions in Chapter 5. Chapter 6 describes the methodological approach of this study. Chapter 7 outlines the main results of this study, which are then discussed in Chapter 8 with reference to the international evidence. Chapter 8 also discusses the strengths and limitations of this project, and avenues for future research. This is followed by a conclusion summarising the key contributions of this research to the literature. 



\section{Chapter 2 Literature review}

This chapter provides a review of the international literature on car sharing. This includes an outline of the different types of car sharing, an overview of the history of car sharing, market developments and emerging trends, the benefits of car sharing, who uses car sharing, the relationship between car sharing and compact living, sustainable transport and modern technologies, the main barriers facing car sharing and how these barriers can be overcome.

Car sharing has been operating in New Zealand for approximately ten years; however, the service is still not widely used or well-known, particularly outside of Auckland and Wellington. As such, there is very little research on car sharing in New Zealand, and limited publicly available information on New Zealand-based car share providers and car share users. Therefore, this chapter focuses on the international literature on car sharing practices. Information about car sharing in New Zealand is covered in the study context chapter (Chapter 3).

\subsection{What is car sharing?}

The term 'car sharing' does not have a standardised definition (Le Vine, Zolfaghari, \& Polak, 2014). In general, car sharing refers to a system in which a group of people share a fleet of vehicles. The basic premise is that vehicle costs and usage are shared amongst the group (Barth \& Shaheen, 2002). Individuals can benefit from having access to a car without the responsibilities and costs of private vehicle ownership (Shaheen \& Cohen, 2013). Internationally, car sharing encompasses a range of business and operational models, including schemes run by for-profit companies, community cooperatives, and not-for-profit organisations (Dowling \& Kent, 2015). In the United Kingdom (UK), car sharing refers to carpooling or ridesharing (multiple people travelling together in a private vehicle at the same time). The term 'car clubs' is used in the UK to refer to what is elsewhere known as car sharing (Le Vine et al., 2014). 
Le Vine, Zolfaghari and Polak (2014) have compiled a comprehensive list of the characteristics frequently associated with car sharing. In general, the authors suggest that car sharing includes the following:

- The user of a car share service must first go through a verification process to gain membership with the car share provider. Once approved for membership, the member can gain access to the car share vehicles without interacting with staff of the organisation each time.

- The member drives the car share vehicle themselves, as with traditional car rental, as opposed to a taxi service. Car share vehicles tend to be models that are not complicated to operate, as with traditional rental cars.

- Car share vehicles can typically be used by the minute or hour, and therefore, usage is billed accordingly. This is opposed to traditional rental cars which generally are rented and billed by the day. Some providers allow full-day or multi-day usage at discounted rates.

- Car share services also usually have a sign-up fee or annual subscription fee, on top of the usage charge.

- Some car share services enable spontaneous pick-up whereas others require reservations in advance.

- Car share vehicles are typically distributed throughout a city or neighbourhood. For example, car share vehicles might be parked across a residential neighbourhood, at employment centres and at transit hubs. This contrasts with traditional car rental in which vehicles are only available from a small number of storefront or airport locations.

- Servicing and cleaning of car share vehicles is undertaken by the organisation's staff on an occasional basis, rather than after each usage. The organisation may incentivise members to re-fuel and keep vehicles clean.

Most descriptions of car sharing in the literature refer to some or all of these characteristics (Barth \& Shaheen, 2002; Kent \& Dowling, 2013; Shaheen \& Cohen, 2013). In addition, Shaheen and Cohen also state that car share operators tend to manage their services with modern technologies. This may include automated 
reservations, smart-card vehicle access, and real-time vehicle tracking (Shaheen \& Cohen, 2013).

While car sharing generally incorporates the elements listed above, there are still several business models of car sharing which have significant differences. The three main business models are 'round-trip', 'point-to-point' and 'peer-to-peer' car sharing. These are briefly described below.

\subsubsection{Round-Trip}

'Round-trip' car sharing (also commonly referred to as 'traditional' car sharing) is the most established type of car sharing and has been studied the most extensively (Le Vine et al., 2014). It is known as 'round-trip' as the user must return the car to the same place it was accessed, and pay for the entire time between when they gain access to the car and when they return it (Le Vine et al., 2014). In this model, the fleet of car share vehicles is generally owned (or leased) by a professional car share operator (Le Vine et al., 2014).

Round-trip car sharing can also be divided into either 'neighbourhood' or 'station' based car sharing models (Barth \& Shaheen, 2002). Neighbourhood car sharing refers to a system where the car share vehicles are dispersed across a neighbourhood. Station based car sharing refers to a model where the fleet of car share vehicles are based at busy transport hubs, such as railway stations. The station based system is a way of increasing public transport patronage by offering dedicated cars for journeys to and from public transport hubs (Barth \& Shaheen, 2002). Figures 2.1 and 2.2 are adapted from Barth and Shaheen (2002), and indicate how round-trip car sharing operates for both neighbourhood and station based models. 


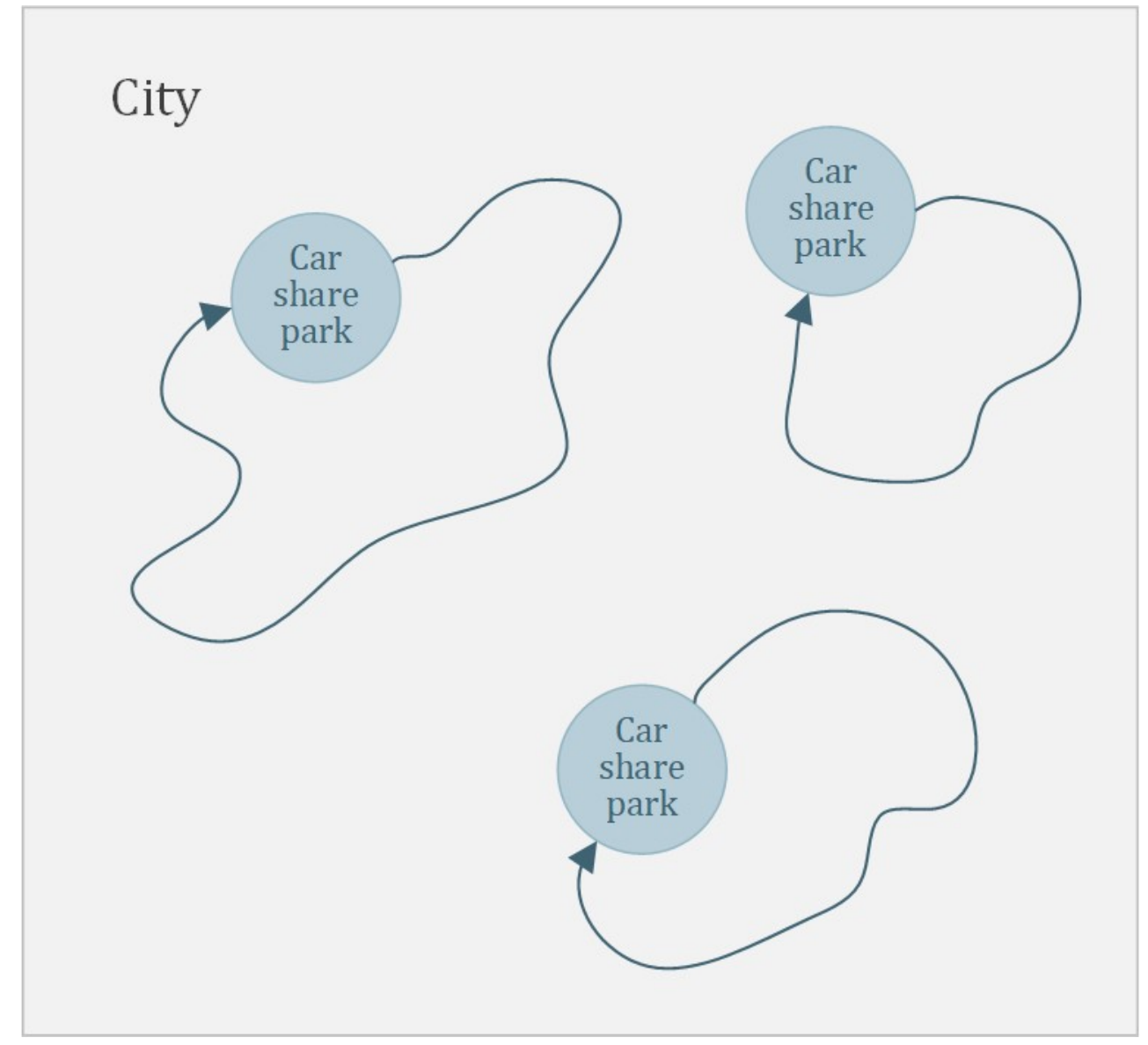

Figure 2.1. Neighbourhood car sharing (adapted from Barth and Shaheen (2002), Figure 1, p. 106).

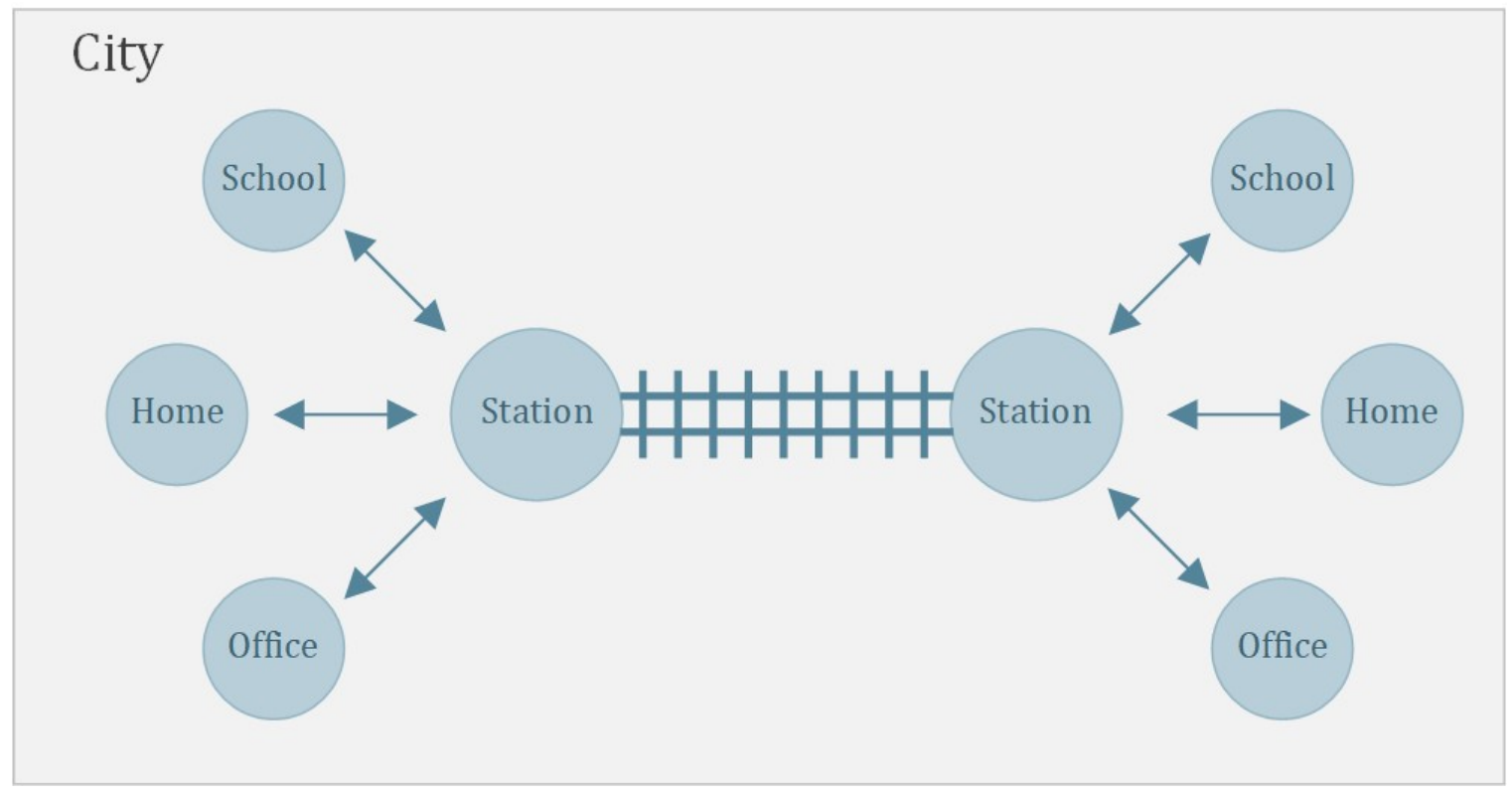

Figure 2.2. Station based car sharing (adapted from Barth and Shaheen (2002), Figure 2, p. 107). 


\subsubsection{Point-to-Point}

'Point-to-point' car sharing (also known as 'A to B' or 'one-way' car sharing) enables one-way journeys within a specified geographic zone, in contrast to round-trip car sharing. The fleet is generally owned (or leased) by a professional car share operating entity (Le Vine et al., 2014). Point-to-point usually means that users can pick up the car share vehicle from one dedicated car share park, and return it to a different dedicated car share park. Some point-to-point schemes offer free-floating car share, which means that members can park the vehicle in any legal on-street parking space. This usually requires an agreement to be formed between the car share organisation and the entity that manages on-street parking (Le Vine et al., 2014).

Point-to-point schemes with dedicated car parks are easier to manage in comparison to free-floating but provide less flexibility (Le Vine et al., 2014). Pointto-point car sharing requires careful balancing of the network, as one-way trips can disproportionately distribute cars across the network. As a result, it is sometimes necessary to relocate vehicles periodically each day so that the system operates efficiently (Barth \& Shaheen, 2002). The benefit of point-to-point car sharing in comparison to the round-trip model is that users have far greater flexibility in their travel choices (Barth \& Shaheen, 2002). Figure 2.3, adapted from Barth and Shaheen (2002), indicates how point-to-point car sharing operates. 


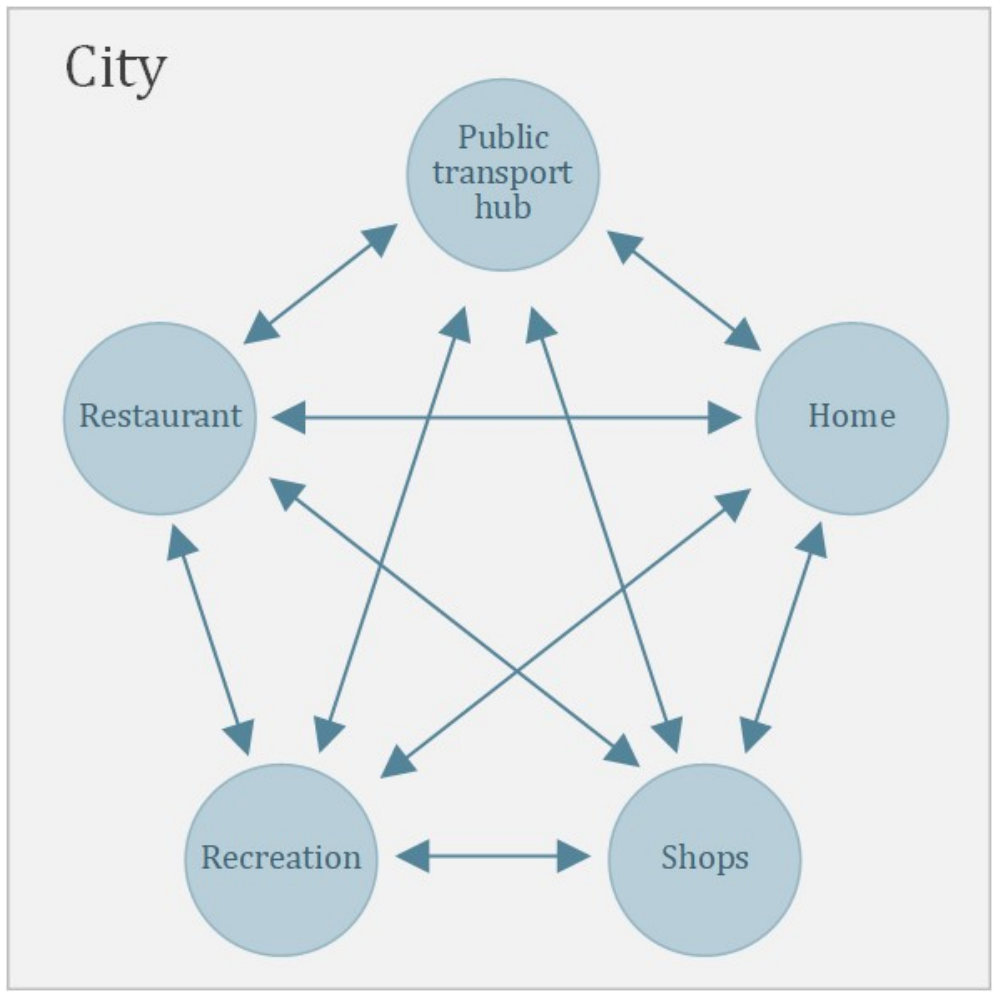

Figure 2.3. Point-to-point car sharing (adapted from Barth and Shaheen (2002), Figure 3, p. 107).

\subsubsection{Peer-to-Peer}

'Peer-to-peer' car sharing (also known as 'personal vehicle' sharing) is distinct from the other forms of car sharing in that it is de-centralised, with the vehicles owned by private individuals rather than a central operator (Le Vine et al., 2014). Individuals choose to make their personal vehicles available for others in exchange for payment. The car share organisation has to facilitate an online marketplace to connect vehicle owners with prospective renters (Le Vine et al., 2014). The organisation typically also arranges insurance that protects the car owner, and collects a percentage of each rental transaction through their online marketplace (Le Vine et al., 2014). Generally, peer-to-peer car sharing is also round-trip, requiring the vehicles to be picked up and returned to the same place. Some peer-to-peer operators install keyless technologies into the private vehicles; otherwise the vehicle-owner has to arrange to hand over the keys to the renter (Le Vine et al., 2014). 
The benefit of peer-to-peer car sharing is that the upfront costs for the car share operator are reduced because they utilise private vehicles. This means that it is more economically viable for peer-to-peer car share providers to operate in lowerdensity neighbourhoods compared to the other car share models (Hampshire \& Gaites, 2011). Peer-to-peer car sharing also gives people the opportunity to earn an income from renting out their private vehicles, which otherwise would sit idle for most of the day (Hampshire \& Gaites, 2011). However, disadvantages include liability issues for the owner and uncertainty regarding vehicle quality and reliability for the user.

\subsection{Car sharing overview}

\subsubsection{Historical overview}

Car sharing began in 1948 in Zurich, Switzerland in the form of a cooperative known as 'Sefage' (abbreviation of Selbstfahrergemeinschaft). Sefage operated until 1998 (Shaheen, Chan, \& Micheaux, 2015). It consisted of a club in which members shared vehicles, in order to spread the cost of car ownership (Shaheen et al., 2015). Sefage was a private car share service, based on friendships rather than formal agreements (Shaheen et al., 2015). A number of car sharing schemes were attempted in the 1970s and 1980s in Europe and North America (Shaheen \& Cohen, 2007). These early schemes were often short-lived demonstration projects. The aim was to exhibit car share operations and technologies, and eventually many were replaced with permanent car sharing services (Shaheen \& Cohen, 2007). One of the most successful early car share providers is the Mobility Cooperative in Switzerland, which came about as a result of a merger between two regional cooperatives in 1997 (Shaheen et al., 2015). As of 2014, the company had over 110,000 customers, 2,650 vehicles and 1,400 vehicle locations across Switzerland (Le Vine et al., 2014).

\subsubsection{Market developments}

Car sharing has now expanded worldwide. As of October 2014, car sharing was operating in 33 countries, five continents, and an estimated 1,531 cities with approximately 4.8 million users sharing over 104,000 vehicles (Shaheen \& Cohen, 2016). Europe and North America are the largest car sharing markets. In 2014, Europe accounted for 46 percent of worldwide membership and 56 percent of 
vehicle fleets. North America accounted for 34 percent of worldwide members and 23 percent of vehicle fleets (Shaheen \& Cohen, 2016). Round-trip car sharing accounted for 82.4 percent of global car share memberships, and 76.7 percent of the vehicle fleets. Point-to-point car sharing accounted for 17.6 percent of global car share membership and 23.3 percent of fleets deployed (Shaheen \& Cohen, 2016). Note that this data does not include most peer-to-peer operators (Shaheen \& Cohen, 2016). As of October 2012, there were 33 peer-to-peer operators worldwide, according to Shaheen and Cohen (2014).

\subsubsection{Emerging trends}

In recent decades, car sharing has garnered a great deal of attention as a mobility innovation (Barth \& Shaheen, 2002). It has been fostered by technological developments, such as automated booking and smart-card vehicle access. It is likely that technology will continue to play a significant role in the development of car sharing, in particular the integration of electric vehicles (EVs) and plug-in hybrid vehicles into car sharing fleets (Shaheen \& Chan, 2015; Shaheen \& Cohen, 2013). It also seems likely that in the future autonomous vehicles will provide a range of opportunities to car share providers. The ability of autonomous vehicles to reposition themselves, without human drivers, to where and when the demand is likely to be highest could be a transformative feature for car sharing (Le Vine et al., 2014).

In recent years, some of the world's largest car share operators have expanded into large multi-national organisations. Shaheen and Cohen (2013) argue that this multinationalisation and mainstreaming of car sharing will continue. They also suggest that there will be further expansion of traditional rental car providers and automakers into the car sharing market (Shaheen \& Cohen, 2013). There is also likely to be further growth in point-to-point and peer-to-peer car sharing, stronger linkages among mobility options, such as car sharing and bike sharing, and expansion into new nations and regions (Shaheen \& Cohen, 2013). 


\subsection{The benefits of car sharing}

Internationally, car sharing has resulted in a wide range of social, economic and environmental benefits. These benefits include reducing congestion and demand for parking, decreasing GHG emissions, facilitating the uptake of alternative transport modes, improving public health, economic savings, increasing people's transport choices and equity, and introducing modern technologies to the public. Many of these benefits are now substantiated by a growing body of empirical evidence, as explained briefly in this section.

\subsubsection{Reduces congestion and parking demand}

Car sharing has the potential to reduce congestion and demand for parking, as a result of reducing car ownership and VKT. Car sharing offers an alternative to car ownership, as it enables individuals to access a car without needing to own a vehicle. Shaheen and Cohen (2013) analysed a range of studies on the impact car sharing has on car ownership. They found that one car sharing vehicle reduces the need for 4 to 10 privately owned cars in Europe, 9 to 13 cars in North America, and 7 to 10 cars in Australia (Shaheen \& Cohen, 2013). They also found that in Europe 15 to 34 percent, and in North America 11 to 29 percent, of car share participants sold their private vehicle after joining car share (Shaheen \& Cohen, 2013). Clearly, car sharing can significantly reduce car ownership in households that already own one vehicle or more. However, it is also an important tool for deterring carless households from acquiring a vehicle (Martin \& Shaheen, 2011a; Martin, Shaheen, \& Lidicker, 2010). Research undertaken in North America found that 25 percent of car share members would consider purchasing a vehicle if car sharing was no longer available (Martin et al., 2010).

Individuals who join car share organisations also tend to drive car share vehicles less than they would use a private car (Shaheen \& Cohen, 2007). More importantly, Shaheen and Cohen found that car sharing reduced VKT in Europe by 28 to 45 percent, and on average by 44 percent in North America. Car sharing can, however, increase car use for households who previously did not have access to a car. But this is usually offset by the reduced VKT among drivers who would otherwise own a personal vehicle (Litman, 2000; Martin \& Shaheen, 2010). 
By decreasing VKT, car sharing can help reduce congestion (Litman, 2000). Depending on how it is evaluated, reducing congestion can result in a range of benefits, such as increasing people's productivity and cutting fuel consumption (Litman, 2017). Reducing car ownership and VKT also frees up parking spaces, helping to mitigate parking demand and freeing up valuable space for development (Litman, 2000).

\subsubsection{Reduces $\mathrm{GHG}$ emissions}

By reducing car ownership and VKT, car sharing also affects GHG emissions. Car sharing has the potential to increase emissions by enabling driving among people who previously might not have had access to a vehicle. These people might drive more than before they joined car sharing. However, car sharing can also decrease emissions by encouraging people who used to be reliant on their private vehicles to use cars more sparingly. These people usually replace private vehicle ownership with a range of travel modes, including public transport, walking and cycling, as well as car sharing (Martin \& Shaheen, 2010). Several studies have looked at the impact car sharing has had on GHG emissions; however, they often find inconsistent results due to different evaluation methods and sample sizes (Baptista, Melo, \& Rolim, 2014; Cairns \& Harmer, 2012; Firnkorn \& Müller, 2011; Martin \& Shaheen, 2010; Nijland \& van Meerkerk, 2017; Rabbitt \& Ghosh, 2016).

One of the most comprehensive studies is by Martin and Shaheen (2010). In late 2008, the authors conducted a survey of nearly 6300 members of 11 car sharing organisations throughout North America (2010). From the survey data, the authors were able to evaluate the annual rate of household GHG emissions before and after a member of the household joined car sharing (Martin \& Shaheen, 2010). The study explored the 'observed impact' on GHG emissions (the emission change that actually occurred) and the 'full impact' on GHG emissions (the observed impact as well as avoided emissions). 'Avoided emissions' refers to emissions that would have occurred in the absence of car sharing but did not because car sharing was available. In this case, avoided emissions were estimated based on forgone vehicle purchases resulting from the availability of car sharing (Martin \& Shaheen, 2010). 
The authors found that 71 percent of respondents increased emissions for the observed impact, while 29 percent decreased emissions for the observed impact. For full impact, the balance was more evenly distributed, with 53 percent increasing emissions, and 47 percent decreasing emissions. This highlights the importance of considering the full impact of car sharing, which includes avoided emissions. Importantly, the authors found that net emissions decreased, and the impact was statistically significant for both the observed and full impact. The average change across all respondents was $-0.58 \mathrm{t} \mathrm{CO}_{2}$ per household per year for the observed impact, and -0.84 $\mathrm{t} \mathrm{CO}_{2}$ per household for full impact. Car sharing facilitates large reductions in the annual emissions of some households, which compensates for the small emission increases of other households (Martin \& Shaheen, 2010).

Most car share organisations predominantly use internal combustion engine vehicles. However, a key worldwide emerging trend is the incorporation of plug-in hybrid vehicles and EVs into car share fleets (Shaheen \& Chan, 2015; Shaheen \& Cohen, 2013). This could have a significant influence on the impact car sharing has on GHG emissions, particularly in countries which have a high level of renewable electricity (Shaheen \& Chan, 2015; Shaheen \& Cohen, 2013).

\subsubsection{Facilitates the uptake of alternative transport modes}

Car sharing has the potential to facilitate change in people's travel behaviour. Car share members must pay each time they use a car share vehicle. Therefore, they have a strong incentive to limit their driving and use alternative transport modes (public transport, walking and cycling) where possible. Conversely, car sharing can also reduce the needs of members to use alternative modes of transport by giving them greater access to a car (Litman, 2000; Martin \& Shaheen, 2010).

Martin and Shaheen (2011b), using the same survey data from their earlier report on car sharing's impact on GHG emissions (Martin \& Shaheen, 2010), evaluated how alternative transport use shifted amongst members of car sharing organisations in North America. The study results suggest that car sharing's impact on public transport was mixed. Most people who joined car sharing were carless; therefore, car sharing provided additional vehicle access which came at the expense of public transport usage. This drop in public transport use was offset by a similarly sized 
increase from the other members who joined car sharing and reduced their car ownership and VKT. In contrast, modal share of walking and cycling increased within the entire sample. When the impacts were combined, the overall shift towards public transport, walking and cycling were positive (Martin \& Shaheen, 2011b).

These results, it is suggested, are reflective of the first decade of car sharing, in which car sharing has absorbed large numbers of carless households, which have gained a new mobility option (Martin \& Shaheen, 2011b). In the future, as car sharing becomes more ubiquitous, more car dependent households may turn to car sharing. This may improve car sharing's ability to facilitate increases in alternative transport modes (Martin \& Shaheen, 2011b).

\subsubsection{Public health benefits}

Car sharing has the potential to improve public health. As discussed above, car sharing can change people's travel behaviour. Martin and Shaheen (2011b) found that car sharing resulted in increased walking and cycling. After reviewing a range of studies on the impacts of car sharing, Kent (2014) found that all the studies demonstrated a decrease in VKT and increased walking and cycling. These changes to travel behaviour are likely to generate health benefits. Decreased VKT results in reductions in car-related emissions, including nitrogen dioxide, carbon monoxide and particulate matter, which help to reduce mortality and morbidity from respiratory disease (Kent, 2014). A decrease in GHG emissions has the potential to mitigate the impact of climate change and related health impacts, such as vulnerability to natural disasters (Kent, 2014). Increased physical activity from more walking and cycling reduces the risk of mortality and morbidity from obesity (Kelly et al., 2014; Kent, 2014).

Car sharing may also lead to a range of less tangible benefits, such as inducing a sense of belonging through 'collaborative consumption'. Collaborative consumption refers to a system of organised sharing in which people can gain the benefits of ownership at reduced personal cost (Kent, 2014). Kent suggests that collaborative models, such as car sharing, have the potential to replace the sense of community which is increasingly considered absent from modern life. Car sharing may 
contribute to a sense of inclusion and belonging-the absence of which can contribute to the risk of mental health issues (Kent, 2014). However, more research is needed to investigate this potential benefit.

\subsubsection{Economic savings}

One of the primary reasons people choose to car share is the savings they can make compared to car ownership (Katzev, 2003; J. Kim, Rasouli, \& Timmermans, 2017; Steininger, Vogl, \& Zettl, 1996). The cost of operating and maintaining a private car is increasing in many cities around the world. Much of this cost is fixed, as a large percentage of vehicle expenses are paid regardless of how much the car is driven (Litman, 1999). For people who only need to use a car occasionally, car sharing can be a more affordable alternative to car ownership. Car sharing is considered a costeffective alternative to owning a vehicle driven fewer than approximately 10,000 kilometres per year (Barth \& Shaheen, 2002; Litman, 2000). The service offers people an affordable way to use a car when a car is the optimal travel choice, without incurring the fixed car ownership costs that may encourage driving (Litman, 1999). This enables individuals to have the benefits of private vehicle use without the costs and responsibilities of car ownership (Shaheen \& Cohen, 2013).

Businesses, charities, universities and governments can also make savings by reducing their vehicle fleets, or using car sharing instead of traditional car rental (K. Kim, 2015; Loose, 2010). For example, a small business may find that car sharing is more efficient and offers a flexible alternative to car ownership (Litman, 2000).

\subsubsection{Improves transport choices and equity}

Car sharing can improve people's transport choices by providing another mobility service. Car sharing operates as one of a number of transport options, filling the space left by the limited carrying capacity, timetables, inflexibility and costs associated with other modes (Kent \& Dowling, 2013). It can also improve the types of vehicles people are able to access. Car drivers often purchase vehicles that exceed their usual requirements regarding capacity and performance, for the occasional journey when it is required. Some car share organisations offer a range of vehicle types, so that a user can select a vehicle that best meets the needs of a particular journey (Litman, 2000). Some car share companies also offer more efficient or 
'green' vehicles, which might not be considered affordable for users to own themselves (Wappelhorst, Dobrzinski, Graff, Steiner, \& Hinkeldein, 2016).

Not only can car sharing increase people's transport choices, it can also improve equity by offering another service to people who are disadvantaged by their current transport choices (Kent, 2014; Litman, 2000). In this thesis, 'equity' refers to the fairness with which costs and benefits are distributed (Litman, 2002). Transport affects people's economic and social opportunities, for example some low-income households cannot afford to drive at all, or spend a significant proportion of their incomes on cars they seldom need. Car sharing can improve equity by providing a cost-effective alternative to car ownership (Kent, 2014; Litman, 2000).

\subsubsection{Introduces modern technologies}

Car sharing can also introduce modern technologies to the public, encouraging their adoption (Litman, 2000; Wappelhorst et al., 2016). Modern technologies include the latest EV technology and operational technologies such as automated booking, billing and vehicle access. Several governments have tried to facilitate public uptake of EVs by providing financial support to car sharing schemes which incorporate EV technology. Support has included investment, rebates and subsidies, for example, subsidised access to public on-street parking (Shaheen \& Chan, 2015). Support for schemes encouraging the uptake of EVs is for the most part driven by their potential to reduce GHG emissions and air pollution.

The incorporation of EVs into a car share fleet can raise awareness of the technology and enable car share members to gain experience driving EVs. German research found there were two main perceived barriers facing the adoption of EVs for personal use: their cost and their limited range in comparison to conventional (combustion engine) vehicles (Wappelhorst et al., 2016). The study found that most users of car share EVs did not have specific problems with the 'electric' component of the vehicles, and for the majority of users it was a reason for them to use the service. The research found that car sharing provides a good platform for introducing EV technologies (Wappelhorst et al., 2016). 


\subsection{Who uses car sharing?}

Car sharing services are used for both personal and commercial purposes. However, there is limited publicly available information about the individual and business users of car sharing schemes. The most robust information is available for personal users of traditional round-trip car sharing. Several studies have been conducted internationally that indicate the general characteristics of individuals who use round-trip car sharing (Burkhardt \& Millard-Ball, 2006; Le Vine et al., 2014; Loose, 2010; Martin \& Shaheen, 2010; Millard-Ball, Murray, Ter Schure, Fox, \& Burkhardt, 2005). These characteristics include:

- Well-educated

- Young adults (predominantly between the ages of 25 and 45)

- From households made up of a single person living alone or a couple without children living at home

- Earning a medium to high income

- Living in a carless or single-car household

- Living in urban neighbourhoods

- Relatively heavy users of non-car forms of urban transport (e.g. public transport, walking and cycling).

Burkhardt and Millard-Ball (2006) also found that car sharing members have a number of shared attitudes. These include a high level of concern about environmental and social issues; they consider themselves to be innovators; and do not like the inconveniences and costs associated with car ownership. They are also more pragmatic about car use and less interested in vehicle models/branding, and are sensitive to transport costs (Burkhardt \& Millard-Ball, 2006).

There is limited evidence on the socio-demographic profile of point-to-point car share users (Le Vine et al., 2014; Shaheen et al., 2015). Shaheen, Chan and Micheaux (2015) conducted a survey with point-to-point car share operators in the United States, Canada, Mexico and Brazil. The survey asked the operators about the users of their service, and this was then compared with users of traditional round-trip car sharing. The authors found that members of point-to-point car sharing did not appear significantly distinct to the members of round-trip car sharing. The main 
difference identified was that point-to-point users reside in denser city centres; however this is likely due to where the operators are currently located (Shaheen et al., 2015).

There is also very little evidence on the socio-demographic profile of peer-to-peer car share users. Peer-to-peer car sharing requires less capital investment because it uses existing private vehicles, which makes it more viable in lower-density areas (Hampshire \& Gaites, 2011; Shaheen, Mallery, \& Kingsley, 2012). This means that it has the potential to reach a wider market than traditional round-trip car sharing. However, despite its potential to expand to lower-density neighbourhoods, initial markets appear to be in high-density areas where traditional car sharing operates. This means that current peer-to-peer users are very similar to traditional car share users (Hampshire \& Gaites, 2011; Shaheen et al., 2012).

Some car share providers specifically target the business market; however, there is very little information available about commercial users of car sharing. One study found that in Europe 15.7 percent of car share users were business customers, based on analysis of 58 car share providers (Loose, 2010).

\subsection{Car sharing and compact living}

As noted in the previous section, car sharing schemes are generally located in higher density suburbs, and areas well serviced by public transport, walking and cycling infrastructure and networks (Burkhardt \& Millard-Ball, 2006; Le Vine et al., 2014; Loose, 2010; Martin \& Shaheen, 2010; Millard-Ball et al., 2005; Stillwater, Mokhtarian, \& Shaheen, 2008). Millard-Ball et al. (2005) analysed in more detail the characteristics of neighbourhoods in the United States (US) where car sharing has been successful. The authors found that successful car sharing neighbourhoods, for the most part, have the following characteristics:

- Parking pressure: car sharing is more attractive when car ownership is expensive and parking is scarce.

- Households can live without a car: car sharing cannot meet a household's entire mobility need but instead complements other transport modes; therefore, neighbourhoods have to have good walking, cycling and/or public transport links. 
- High population density: this provides a large customer base within walking distance of each car sharing location (these areas also have lower rates of vehicle ownership and travel).

- Mix of uses: business customers during the workday can be paired with residential users in the evenings and weekends.

These factors are all highly correlated. For example, parking tends to be scarce in high-density neighbourhoods and higher density makes public transport more viable (Millard-Ball et al., 2005). Millard-Ball et al. (2005) compiled a guideline for where car sharing is most likely to succeed in the US (Table 2.1). Table 2.1 shows that, based on their analysis, the best proxies for the types of neighbourhoods where car sharing succeeds are household type, commute mode, and vehicle ownership. In particular, neighbourhoods with high rates of single-person households, a high share of walking, and households with no vehicle, are the locations where car sharing is more likely to succeed (Millard-Ball et al., 2005).

Table 2.1. Guideline for where car sharing succeeds (Millard-Ball et al. (2005) Exhibit 3-15, p. 3-40).

\begin{tabular}{|c|c|c|}
\hline \multirow{2}{*}{ Variable* } & \multicolumn{2}{|c|}{ Level of Service } \\
\hline & Low & $\operatorname{High}^{\dagger}$ \\
\hline \multicolumn{3}{|l|}{ Demographics } \\
\hline$\%$ 1-person households & $30 \%$ & $40-50 \%$ \\
\hline \multicolumn{3}{|l|}{ Commute Mode Share } \\
\hline$\%$ drive alone to work & $55 \%$ & $35-40 \%$ \\
\hline$\%$ walk to work & $5 \%$ & $15-20 \%$ \\
\hline \multicolumn{3}{|l|}{ Vehicle Ownership } \\
\hline$\%$ households with no vehicle & $10-15 \%$ & $35-40 \%$ \\
\hline$\%$ households with 0 or 1 vehicle & $60 \%$ & $70-80 \%$ \\
\hline \multicolumn{3}{|l|}{ Neighbourhood Characteristics } \\
\hline Housing units per acre & 5 & 5 \\
\hline
\end{tabular}

* For most variables, the values are the suggested minimums that are needed to achieve a given level of car-sharing service. For the "\% drive alone to work" variable, the values are the suggested maximums.

† High service roughly equates to 10 or more car-sharing vehicles within a half-mile $(800 \mathrm{~m})$ radius. 
Stillwater et al. (2008) also investigated the importance of density for car sharing in the US. They too found that the proportion of commuters who drive alone is negatively related with car sharing, and single vehicle households are positively related to car sharing. In addition, the authors found that increased street width was negatively related to car sharing. This may indicate the close relationship between walking and car share, as narrow streets are more pedestrian friendly (Stillwater et al., 2008).

Car share can work outside urban locations, such as at university campuses and in small towns. However, the preconditions for their success are likely to be different to those in an urban environment (Millard-Ball et al., 2005). For example, car sharing services in small towns are often characterised by a high level of member involvement and programmes run by volunteers (Millard-Ball et al., 2005).

Overall, the international evidence suggests that car sharing is more likely to succeed in a compact city. This is in part due to the close correlation higher densities have with parking pressure, carless and single-car households and the availability of alternative transport modes. This does not preclude car sharing from working in lower densities provided there is community support for the service.

\subsection{Car sharing and sustainable transport}

As discussed previously, car sharing can facilitate the uptake of public transport, walking and cycling (Martin \& Shaheen, 2011b). It also improves people's transport choices, filling the space left by the limited carrying capacity, timetables, inflexibility and costs associated with other transport modes (Kent \& Dowling, 2013). This section examines in more detail how car sharing fits within the wider transport system.

Figure 2.4 shows how car sharing can fill an important gap in an effective transport system in terms of flexibility and distance (Britton, 1999). Public transport can be used for short and long trips but does not offer flexibility for all purposes. Walking and cycling can be very flexible but only for short distances. Taxis require less effort and time than walking and cycling but are also limited by distance due to cost. Car rental is useful for multiday trips that require flexibility. However, for some journeys these modes may not be suitable. For example, when people want to go to an out of 
the way location not well-serviced by public transport, are transporting something, travelling at an unusual time, or want to drive themselves, car sharing can help bridge this gap (Britton, 1999).

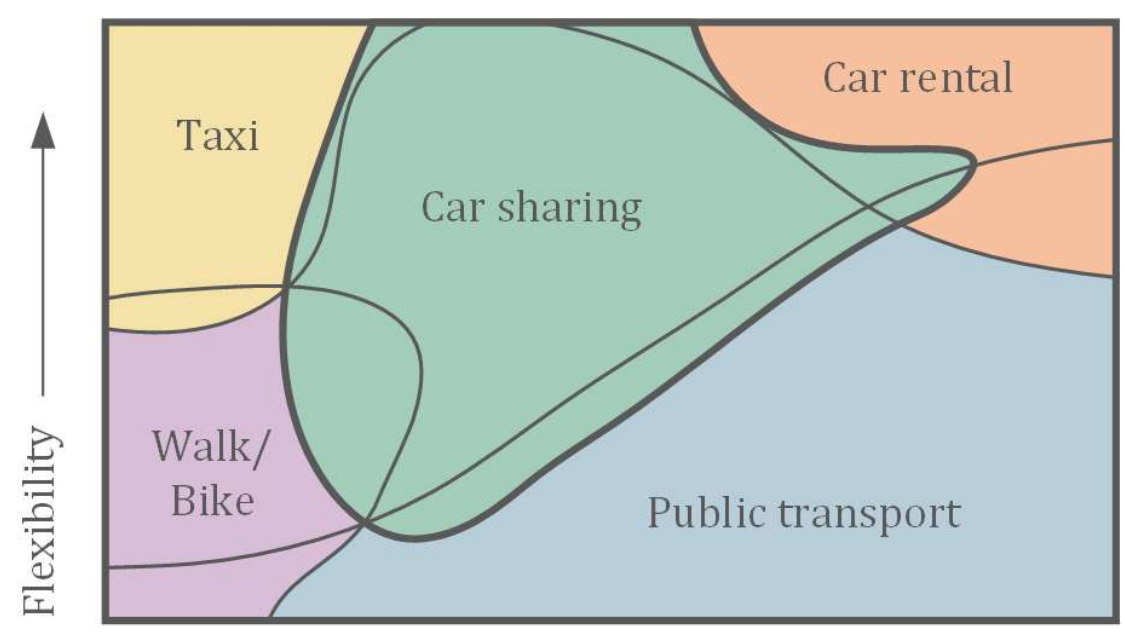

Distance

Figure 2.4. Car sharing's role in the transport system based on flexibility and distance (adapted from Britton (1999), Figure i, p. 9).

Nawangpalupi and Demirbilek (2008) highlight the relationship between different transport modes in terms of access and privacy values (Figure 2.5). A private car is almost always available and gives the user total privacy. Car sharing offers privacy with intermediate access. Compared with car rental, car sharing gives more flexibility as the member can use it for as long as needed, rather than having to hire the vehicle for an entire day. In addition, the car is located nearby in the neighbourhood and is easy to access. This is unlike traditional car rental vehicles, which are usually located quite far away from residential areas. Public transport and carpooling offer limited access due to limited operation times, distances, and availability. As the passengers share the space in the vehicle with other people, privacy is also limited (Nawangpalupi \& Demirbilek, 2008). 


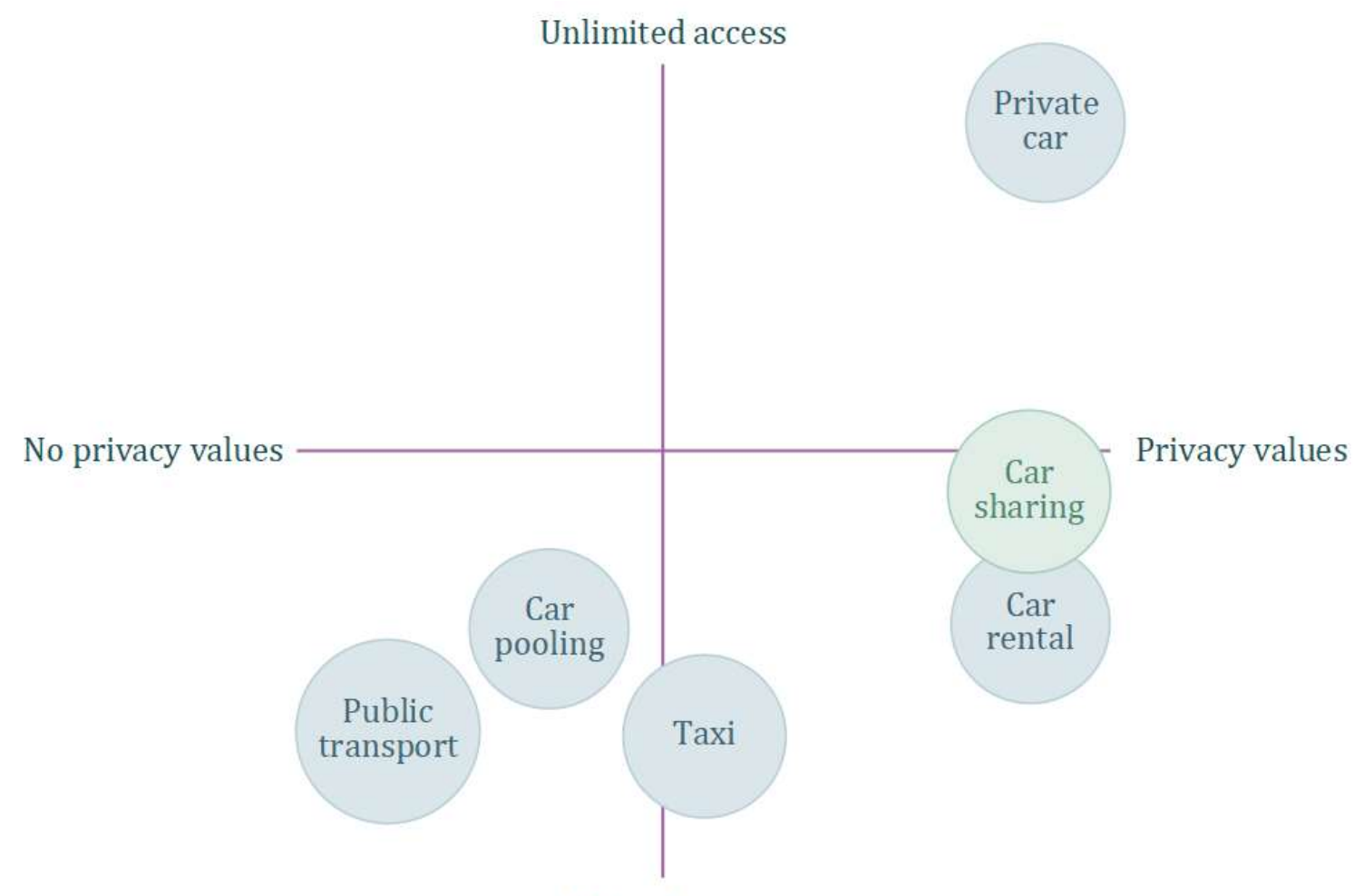

Limited access

Figure 2.5. Car sharing's role in the transport network based on access and privacy values (adapted from Nawangpalupi and Demirbilek (2008), Figure 1, p. 3).

Table 2.2 shows how car sharing can provide a middle option between having no private vehicle, and owning a private vehicle (Litman, 2000). It allows members to use a combination of modes rather than relying on car travel (Litman, 2000).

Table 2.2. Car sharing as a middle option between not owning a car and car ownership (adapted from Litman (2000), Figure 1, p. 32).

\begin{tabular}{|l|}
\hline No vehicle \\
\hline Minimum opportunity \\
to drive \\
Relies on walking, \\
cycling, carpooling, \\
public transport \\
Mobility \\
disadvantaged \\
\hline
\end{tabular}

\begin{tabular}{|l|}
\hline Car sharing \\
\hline Relies on a \\
combination of \\
walking, cycling, \\
carpooling, public \\
transport, and car \\
sharing \\
Moderate mobility \\
Maximum mobility \\
choices \\
\hline
\end{tabular}

\begin{tabular}{|l|}
\hline Private vehicle \\
\hline - \\
Relies primarily on \\
driving \\
\hline \\
\hline
\end{tabular}




\subsection{Car sharing and modern technologies}

Modern technologies and car sharing are very closely connected. As discussed previously, car sharing can help to encourage the uptake of particular modern technologies (Litman, 2000; Wappelhorst et al., 2016). Several governments have provided financial support to car share companies which incorporate EVs into their fleets (Shaheen \& Chan, 2015). In the 1990s, EVs were a major part of early roundtrip car sharing services (Shaheen \& Chan, 2015). It was an avenue for improving the environmental benefits of car share systems. By 2006, the vast majority of EVs within car sharing programmes were replaced by hybrid vehicles (Shaheen \& Chan, 2015). This may have been for a number of reasons, including the high cost of EVs, high insurance rates, low reliability of the first generation EVs, preference for hybrid vehicles, operational barriers, decreased user demand and support, and economic conditions (Shaheen \& Chan, 2015).

In recent years, there has been a resurgence of EVs in car sharing operations (Shaheen \& Chan, 2015). Car manufacturers are launching EV car sharing schemes in several cities in Europe, Japan and North America. Existing car share operators are increasingly introducing or reintroducing EVs into their fleets (Shaheen \& Chan, 2015). Shaheen and Chan (2015) suggest that this is a result of technological advancements, which have lowered costs and increased battery ranges, removing many of the barriers facing car share operators using EVs. As of 2015, EVs were included in car sharing schemes in over half the countries where car sharing currently operates (Shaheen \& Chan, 2015).

In terms of operational technologies, many car share providers are moving away from manual operations to partially or fully automated systems. For example, many car share providers have adopted automated reservations, billing and vehicle access (Shaheen \& Cohen, 2013). It is now more common for car share providers to launch with partially or fully automated systems. This reflects the increasing availability and affordability of modern technologies (Shaheen \& Cohen, 2013). Shaheen and Cohen have found that car sharing technologies now emphasise 'advanced services' including open-ended booking systems (no fixed return times), instant access (no reservation required), interoperability, point-to-point and peer-to-peer sharing. 
As noted previously, it seems likely that in the future car share organisations will also adopt autonomous vehicle technology (Le Vine et al., 2014). The ability of autonomous vehicles to reposition themselves without human drivers could be transformative for car share companies. It could help the car share providers manage their networks, with the vehicles going automatically to where and when the demand is highest. However, it is unclear at what point in the future this technology will become widely available.

\subsection{The barriers facing car sharing}

Previous discussion highlighted the potential for car sharing to result in a range of social, economic and environmental benefits. Car share operations generally face a range of barriers before they can provide the full benefits of their services. Due to the public good benefits that car sharing can offer, there is an argument for public authorities to support car share providers, particularly in the early stages of their development (Enoch \& Taylor, 2006).

There is very little research on the barriers facing individual users of car sharing. Nawangpalupi and Demirbilek (2008) investigated the barriers facing car share users in Sydney, Australia. The authors found that the main issue that users had with the service was the availability of the car share vehicles. This was followed by parking problems, administrative issues (such as incorrect billing and difficulties booking), the condition of the car share vehicles (such as cleanliness, damage), and inconvenience caused by other users (such as returning the vehicle late). Minor barriers included customer service issues, unclear costs and insurance policies, restrictions on having pets in the vehicle, and inconvenient booking times (Nawangpalupi \& Demirbilek, 2008). Another study investigated the barriers facing potential car share users in Beijing, China (Shaheen \& Martin, 2010), and found that the main apprehensions with car sharing were related to responsibility in the case of car theft or a car accident, and the safety features of the vehicles. 
Nawangpalupi and Demirbilek (2008) also investigated what drove members to use car sharing. The authors found that members were mainly motivated by practicality (such as only occasionally needing a car and the ease of access to the car share vehicles), cost effectiveness (financial benefits of car sharing), and environmental concern (the impact of car ownership on the environment). The authors recommend providing car share services which attempt to overcome the inconveniences of private car ownership, such as providing designated parking spaces for car share vehicles. This could attract people who have limited access to parking for their private vehicles (Nawangpalupi \& Demirbilek, 2008). Similarly, Martin and Shaheen (2010) found in Beijing that parking is one of the main challenges for car drivers, and therefore guaranteed parking spaces for car sharing vehicles would be a considerable benefit of using the service.

Internationally, start-up costs for car share providers has been a significant barrier. Car sharing only becomes financially viable when the car share vehicles are used intensively (Barth \& Shaheen, 2002; Bleischwitz et al., 2009; Enoch \& Taylor, 2006; Litman, 2000). Relatively few car share systems are self-supported from user fees; most depend on financial assistance from government and private investors (Barth \& Shaheen, 2002; Shaheen, Schwartz, \& Wipyewski, 2004). For example, public funding has included start-up grants and guaranteed use of the service by central or local government agencies (Enoch \& Taylor, 2006). Private developers have invested in car share companies by incorporating car share into new developments. This can help the developers overcome parking constraints, by offering car sharing in new developments instead of private car parks (Enoch \& Taylor, 2006).

Most car sharing services overseas have required access to on-street car parking spaces in order to operate (Dowling \& Kent, 2015; Le Vine et al., 2014; Shaheen \& Cohen, 2013). Gaining access to on-street car parking can often be a barrier for car share providers. On-street car parks are often owned and controlled by local governments. Local governments can be fragmented, subject to changes in policy direction, under pressure to deliver a range of outcomes (such as parking for local residents or shops), are under no obligation to support car share operators, and may respond more slowly than the private sector (Le Vine et al., 2014). The provision of free or reduced cost public car parks is important for supporting the growth of car 
sharing (Dowling \& Kent, 2015; Enoch \& Taylor, 2006; Shaheen \& Cohen, 2013). In 2010, on-street reduced-cost parking was available for car sharing companies in 76 percent of car sharing countries. The countries that did not have parking available for car share tended to be new car sharing markets. The mature car sharing markets were more likely to have public policy support to enable reduced-cost on-street parking (Shaheen \& Cohen, 2013).

The cost of insurance for car share providers has also been another major barrier for car sharing companies overseas (Le Vine et al., 2014; Shaheen \& Cohen, 2013; Shaheen et al., 2004). However, Shaheen and Cohen (2013) suggest that insurance is no longer considered prohibitive in most markets around the world.

\subsection{Summary}

Despite car sharing being a relatively new area of research, there is now a reasonable number of international studies available. Several studies indicate potential benefits of car sharing, such as reducing car ownership and usage, which in turn can reduce congestion, demand for parking and GHG emissions. A number of studies also outline the characteristics of car share users and car sharing neighbourhoods. Importantly, car sharing appears to be more successful in compact cities because of the close correlation between high densities and parking scarcity, carless and single-car households and the availability of alternative modes of transport. Car sharing is an important component of a sustainable transport system, filling the gap left by the limited carrying capacity, timetables, inflexibility and costs associated with other transport modes. The service provides a middle option between not owning a car and car ownership. A number of studies have also highlighted the close connection between car sharing and modern technologies, and the increasing role that technology will play in the future of the service. Importantly, several studies indicate the barriers facing car sharing services, and how these barriers might be overcome with government support. The public good benefits that can result from car sharing suggests that this support may be warranted. 


\section{Chapter 3 Study context}

This thesis aims to contribute to the literature by focusing on car sharing in the New Zealand context. This chapter will first provide important contextual information about Auckland and Wellington, as these cities are the centre of New Zealand's car share operations and policies. ${ }^{1}$ Auckland and Wellington's population density, car ownership rates and transport mode share are all significant factors for the success of car sharing. This chapter will also look at the policy context, focusing on car share policies adopted by New Zealand's central government, Auckland Transport and Wellington City Council. This is followed by a brief description of New Zealand's car share providers. This chapter will also summarise the available research on car sharing in New Zealand. Chapter 4 will then discuss the research gap identified, and the study framework for this thesis.

\subsection{Auckland and Wellington}

Internationally, car sharing schemes are generally located in higher-density areas, as this provides a large customer base within walking distance of each car share vehicle. Auckland and Wellington have the most potential to support car sharing services in New Zealand, as they are two of the country's three largest and densest cities. Auckland's population is approximately 1.5 million, and it is projected to grow to over 2.3 million by 2043 (Statistics New Zealand, 2013). Wellington Region's population is approximately 470,000 , and it is projected to grow to 535,000 by 2043. The majority of Wellington Region's population growth is expected to happen in Wellington City (Statistics New Zealand, 2013).

Auckland is the third-densest city in Australasia, with a population-weighted density of 43.1 people per hectare in 2013 (Nunns, 2014). ${ }^{2}$ Auckland's density grew by 33

1 Christchurch also has a car share policy. However, at the time of writing no round-trip car sharing services operated in the city. Therefore, this chapter focuses solely on car sharing in the Wellington and Auckland context. Future research on car sharing in New Zealand could take Christchurch into consideration, as based on the Council's policy there may be a round-trip car share operation in the city in the near future (Christchurch City Council, 2016).

2 Population density can be measured several ways. The most common approach is to divide a city's total population by its total area. This can significantly underestimate the density of large cities which include both high-density inner urban areas and low-density neighbourhoods. In contrast, population-weighted density reflects the density of the neighbourhood in which the city's average resident lives. This is a more meaningful measure of population density, reflecting the lived experience of a city's average resident (Nunns, 2014). 
percent between 2001 and 2013. Wellington Region has a population-weighted density of 37.8 people per hectare. Wellington's density grew by 17 percent between 2001 and 2013 (Nunns, 2014). Although Auckland has a higher population-weighted density than Wellington Region, parts of central Wellington support higher densities (Nunns, 2014). Nunns found that population densities in neighbourhoods throughout Auckland's urbanised area are consistently in the $30-40$ or 40-50 people per hectare ranges (2014). In comparison, Wellington City has over 100 people per hectare in some places. This may be a reflection of Wellington's naturally compact central city due to the harbour and surrounding hills (Nunns, 2014). Auckland and Wellington Region are both projected to increase in density. This means that in the future, based on international evidence, car sharing is likely to become increasingly viable in these cities (Le Vine et al., 2014; Millard-Ball et al., 2005).

Internationally, car sharing is popular with carless or one car households (Le Vine et al., 2014). The New Zealand 2013 census found that 38.4 percent of households owned two motor vehicles (Statistics New Zealand, 2013). This was followed by 37.6 percent of households which owned one vehicle, and 16.1 percent which owned three or more vehicles. Only 7.9 percent of households owned no vehicles (Statistics New Zealand, 2013). Figure 3.1 compares the number of vehicles per household in Auckland and Wellington with New Zealand (Statistics New Zealand, 2013). In Auckland 39.9 percent of households owned two motor vehicles, compared with 33.3 percent in Wellington; 34.2 percent of Auckland households owned one vehicle, compared with 43.9 percent in Wellington. In Auckland 18.4 percent of households owned three or more vehicles, compared to 11.1 percent in Wellington. Only 7.6 percent of Auckland households owned no vehicles, compared to 11.7 percent of Wellington households (the highest proportion of non-car ownership in New Zealand). 


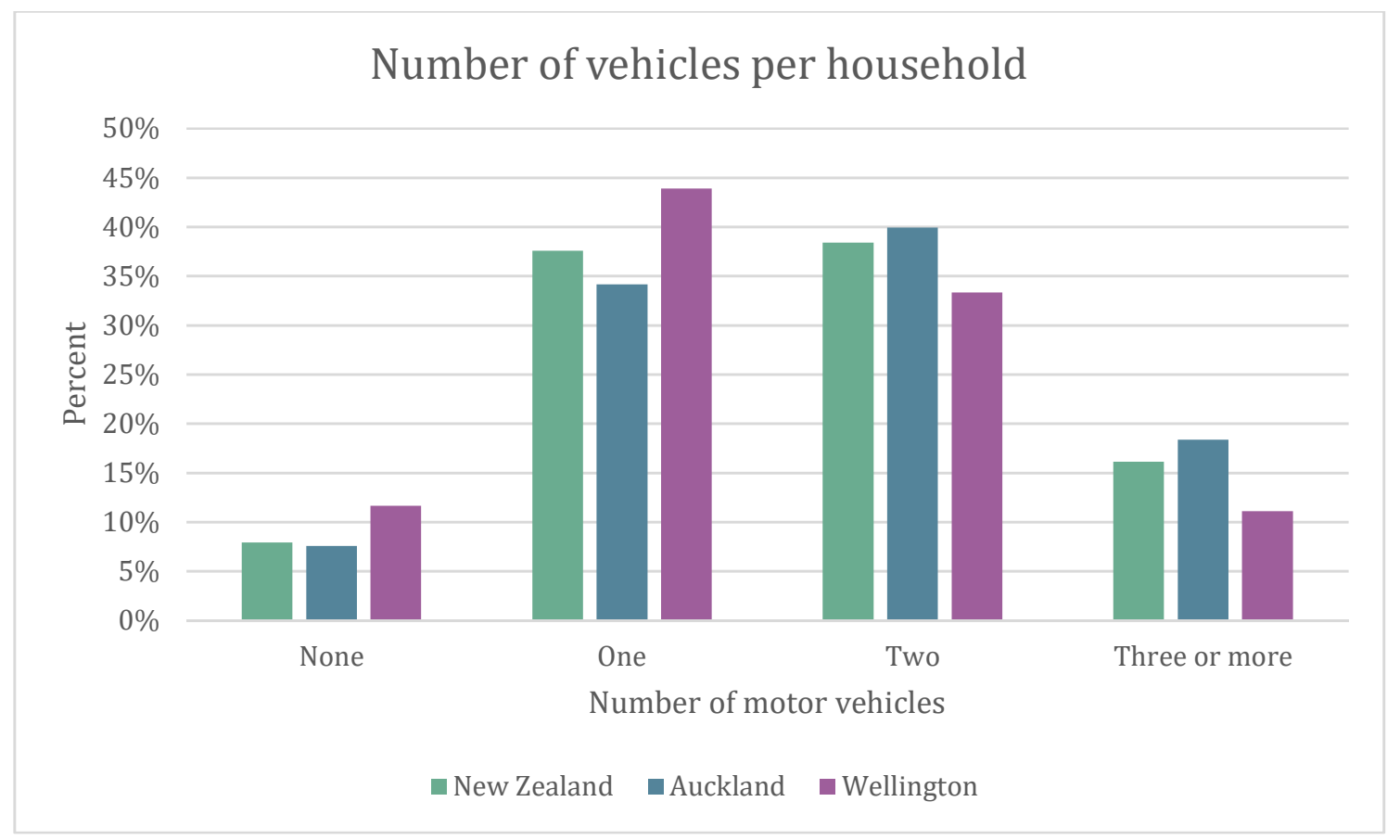

Figure 3.1. Number of vehicles per household on census day 2013

Car sharing also works best in areas that have good alternative modes of transport, such as public transport, walking and cycling (Le Vine et al., 2014). People will not forgo car ownership in favour of car sharing if they need to drive most of the time. In New Zealand, approximately 79 percent of people's travel time is spent in a car, either as a driver or passenger (Ministry of Transport, 2015b). This is followed by 13 percent of people's travel time spent walking, 4 percent on local public transport, and 1.6 percent by bicycle (Ministry of Transport, 2015b). Figure 3.2 compares mode of travel to work on census day in 2013 for Auckland, Wellington and New Zealand (Statistics New Zealand, 2013). ${ }^{3}$ The main mode by far was driver/passenger in a vehicle. Wellington had substantially fewer car users than Auckland at 67.1 percent compared to Auckland's 85.1 percent. About twice as many people in Wellington used public transport, at 17.5 percent, compared to Auckland's 8.5 percent. In terms of active transport (including walking, cycling and jogging), 15.4 percent of people travelling to work in Wellington used active modes, compared to only 6.4 percent in Auckland (Statistics New Zealand, 2013).

3 'Vehicle' includes cars, trucks, vans, motorbikes and scooters, as well as private or work vehicles. 'Public transport' includes buses and trains. 'Active transport' includes walking, cycling and jogging. The analysis excludes those who worked at home, did not go to work that day, other, and not elsewhere included (Statistics New Zealand, 2013). 


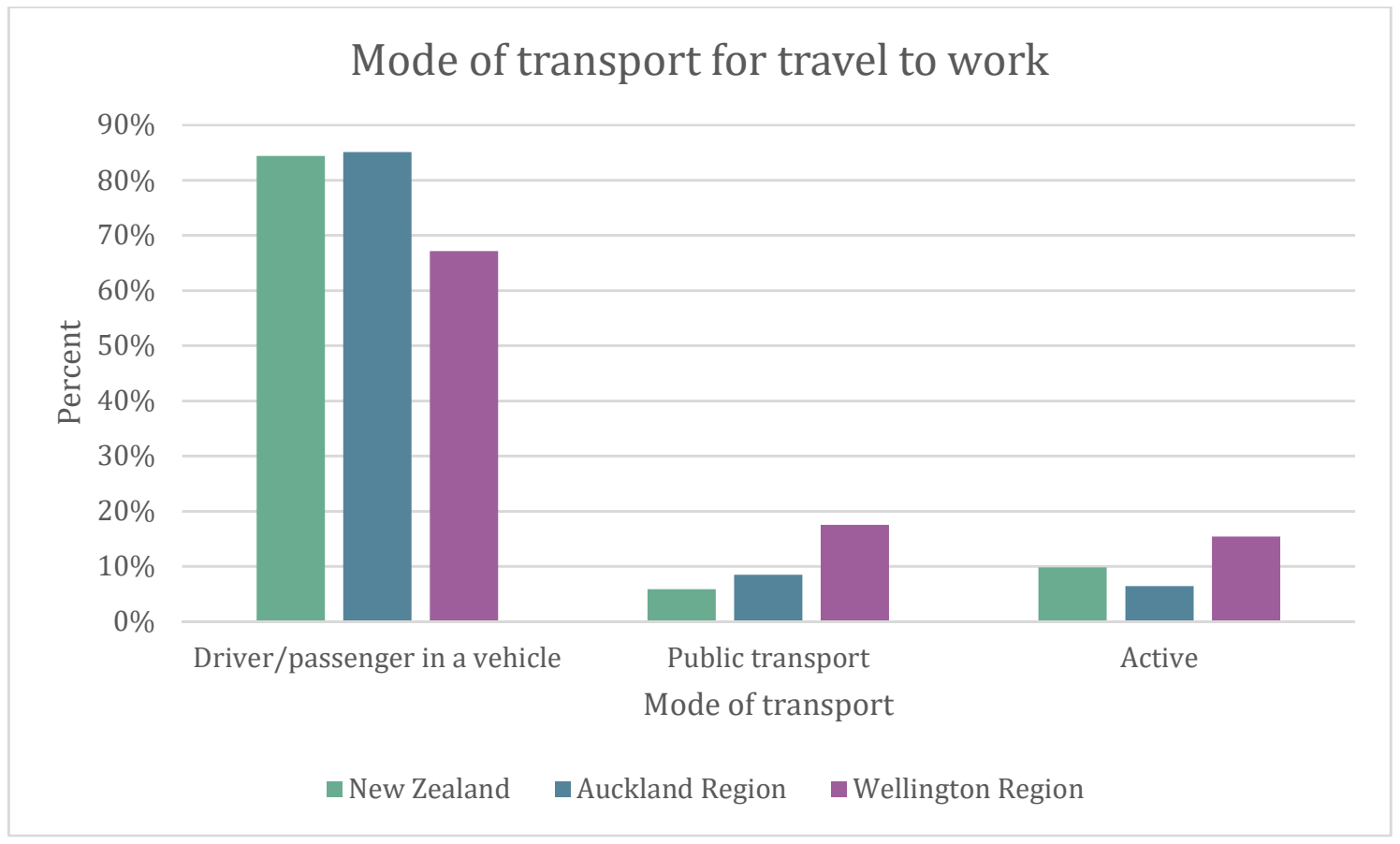

Figure 3.2. Mode of transport for travel to work on census day 2013

In summary, Auckland has a much larger population than Wellington, and overall a greater population-weighted density. However, Wellington's density is not substantially less than Auckland, and parts of Wellington city are significantly more compact, at 100 people per hectare or more, than Auckland's neighbourhoods. Wellington has more carless and single-car households than Auckland, and people in Wellington are far more likely to travel by public transport and active modes than in Auckland. Wellington does therefore appear to be somewhat better suited than Auckland to car sharing.

\subsection{Car share policies in New Zealand}

The central government of New Zealand does not have a specific policy regarding car sharing, although it has announced one in relation to electric vehicles. The government is aiming to double the number of EVs in the country every year, to reach approximately 64,000 by 2021 . So far, New Zealand has been slow to adopt EV technology. As of December 2015, only 0.025 percent of New Zealand's car fleet was made up of EVs (Ministry of Transport, 2015a). To reach its target, the government has undertaken a range of initiatives to support EV uptake (Ministry of Transport, 2017). This includes the Low Emission Vehicles Contestable Fund which provides up to \$6 million per year to co-fund projects which support the uptake of EVs (Energy 
Efficiency and Conservation Authority, 2017). Car share companies can apply for this funding if they include EV technology in their services. Mevo, one of the car share providers operating in New Zealand, has been awarded funding through this scheme. This will be discussed in more detail in the next section of this chapter. Auckland Transport has a policy in place to provide dedicated car share parking spaces both in car parking buildings and on-street in Auckland (Auckland Transport, 2015a). However, this policy does not clearly stipulate how many parks it will provide to car share providers. In 2015, Auckland Transport looked for a car share operator to launch a large-scale scheme in Auckland, using EVs. Auckland Transport were interested in an initial fleet of 200-300 vehicles, which it would match with a similar number of car parks dedicated to car share vehicles (Auckland Transport, 2015b). In 2016, Auckland Transport abandoned its plan, after rejecting every single applicant for the tender. The applicants failed to meet Auckland Transport's minimum requirements, which included providing an all-electric car fleet (Maude, 2016). There does not appear to be any immediate plan to revisit the tender.

In the Wellington Region, Wellington City Council (WCC) supports car sharing through its Low Carbon Capital Plan. ${ }^{4}$ WCC proposes to identify 100 car parks citywide, to be made available for car-sharing operations and electric charging infrastructure, based on demand (Wellington City Council, 2016b). In September 2016, WCC approved a new Car Share Policy, which allows operators of existing and new car share schemes to apply for access to on-street car parks (Wellington City Council, 2016a). In April, 2017 the Council began consultation on making 24 car parking spots available to car share providers in Wellington (Wellington City Council, 2017).

\subsection{Car share providers in New Zealand}

There are currently four car share providers operating in New Zealand. Cityhop was the first car share provider to operate in New Zealand. The company launched in 2007 and currently operates in Auckland and to a lesser extent in Wellington (Cityhop, 2017). Cityhop is a traditional round-trip car sharing service, providing

\footnotetext{
4 At the time of writing, none of the other councils in the Wellington Region had specific policies in place to support car sharing.
} 
vehicles in central locations that members can hire by the hour. The company has over 2,500 customers, with 35 vehicles in Auckland, and four cars in Wellington (MacManus, 2017). The company recently announced a new partnership with the energy company Mercury, which has provided an EV for Cityhop's car share fleet. This enables Cityhop's members to experience driving an EV (Mercury Energy, 2017). Cityhop vehicles can be booked online and have smart-card vehicle access.

In 2015, Cityhop was joined by two peer-to-peer car share companies called YourDrive and Roam. YourDrive has over 60 vehicles available to rent across New Zealand (YourDrive, 2016). In October 2016, the car rental company Jucy formed a partnership with YourDrive. This partnership will help Jucy expand without requiring the company to increase its own vehicle fleet. Jucy's surplus customer demand could be channelled to the YourDrive network (Edmunds, 2016). Roam is a smaller peer-to-peer company, operating only in Wellington. Roam is slightly different from the other car share providers because it was developed for the purpose of testing car share software (Devlin, 2015). Andrew Kissling, the founder of Roam, aims to market the car share software to car sharing platforms overseas (Devlin, 2015). YourDrive and Roam both provide online booking, and Roam also has smartphone vehicle access.

The latest car share company to launch in New Zealand is called Mevo, which began operations in Wellington in December 2016. Mevo is a round-trip car sharing service, and currently operates a fleet of six plug-in hybrid electric vehicles (Mevo, 2017b). Mevo has online booking, open-ended bookings, and smart-phone vehicle access. In addition, Mevo is the world's first 'climate positive car share'. This means that the company uses carbon credits to remove more emissions from the atmosphere than it produces (Mevo, 2017b). In 2017, Mevo was awarded $\$ 500,000$ in matched funding through the Low Emission Vehicles Contestable Fund. Mevo plans to use this to grow their hybrid vehicle fleet to 50 during 2017, with dedicated charging stations across Wellington (Mevo, 2017a). As discussed earlier, the Low Emission Vehicles Contestable Fund was set up by the government to co-fund projects which encourage the uptake of EV technologies in New Zealand. 


\subsection{New Zealand car share research}

Overall there has been very little research undertaken on car sharing in New Zealand. In 2014, Auckland Transport undertook a small survey of 100 car share users in Auckland. They found that over half of those surveyed reduced the number of cars they owned, or delayed purchasing a vehicle (cited in Wellington City Council, 2016a). A survey carried out by WCC in May 2016 found that the main incentives for joining car sharing were convenience, not owning a car, not wishing to purchase a car, low use of a car, and to achieve environmental and health benefits (cited in Wellington City Council, 2016a). These survey results are not publicly available; however, they appear to be based on small sample sizes and are of limited scope.

There was no academic literature found during this study that focused solely on car sharing in the New Zealand context. However, several studies from the Centre for Sustainability at Otago University have investigated car sharing as part of wider research into transport innovation in New Zealand. For example, Hyde (2015) explored the potential for sustainable transitions in New Zealand's transportation industry, from the perspectives of organisations leading sustainability through the development of innovations such as biofuel, electric vehicles and car sharing schemes. As part of the study, the author found that the main barriers facing innovative transport technologies was lack of funding and awareness. The author suggested that increased support from government could make the environment for technologies like car share more favourable (Hyde, 2015).

In a similar vein, Walton, Hyde and Patel (2016) explored the barriers facing entrepreneurial actors in the New Zealand transport system. As part of this study, the researchers interviewed the car share companies Cityhop and YourDrive as well as a number of other actors in the transport sphere (Walton et al., 2016). The authors found that barriers included lack of understanding and awareness of the businesses, New Zealand's car culture and complacency around environmental issues, unsupportive and inflexible central and local governments, financial barriers such as lack of funding/investment, and difficulties scaling up the businesses (Walton et al., 2016). The authors found that from the participants' perspectives, 
there is a clear need for the public to change, perhaps through education and supportive practices (Walton et al., 2016).

The two articles discussed above highlight some of the potential barriers facing innovative transport actors in New Zealand, including car share providers. However, there is clearly a lack of academic research that focuses solely on car sharing in New Zealand.

\subsection{Summary}

Auckland is New Zealand's most populated city, and has a higher populationweighted density than Wellington. Auckland also currently has the largest number of car share vehicles in the country. However, Wellington's population density is not substantially less than Auckland, and parts of Wellington city are significantly denser than Auckland's neighbourhoods. Wellington also has more carless and single-car households than Auckland, and people in Wellington are far more likely to travel by public transport and active modes than in Auckland. High density, low car ownership rates, and the availability of alternative transport modes are all thought to be important for the success of car sharing. In this respect, Wellington appears to be more suited to car sharing than Auckland.

In terms of policy, both Auckland Transport and WCC support car sharing through the provision of car parking spaces. However, WCC's support is more clearly articulated in its new car share policy and in the Low Carbon Capital Plan. The council aims to make 100 car parks available for car sharing and EV charging. In terms of car share providers, two currently operate in Auckland, whereas four operate in Wellington. In addition, Mevo is likely to expand considerably in Wellington over the next year due to the funding it has been awarded by central government through the Low Emission Vehicles Contestable Fund.

Overall, there is clearly a lack of research that focuses predominantly on car sharing in the New Zealand context. This research gap will be explored in more detail in the next chapter. 


\section{Chapter 4 Research gap and study framework}

Internationally, there is a growing body of literature on car sharing. Research undertaken overseas has identified the main benefits of car sharing, who uses car sharing, the relationship between car sharing and compact living, sustainable transport and modern technologies, the barriers facing car sharing and how they can be overcome. The previous chapter outlined two studies which have looked at the barriers facing innovative transport actors in New Zealand, including car sharing schemes. However, there is clearly a research gap when it comes to literature that focuses on car sharing in the New Zealand context.

The previous chapter compared Auckland and Wellington in terms of three integral factors for the success of car sharing: population density, car ownership rates and transport mode share. Wellington appears to be better suited to car sharing than Auckland because of its dense central city, higher percentage of carless and singlecar households and a higher mode share of public and active transport. In addition, car sharing looks set to grow significantly over the next year in Wellington due to the support of both local and central government. Considering these factors, it is evident that Wellington could benefit from research undertaken on car sharing in the city. Therefore, this study is focused on car sharing in Wellington.

To guide this research, a study framework was developed based on the variables discussed in the literature review and study context (Figure 4.1). Car sharing in Wellington is the central variable. Two main variables direct the research on car sharing in Wellington. First, the 'international evidence' which is based on the literature review. Second, the 'context' which is based on the available information and research on New Zealand's car share providers and car share policies, as well as important contextual information about Wellington. These two variables have several constituent parts, and relationships are indicated by either one-way or twoway arrows. The one-way arrows indicate that one variable feeds into the other. Two-way arrows suggest that they have a bidirectional relationship with each other. 'International evidence' includes the benefits of car sharing, the main users of the service, its relationship to compact living, sustainable transport and modern technologies, and the barriers that face car sharing (these variables are displayed in 
green boxes). In addition, the benefits of car sharing and the barriers facing car sharing are broken down an extra level (with variables shown in boxes of a different colour) to identify their relationships to the wider issues. For example, 'car sharing and modern technologies' is related to the benefit 'introducing modern technologies.'

'Context' includes New Zealand's car share policies and car share providers, as well as population density, car ownership and transport mode share in Wellington. This section also includes New Zealand-based research, which is linked to the barriers facing car sharing under 'international evidence'. This is because the research available in New Zealand indicated a range of barriers facing car sharing in this country, which could be compared with the international evidence on barriers.

This study framework forms the basis for the research aim and research questions of this study, which are presented in the next chapter. 


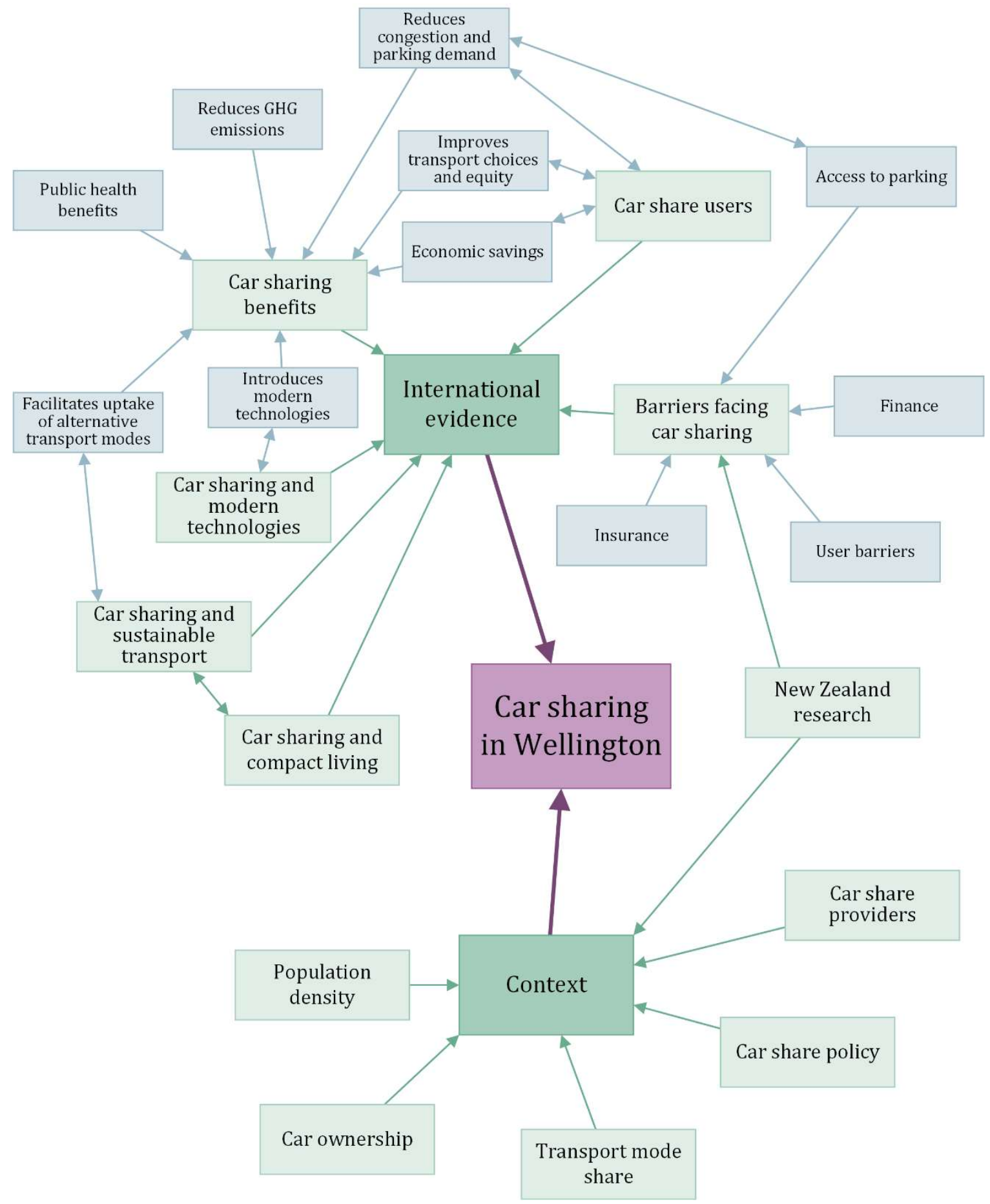

Figure 4.1. Study framework 


\section{Chapter 5 Research aim and questions}

This research aims to contribute to the literature by focusing on car sharing in New Zealand, specifically in Wellington. As car sharing in Wellington is still in the early stages of development, this research is exploratory in nature. It aims to identify the benefits of car sharing in Wellington, potential car share users, whether car sharing can support people living in the central city and sustainable transport patterns, and the importance of modern technologies for car sharing. Further, it aims to identify the barriers facing car sharing in Wellington and how these might be overcome. By comparing the findings of this study to the international literature, it will also be possible to establish whether there is anything distinct about the New Zealand context compared to overseas.

This thesis has two central research questions and a series of sub-questions:

1. What are the potential benefits of car sharing in Wellington? In particular, how could car sharing support compact living and sustainable transport patterns in the city?

In regard to Wellington:

- What do stakeholders see as the main benefits of car sharing?

- Who is interested in using car sharing?

- How important is high population density for car sharing? And how can car sharing support people who live in the central city?

- Does car sharing offer an alternative to private vehicle ownership, and is it complementary to public transport, walking and cycling?

- How important are modern technologies for car sharing?

2. What are the main barriers facing car sharing in Wellington? And how might these barriers be overcome?

- What concerns do Wellington residents have about using car sharing, and what might encourage them to use the service?

- What do stakeholders see as key barriers facing car sharing in Wellington, and how might these barriers be overcome? 


\section{Chapter 6 Methodology}

\subsection{Research worldview}

The philosophical worldview for this study is pragmatism. Pragmatism is not based on any single philosophical view of reality. Instead, pragmatism appreciates that research occurs within a social, historical and political context, and therefore should be designed around what works best, and based on the intended outcomes of the study (Creswell, 2014b; Creswell \& Clark, 2011). The research questions and how best to answer them are of primary importance, rather than any one method. This enables different forms of data collection and analysis (Creswell, 2014b; Creswell \& Clark, 2011). The pragmatic worldview lends itself to this study because the research questions and how to answer them are the central consideration. Pragmatism is more open than other philosophical worldviews, such as post positivism and constructivism, to multiple methods of data collection and analysis (Creswell, 2014b; Creswell \& Clark, 2011). The adoption of a pragmatic worldview enabled this study to collect both quantitative and qualitative data using the most appropriate methods for the context. This has resulted in a more nuanced understanding of the research questions.

\subsection{Research design}

This study employed a mixed method design. Mixed method research typically involves collecting both quantitative and qualitative data and integrating this data for interpretation (Creswell, 2014a). This approach enables a more comprehensive understanding of the research problem than either a quantitative or qualitative approach alone, and supports interpretations based on the combined strength of both sets of data. This study adopted a convergent approach in which the quantitative and qualitative data were collected at roughly the same time and the information integrated in the interpretation of the overall results. The purpose of a convergent design is to collect different but complementary data to best understand the complementary aspects of the research problem (Creswell \& Clark, 2011). 
The quantitative data was used to analyse the relationship between a range of characteristics of Wellington residents, such as socio-demographics, car ownership and travel preferences, and their interest in using car sharing. The qualitative data was used to explore in-depth the potential benefits of developing car sharing in Wellington and how car sharing can support compact living and sustainable transport patterns from the perspectives of a range of stakeholders. In addition, it explored the barriers facing car sharing from the perspective of Wellington residents and a range of stakeholders, and how these barriers might be overcome. A mixed method convergent approach was adopted in this research because it was an efficient way to collect both data sets over a limited period, and there was value in collecting and analysing both quantitative and qualitative data to understand the research problem. This design also enabled triangulation, as the findings from the quantitative and qualitative data are compared and contrasted for the purposes of corroboration and validation (Creswell, 2014b; Creswell \& Clark, 2011).

\subsection{Research methods}

The quantitative data was collected via closed-ended questions in an online survey. The qualitative data was obtained through asking open-ended questions in an online survey and, separately conducting semi-structured interviews and asking openended questions in an online survey. This section provides the rationale for using each research method, how each method was carried out and how each data set was analysed. This study was granted ethics approval by the Victoria University Human Ethics Committee. ${ }^{5}$

5 The approval letter can be found in Appendix A. 


\subsubsection{Online Survey}

\section{Rationale}

This study surveyed Wellington residents about their interest in using car sharing and related considerations such as where they live, their main modes of travel and attitudes towards car ownership. Surveys provide a quantitative description of trends, attitudes or opinions of a population by analysing a sample of that population (Creswell, 2014). This method was chosen because it provides a fast, economic and straightforward way of reaching a large population (Sue \& Ritter, 2012).

As discussed previously, car sharing in Wellington is still in the early stages of development, with only a few car share vehicles currently available in the city. Therefore, instead of evaluating current car share users, it was decided that more could be gained from surveying the wider Wellington population about their interest in car sharing. This resulted in a reasonably large sample size which would have been difficult to achieve if the survey was restricted to current car share users. In addition, surveying the wider Wellington population enabled a more complete analysis of the groups who are very interested in car sharing as well as those who are opposed to using the service. The survey recruitment method and responses will be discussed in more detail shortly.

Online surveys do have several disadvantages, including the biases created by limiting participants to those who have internet access and basic computer literacy (Fowler, 2014). 
The survey included both closed-ended and open-ended questions. The closedended questions included 'tick the box' methods and ranking attitudes on a scale. The open-ended questions were used for the collection of supporting qualitative data. Qualtrics survey software was used to design and launch the survey. Qualtrics was used to host the survey as Victoria University of Wellington has a licence agreement with Qualtrics for this service. The survey was designed to be confidential and anonymous. ${ }^{6}$

\section{Survey questions}

The survey questions were formulated after an extensive literature review. The survey was designed to gather information on residential, travel and car ownership characteristics of Wellington residents, and their perceptions and opinions about their travel modes, car ownership and car sharing. Additional questions captured demographic information to allow comparison with census data.

As it was thought that many of the participants may not have heard of car sharing before completing the survey, a description of car sharing was given before any questions were asked about car sharing. While car sharing can be a challenging concept to convey to those unfamiliar with it, the description was carefully tailored in the light of the literature review. Nonetheless, physical examples of car sharing are not widespread and well-known in Wellington. Many of the respondents answered questions on car sharing having never heard of or used the service before. Therefore, results should be considered exploratory.

Participants consented to taking the survey by indicating they had read and understood the Participant Consent information which was provided online. ${ }^{7}$ The first question limited eligibility to those living within the Greater Wellington region. Those who indicated they did not live in the region were redirected to an end of survey message.

A copy of the online survey can be found in Appendix B.

7 The participant consent information can be found in Appendix B at the start of the online survey 
The survey was piloted by friends, family and post-graduate university students and staff in the Environmental Studies Programme of Victoria University of Wellington. A total of 20 participants completed the pilot survey. The feedback was important to the redesign of the final survey, with several questions reworded for clarity.

\section{Recruitment method}

Recruitment for the survey was done via the snowball method, a type of nonprobability sampling. Nonprobability samples do not use random selection and therefore may not produce an accurate representation of the population (Fricker, 2011; Sue \& Ritter, 2012). The snowball method begins with identifying individuals who meet the participation criteria. These individuals are then asked to refer more potential participants for the survey (Sue \& Ritter, 2012). In this study, an email containing information about the study and a link to the survey was sent to a number of individuals and organisations in the Wellington Region. They were requested to forward the email on to anyone who they believed might be interested in completing the survey. Participation in the survey was limited to those living in the Wellington Region and 18 years of age or older.

The snowball technique can bias responses by allowing self-selection, and overrepresentation of particular social groups (Fowler, 2014; Sue \& Ritter, 2012). The representativeness of the sample is discussed in Chapter 7. The advantage of the snowball method is that it allows the survey to reach a large number of people quickly and with little cost, a requirement of this study. With very limited research done on car sharing in New Zealand, this is a relatively exploratory study, and such data is unlikely to be collected any other way due to cost and time limitations. Supplementary research will be necessary to support the study's findings in the wider New Zealand context; however, they may be consistent with research undertaken overseas. 
The survey was launched on 27 November 2016 and closed on 1 February 2017, giving over two months for responses. The survey had a total of 385 responses. As the snowball recruitment method was used and the responses were anonymous, the recruitment emails were not tracked. This means that it is not possible to know how many people received the recruitment email nor is it possible to calculate a response rate for the survey. ${ }^{8}$ Respondents who did not complete more than half the survey questions were removed from the data for a more complete analysis. This left a total of 356 viable responses which were used in the analysis. The data was also checked for duplicate cases using the demographic information and IP addresses. No duplicates were found.

\section{Survey data analysis}

The data from the online survey was analysed in two parts according to whether they were closed-ended or open-ended responses. Data preparation and analysis was performed in Microsoft Excel and IBM SPSS. Missing data was excluded pairwise in the analysis.

Firstly, responses to the close-ended questions were re-coded where necessary, such as where a respondent typed a separate answer in an 'other' category. The sample was then analysed to identify the demographic characteristics of the participants and whether the sample was representative of the Wellington Region. The gender, age group, income and highest qualification of the sample were compared in frequency charts with the New Zealand 2013 Census data for the Wellington Region. The data was analysed using cross-tabulations, Pearson's chisquare test for association, multinomial logistic regression and Spearman's rankorder correlation test to better understand the relationship between the variables, in particular, the relationship between socio-demographics, neighbourhood and housing characteristics, travel preferences, attitudes to car ownership and interest in car sharing.

8 The response rate (or nonresponse) is calculated by dividing the number of individuals who receive the email invitation to complete the survey but fail to participate by the total number of potential participants invited to complete the survey. This cannot be determined for this study as the total number of potential participants is unknown (Sue \& Ritter, 2012). 
The analysis method for the open-ended survey responses will be discussed in the next section alongside the data analysis method for the semi-structured interviews.

\subsubsection{Interviews}

\section{Rationale}

Thirteen interviews were undertaken to explore in-depth the potential benefits of developing car sharing in Wellington and how it can support compact living and sustainable transport patterns. Interview participants were purposefully selected to best help with understanding the research problem and answering the research questions (Creswell, 2014b). The interviewees all had experience with car sharing, and diverse knowledge and perspectives on car sharing in Wellington (Creswell \& Clark, 2011). Business sector interviews were undertaken with representatives of the four Wellington-based car share providers and Meridian Energy. Meridian Energy has a business partnership with Mevo, one of the four, to supply the electricity for Mevo's hybrid-electric vehicles, and is a client of the car share company. Government sector interviews were also carried out with two officers and a councillor from Wellington City Council (WCC), two officers from Greater Wellington Regional Council (GWRC), two officials from the Ministry of Transport (MoT), and one official from the Energy Efficiency and Conservation Authority (EECA). The interviews with these agencies were particularly important as they provided necessary local and central government context, vital because of the lack of New Zealand based academic research on car sharing. Interviews were not undertaken with representatives of non-governmental organisations (NGOs). There appears to be very little active involvement of NGOs, as yet, in regard to car sharing issues in Wellington.

\section{Interview structure and guide}

The interviews took place face-to-face in Wellington, with one exception - an interview over Skype took place as the participant is based in Auckland. The interviews took between thirty minutes and one hour each, and were recorded and fully transcribed for analysis. An information sheet was given to all participants prior to the interviews; explaining the purpose of the research and what would be 
involved if they chose to participate. A consent form was also sent prior to the interview and was signed by the participant preceding the interview. All the interviewees are identified by their organisation only. ${ }^{9}$

The interviews were semi-structured, where an interview guide with open-ended questions was used but not strictly adhered to, which allowed the interviewees to expand on topics of significance to them and on topics of which they had more knowledge. The questions were formulated taking into account the literature review. The guide contained the following questions:

- How are you involved with car sharing in Wellington?

- What do you see as the main benefits of developing car sharing in Wellington?

- Who do you think will use car sharing in Wellington and why?

- What do you see as the main barriers facing car sharing in Wellington?

- How do you think these barriers might be overcome?

- How important are public transport, walking and cycling infrastructure for the success of car sharing?

- How important is compact/dense city form for the success of car sharing?

- How important is the use of hybrid/electric vehicles for the success of car sharing?

- How important are modern technologies for the success of car sharing?

- What is different/distinct about the New Zealand/Wellington context, compared with overseas?

Four of the thirteen participants requested full transcripts of their interviews and eight participants requested summaries of their interviews. These were sent to them following their interviews, and they had an opportunity to submit feedback. This feedback was taken into consideration during the analysis of the data.

9 The information sheet and consent form can be found in Appendix C. 
As noted previously, interviewees were purposefully selected for their relevance and knowledge in answering the research questions. The four car share providers who operate in Wellington (Mevo, YourDrive, Roam and Cityhop) were all contacted directly and representatives from each company agreed to an interview. Contacts within the city and regional councils were also approached who were known to have worked on or have knowledge of car share policy in Wellington. These initial contacts made further recommendations. This resulted in interviews with additional officers from the councils, as well as officials from MoT and EECA, and a representative from Meridian Energy. Table 6.1 shows the number of participants interviewed from each organisation.

Table 6.1. Organisation and number of participants interviewed

\begin{tabular}{|l|l|}
\hline $\begin{array}{l}\text { Organisation } \\
\text { Car share providers (Mevo, YourDrive, Roam, } \\
\text { Cityhop) }\end{array}$ & $\begin{array}{l}\text { N representatives (1 per } \\
\text { provider) }\end{array}$ \\
\hline Wellington City Council & 2 officers and 1 councillor \\
\hline Greater Wellington Regional Council & 2 officers \\
\hline Ministry of Transport & 2 officials \\
\hline Energy Efficiency and Conservation Authority & 1 official \\
\hline Meridian Energy & 1 representative \\
\hline Total & $\mathbf{1 3}$ \\
\hline
\end{tabular}

The number of participants was influenced by both coverage (as described above) and by saturation. Saturation is when gathering fresh data no longer generates new insights about the research problem (Creswell, 2014b). Guest, Bunce and Johnson make the evidence-based recommendation that twelve interviews should be sufficient for saturation for most research enterprises when the aim is to understand 'common perceptions and experiences among a group of relatively homogeneous individuals' (Guest, Bunce, \& Johnson, 2006, p. 79). They suggest that six interviews may be sufficient when the research is interested in high-level, overarching themes (Guest et al., 2006). After interviewing the representatives from the car share providers and the policy experts from WCC, GWRC, MoT and EECA, it was decided 
that saturation had been met for these groups, and further interviews would not substantially add to the data already collected.

A further opportunity arose to interview a representative from Meridian Energy. Meridian Energy's involvement with car sharing includes a business partnership with Mevo to supply the electricity for Mevo's hybrid-electric vehicles, and as a client of the car share company. This interview was pursued as it provided a different perspective on car sharing, and resulted in some fresh insights on car sharing from a business's perspective. Time constraints meant that further interviews with businesses were not sought. This is a limitation of this study, and an area for further research. This is discussed further in Chapter 8.

\section{Interview data analysis}

The interviews were transcribed and coded for common elements and themes, following a thematic analysis approach. Thematic analysis is a method for identifying, analysing, and reporting patterns and themes within a data set (Braun \& Clarke, 2006). A deductive approach was adopted (Figure 6.1) in which coding and theme development were directed by existing ideas and concepts from the literature review (Braun \& Clarke, 2006). This approach enabled a more detailed analysis of aspects of the data that would best answer the research questions, rather than a rich description of the data overall. Figure 6.1 outlines the different phases undertaken in the thematic analysis (Braun \& Clarke, 2006). The open-ended questions from the survey were also analysed using a thematic analysis approach. 


\begin{tabular}{|c|c|}
\hline $\begin{array}{r}\text { Familiarisation with } \\
\text { the data }\end{array}$ & $\begin{array}{l}\text { - The data was transcribed, and then read in its entirety so that } \\
\text { the content was familiar } \\
\text { - Initial ideas were noted down }\end{array}$ \\
\hline Codil & $\begin{array}{l}\text { - Coding was developed that identified the main features of the } \\
\text { data relevant to answering the research questions, directed } \\
\text { by existing ideas and concepts from the literature review } \\
\text { - The data was systematically coded }\end{array}$ \\
\hline $\begin{array}{r}\text { Searching for } \\
\text { themes }\end{array}$ & $\begin{array}{l}\text { - The codes were collated into potential themes, and then all } \\
\text { the data relevant to each potential theme was grouped } \\
\text { together }\end{array}$ \\
\hline Reviewing theme & $\begin{array}{l}\text { - The themes were refined, and checked back against the data } \\
\text { to ensure they still told a convincing story of the data }\end{array}$ \\
\hline $\begin{array}{r}\text { Defining and naming } \\
\text { themes }\end{array}$ & $\begin{array}{l}\text { - Detailed analysis of each theme was then undertaken, and } \\
\text { how each related to answering the research qeustions } \\
\text { - Informative name for each theme decided on } \\
\text { - A thematic 'map' of the analysis was generated }\end{array}$ \\
\hline & $\begin{array}{l}\text { - Compelling extract examples were selected, and weaved } \\
\text { together with analysis and related back to the research } \\
\text { questions and existing literature }\end{array}$ \\
\hline
\end{tabular}

Figure 6.1. Phases of thematic analysis (adapted from Braun and Clark (2006), Table 1, p.35).

Thematic maps of the analysis for both the interview results and open-ended survey questions can be found in Appendix D.

\subsection{Data collection limitations}

There are several limitations with the methods of data collection used in this study, which have already been mentioned briefly. An online survey was chosen because it is a fast and economic way of reaching a large population; however, it can limit participants to those who have internet access and basic computer literacy. The snowball recruitment method of encouraging people to forward the survey link on to their contacts resulted in a reasonably large sample size of 356 people. This provides strength to the results and conclusions that are drawn. However, this method also results in participants being self-selected, which can result in bias towards certain demographic groups. In terms of the interviews, coverage and saturation were achieved for both the car share providers and policy experts. 
However, further interviews could have taken place with businesses who use car sharing to gain a wider set of insights on the research problem. Further limitations of this research are discussed in Chapter 8.

\subsection{Summary}

In summary, this study has employed a pragmatic mixed method approach to collect quantitative and qualitative data on car sharing in Wellington. Data collected from the online survey of Wellington residents enabled statistical analysis of several key variables, such as attitudes to car ownership, travel preferences and interest in car sharing. The interviews with purposefully selected participants with diverse knowledge and perspectives on car sharing provided data for a thematic analysis of car sharing in Wellington. In particular, data collection focused on the benefits of car sharing, how it can support compact living and sustainable transport, and the barriers it is facing in Wellington. Chapter 7 presents the results of both the quantitative and qualitative analysis, addressing each of the research questions in turn. 


\section{Chapter 7 Results}

This chapter presents the main results of this study. It begins with an overview of the socio-demographic characteristics of the survey sample in comparison with the New Zealand 2013 census data for the Greater Wellington Region (Section 7.1). This is followed by both the quantitative and qualitative results from the survey and interview data, organised in order of the research questions and sub-questions. Section 7.2 addresses the first research question. It includes analysis of the potential benefits of car sharing in Wellington, who is interested in using car sharing, the importance of density for car sharing, and how it can support people living in central Wellington, whether car sharing offers an alternative to car ownership and is complementary to public transport, walking and cycling, and the importance of modern technologies for car sharing.

This is followed by Section 7.3 which addresses the second research question. It includes analysis of what concerns Wellington residents have about using car sharing and what would encourage them to use the service, the main barriers facing car sharing from different stakeholder perspectives and how these might be overcome. The most important results are summarised in the final section of this chapter (7.4).

In Chapter 8 the quantitative and qualitative results are compared and contrasted with each other and the findings from the literature review to answer each of the research questions. 


\subsection{Survey sample characteristics}

To understand the characteristics of the survey respondents, Figures 7.1 to 7.5 compare selected socio-demographics of the sample with the most recent New Zealand census data (2013) for the Wellington Region (Statistics New Zealand, 2013). As these figures demonstrate, the study sample was not representative of the population of the Wellington Region. This is likely due to the self-selection sampling method, the limitations of which were discussed previously in Chapter 6.

Most of the survey respondents lived in Wellington City (Figure 7.1). Wellington City, although it has the largest population base in the region, was nevertheless overrepresented in the sample compared to the other cities in the region. Females were overrepresented and males underrepresented in the survey sample compared to the Wellington Region (Figure 7.2). ${ }^{10}$ The age distribution of the sample (Figure 7.3) shows that there was a strong bias towards those aged between 25 and 34 and an underrepresentation of those aged 65 and over. There were also biases towards those with incomes between $\$ 50,001$ and $\$ 100,000$ (Figure 7.4) and those with a tertiary degree (Figure 7.5). ${ }^{11}$

10 The survey respondents were asked to identify which gender they most strongly identified with. The possible answers included 'male', 'female' and 'other'. The option to select 'other' was not available in the 2013 census. However, none of the survey respondents selected the 'other' option so it was not necessary to include this in the analysis.

11 The survey was only open to those 18 years of age or older. For Highest Qualification and Personal Income, the census includes those aged 15 and older. Therefore, for those two variables, the survey underrepresents those with a high-school qualification or no qualification, and those with a low income. 


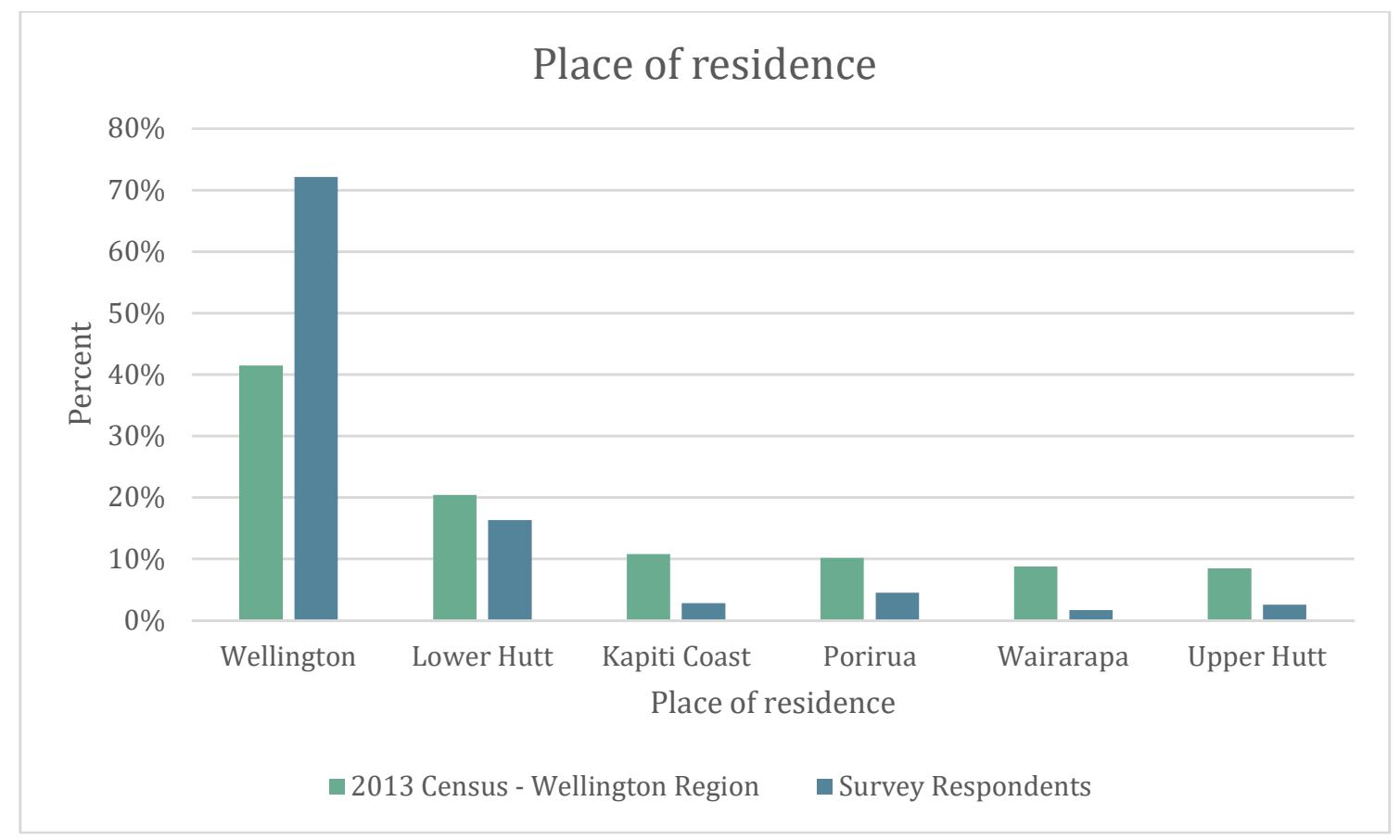

Figure 7.1. Place of Residence of the survey sample ( $n=355)$ compared with 2013 census data for the Wellington Region

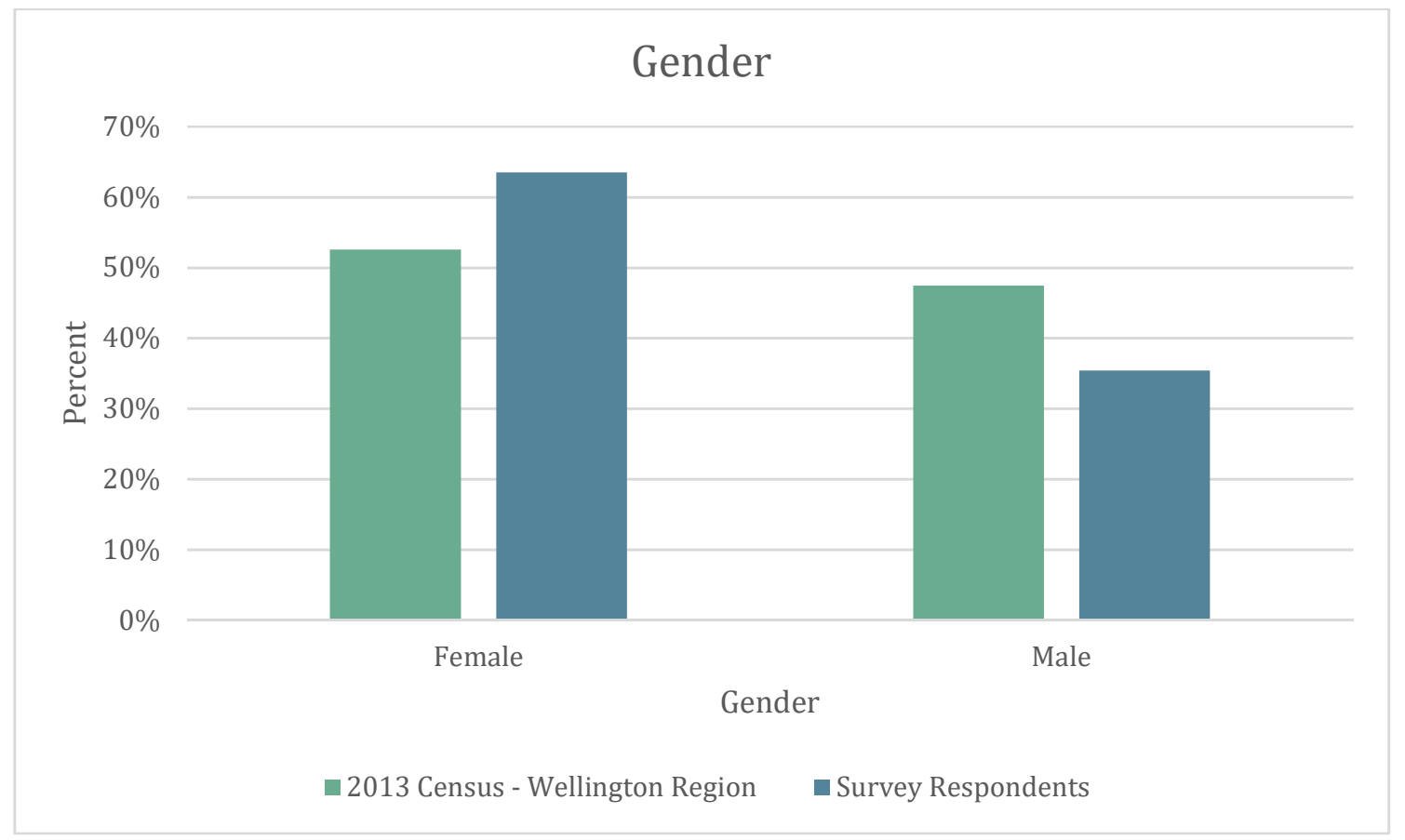

Figure 7.2. Gender of the survey sample (n=355) compared with 2013 census data for the Wellington Region 


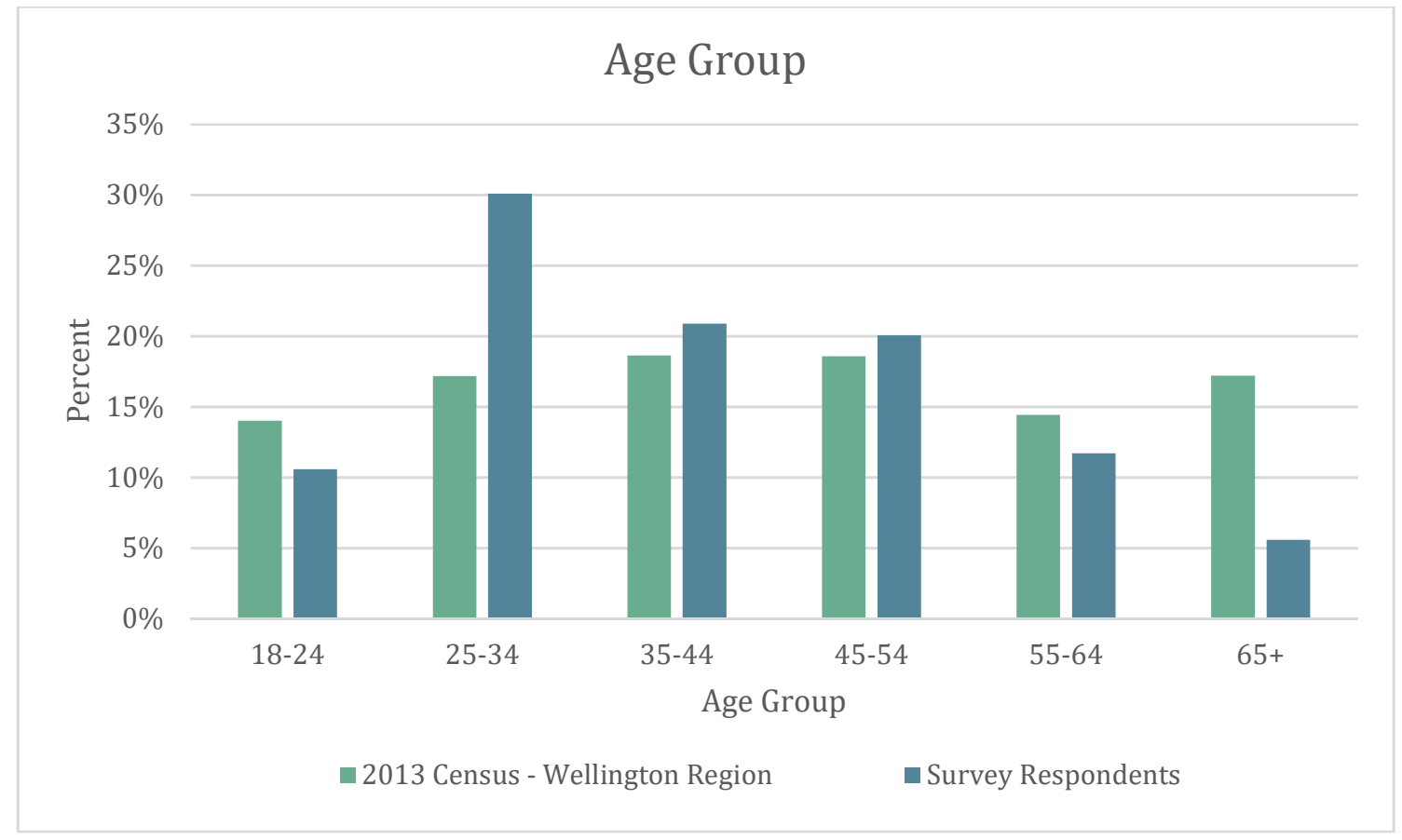

Figure 7.3. Age Group of the survey sample (n=355) compared with 2013 census data for the Wellington Region

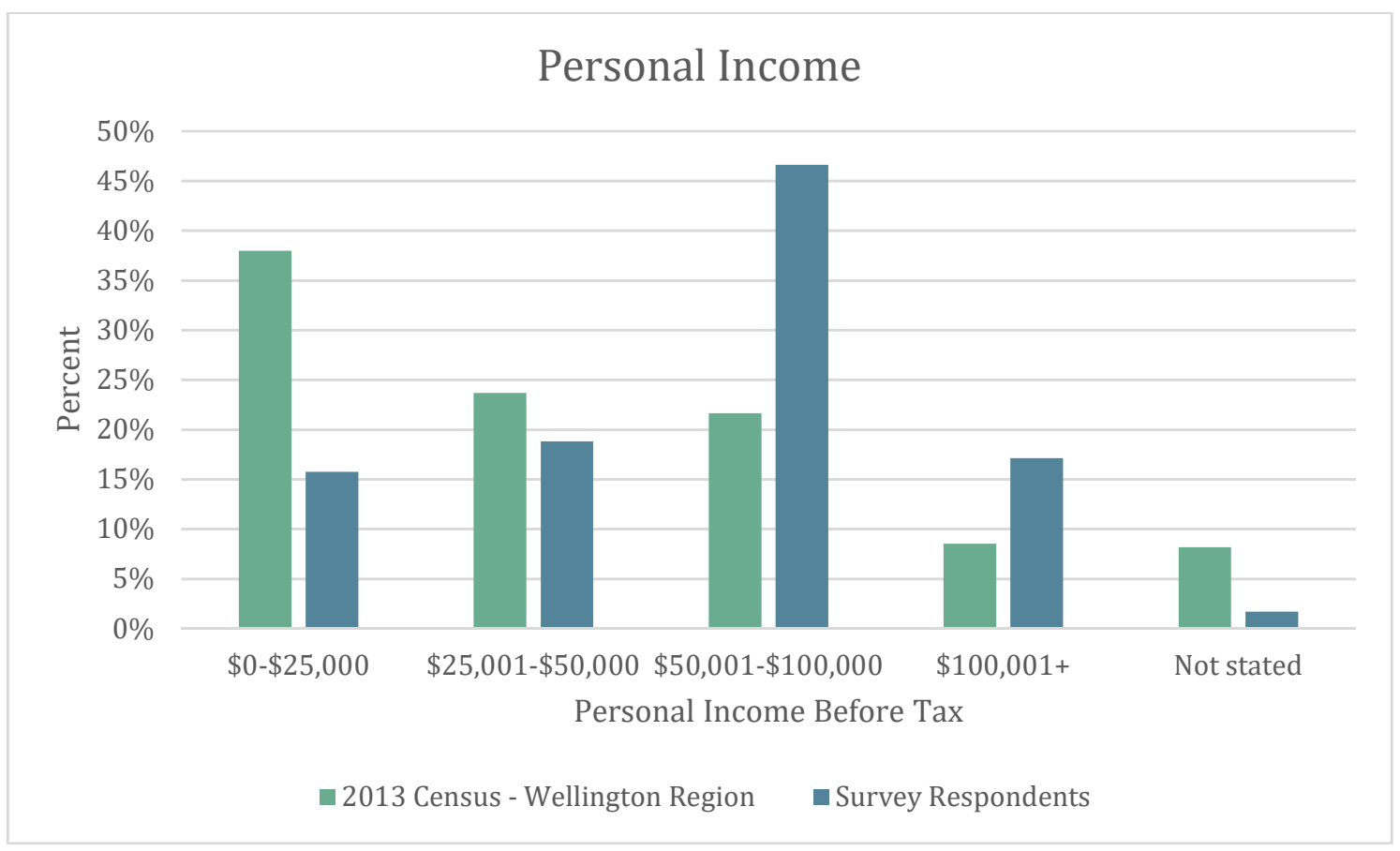

Figure 7.4. Personal Income Before Tax of the survey sample (n=356) compared with 2013 census data for the Wellington Region 


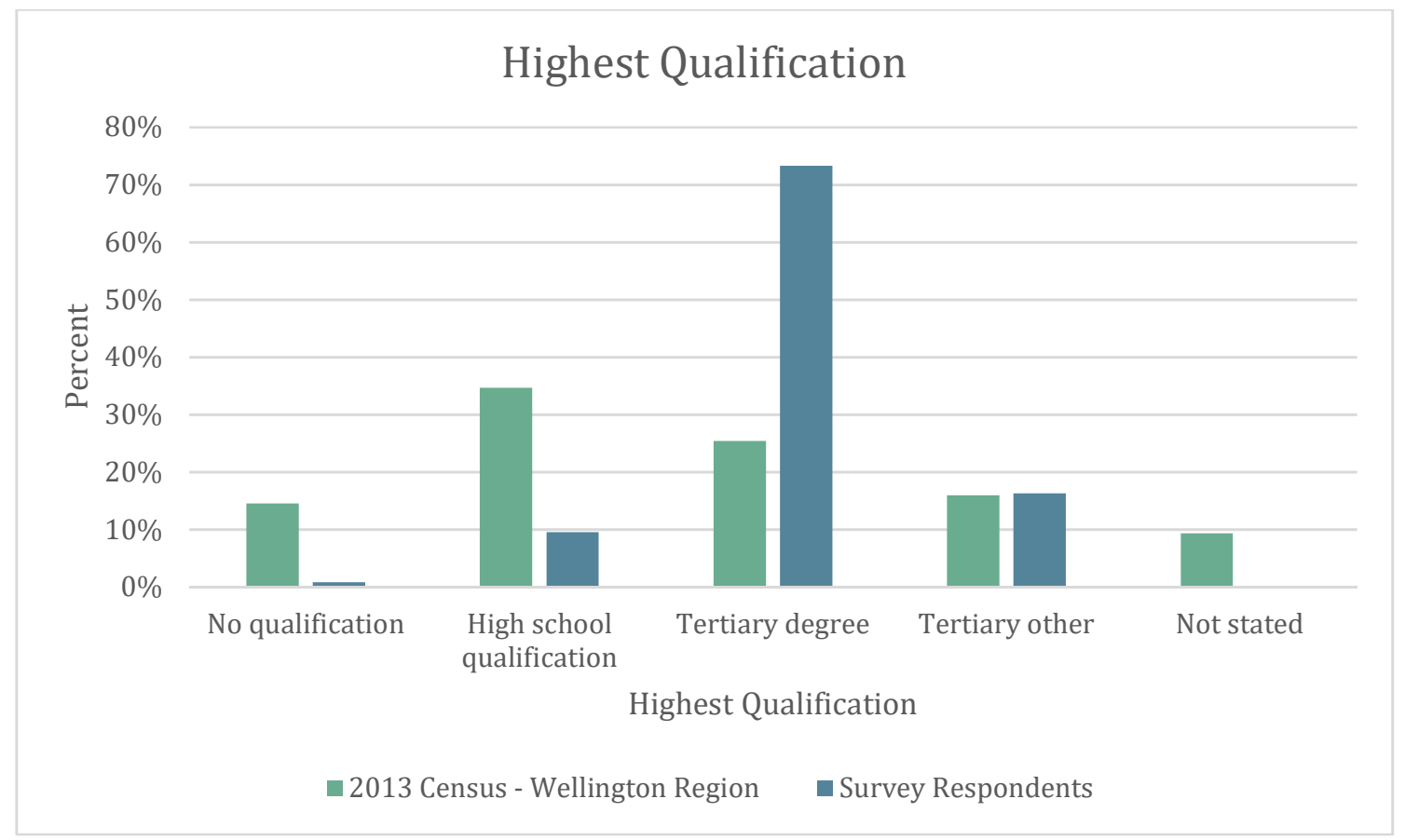

Figure 7.5. Highest Qualification of the survey sample ( $n=356)$ compared with 2013 census data for the Wellington Region 


\subsection{Research question 1}

\subsubsection{What do stakeholders see as the main benefits of car sharing?}

Interview results

The literature review showed that car sharing has potential to offer a range of social, economic and environmental benefits for a city. The stakeholders interviewed for this study were asked to identify the main benefits of developing car sharing in Wellington. This was with the intention that these benefits could be compared to those found in the literature in the discussion chapter (Chapter 8). The benefits identified by the stakeholders have been divided into seven thematic groups, which are presented in Figure 7.6. This section explains each of these thematic groups, and quotes from the interview participants have been included when they helpfully illustrate the theme under discussion.
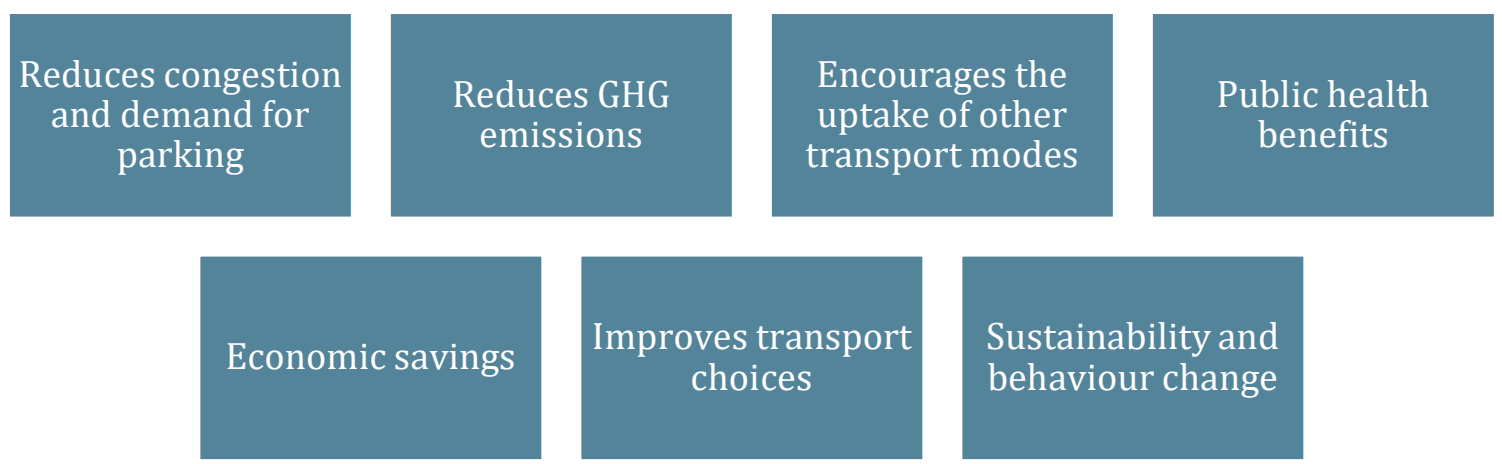

Figure 7.6. Benefits of car sharing 


\section{Reduces congestion and demand for parking}

Most of the participants put forward the potential for car sharing to reduce congestion, or take cars off the road, as its main benefit. This was closely tied with car sharing's ability to reduce demand for parking in the city, and free up valuable public space (Box 7.1).

"I think that car sharing can actually benefit the whole of the transport network because you only need to take a small number of cars off that network for it to work better." GWRC officer 1

"The real plus side of car share, for the public, is that it actually frees up a lot of very valuable public space. Which is parking. Parking, I just see as storage of a motor vehicle. And that's somewhat redundant, especially in a city, where real estate is valuable. And it's public space. And public space shouldn't be used for vehicle storage." WCC councillor

\section{Box 7.1. Reduces congestion and demand for parking}

\section{Reduces GHG emissions}

Several participants also considered the potential of car sharing to reduce GHG emissions a key benefit of the service. Many of the participants spoke about reducing GHG emissions and pollution, as well as improving air quality, as part of a discussion on the wider benefits of taking cars off the road (Box 7.2).

"I guess it's the number of cars each car share vehicle takes off the road. So, in terms of GHG emissions, conservatively 12 to 15 cars for every car share car is a good hit." WCC officer 1

"When people look at it [car sharing] marginally, they start to make more rational transport decisions, and that obviously reduces emissions, helps clean air, good for public health benefits, more walking and cycling. I think all those things we've seen to some degree already in New Zealand." YourDrive Representative

\section{Box 7.2. Reduces GHG emissions}




\section{Encourages the uptake of other transport modes}

Several participants spoke about how car sharing encourages the uptake of other modes of transport, including public transport, walking and cycling (Box 7.3). They discussed how people who car share, and do not own a car, do not have an implicit bias towards driving. Instead they tend to look at which travel mode is best for each journey, which can result in more sustainable transport choices.

"Taking cars off the road. Encouraging people to use other modes for short trips. So, in terms of those sort of car sharing benefits, is you can book a car when you need it for something specific, but you could be using a bike, or an electric bike, or walking or public transport for those shorter trips." GWRC officer 1

\section{Box 7.3. Encourages the uptake of other transport modes}

\section{Public health benefits}

Several participants noted that car sharing can also have public health benefits. These benefits are normally associated with the increase of active modes of travel (such as walking and cycling) when people forgo car ownership in favour of car sharing. A different perspective was provided by the representative from Meridian Energy, who spoke about how car sharing could improve the health and safety of their employees. Car share vehicles, like rental vehicles, are often modern vehicles with the latest safety features. This reduces the risk of accidents and injuries from driving. From this perspective, car sharing can not only benefit businesses concerned with health and safety, but also private users, who have the opportunity to drive safer vehicles.

\section{Economic savings}

Several participants spoke about the cost savings for individuals and businesses who take up car sharing instead of owning or buying a vehicle. Car sharing can offer individuals and businesses the freedom to use a car occasionally, without many of the costs associated with car ownership (Box 7.4). The representative from Meridian Energy spoke about how services like car sharing can help businesses avoid buying 
vehicles, which can be costly assets. Meridian Energy is moving away from buying fixed assets to adopting a 'Mobility as a Service' strategy. ${ }^{12}$

"There is no freedom like not owning a car. It is the best feeling in the world, to know that there's one there when you need it but you don't have to own it, you don't have to pay insurance, you don't have to maintain it, you don't have to do registration, you don't have to get a warrant of fitness, you don't have to worry about getting car parks. Real freedom is not owning a car, and it's how we allow people to have that experience" WCC officer 1

\section{Box 7.4. Economic savings}

One of the WCC officers also discussed the economic benefit from local car share companies keeping their profits in town (Box 7.5).

"Economically it's nice because you create a business that keeps the money in town, rather than if you purchase five vehicles, the vast majority of that money is going off to the manufacturers in Japan or Germany. Whereas having one vehicle in a car sharing operation that's being used by five people, the vast majority of that money stays with the car share operation." WCC officer 2

Box 7.5. Local economy benefits

\section{Improves transport choices}

Many of the participants also spoke about how car sharing can improve people's transport choices, giving them greater mobility (Box 7.6). Car sharing can also be a more flexible option than car ownership, giving people a range of vehicles to choose from to suit the purpose of their journey.

12 The term 'Mobility as a Service' (MaaS) refers to buying mobility services based on consumer requirements, instead of buying the means for mobility. For example, instead of owning a vehicle, a company could use a MaaS platform which includes an intermodal journey planner (providing combinations of different transport modes, such as car share, taxi, public transport), a booking system, easy-payment, and real-time information (Kamargianni, Li, Matyas, \& Schäfer, 2016). 
“It's giving people choice. We're very clear all the way along that it's not anti-car, it's pro-choice. And if we give people choices that are cheaper overall, are convenient and are easy then they're more likely to pick those things" WCC officer 1

\section{Box 7.6. Improves transport choices}

\section{Sustainability and behaviour change}

Several participants spoke about how important car sharing is for sustainability and behaviour change (Box 7.7). Car sharing could help move New Zealand away from being a car-centric culture. One of the WCC officers spoke about how car sharing can help speak about sustainability because it makes economic, social and environmental sense, and is not politically divisive.

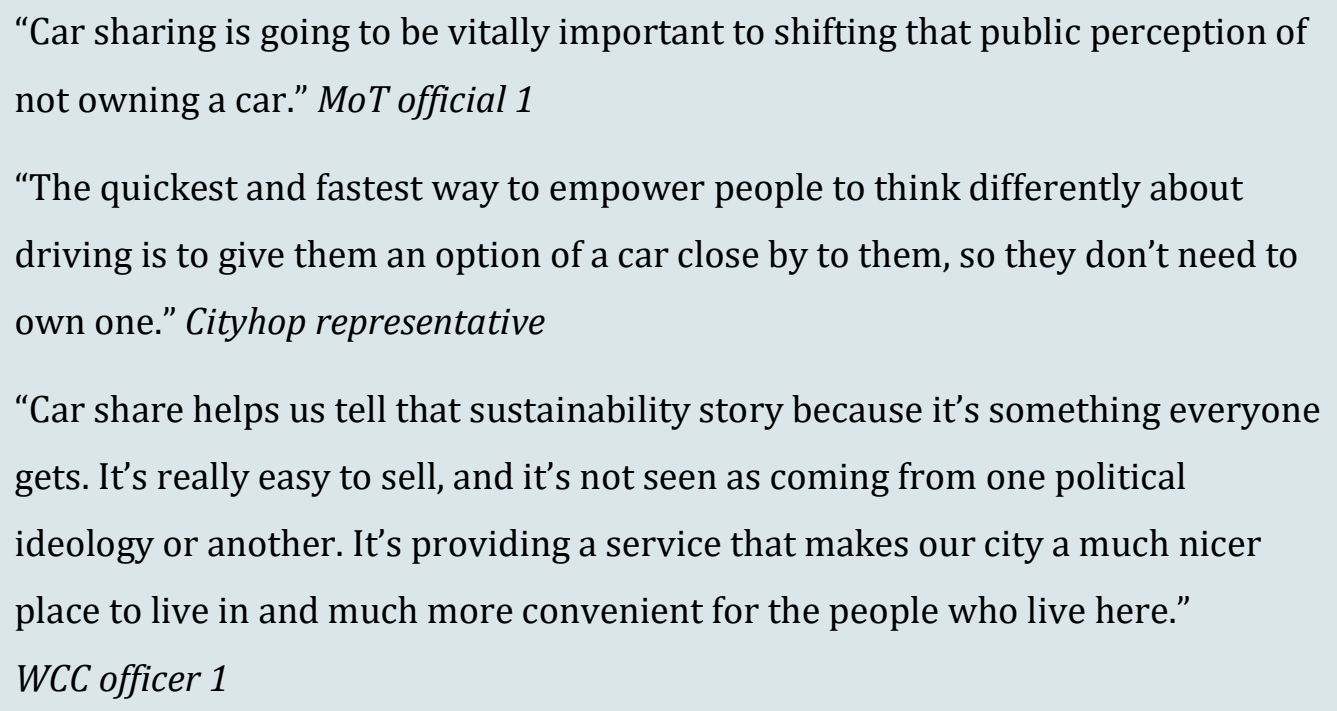

Box 7.7. Sustainability and behaviour change 


\subsubsection{Who is interested in using car sharing?}

The literature review showed that car sharing services are popular with certain socio-demographic groups and neighbourhood types. This section compares the survey respondents' socio-demographics, dwelling and neighbourhood characteristics, access to a car, car ownership and car use with their interest in using car sharing. ${ }^{13}$ These variables are all tested for their statistical significance using the Pearson's chi-square test for association. This is followed by a multinomial logistic regression model, to determine which of these variables is the most statistically significant for predicting interest in car sharing. The interview participants were also asked who they thought will use car sharing in Wellington or, for the car share providers already operating in New Zealand, who currently uses their services.

Survey results

Figure 7.7 shows that 18 percent of respondents were 'very interested' in car sharing, 57 percent were 'somewhat interested' and 25 percent were 'not at all interested'. Figure 7.8 compares the survey respondents' interest in car sharing based on their place of residence, divided into Wellington City and Wellington Region (excl. Wellington City). There were fewer respondents from outside Wellington City, so they were grouped together for comparison with Wellington City. ${ }^{14}$ A higher percentage of Wellington City respondents were 'very interested' in car sharing compared to the other group. A Pearson's chi-square test of association was conducted between the two variables, and found they did not have a statistically significant association $\left(\chi^{2}(1)=3.068, p=0.216\right) .{ }^{15}$

13 As discussed in the methodology, the survey was open to all Wellington residents, 18 years of age and older. As the survey did not solely target current car share users, there are very few in the sample $(n=10)$. However, the survey asked all the respondents about their level of interest in car sharing. This enabled analysis of the survey respondents most interested in car sharing, for comparison with the characteristics of car share users overseas.

14 The 'Wellington Region (excl. Wellington City)' group includes Lower Hutt, Upper Hutt, Porirua, the Kapiti Coast and the Wairarapa. This group had $n=98$ responses versus Wellington City's $\mathrm{n}=246$ responses.

15 For the Pearson's chi-square test of association, a value is considered statistically significant if $p<0.05$. The test also assumes all expected cell frequencies are greater than five. 


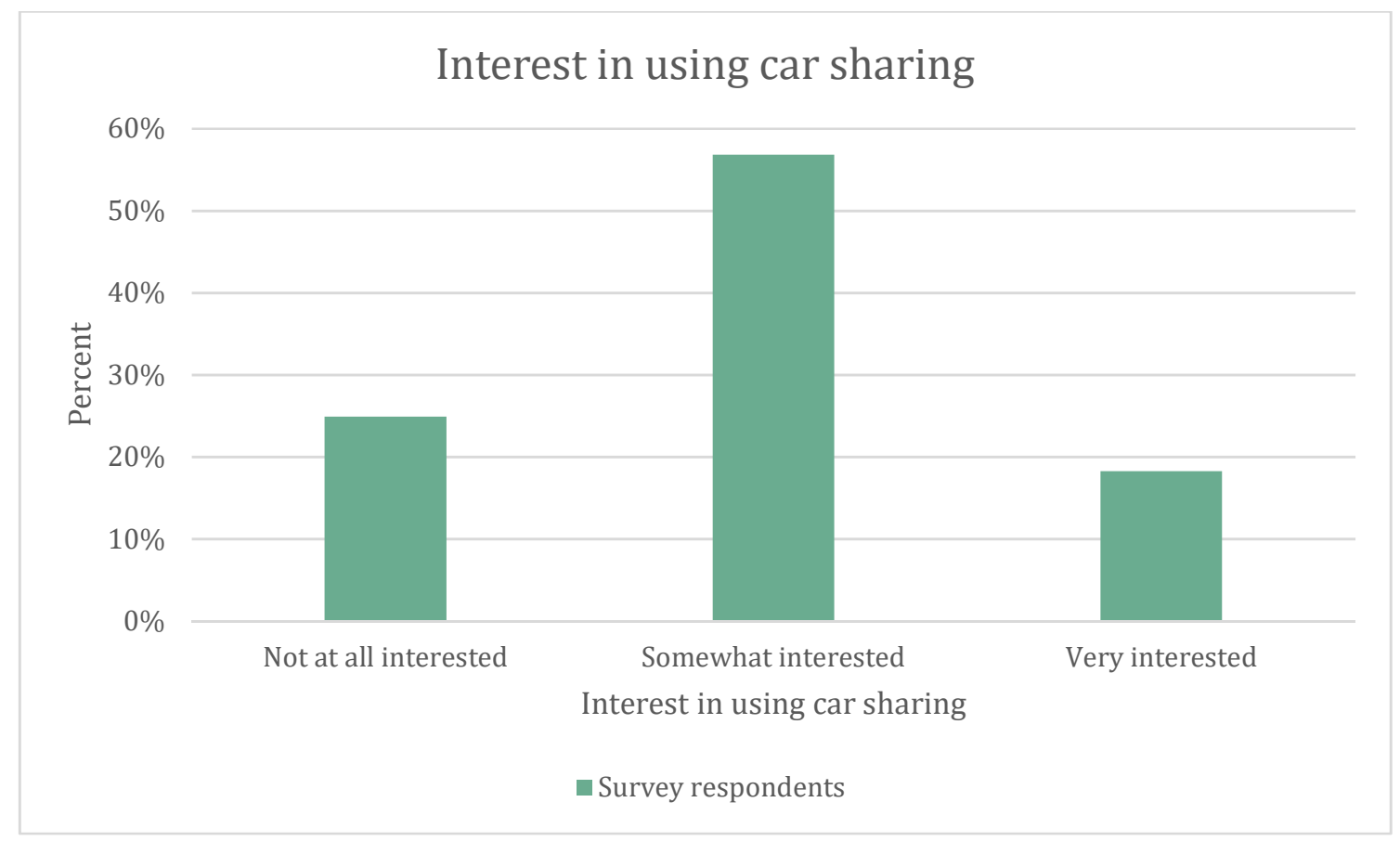

Figure 7.7. Interest in using car sharing ( $n=345)$

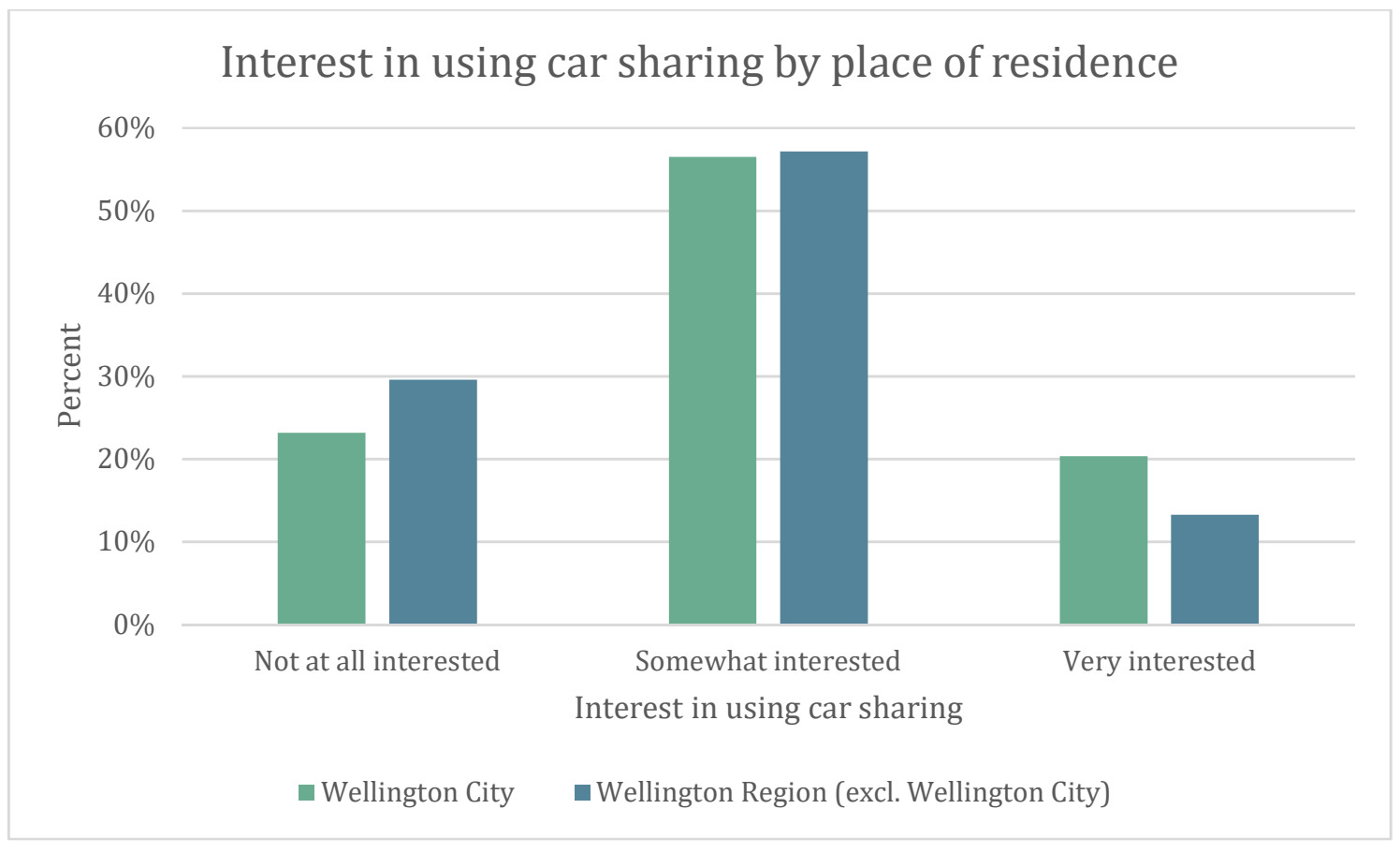

Figure 7.8. Interest in using car sharing by place of residence $(n=344)$ 
Figure 7.9 shows the survey respondents' interest in car sharing by their gender. A chi-square test found that these variables did not have a statistically significant association $\left(\chi^{2}(1)=0.839, p=0.657\right)$.

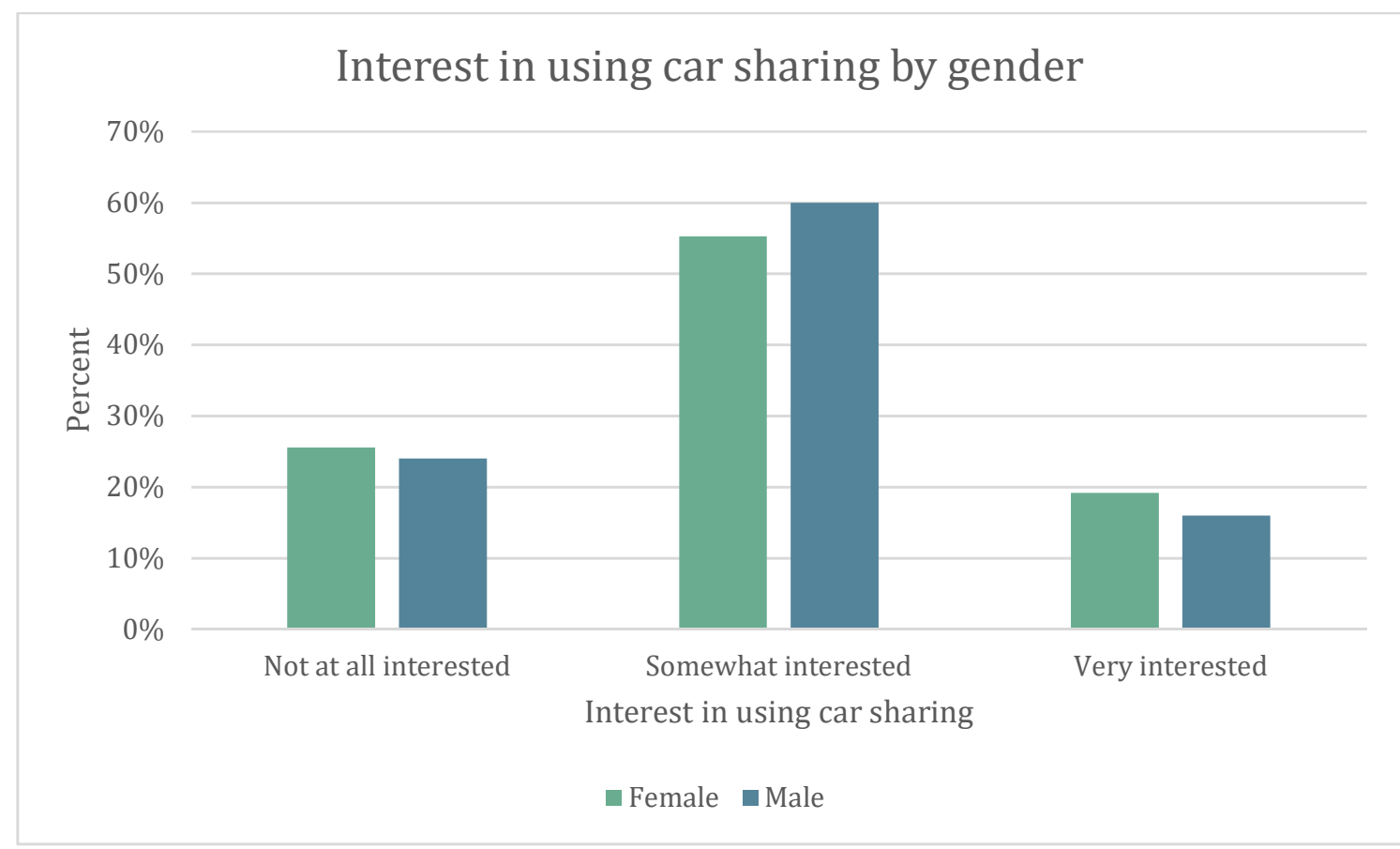

Figure 7.9. Interest in using car sharing by gender $(n=345)$

Figure 7.10 compares the survey respondents' interest in car sharing by their age group. A higher percentage of the survey respondents in the younger age brackets were 'very interested' in car sharing in comparison to those in the older age brackets. The middle to older age groups, particularly the group '45-54', were the highest percentage in the 'not at all interested' category. A chi-square test found that the two variables did not have a statistically significant association $\left(\chi^{2}(1)=13.663\right.$, $p=0.189) \cdot{ }^{16}$

Figure 7.11 compares the survey respondents' interest in car sharing by their personal income. The survey respondents earning more than $\$ 100,000$ were the highest percentage in the 'not at all interested' in car sharing category. This group were also the lowest percent in the 'very interested' in car sharing category. A chi-

16 This test did not meet the assumption that all expected cell frequencies are greater than 5 ( 2 cells $(11.1 \%)$ had an expected count of less than $5(3.66,4.9))$. This means that this result might not be valid. 
square test found that these two variables did not have a statistically significant association $\left(\chi^{2}(1)=7.520, p=0.275\right)$.

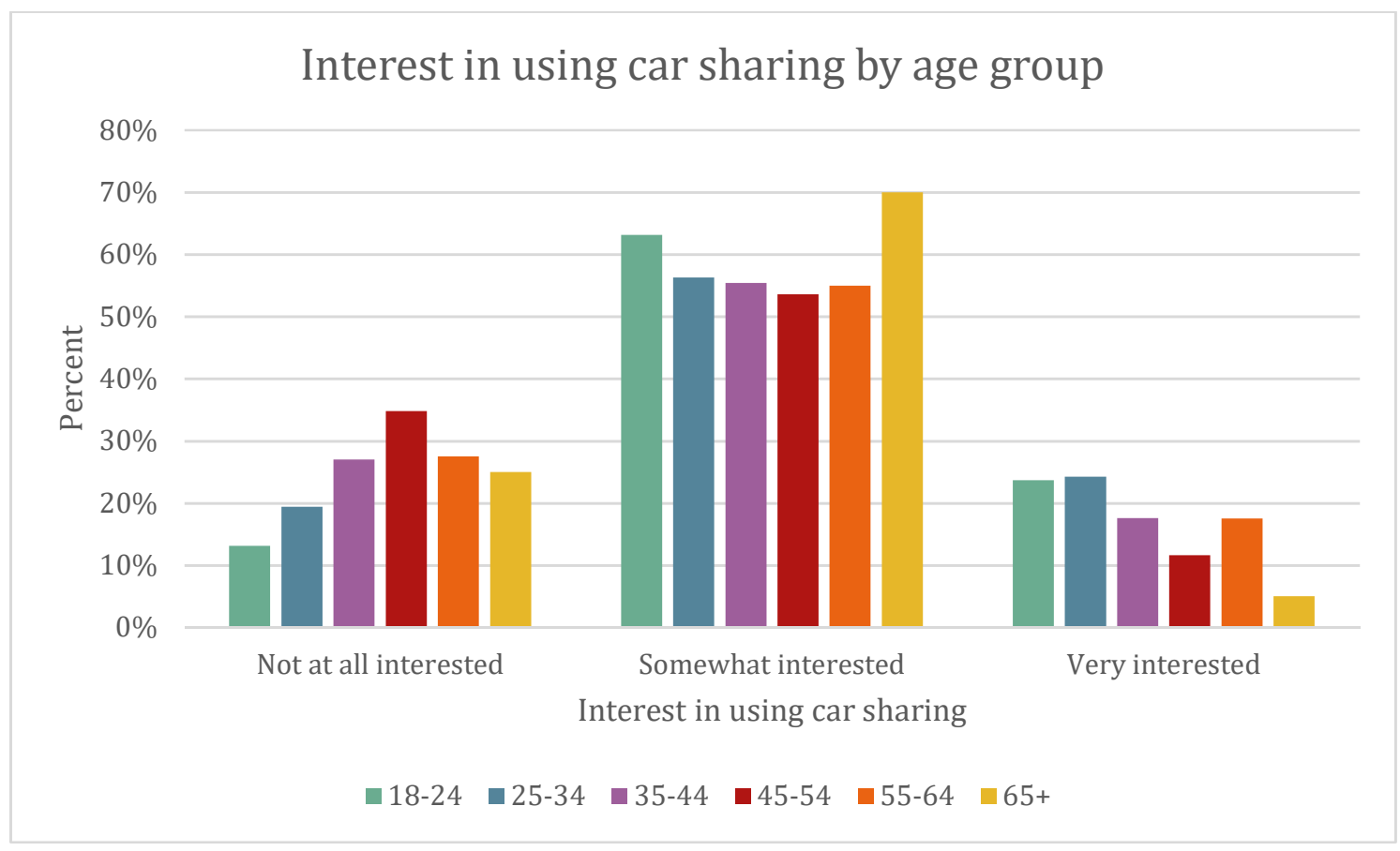

Figure 7.10. Interest in using car sharing by age group ( $n=344)$

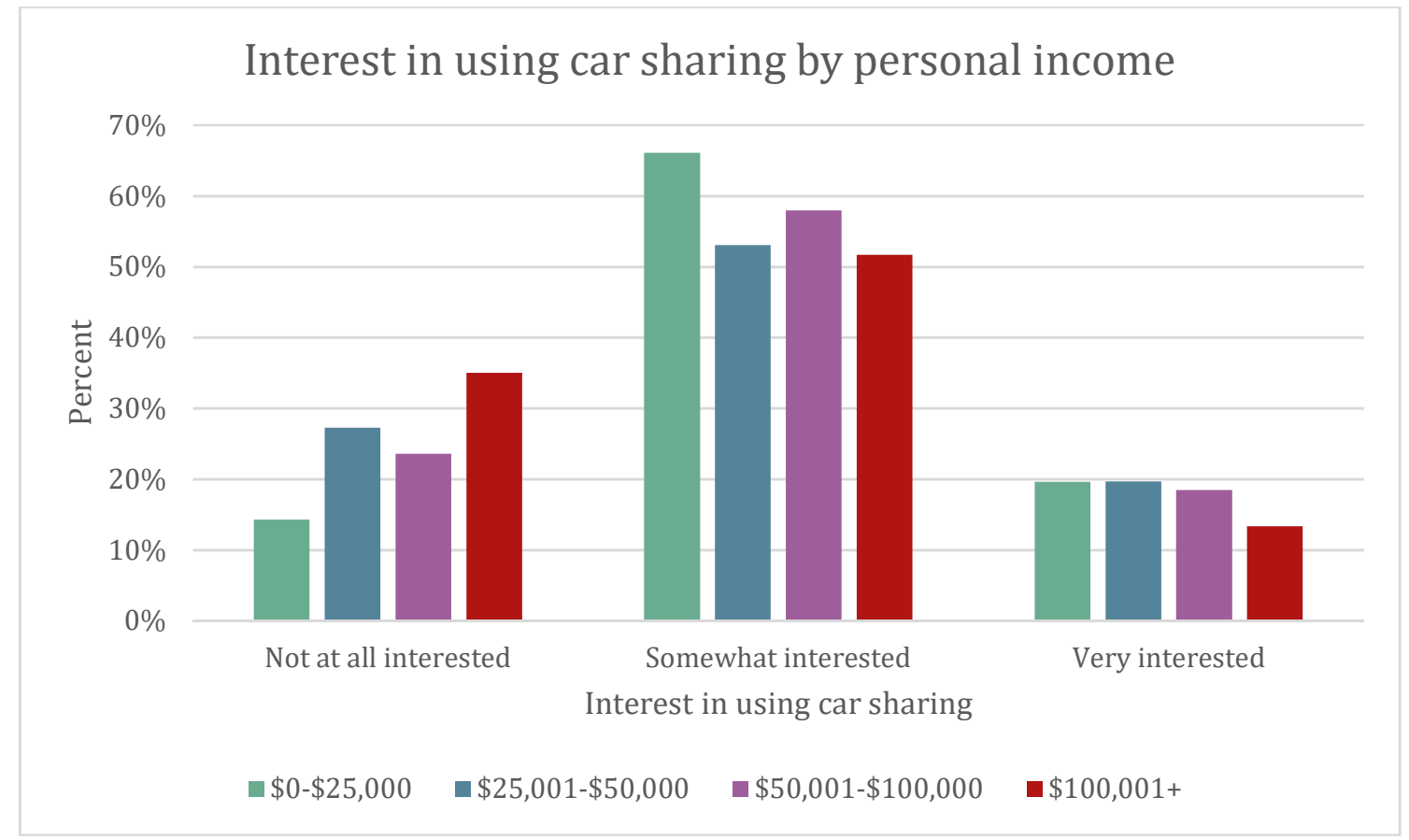

Figure 7.11. Interest in using car sharing by personal income before tax ( $n=339)$ 
Figure 7.12 compares the survey respondents' interest in car sharing by their highest qualification. Those with a high-school qualification were the highest percentage in the 'not at all interested' in car sharing category. They were also the lowest percentage in the 'somewhat interested' and 'very interested' in car sharing categories. ${ }^{17} \mathrm{~A}$ chi-square test found that the two variables did not have a statistically significant association $\left(\chi^{2}(1)=2.388, p=0.665\right)$.

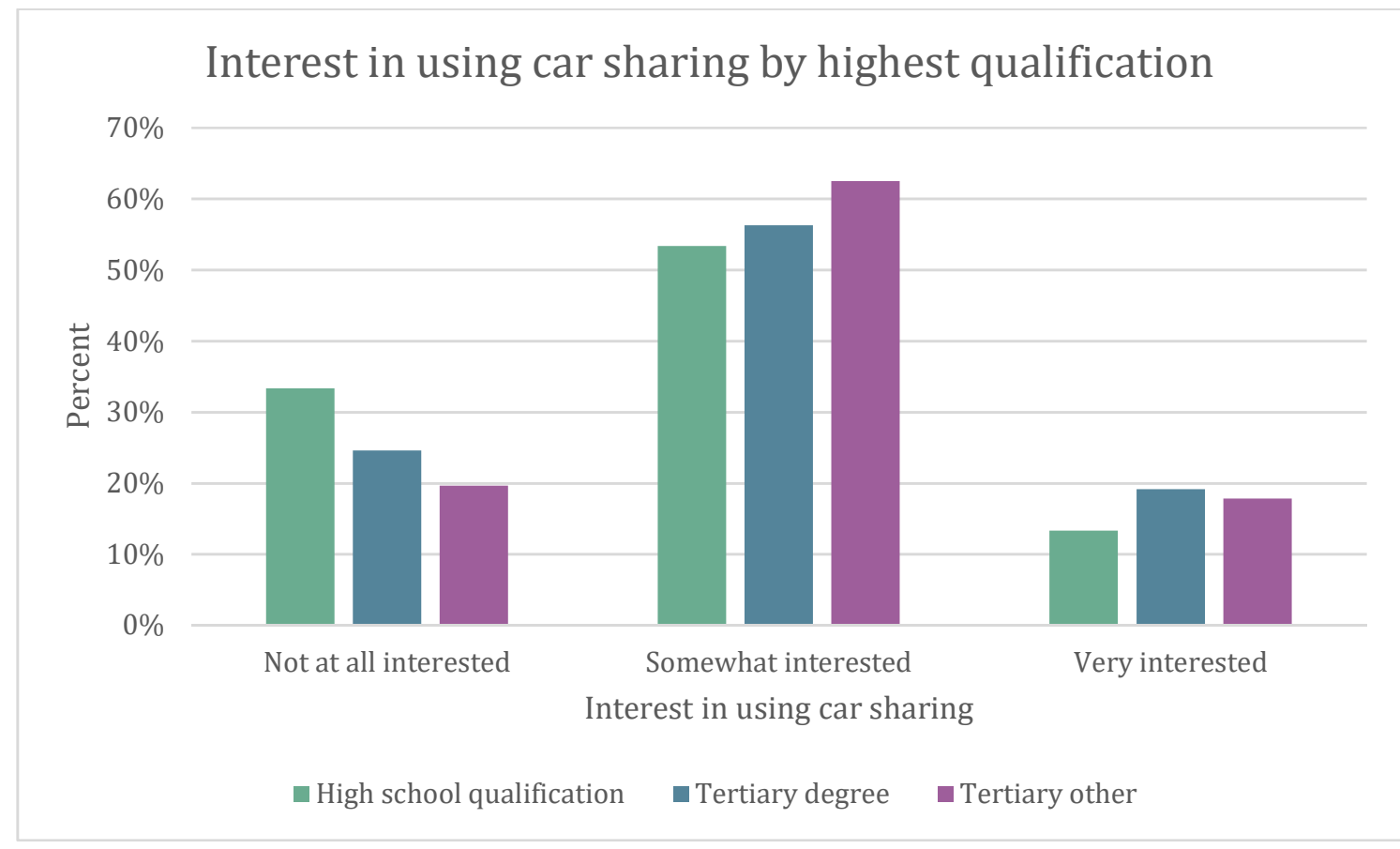

Figure 7.12. Interest in using car sharing by highest qualification $(n=342)$

17 Only three respondents selected 'no qualification', so this option was removed from analysis because it skewed the results. 
Figure 7.13 compares the survey respondents' interest in car sharing by their employment. The respondents who were not in paid employment/retired were the highest percentage in the 'not at all interested' in car sharing category. They were also the lowest percentage in the 'very interested' category. ${ }^{18} \mathrm{~A}$ chi-square test found that these two variables did not have a statistically significant association $\left(\chi^{2}(1)=7.529, p=0.275\right) .{ }^{19}$

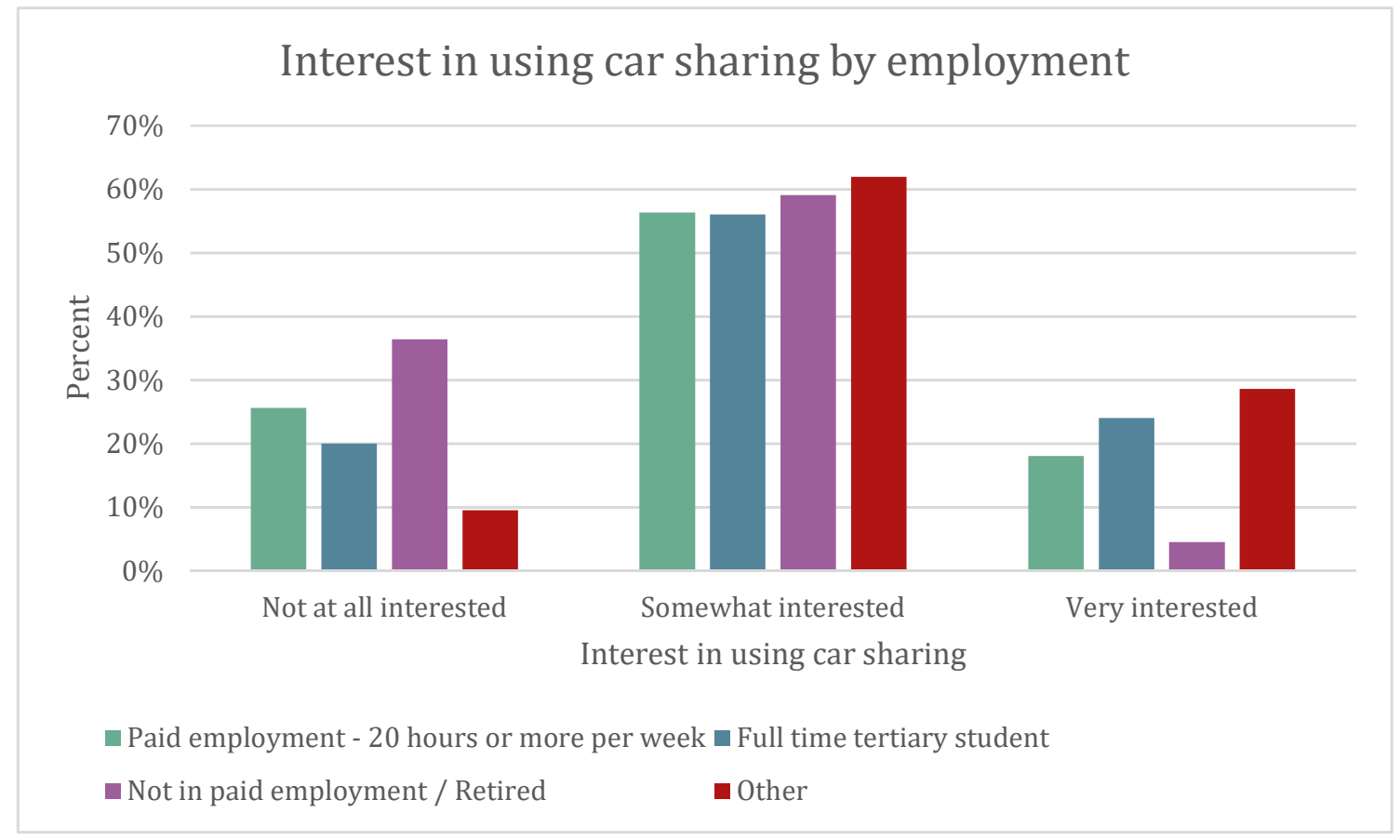

Figure 7.13. Interest in using car sharing by employment $(n=345)$

18 The category 'other' $(\mathrm{n}=21)$ includes those who work part-time, study part-time, work and study part-time, or selected the 'other' option in the survey. They were grouped together as there were few responses for each of their individual categories.

19 This test did not meet the assumption of all expected cell frequencies being greater than five (3 cells $(25 \%)$ had an expected count of less than five $(3.8,4.0,4.6))$. This means that this result might not be valid. 
Figure 7.14 compares the survey respondents' interest in car sharing by their household type. The household types which included children living at home had much higher percentages in the 'not at all interested' in car sharing category compared with the other groups. A chi-square test was conducted between interest in car sharing and household type, and found that they did have a statistically significant association $\left(\chi^{2}(1)=16.857, p=0.032\right)$. However, this test did not meet the assumption of all expected cell frequencies being greater than five (3 cells $(20 \%)$ had an expected count of less than $5(1.5,2.0,4.5))$. These counts were all in the 'Single with children living at home' category. This is due to the small number of respondents in this group $(n=8)$. These respondents were removed, and the chisquare test re-run, which resolved the cell frequency problem $\left(\chi^{2}(1)=15.753\right.$, $p=0.015$ ). The two variables had a weak association (Cramer's V $=0.153, p=0.015$ ).

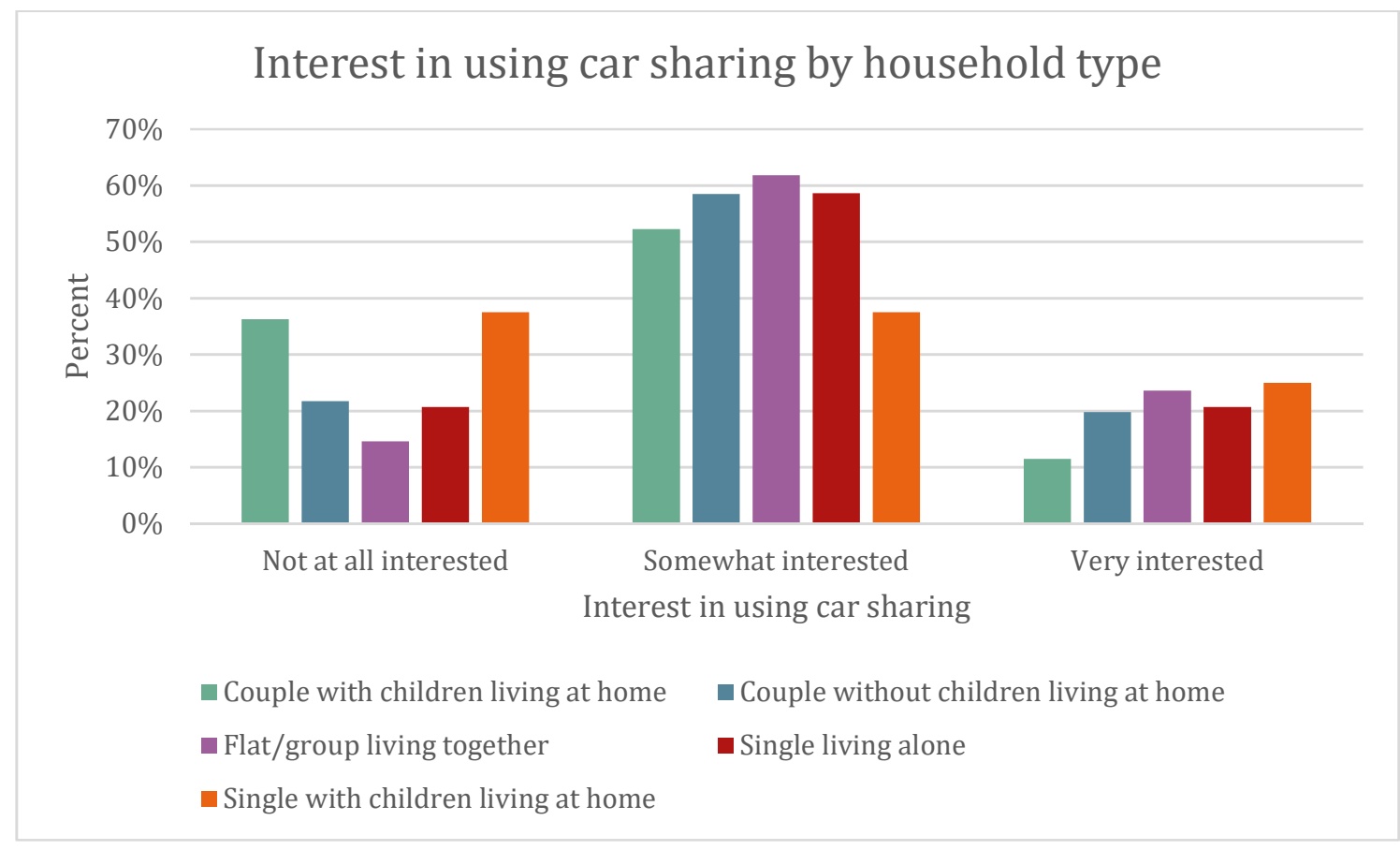

Figure 7.14. Interest in using car sharing by household type ( $n=345)$ 
Figure 7.15 compares the survey respondents' interest in car sharing by their type of dwelling. A higher percentage of respondents who lived in apartments (high or low rise) were 'very interested' in car sharing compared to the other dwelling types.

Conversely, the respondents who lived in town houses or standalone houses had the highest percentages in the 'not at all interested' in car sharing category. A chi-square test was conducted between interest in car sharing and dwelling type, and found that they did not have a statistically significant association $\left(\chi^{2}(1)=9.263\right.$, $p=0.159) .20$

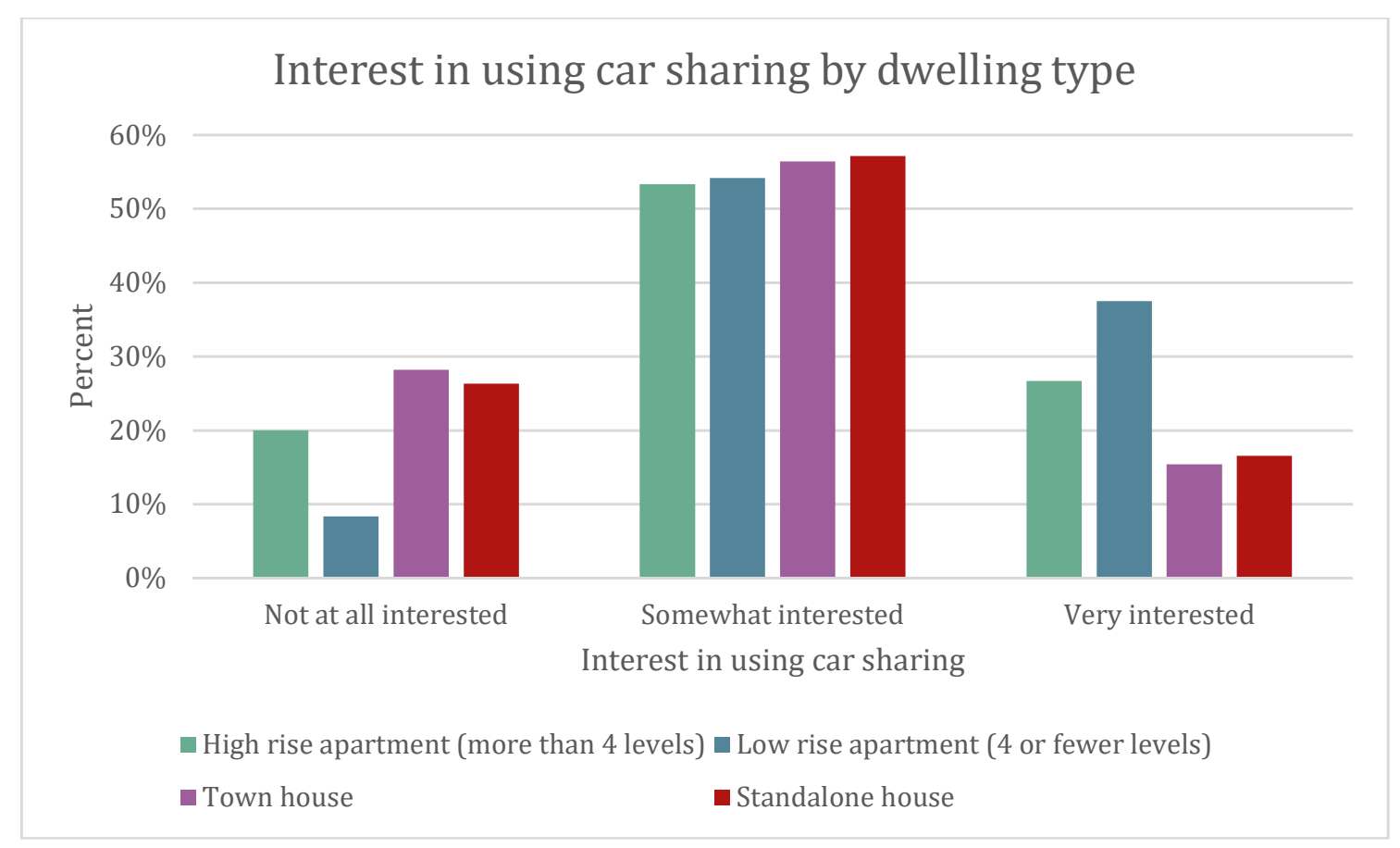

Figure 7.15. Interest in using car sharing by dwelling type $(n=345)$

20 This test did not meet the assumption of all expected cell frequencies being greater than five 3 cells $(25.0 \%)$ had an expected count of less than $5(2.7,3.8,4.4))$. These cells were in the high and low-rise apartment categories, and so these two categories were grouped together and the chisquare test re-run. The test found that the two variables, while closer, still did not have a statistically significant association $\left(\chi^{2}(1)=8.167, p=0.086\right)$. This time there were no expected cell frequencies less than five. 
Figure 7.16 compares the survey respondents' interest in car sharing by the density of their neighbourhood. The respondents who lived in areas primarily made up of apartments/town houses or a mix of standalone houses and apartments/town houses had higher percentages in the 'very interested' category in comparison to those who lived in areas made up of primarily standalone houses. Conversely, those who lived in areas made up of primarily standalone houses were the highest percentage in the 'not at all interested' in car sharing category. A chi-square test found that the two variables did not have a statistically significant association $\left(\chi^{2}(1)=7.770, p=0.100\right) \cdot{ }^{21}$

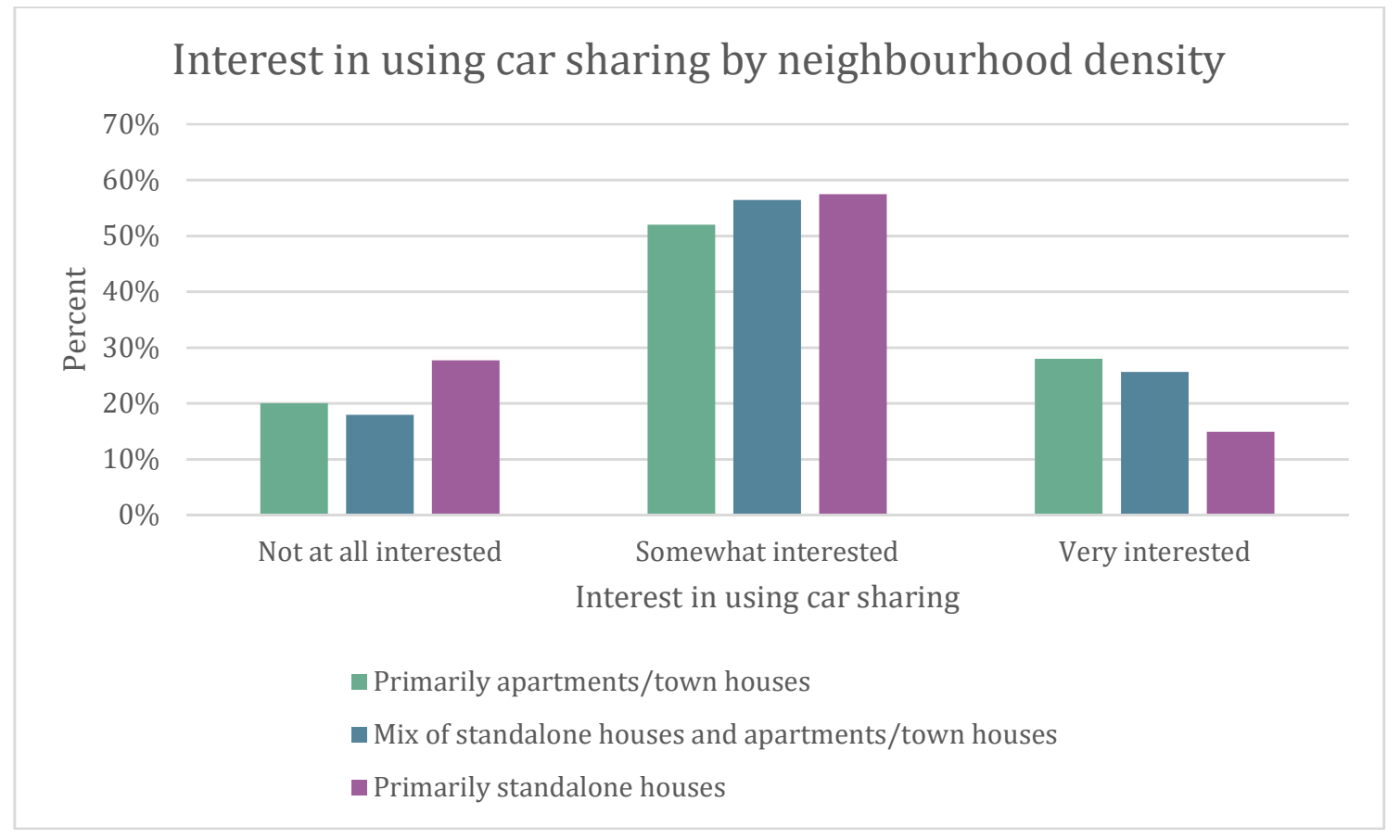

Figure 7.16. Interest in using car sharing by neighbourhood density ( $n=345$ )

21 This test did not meet the assumption of all expected cell frequencies being greater than five (1 cell (11.1\%) had an expected count of less than 5 (4.57)). This means that this result may not be valid. 
Figure 7.17 compares the survey respondents' interest in car sharing by their level of access to a car. The respondents who 'rarely' had access to a car are by far the highest percentage in the 'very interested' in car sharing category. Those who 'never' had access to a car are the highest percentage in the 'not at all interested' in car sharing category. This may reflect the small number of respondents who stated that they never have access to a car $(n=10)$. The respondents who had access to a car 'all of the time' were the next highest percentage in the 'not at all interested' category. A chi-square test for association was conducted between interest in car sharing and car access, and found that they do have a statistically significant association $\left(\chi^{2}(1)=38.368, p<0.0001\right) .{ }^{22}$ The variables were found to have a moderately strong association (Cramer's $\mathrm{V}=0.236, p<0.0001$ ).

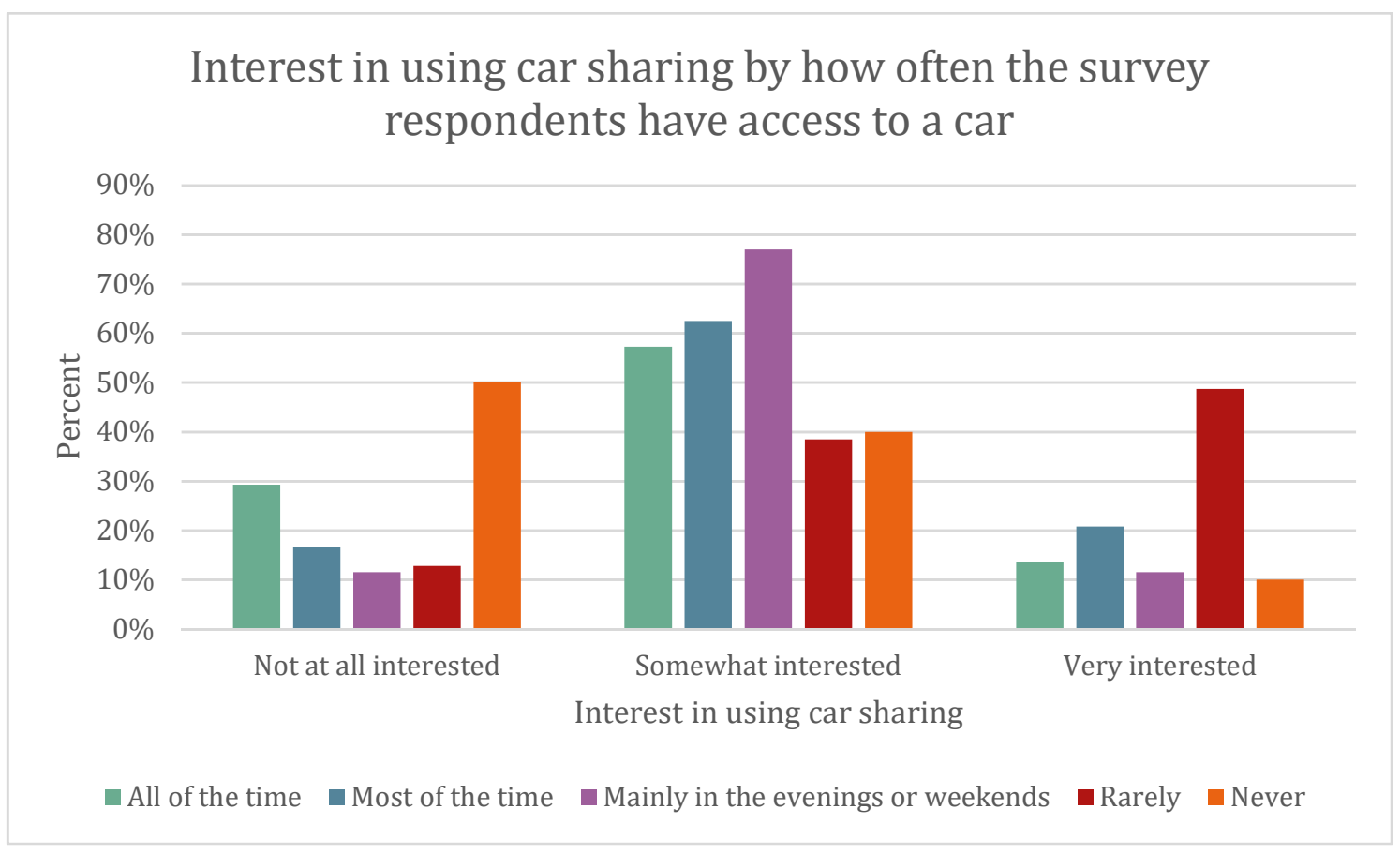

Figure 7.17. Interest in using car sharing by access to a car ( $n=345)$

22 This test did not meet the assumption of all expected cell frequencies being greater than five (3 cells $(20.0 \%)$ had an expected count of less than $5(1.8,2.5,4.7))$. These cells were across three different groups, and therefore it was not practical to remove or merge any of these groups to remove the cell frequency issue in the analysis. Therefore, the results may not be valid. 
Figure 7.18 compares the survey respondents' interest in car sharing by whether or not they owned one or more vehicles. The survey respondents who did not own a car had a far higher percentage in the 'very interested' in car sharing category than those who did own one or more vehicles. Those who did own a car or cars had a higher percentage in the 'not at all interested' category than those who did not own a car. A chi-square test found that the two variables do have a statistically significant association $\left(\chi^{2}(1)=18.421, p=0.0001\right)$. There was a moderately strong association between the variables (Cramer's $\mathrm{V}=0.231, p=0.0001$ ).

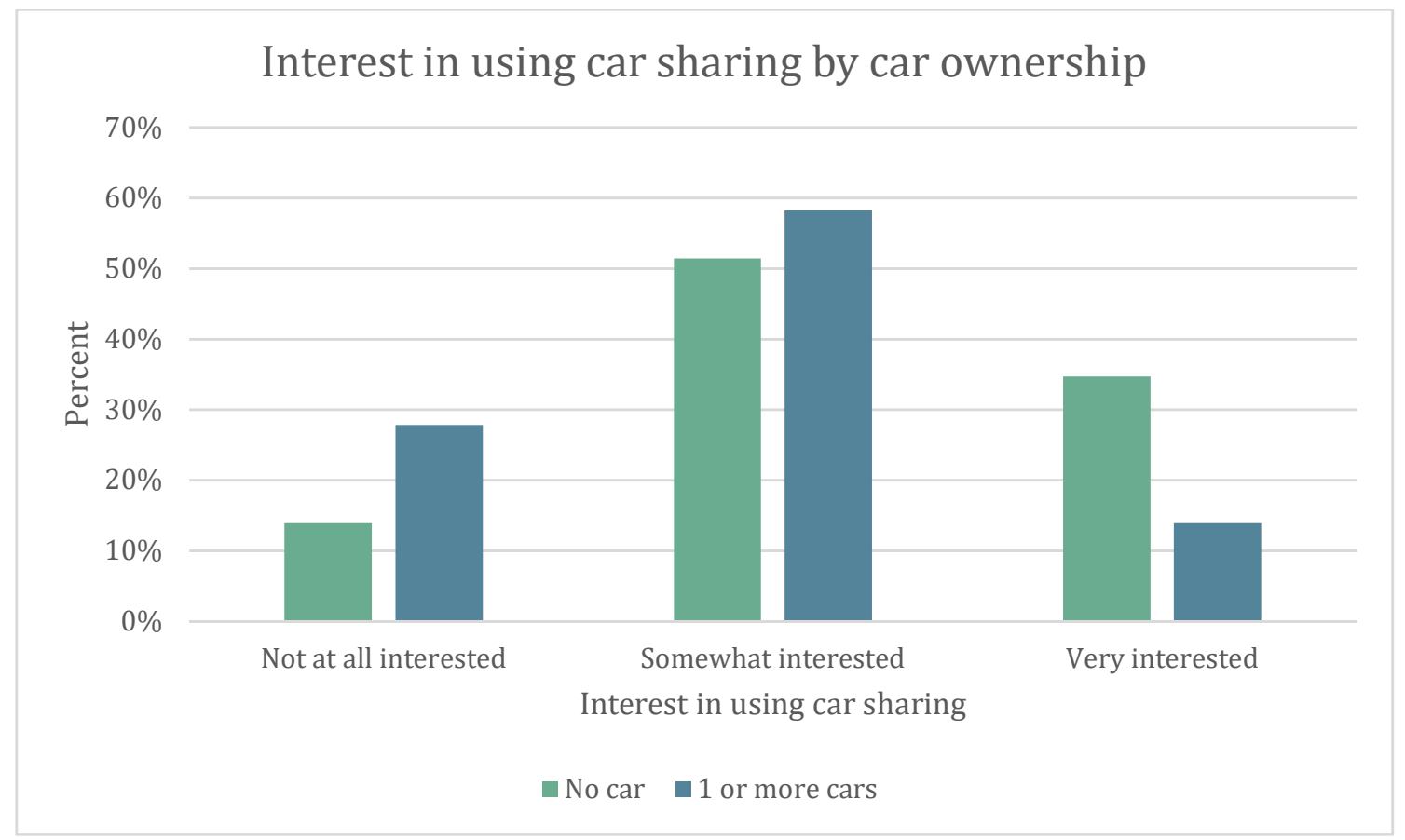

Figure 7.18. Interest in using car sharing by car ownership ( $n=345)$ 
Figure 7.19 compares the survey respondents' interest in car sharing with how often they used a car. The respondents who used their car 'one day or less a week' and 'never' had the highest percentages in the 'very interested' in car sharing category. Those who 'never' used a car are also the second highest percentage in the 'not at all interested' in car sharing category. The highest percentage in the 'not at all interested' category was by the group who used their car 'every day of the week'. A chi-square test found that the two variables did have a statistically significant association $\left(\chi^{2}(1)=42.012, p<0.0001\right) .{ }^{23}$ There was a moderately strong association between the variables (Cramer's V $=0.247, p<0.0001$ ).

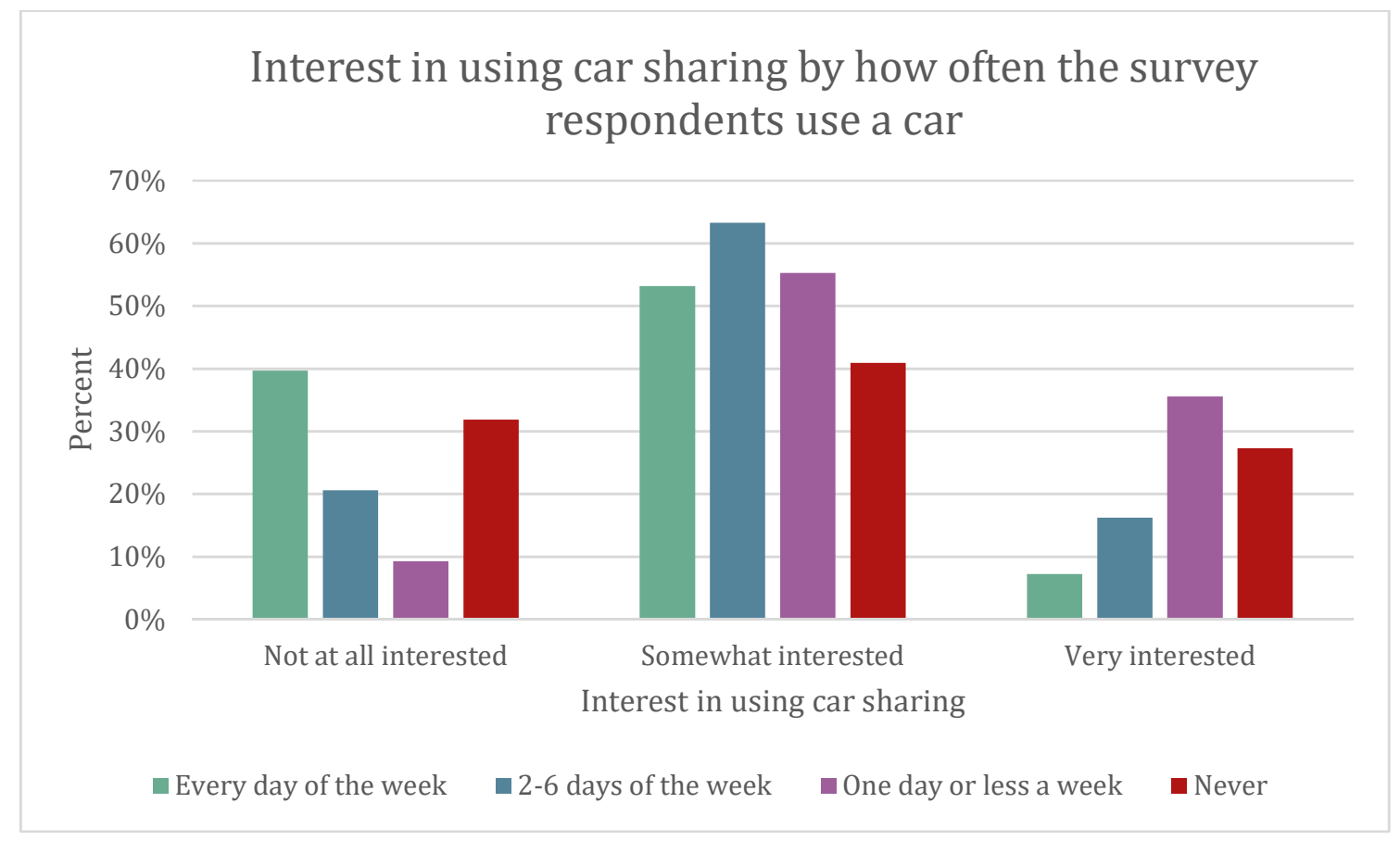

Figure 7.19. Interest in using car sharing by car use ( $n=345)$

23 This test did not meet the assumption of all expected cell frequencies being greater than five (1 cell (8.3\%) had an expected count of less than 5 (4.02)). This means that this result may not be valid, however the test was not rerun as merging the categories would have limited the analysis. 


\section{Multinomial logistic regression}

The previous section showed that interest in car sharing had a weak association with household type, and moderately strong associations with access to a car, car ownership and car use. This section takes this analysis further by conducting a multinomial logistic regression to determine which, if any, of the variables discussed above is the best predictor of interest in car sharing. Multinomial logistic regression (multinomial regression) is used to predict a nominal dependent variable given one or more independent variables. Figure 7.20 shows the variables used in the multinomial regression model. The dependent variable is the survey respondents' interest in car sharing. The independent variables are gender, age group, personal income, employment, household type, dwelling type, neighbourhood density, car ownership and car use.

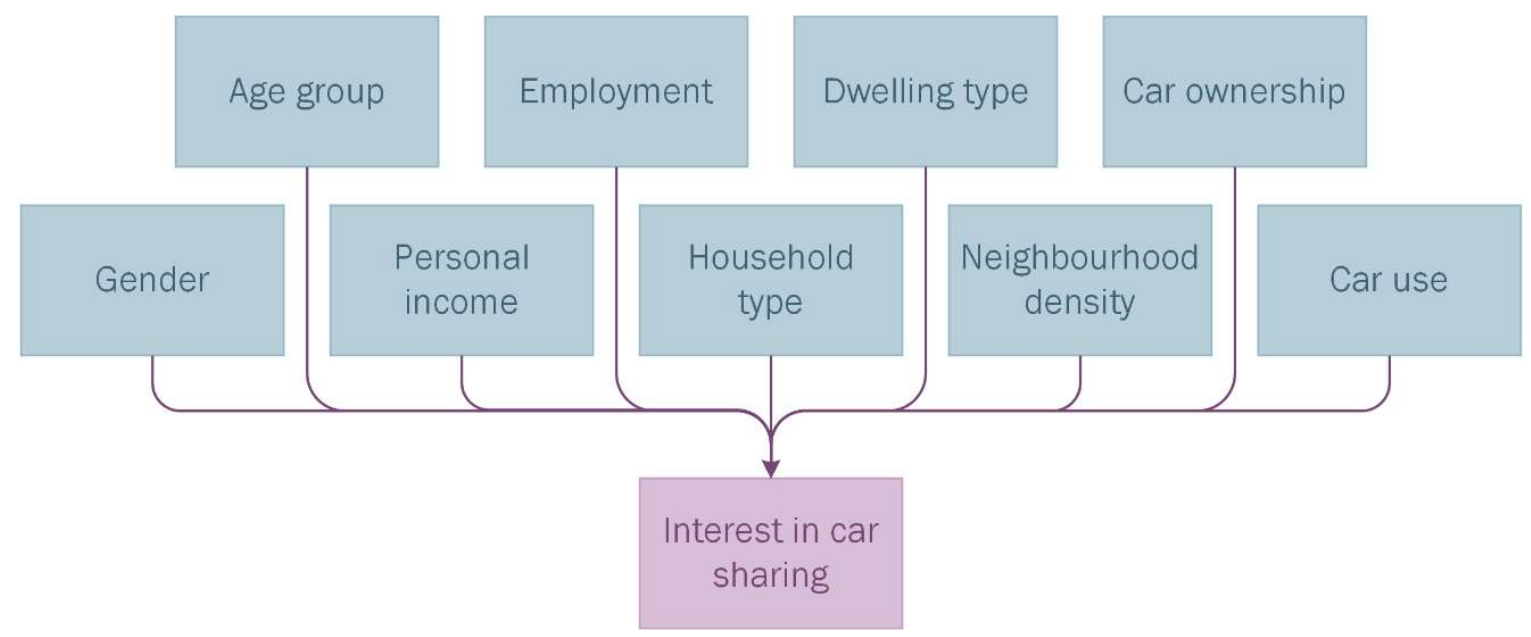

Figure 7.20. Multinomial logistic regression model

Multinomial regression assumes that there is no multicollinearity. Multicollinearity occurs when two or more independent variables are highly correlated with each other. This can lead to problems understanding which variables contribute to the explanation of the dependent variable. Multicollinearity testing found that the following variables had collinearity problems: highest qualification, place of residence, access to a car and car use. These offending variables were removed from the analysis one at a time, until no collinearity problems could be identified. After the removal of highest qualification, place of residence and access to a car, the 
variable 'car use' no longer had a collinearity problem and was kept in the analysis. ${ }^{24}$ Further, multinomial regression assumes that there are no unusual points in the data, including outliers, high leverage points and highly influential points. The data was tested for each of these unusual points, and none were found.

\section{Model results}

The Pearson and Deviance chi-square tests indicate that the model is a good fit for the data (Pearson: $\mathrm{X}^{2}(458)=500.206, p=0.084$, Deviance: $\mathrm{X}^{2}(458)=441.886$, $p=0.697) .{ }^{25}$ The model explains between 21.8 and 25.5 percent of the variance in interest in using car sharing (Cox and Snell $\mathrm{R}^{2}$ and Nagelkerke $\mathrm{R}^{2}$ ).

Table 7.1 shows whether the variables added to the model significantly improve it compared to the intercept alone (no variables added). The model does statistically significantly predict the dependent variable over and above the intercept-only model $\left(\mathrm{X}^{2}(50)=83.021, p=0.002\right)$.

\section{Table 7.1. Model fitting information}

\begin{tabular}{|l|r|r|r|r|}
\hline Model & Model Fitting Criteria & \multicolumn{3}{|c|}{ Likelihood Ratio Tests } \\
\hline Intercept Only & -2 Log Likelihood & Chi-Square & df & Sig. \\
\hline Final & 575.184 & & & \\
\hline
\end{tabular}

Table 7.2 shows that the independent variable 'car use' is the only statistically significant predictor of interest in car sharing, of all the variables included in the model. The parameter estimates table (Appendix E) indicates that the coefficient 'one day or less a week' under the variable 'car use' is statistically significant. The survey respondents who use their car one day or less a week are 6.805 (95\% CI, 1.270 to 36.468 ) times more likely to be 'very interested' than 'not at all interested' in car sharing compared to the respondents who never use a car. This is the most relevant finding from the parameter estimates table; however, the other significant coefficients are highlighted in the table in Appendix E.

\footnotetext{
24 The multicollinearity issues with the data are further explained in Appendix E. This includes tables of the Tolerance and VIF (Variance Inflation Factor) values which indicate whether there is a collinearity problem.

25 The Pearson and Deviance goodness-of-fit tests need to show no statistical significance to indicate a good model fit (i.e. $p>.05$ ).
} 


\begin{tabular}{|l|r|r|r|r|}
\hline Effect & $\begin{array}{c}\text { Model Fitting } \\
\text { Criteria }\end{array}$ & \multicolumn{3}{|c|}{ Likelihood Ratio Tests } \\
\hline -2 Log Likelihood & $\begin{array}{c}\text { Chi- } \\
\text { of Reduced Model }\end{array}$ & Square* & df & \multicolumn{1}{|c|}{ Sig. } \\
\hline Intercept & $492.164^{\dagger}$ & 0.000 & 0 & \\
\hline Household & 502.013 & 9.849 & 8 & 0.276 \\
\hline Dwelling type & 494.074 & 1.910 & 6 & 0.928 \\
\hline Neighbourhood & 493.441 & 1.278 & 4 & 0.865 \\
\hline Employment & 503.259 & 11.096 & 6 & 0.085 \\
\hline Income & 501.799 & 9.636 & 6 & 0.141 \\
\hline Gender & 493.228 & 1.065 & 2 & 0.587 \\
\hline Age & 496.119 & 3.956 & 10 & 0.949 \\
\hline Car ownership & 494.676 & 2.512 & 2 & 0.285 \\
\hline Car use & 521.739 & 29.575 & 6 & 0.000 \\
\hline
\end{tabular}

\footnotetext{
* The chi-square statistic is the difference in -2 log-likelihoods between the final model and a reduced model. The reduced model is formed by omitting an effect from the final model. The null hypothesis is that all parameters of that effect are 0 .

$\dagger$ This reduced model is equivalent to the final model because omitting the effect does not increase the degrees of freedom.
}

\section{Summary of survey results}

This section compared a range of variables with the survey respondents' interest in car sharing. Chi-square testing found that household type, access to a car, car ownership and car use all had statistically significant associations with interest in car sharing. Household types with children living at home were the most likely to be 'not at all interested' in car sharing. The survey respondents who rarely had access to a car were the highest percentage in the 'very interested' in car sharing category. The respondents who did not own a car were more likely to be 'very interested' in car sharing than those who did own one or more vehicles. The respondents who used a car one day or less a week were the highest percentage in the 'very interested' in car sharing category. The multinomial regression analysis found that of these variables (excluding access to a car, which was removed from the regression because of multicollinearity issues) 'car use' was the best predictor of interest in car sharing. 
The stakeholders interviewed for this study were asked to identify who they think will use car sharing, or for the car share providers already operating in New Zealand, who uses their service. These users/potential users of car sharing were divided into five thematic groups, presented in Figure 7.21. Each of these thematic groups are explained in this section, and quotes from the interview participants are included when they helpfully illustrate the theme under discussion.

It is worth noting that several interviewees stated that they could see car sharing in the future working for all age and household groups, and in suburbia as well as the central city. However, this would require increased density and investment in supporting transport networks. For now, the car share providers need to go for the 'low-hanging fruit'. The following discussion is an indication of who the participants think will use car sharing now, in the early stages of car share development in Wellington.
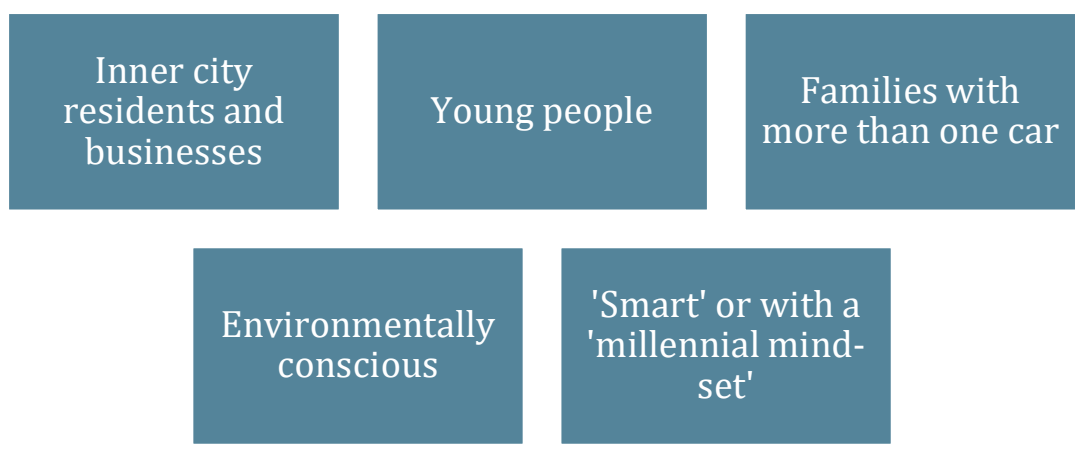

Figure 7.21. Potential car share users

\section{Inner city residents and businesses}

The majority of the participants suggested that the people most interested in using car sharing are inner city residents and businesses. Inner-city residents often have limited access to parking, do not need to drive to access amenities, and owning a car is often inconvenient and/or expensive. Businesses may want access to a vehicle occasionally, and car sharing may offer a more affordable alternative to owning a vehicle. The representative from Cityhop said that they also have several charities using their business, which they considered to be a "smart use of the charity dollar". 


\section{Young people}

Nearly all the participants also thought that younger people will be more interested in using car sharing, especially young people who cannot afford a car or would find it inconvenient to own a car (Box 7.8). Several participants also suggested older people or 'empty-nesters', who live in the central city and do not really need a car. However, one participant pointed out that older people who have owned cars most of their lives might be habituated to car ownership.

"I think mostly young urban professionals, they're the low-hanging fruit because they haven't necessarily made the decision to own a car yet, or if they have made the decision to own a car it's financially problematic and they might be more willing to go with a lower cost option that allows them to use the vehicles when they absolutely need it but use a substitute the rest of the time." WCC officer 2

\section{Box 7.8. Young people}

\section{Families with more than one car}

Several participants suggested that families might look at car sharing instead of owning a second vehicle. Most of the car share providers said that families were not their market focus as they tend to use their cars frequently and were less likely to give up car ownership. However, while families are not likely to go completely carless, several participants suggested that car share could be an affordable alternative for them compared to buying a second vehicle.

\section{Environmentally conscious}

Some of the participants also mentioned that people driven by environmental concerns are more likely to be interested in car sharing. They might see car sharing as a more sustainable option compared with owning a private vehicle, especially if the car share vehicle is a hybrid/electric model. 
Two of the car share providers suggested that the people who use car sharing are 'smart' or have a 'millennial mind-set' (Box 7.9).

"I think it's quite interesting that it's the smart people, the smart people, who use us. Because they recognise they have one, they don't need two or three cars, they'll have one car, and then when that car isn't available to use, we're the back-up car." Cityhop representative

"Those of a millennial mind-set, early adopters who always keep ahead of the curve, or are looking for things that are smart and innovative, forward thinking." Mevo representative

Box 7.9. 'Smart' or with a 'millennial mind-set' 


\subsubsection{How important is high population density for car sharing? And how can car sharing support people who live in the central city?}

The literature review indicated that car sharing is more popular in dense urban environments where there are parking pressures and lower rates of car ownership. The previous section showed that a higher percentage of the survey respondents who lived in apartments were 'very interested' in car sharing than those that lived in standalone houses. This section takes that analysis further by examining how the survey respondents' places of residence affected their interest in car sharing, based on their proximity to central Wellington. It also investigates how interest in car sharing is affected by the respondents' access to parking both at home and at work/study. This analysis includes chi-square tests for association and a Spearman's rank-order correlation matrix. Finally, this section outlines the importance of high density and compact living for car sharing, from the perspectives of the different stakeholders. 
The survey respondents were divided into zones based on how close their place of residence was to Wellington's CBD. Figure 7.22 shows these zones, which are based on the Metlink fare zones (Greater Wellington Regional Council, 2016). ${ }^{26}$ Metlink is the Wellington Region's public transport network. The Metlink fare zones provide a convenient breakdown of the Wellington Region, radiating out from the Wellington CBD.

Figure 7.23 shows that a higher percentage of survey respondents who lived in Zone 1 and 2 (closest to the CBD) were 'very interested' in car sharing compared to those who lived further away. Those in Zone 5+ (furthest away from the CBD) had the highest percentage of 'not at all interested' in car sharing compared to the other zones. ${ }^{27}$ Interestingly, slightly more than 20 percent of the respondents who lived in Zone 1 were 'not at all interested' in car sharing. There were too few respondents in this group $(n=11)$ to analyse why they were not interested in car sharing. However, it may be that they had sufficient access to amenities to not require a car or in some cases were too attached to car ownership to consider car sharing.

A chi-square test found that there was a statistically significant association between the two variables $\left(\chi^{2}(1)=16.925, p=0.031\right)$. They had a weak association (Cramer's V =0.157, $p=0.031$ ).

26 For the full map, covering the entire Wellington Region, see Appendix F

27 As there were a small number of respondents living in zones $5-14$, they were all added to a group identified as ' $5+$ '. This also removed issues with expected cell frequencies, enabling a valid chi-square test for association. 


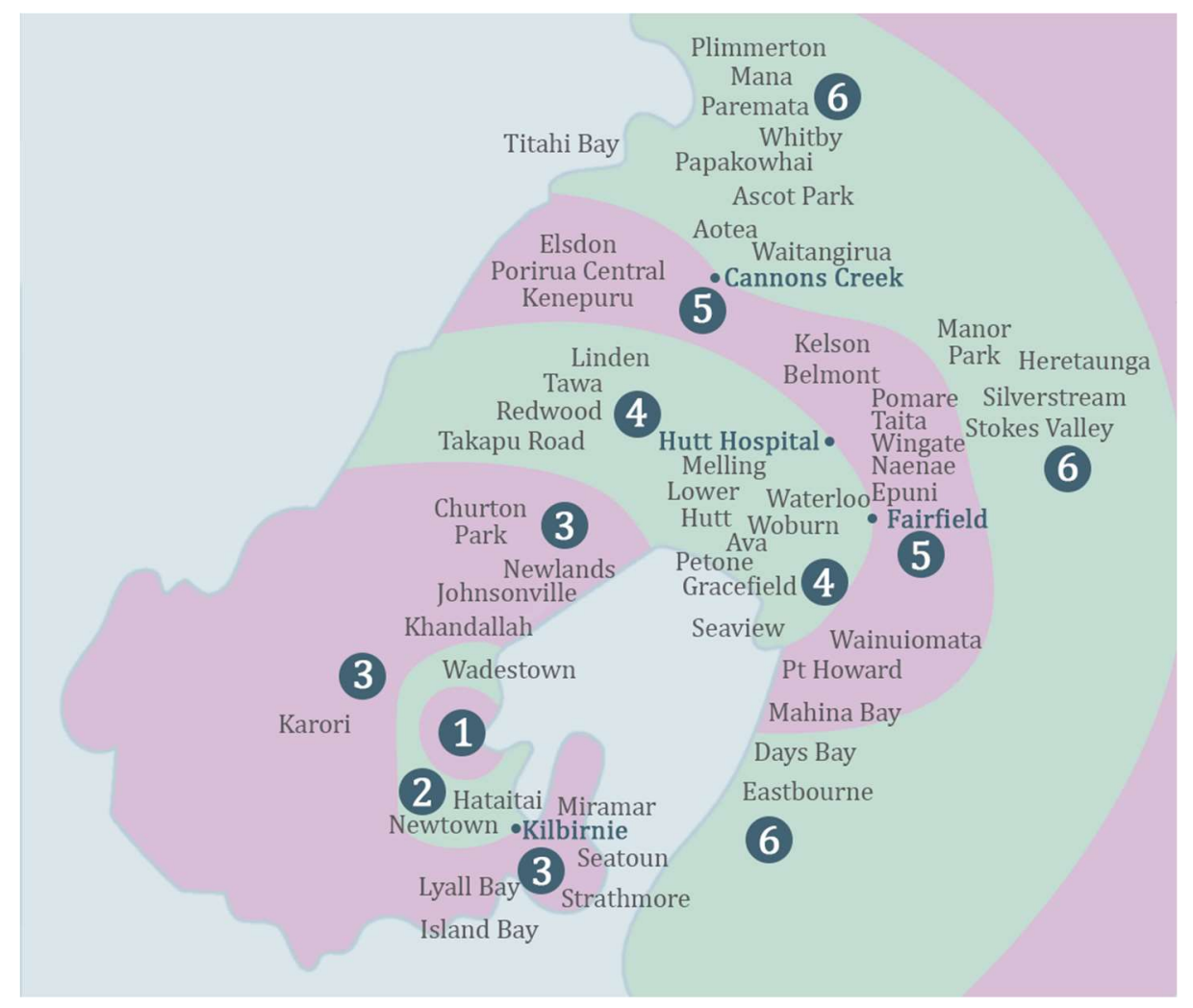

Figure 7.22. Metlink fare zones 1-6, adapted from Greater Wellington Regional Council (2016)

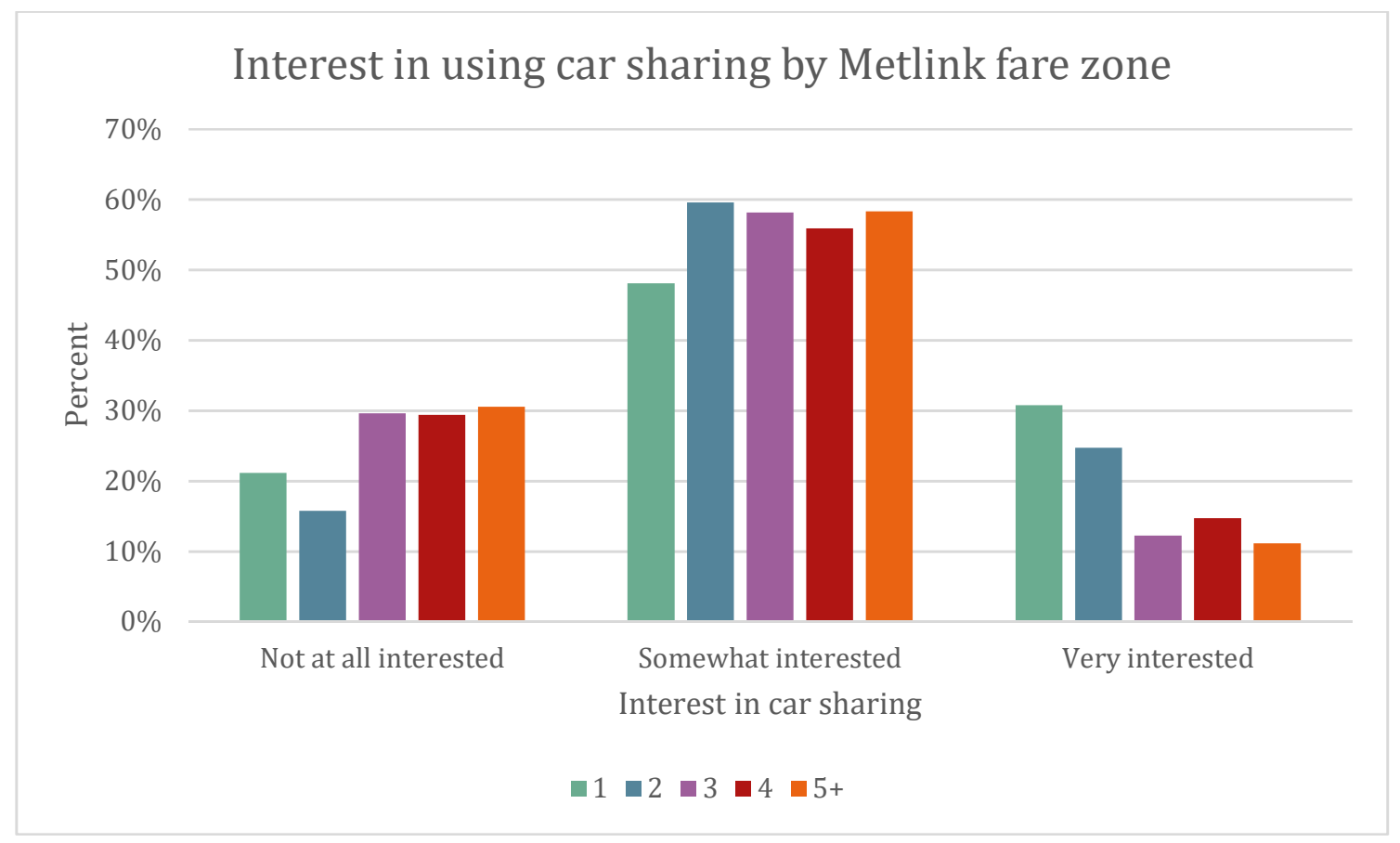

Figure 7.23. Interest in using car sharing by Metlink fare zone ( $n=345)$ 
The survey asked respondents whether they have access to free parking, paid parking or no access to parking at both their place of residence and place of work or study. ${ }^{28}$ Figure 7.24 compares the survey respondents' interest in car sharing by their access to parking at their place of residence. ${ }^{29} \mathrm{~A}$ higher percentage of the survey respondents who only had access to paid parking were 'very interested' in car sharing in comparison to those with access to free parking. A higher percentage of respondents with access to free parking were 'not at all interested' in using car sharing than those who only had access to paid parking. A chi-square test found that there was not a statistically significant association between the two variables $\left(\chi^{2}(1)=3.876, p=0.144\right)$.

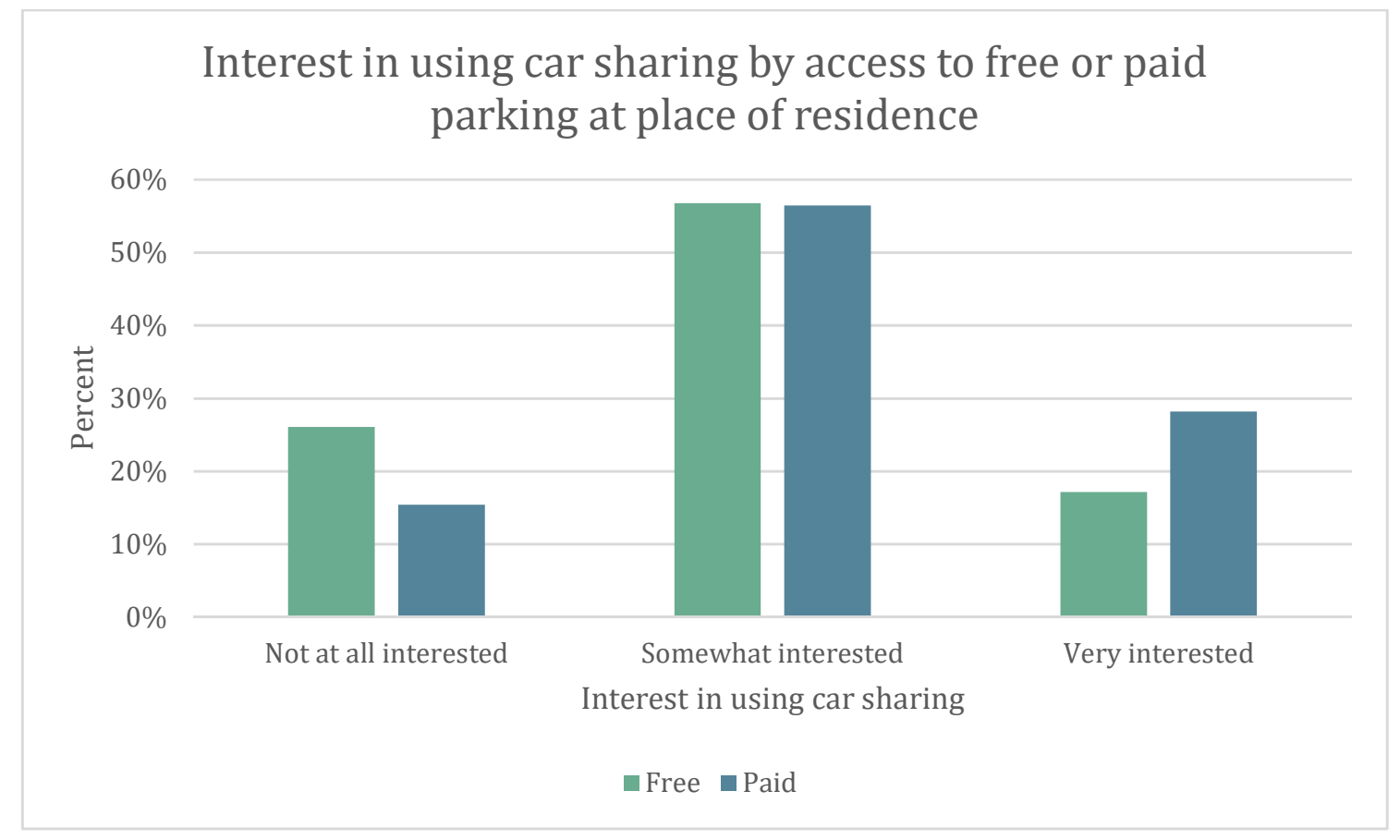

Figure 7.24. Interest in using car sharing by access to parking at place of residence $(n=342)$

28 To make the analysis more straightforward, those with access to both free and paid parking were added to the group with access to only 'free' parking. This is based on the assumption that, given the choice, they would probably use the free parking over the paid parking.

29 There was only $\mathrm{n}=2$ respondents with no access to parking at their place of residence, and so they were removed from the analysis as they skewed the results. 
Figure 7.25 compares the survey respondents' interest in car sharing with their access to parking at their place of work or study. 30 The respondents who had free parking at their place of work or study were the highest percentage to be 'not at all interested' in car sharing. Those respondents with no access to parking at their place of work/study had a higher percentage in the 'very interested' category in comparison to those who had free access. A chi-square test found that there was a statistically significant association between the two variables $\left(\chi^{2}(1)=10.231\right.$, $p=0.037$ ). This was a weak association (Cramer's $\mathrm{V}=0.130, p=0.037$ ).

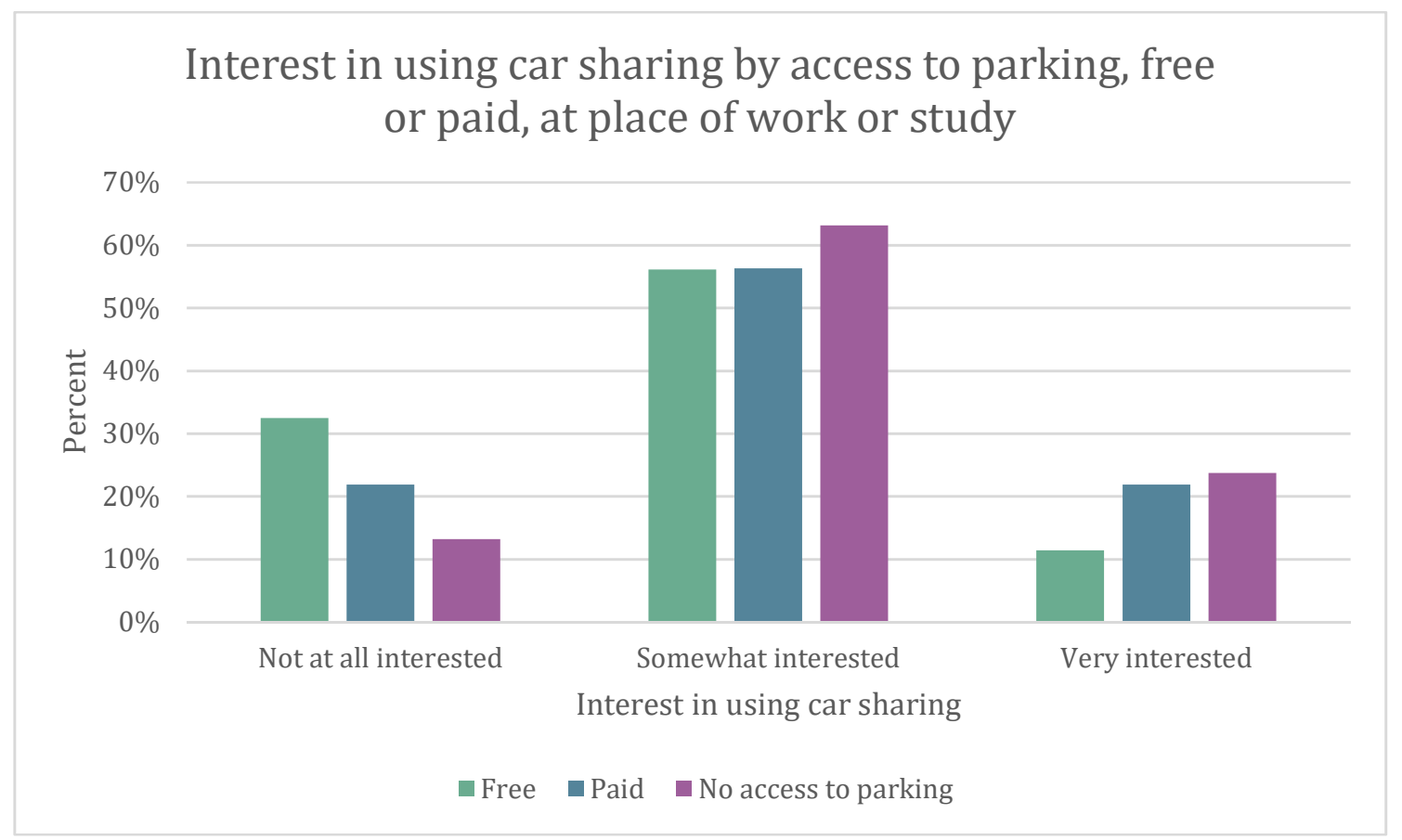

Figure 7.25. Interest in using car sharing by access to parking at place of work or study $(n=303)$

30 Forty-two respondents selected 'not applicable/I don't know' in response to this question. They were removed from the analysis. 
A Spearman's rank-order correlation matrix was generated to help provide insight into the relationship between the survey respondents' perceptions of the convenience and expense of parking, and their interest in car sharing (Table 7.3).

Spearman's rank-order correlation calculates a coefficient, which is a measure of the strength and direction of an association between two ordinal variables. The correlation coefficient is a value from 1 to -1 , which indicates a perfect positive (1) or negative $(-1)$. The closer the correlation is to zero, the weaker the association between the ranks, and the closer the coefficient is to 1 or -1 , the stronger the association.

The survey respondents were asked to what extent they agreed (strongly disagree to strongly agree) with the four following statements on parking:

- There is always a conveniently located car park available at my place of residence

- There is always a conveniently located car park available at my place of work or study

- Parking is expensive at my place of residence

- Parking is expensive at my place of work or study

Table 7.3. Spearman's rank-order correlation matrix: parking and car sharing

\begin{tabular}{|l|r|r|r|r|r|}
\hline & $\begin{array}{c}\text { Interest in } \\
\text { car sharing }\end{array}$ & $\begin{array}{c}\text { Convenient } \\
\text { car park at } \\
\text { residence }\end{array}$ & $\begin{array}{c}\text { Convenient } \\
\text { car park at } \\
\text { work/study }\end{array}$ & $\begin{array}{c}\text { Parking } \\
\text { expensive at } \\
\text { residence }\end{array}$ & $\begin{array}{c}\text { Parking } \\
\text { expensive at } \\
\text { work/study }\end{array}$ \\
\hline Interest in car sharing & 1.000 & & & & \\
\hline $\begin{array}{l}\text { Convenient car park at } \\
\text { residence }\end{array}$ & -0.176 & 1.000 & & & \\
\hline $\begin{array}{l}\text { Convenient car park at } \\
\text { work/study }\end{array}$ & -0.131 & 0.214 & 1.000 & & \\
\hline $\begin{array}{l}\text { Parking expensive at } \\
\text { residence }\end{array}$ & 0.122 & -0.604 & -0.203 & 1.000 & \\
\hline $\begin{array}{l}\text { Parking expensive at } \\
\text { work/study }\end{array}$ & 0.110 & -0.156 & -0.589 & 0.172 & 1.000 \\
\hline
\end{tabular}

Correlation is significant at the...

0.01 level (2-tailed) and coefficient $>0.4$

0.01 level (2-tailed) and positive

0.05 level (2-tailed) and positive
Correlation is significant at the...

0.01 level (2-tailed) and coefficient $<-0.4$

0.01 level (2-tailed) and negative

0.05 level (2-tailed) and negative 
The matrix results suggest that the survey respondents who found parking expensive at their residence also considered it to be not convenient. Similarly, the survey respondents who found parking to be expensive at their place of work or study also considered it to be not convenient. This suggests that for the respondents, expense and convenience were closely connected when it came to parking. The survey respondents who found it convenient to park at their place of residence, also tended to find it convenient to park at their place of work or study. Most importantly, the survey respondents who found car parking to be convenient at their place of residence were less likely to be interested in using car sharing.

\section{Interview results}

The interviewees were asked how important high density or compact living is for car sharing. Figure 7.26 presents the responses divided into four thematic groups. Each of these thematic groups are explained in this section, and participant quotes are used to illustrate the themes under discussion.

Car ownership is expensive/inconvenient in higher-density areas

It is easier to build a car share network in higherdensity areas
Higher-density areas provide better access to amenities and have more transport choices
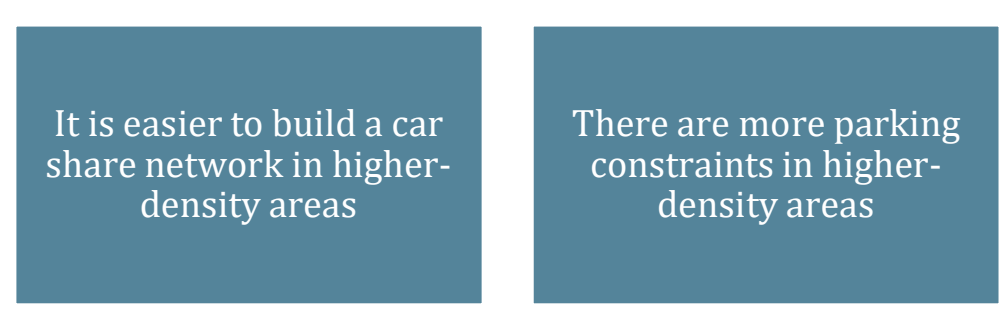

Figure 7.26. Importance of high density for car sharing 
Most of the participants suggested that higher-density and compact city form are important for car sharing to succeed because it makes car ownership more expensive and inconvenient (Box 7.10). It means that there are more likely to be people who do not own cars, or who are prepared to give up car ownership.

"High density means that it's very expensive to consider even owning a car, and it makes it very redundant to even have a vehicle." WCC councillor "As more people move increasingly into apartment buildings, and into the CBD, which is where we see all our growth happening, then just not owning stuff is really easy if you have access to it when you need it" WCC officer 1

Box 7.10. Car ownership is expensive/inconvenient in higher-density areas

Higher-density areas provide better access to amenities and have more transport choices

Several participants spoke about how dense urban environments have lots of transport options and amenities close by (Box 7.11). This reduces the risk of losing freedom when residents give up car ownership.

"If you're in a compact city, it's all there. You could survive without even having a car. It's nice to have, maybe one percent of the time, but the rest of the time, you're living in a very compact, walkable city, with good public transport. It just frees you up by not even having a car." WCC councillor

Box 7.11. Higher-density areas provide better access to amenities and have more transport choices 
Several participants spoke about the importance of urban density for establishing a car share network (Box 7.12). Car sharing requires a network of cars within a range of many users; this is easier in a dense urban environment. The Mevo representative also spoke about the importance of mixed urban density, enabling businesses and residents to use car sharing. Several interviewees specifically mentioned that Wellington's naturally dense CBD will make it easier to build up a network of car share vehicles.

"The more people that live in 800 metres walking the better, because that's more people that would consider signing up. When you get outside 800 metres to a kilometre it's just not viable for people to use it on a day to day basis. So, you need as many people packed into that as possible because not everyone's going to sign up." WCC officer 2

Box 7.12. It is easier to build a car share network in higher-density areas

\section{There are more parking constraints in higher-density areas}

Several participants spoke about how the constraints on parking in dense urban centres encourage the uptake of car sharing (Box 7.13).

"If it's less likely they [city dwellers] have access to a car park, that will increase the likelihood that they might find an offer like this [car sharing] interesting or beneficial. So, urban density definitely plays a role in that." EECA official

Box 7.13. There are more parking constraints in higher-density areas 


\subsubsection{Does car sharing offer an alternative to private vehicle ownership, and is it complementary to public transport, walking and cycling?}

The literature review indicated that car sharing is popular with individuals who want access to a car occasionally. In addition, car sharing can encourage the uptake of alternative modes of transport, such as walking and cycling. Section 7.2.2 showed that there was a statistically significant association between the survey respondents' interest in car sharing and whether they owned a car. The survey respondents who did not own a car were more likely to be 'very interested' in car sharing compared to those who owned one or more vehicles. The multinomial regression showed that car use is the best predictor of interest in car sharing. The survey respondents who used their car one day or less a week were the most likely to be interested in car sharing.

This section takes that analysis further by examining how the survey respondents' main modes of transport to work/study, grocery shopping and regular leisure activities affected their interest in car sharing. This will contribute to an understanding of how alternative transport modes influence interest in car sharing. This is followed by a Spearman's rank-order correlation matrix which provides insight into how the survey respondents' attitudes towards car ownership, travel and car sharing are correlated. This section also outlines how important public transport, walking and cycling is for car sharing from the perspectives of the interview participants. 


\section{Interest in car sharing by main modes of travel}

Figure 7.27 compares the survey respondents' interest in car sharing by their main mode of travel to work or study. ${ }^{31}$ The respondents whose main mode of travel was either active or public transport had higher percentages in the 'very interested' in car sharing category compared to those who mainly travelled by motor vehicle. The respondents whose main mode was the motor vehicle were the highest percentage in the 'not at all interested' in car sharing category. A chi-square test found that there was a statistically significant association between the two variables $\left(\chi^{2}(1)=23.472, p=0.0001\right)$. This was a weak association (Cramer's $V=0.192$, $p=0.0001)$.

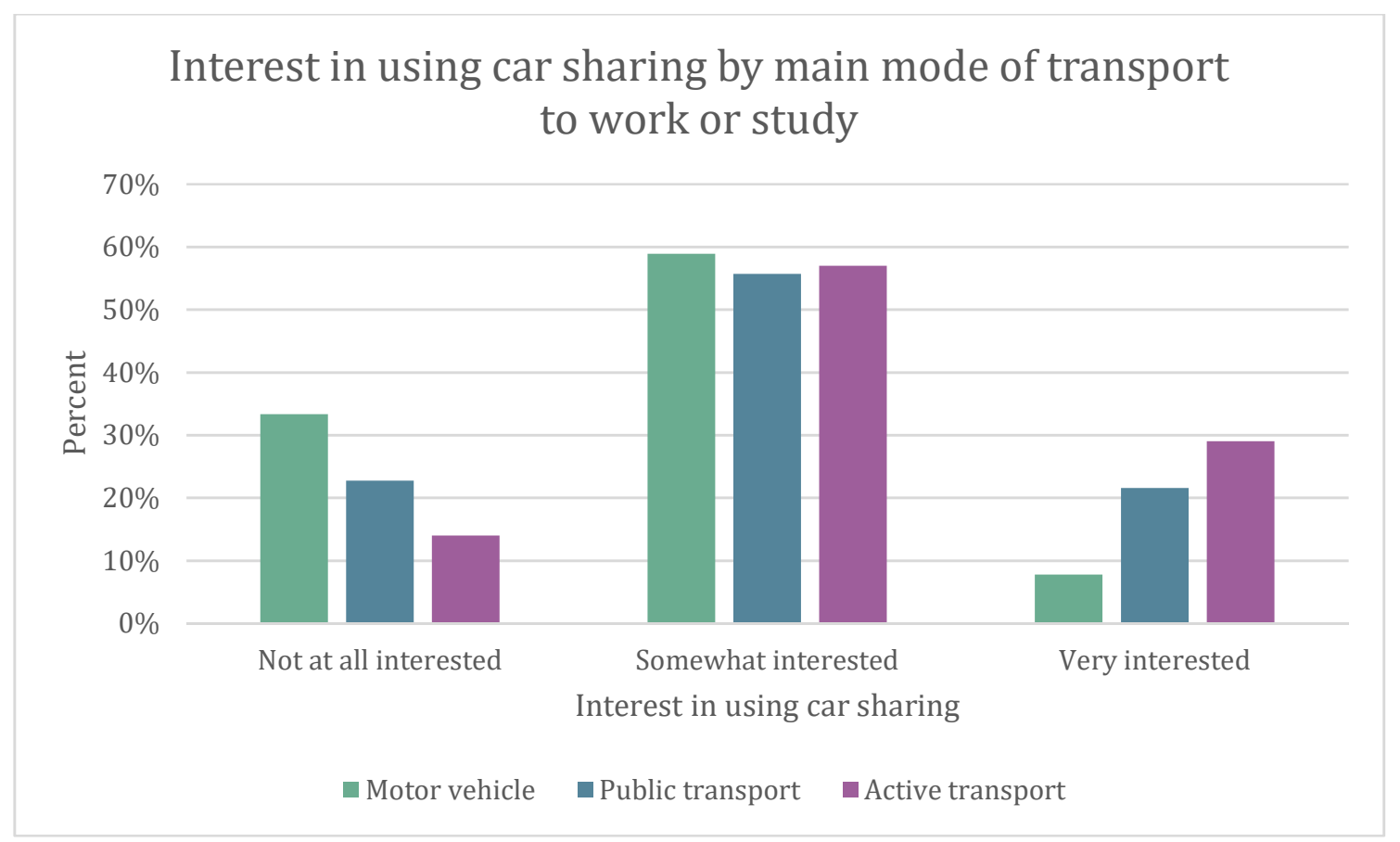

Figure 7.27. Interest in car sharing by main mode of transport to work or study $(n=317)$

31 'Motor vehicle' includes drivers and passengers in a car, van, truck, motorcycle, scooter or taxi. 'Public transport' includes train, bus and ferry. 'Active transport' includes walking and cycling. 
Figure 7.28 compares the survey respondents' interest in car sharing with their main mode of travel to do their grocery shopping. The respondents who mainly used active modes of transport to do their grocery shopping were the highest percentage in the 'very interested' in car sharing category. A chi-square test found that there was a statistically significant association between the two variables $\left(\chi^{2}(1)=28.094\right.$, $p<0.0001$ ). ${ }^{32}$ This was a moderate association (Cramer's $\mathrm{V}=0.204, p<0.0001$ ).

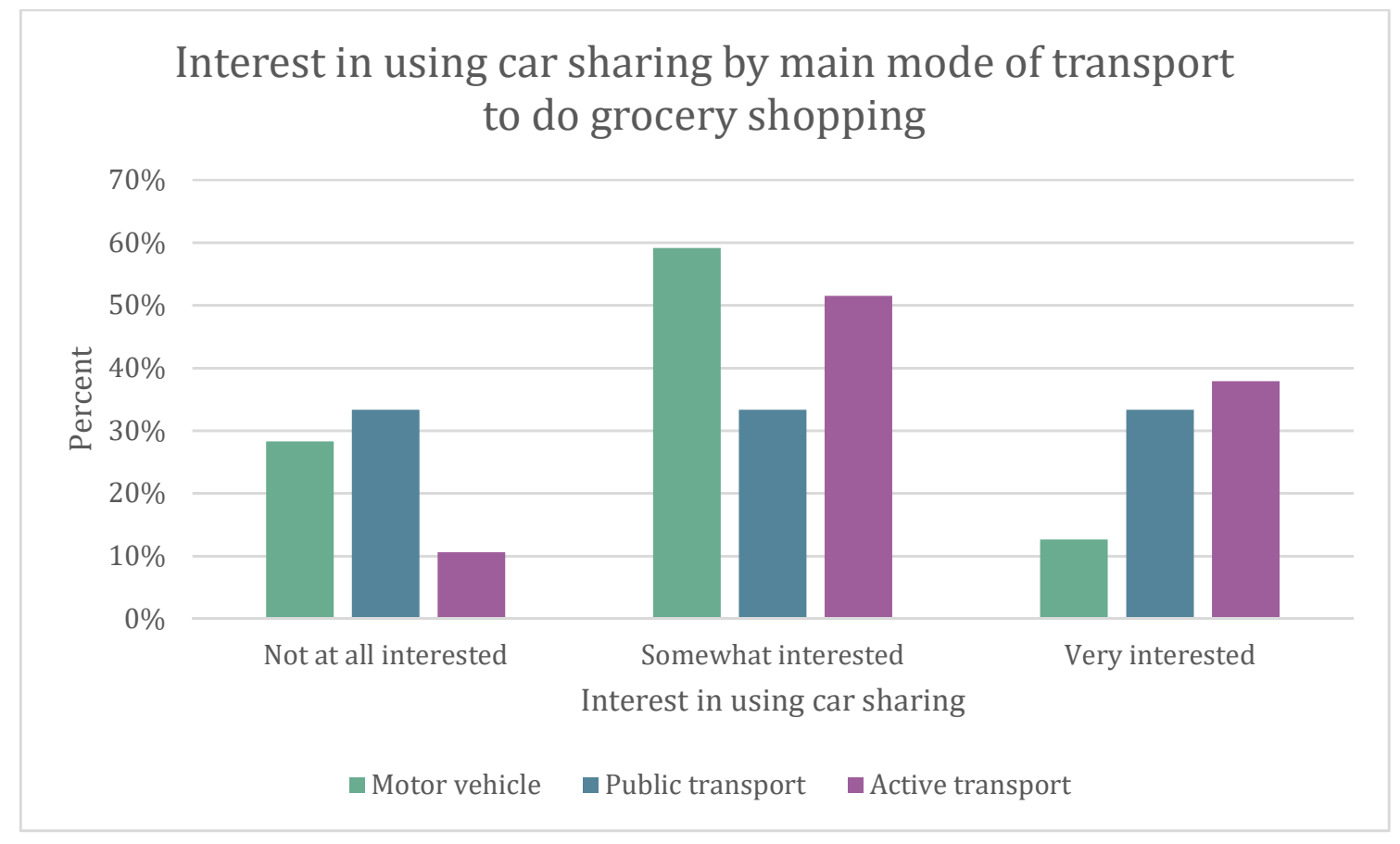

Figure 7.28. Interest in car sharing by main mode of transport to do grocery shopping ( $n=337)$

32 This test did not meet the assumption that all expected cell frequencies are greater than 5 ( 2 cells $(22.2 \%)$ have expected count less than $5(1.6,2.2))$. This means that this result may not be valid, however the test was not rerun as merging the categories would have limited the analysis. 
Figure 7.29 compared the survey respondents' interest in car sharing with their main mode of travel to regular leisure activities. In this case, the survey respondents who mostly used public transport were the highest percentage in the 'very interested' in car sharing category. A chi-square test found that there was a statistically significant association between the two variables $\left(\chi^{2}(1)=11.633\right.$, $p=0.020) .33$ This was a weak association (Cramer's V $=0.131, p=0.020$ ).

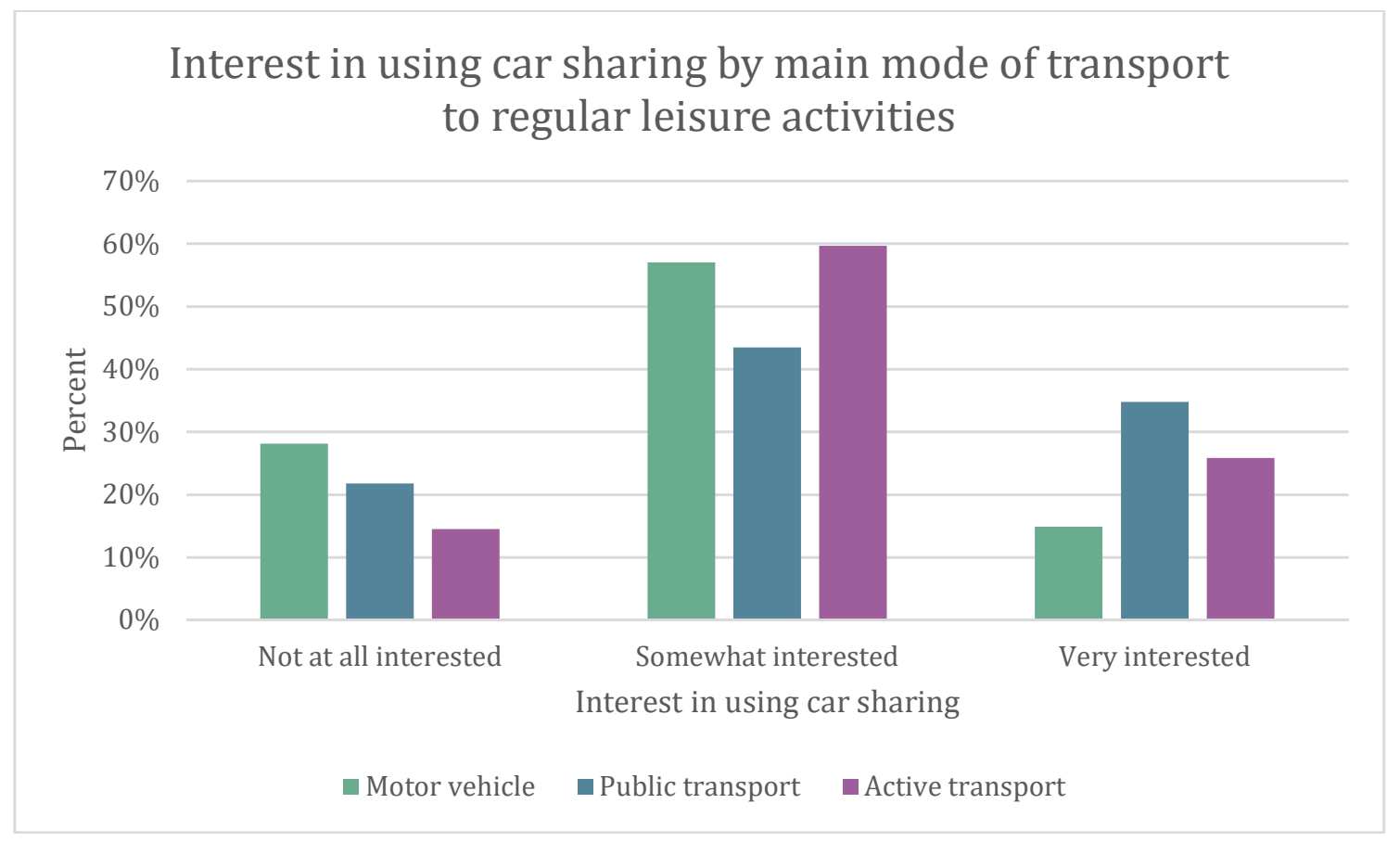

Figure 7.29. Interest in car sharing by main mode of transport to regular leisure activities $(n=341)$

\section{Spearman's rank-order correlation matrix}

The survey respondents were asked to what extent they agreed with a range of statements on car ownership, travel preferences and car sharing. A Spearman's rank-order correlation matrix was generated to help provide insight into the relationship between these statements and interest in car sharing (Table 7.4). The significant correlations are highlighted, with strong positive and negative correlations $(>0.4$ and $<-0.4)$ highlighted in the darkest shades of purple and blue.

33 This test did not meet the assumption that all expected cell frequencies are greater than 5 ( 1 cell $(11.1 \%)$ have expected count less than 5 (4.2)). This means that this result may not be valid; however, the test was not rerun as merging the categories would have limited the analysis. 
Table 7.4. Spearman's rank-order correlation matrix: car ownership, travel preferences and car sharing

\begin{tabular}{|c|c|c|c|c|c|c|c|c|c|c|c|c|c|c|c|c|c|c|c|c|c|}
\hline & 1 & 2 & 3 & 4 & 5 & 6 & 7 & 8 & 9 & 10 & 11 & 12 & 13 & 14 & 15 & 16 & 17 & 18 & 19 & 20 & 21 \\
\hline 1 & 1.000 & & & & & & & & & & & & & & & & & & & & \\
\hline 2 & -0.290 & 1.000 & & & & & & & & & & & & & & & & & & & \\
\hline 3 & 0.705 & -0.128 & 1.000 & & & & & & & & & & & & & & & & & & \\
\hline 4 & -0.073 & 0.279 & -0.126 & 1.000 & & & & & & & & & & & & & & & & & \\
\hline 5 & 0.391 & -0.080 & 0.379 & 0.019 & 1.000 & & & & & & & & & & & & & & & & \\
\hline 6 & 0.534 & -0.060 & 0.552 & -0.092 & 0.409 & 1.000 & & & & & & & & & & & & & & & \\
\hline 7 & -0.501 & 0.076 & -0.527 & 0.047 & -0.328 & -0.768 & 1.000 & & & & & & & & & & & & & & \\
\hline 8 & 0.343 & 0.036 & 0.407 & -0.001 & 0.222 & 0.347 & -0.258 & 1.000 & & & & & & & & & & & & & \\
\hline 9 & -0.286 & 0.274 & -0.214 & 0.086 & -0.236 & -0.341 & 0.369 & -0.109 & 1.000 & & & & & & & & & & & & \\
\hline 10 & -0.527 & 0.246 & -0.454 & 0.018 & -0.188 & -0.374 & 0.385 & -0.247 & 0.258 & 1.000 & & & & & & & & & & & \\
\hline 11 & -0.387 & 0.278 & -0.316 & 0.102 & -0.202 & -0.310 & 0.322 & -0.202 & 0.359 & 0.526 & 1.000 & & & & & & & & & & \\
\hline 12 & -0.353 & 0.189 & -0.337 & 0.079 & -0.130 & -0.237 & 0.233 & -0.213 & 0.268 & 0.514 & 0.416 & 1.000 & & & & & & & & & \\
\hline 13 & -0.232 & 0.125 & -0.302 & 0.119 & -0.147 & -0.263 & 0.270 & -0.194 & 0.204 & 0.413 & 0.298 & 0.340 & 1.000 & & & & & & & & \\
\hline 14 & -0.239 & 0.273 & -0.266 & 0.182 & -0.181 & -0.234 & 0.259 & -0.186 & 0.286 & 0.305 & 0.562 & 0.359 & 0.592 & 1.000 & & & & & & & \\
\hline 15 & -0.177 & 0.185 & -0.146 & 0.130 & -0.125 & -0.072 & 0.095 & -0.128 & 0.256 & 0.209 & 0.277 & 0.285 & 0.223 & 0.298 & 1.000 & & & & & & \\
\hline 16 & 0.210 & 0.099 & 0.188 & 0.006 & 0.426 & 0.274 & -0.221 & 0.121 & -0.044 & 0.005 & 0.053 & 0.170 & -0.053 & 0.012 & 0.017 & 1.000 & & & & & \\
\hline 17 & -0.262 & 0.209 & -0.250 & 0.160 & -0.079 & -0.288 & 0.298 & -0.165 & 0.412 & 0.276 & 0.350 & 0.365 & 0.226 & 0.382 & 0.231 & 0.164 & 1.000 & & & & \\
\hline 18 & -0.230 & 0.253 & -0.183 & 0.167 & -0.059 & -0.176 & 0.191 & -0.118 & 0.259 & 0.315 & 0.356 & 0.382 & 0.216 & 0.372 & 0.227 & 0.207 & 0.436 & 1.000 & & & \\
\hline 19 & -0.086 & 0.289 & -0.094 & 0.190 & -0.045 & -0.130 & 0.137 & 0.078 & 0.252 & 0.210 & 0.301 & 0.230 & 0.153 & 0.335 & 0.251 & 0.176 & 0.367 & 0.457 & 1.000 & & \\
\hline 20 & -0.251 & 0.231 & -0.253 & 0.088 & -0.247 & -0.212 & 0.268 & -0.108 & 0.467 & 0.327 & 0.337 & 0.333 & 0.321 & 0.449 & 0.325 & -0.030 & 0.339 & 0.376 & 0.421 & 1.000 & \\
\hline 21 & -0.377 & 0.322 & -0.314 & 0.127 & -0.192 & -0.230 & 0.241 & -0.145 & 0.388 & 0.509 & 0.466 & 0.552 & 0.295 & 0.394 & 0.248 & 0.017 & 0.353 & 0.461 & 0.340 & 0.413 & 1.000 \\
\hline
\end{tabular}

Correlation is significant at the 0.01 level (2-tailed) and coefficient $>0.4$

Correlation is significant at the 0.01 level (2-tailed) and positive

Correlation is significant at the 0.05 level (2-tailed) and positive
Correlation is significant at the 0.01 level (2-tailed) and coefficient $<-0.4$

Correlation is significant at the 0.01 level (2-tailed) and negative

Correlation is significant at the 0.05 level (2-tailed) and negative 
1. It is important for me to own my own car

2. It is important for me to have access to a car but I do not need to own it

3. It is important for me to have access to a car all of the time

4. It is important for me to have access to a car some of the time

5. It is important to me what make/model of car I drive

6. I prefer to drive a car instead of taking public transport, walking or cycling

7. I prefer to take public transport, walk or cycle instead of driving

8. I do not have an alternative to driving a car

9. I am concerned about the negative impacts of car ownership on the environment

10. Car sharing would be more convenient than owning a car or buying a car

11. Car sharing would be more convenient than owning a second car or buying a second car

12. Car sharing would improve my transport options, giving me greater accessibility to amenities

13. Car sharing would be more affordable than owning a car or buying a car

14. Car sharing would be more affordable than owning a second car or buying a second car

15. Car sharing would work well for occasional activities (but not commuting)

16. If car sharing used high-end vehicles, I would be more likely to use the service

17. If car sharing used electric vehicles, I would be more likely to use the service

18. If car sharing used smartphone technology for locating and booking vehicles, I would be more likely to use the service

19. I would be more likely to use car sharing for occasional trips if it were easier to walk, cycle and take public transport for the majority of my travel

20. Car sharing would be more environmentally friendly alternative to car ownership

21. How interested are you in using car sharing services? 
The matrix results suggest that the survey respondents who thought car ownership was important also believed that it was important to have access to a car all the time, and they preferred to drive over other transport modes. The survey respondents who preferred to drive also tended to care about the make/model of vehicles, and would be incentivised to use car sharing if the service included highend vehicles. The respondents who thought car ownership and access was important did not consider car sharing to be a convenient alternative to car ownership.

The survey respondents who thought that car sharing would be more convenient than car ownership, also believed that it would be more affordable, and could improve their transport choices by giving them greater access to amenities. The respondents most concerned about the impact of car ownership on the environment would be more likely to use car sharing if the service used EVs. The respondents who were more likely to use car sharing if the service used EVs were also more likely to be motivated by the use of smartphone technology.

Perhaps the most important result is that the respondents most interested in car sharing, considered it to be more convenient than owning a car and that it could improve their transport choices, as well as offering an environmentally friendly alternative to car ownership. The respondents most interested in car sharing would also be incentivised by the service using smartphone technology for locating and booking the car share vehicles. 
The interviewees were asked how important public transport, walking and cycling infrastructure are for the success of car sharing. Their responses have been divided into four thematic groups (Figure 7.30). These thematic groups are explained in this section, and participant quotes are used to illustrate the themes discussed.
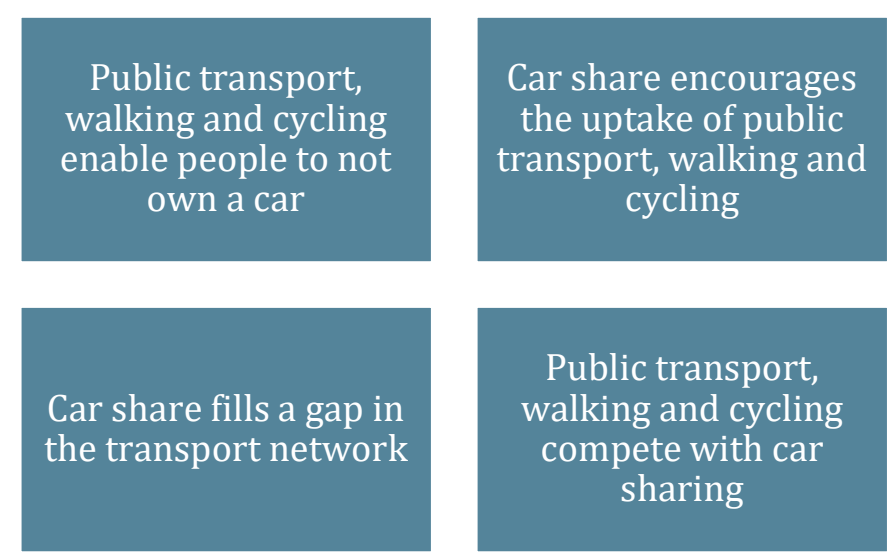

Figure 7.30. Importance of public transport, walking and cycling for car sharing

\section{Public transport, walking and cycling enable people to not own a car}

Most of the interviewees discussed how public transport, walking and cycling support car sharing by enabling people to not own a car (Box 7.14). Car share works best if people only need to use a car occasionally, and otherwise alternative modes of travel meet their transport needs. Public transport, walking and cycling infrastructure gives people the confidence that they will be able to get where they need to go without owning a car. 


\begin{abstract}
"Having a walkable city is really important, having good public transport that can get you around the city is really important, because you don't want to be booking a car share all of the time. And if you don't have the walking and cycling and the public transport infrastructure or capability, or focus, then I think you're more likely to own a car." WCC officer 1

“It's pretty critical, you've got to have other options. People need to travel around, it's critical for their social networks, their economic success, if they have to commute. Every facet of your life relies on transport one way or another, whether that's walking or taking a plane. So, it's absolutely imperative to making car sharing possible so that people have other options, so when they do travel less, because every use of the vehicle is priced, they have something else to fall back on." WCC officer 2
\end{abstract}

Box 7.14. Public transport, walking and cycling enable people to not own a car

\title{
Car share encourages the uptake of public transport, walking and cycling
}

Many of the participants spoke again about the benefit of car sharing facilitating the uptake of public transport, walking and cycling (Box 7.15). As people make the decision to car share instead of owning a car, they increase their use of these alternative modes. In that way not only does public transport, walking and cycling infrastructure support car sharing but car sharing also supports these modes.

\footnotetext{
"They [public transport, walking, cycling and car share] go hand in hand, particularly where a person is choosing to give up a car, and to use a car sharing service in place. So, there's lots of evidence of where somebody gives up ownership of a vehicle, in order to use car sharing and then their total modes that they use for transport goes up. So, they walk more, they catch taxis more, they bus more, they use car sharing more and so all of those things really help." Roam representative

“If you don't own a car you think differently about how you're going to move about, so people are twice as likely to use public transport, walk or cycle, when they don't have a car on their drive." Cityhop representative
} 


\section{Car share fills a gap in the transport network}

Several participants spoke about how car sharing has to be part of a wider transport network and that it cannot work in isolation. However, it is an important component of that network. Driving is sometimes the best mode for a journey, and taxi or traditional car rental are not always suitable (Box 7.16).

"Car sharing is not standalone, it's part of the whole solution but it adds a real important piece that you can't do any other way." YourDrive representative

Box 7.16. Car share fills a gap in the transport network

\section{Public transport, walking and cycling compete with car sharing}

Several participants also spoke about how the gap for car share in Wellington may be quite small because people can walk or take public transport so easily (Box 7.17).

“In Wellington, it's a little bit hard because people are very mobile, they've got good public transport, and it's a compact city so people can move around a lot...So your gap is actually quite small for car share." WCC councillor

Box 7.17. Public transport, walking and cycling compete with car sharing 


\subsubsection{How important are modern technologies for car sharing?}

The literature review discussed how car sharing can help introduce certain modern technologies to the public. Internationally, car share providers have also adopted innovative modern technologies to run their networks and improve the convenience of their services. In New Zealand, all the car share providers have included some level of modern technology into their services. This section examines whether the survey respondents were more likely to be interested in car sharing services if they incorporate EVs and smartphone technology for locating and booking vehicles. This is followed by an outline of the importance of modern technologies from the perspectives of the stakeholders.

\section{Survey results}

Figure 7.31 shows that those who 'strongly disagree' with the statement 'If car sharing used electric vehicles, I would be more likely to use the service' were the most likely to be 'not at all interested' in using car sharing. The respondents who 'strongly agree' with the statement were the most likely to be 'very interested' in using car sharing. The Spearman's correlation matrix in Section 7.2.4 showed that there was a statistically significant moderate positive correlation between these two variables $(0.353)$. The matrix also showed that there was a statistically significant strong positive correlation between concern about the impact of car ownership on the environment and being more likely to use car sharing if the service used EVs $(0.412)$.

Figure 7.32 shows that those who 'strongly disagree' and 'somewhat disagree' with the statement 'If car sharing used smartphone technology for locating and booking vehicles, I would be more likely to use the service' were the most likely to be 'not at all interested' in using car sharing. The Spearman's correlation matrix in Section 7.2.4 showed that there was a statistically significant strong positive correlation between these two variables (0.461). These results suggest that for the survey respondents most interested in car sharing, the use of modern technologies could act as an incentive to use the service. The respondents not at all interested in car sharing are the most likely to be discouraged by the use of modern technologies. 


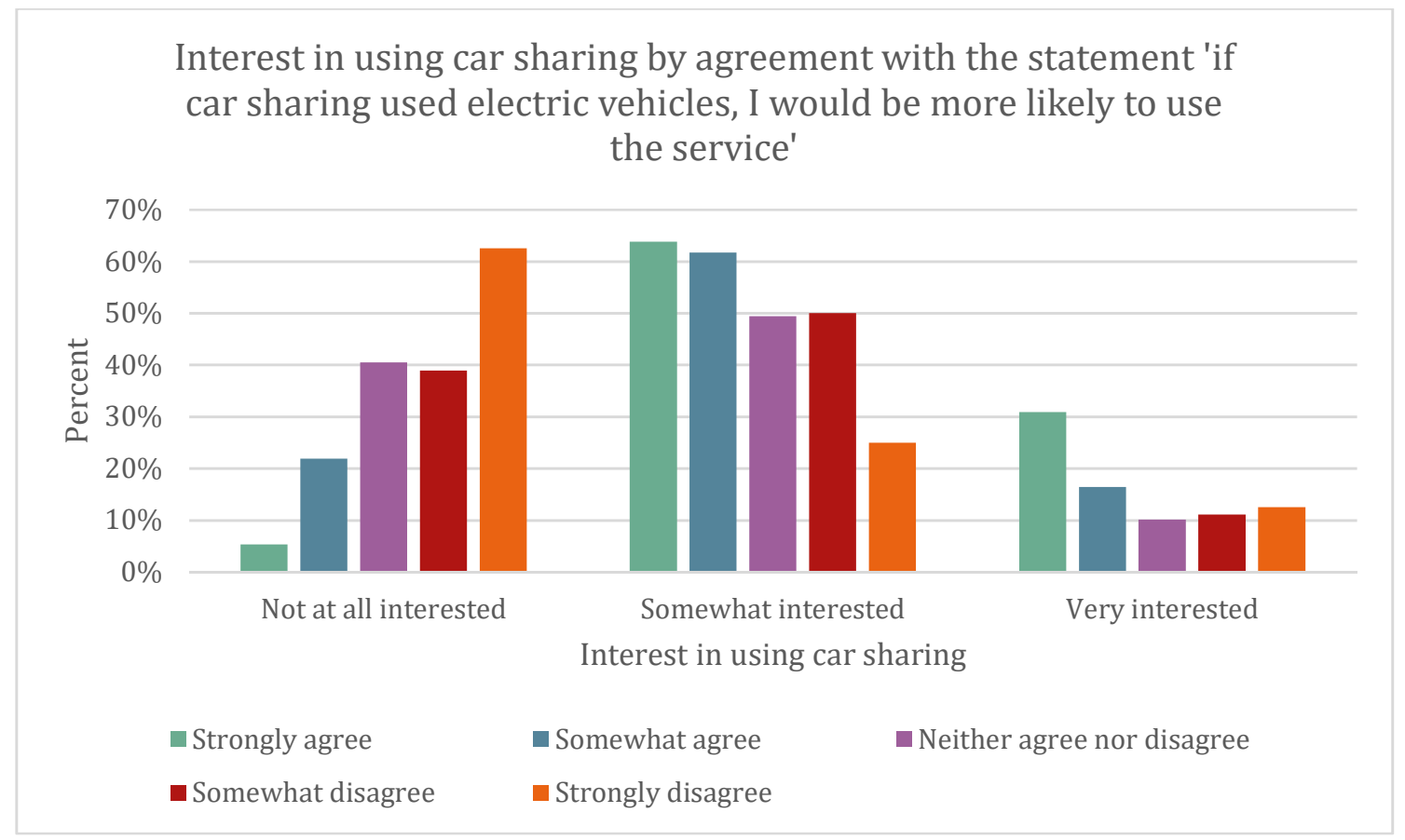

Figure 7.31. Interest in using car sharing by level of agreement with the statement 'if car sharing used electric vehicles, I would be more likely to use the service' ( $N=345)$

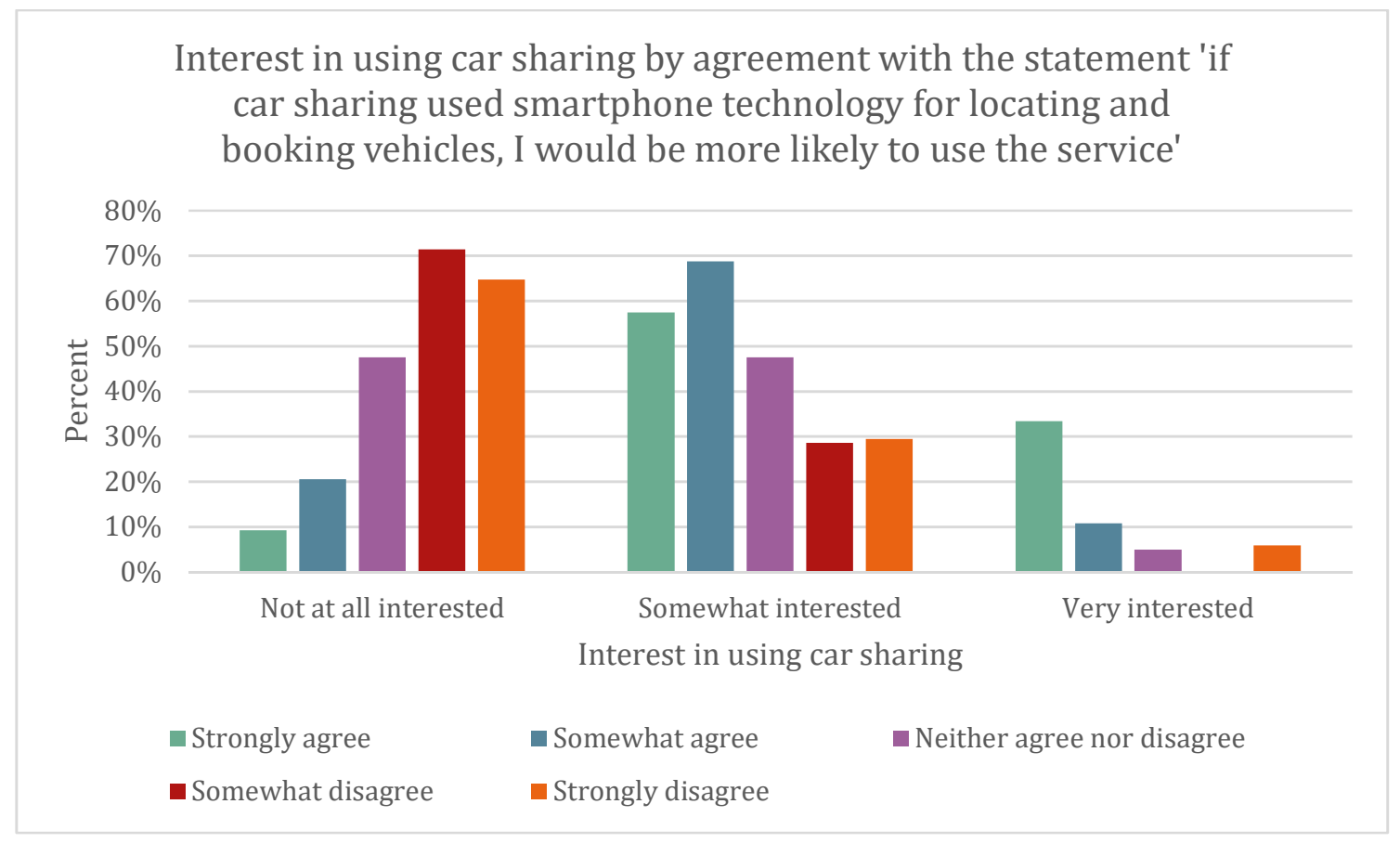

Figure 7.32. Interest in using car sharing by level of agreement with the statement 'if car sharing used smartphone technology for locating and booking vehicles, I would be more likely to use the service' $(N=345)$ 
The interview participants were asked how important the use of EVs and modern technologies are for car sharing. Six thematic groups were identified from their responses (Figure 7.33). Each of these thematic groups are explained below and participant quotes have been included when they helpfully illustrate the theme under discussion.
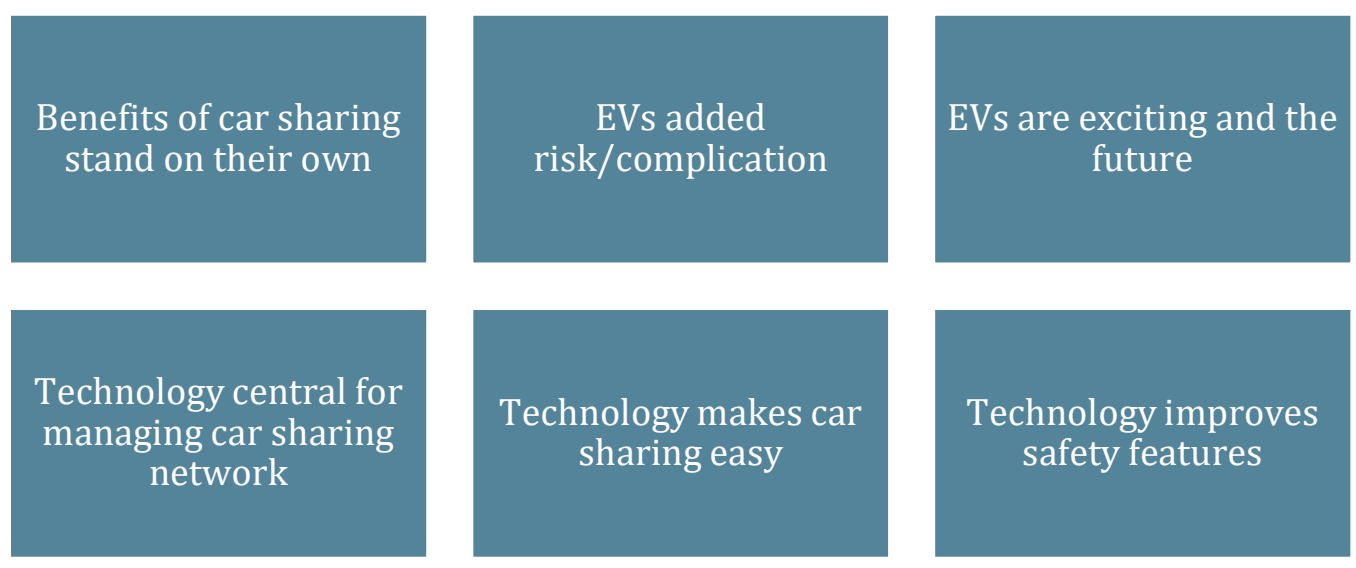

Figure 7.33. Importance of modern technologies for car sharing

\section{Benefits of car sharing stand on their own}

It was clear that most of the participants considered the benefits of car sharing to stand on their own (Box 7.18). The WCC officers, specifically, made it clear that EVs are "the cherry on top" but that car sharing offers a wide range of compelling benefits without the addition of EVs.

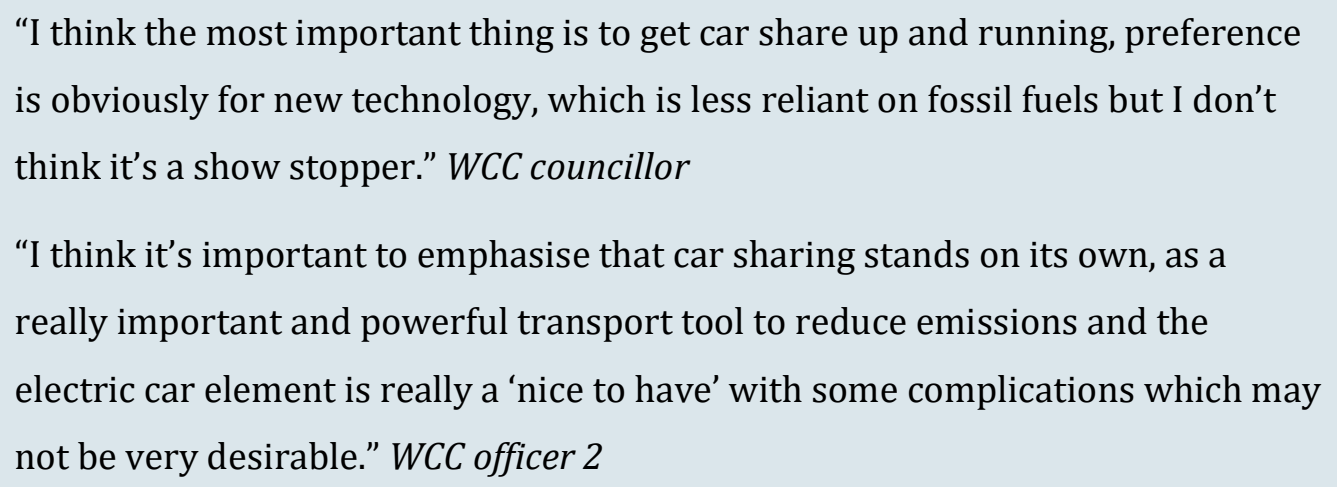

Box 7.18. Benefits of car sharing stand on their own 


\section{EVs are added risk/complication}

Several participants spoke about the difficulty of using fully electric vehicles, and the added risk for car share providers (Box 7.19). EVs currently have to be taken off the network when they need recharging. This can make it difficult for them to compete financially with a standard internal combustion engine vehicle which can be used all of the time. This will change as battery technology improves and charging times are reduced. EVs also require more infrastructure, such as charging stations, the installation of which may be a barrier. Inexperience with driving an EV may also make some individuals more hesitant about using them, or they may be put off by their limited range. Conversely, some people may be attracted by EVs and their environmental benefits.

“They're two separate technologies and they can work together but when you combine them and force them to work together then you're making the customer move from an internal combustion engine car and private ownership, so you're doubling your effort to change behaviour." YourDrive representative

\section{Box 7.19. EVs are added risk/complication}

\section{EVs are exciting and the future}

While the officers from WCC agreed that EVs are a "nice to have" and the benefits of car sharing stand on their own, they also acknowledged that EVs are appealing and can raise the profile of car sharing (Box 7.20). One of the WCC officer's spoke about the benefit of adopting hybrid vehicles as an interim step until full EV technology improves. Most participants stated that EVs will be the future of car share, and that inevitably the car share companies will adopt fully electric vehicles once the technology has developed further and battery range has improved. 
"So, it's [EVs] great. I love that it [EVs] raises the profile of car share. It gets people excited. But until the technology is there, particularly when you've got a car that's doing, in order to be deemed successful and in order to be able to expand or even hold on to the car parks they have, the cars are going to be out and used a lot, that at the moment doesn't lend itself particularly well to EVs, full EVs." WCC officer 1

"Hybrids are great, it makes it more financially sustainable to run a car share because your operating costs are lower, and it makes the carbon benefits even higher." WCC officer 2

Box 7.20. EVs are exciting and the future

\section{Technology central for managing car sharing network}

Several participants discussed how important technology is for managing a car share network, especially when that network incorporates EVs that have to be taken offline for recharging.

\section{Technology makes car sharing easy}

Most of the participants said technology was important for making car sharing really easy, including services such as online booking and remote access to unlock the vehicles.

\section{Technology improves safety features}

Several participants spoke about how technology is important because it improves the safety features of vehicles. Autonomous vehicles will take that one step further, removing drivers from the equation. 


\subsection{Research question 2}

7.3.1. What concerns do Wellington residents have about using car sharing? And what would encourage them to use car sharing?

There is limited international literature on the barriers facing individual users of car sharing. To understand what might prevent people from using car sharing in Wellington the survey participants were asked both closed-ended and open-ended questions regarding their concerns with car sharing. The respondents were also asked what would encourage them to use the service. This section outlines their responses.

Survey results (closed-ended questions)

Figure 7.34 shows the extent to which the survey respondents agreed with a range of concerns about using car sharing. The statement 'I am concerned about the availability of the car share vehicle' had the highest level of agreement, with 41 percent strongly agreeing, and 46 percent somewhat agreeing. This is closely followed by concerns about cost (31\% strongly agree, $49 \%$ somewhat agree) and picking up and returning the car share vehicles at set times (29\% strongly agree, $45 \%$ somewhat agree). These are followed by concerns about the distance to the vehicle from place of residence, cleanliness and insurance.

The statement 'I am concerned about not being able to smoke in the car share vehicle' had the largest percent of disagreement with 79 percent strongly disagreeing. Most respondents disagreed (strongly disagree 38\%, somewhat disagree 22\%) with the statement 'I am concerned that a smartphone will be required for using the car sharing service'. The survey respondents were also not very concerned about the make/model of the car share vehicle or about whether they can take pets in the vehicle. 


\section{The survey respondents' level of agreement with a range of statements regarding concerns with car sharing}

I am concerned about the availability of the car share vehicle (when I want to use it)

I am concerned about how much car sharing costs (e.g. the hourly rate and membership fee)

I am concerned about having to pick up and return the car share vehicles at set times

I am concerned about the distance between my place of residence, work or study and the pick-up/return point for the car share vehicles

$1210 \%$

$46 \%$ $41 \%$

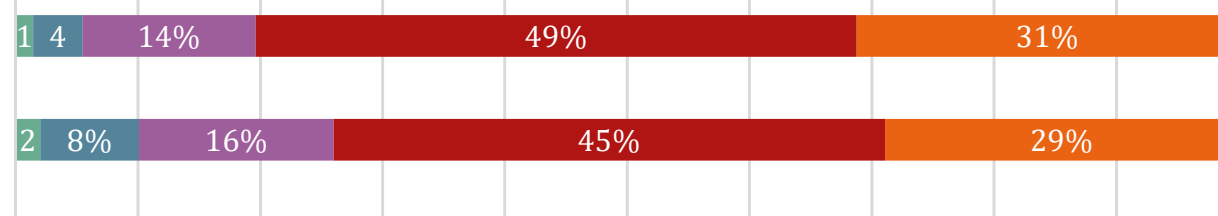

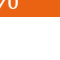
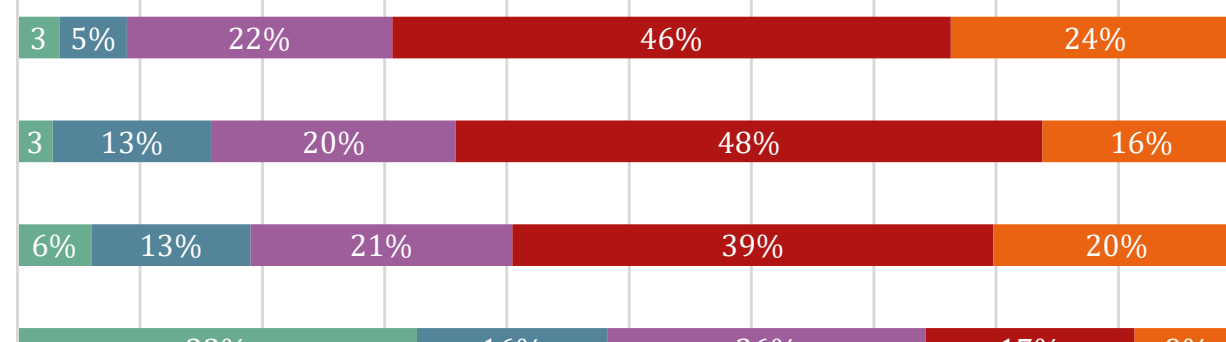

I am concerned about not being able to take pets in the car share vehicle

I am concerned about the make/model of the car share vehicles available

I am concerned that a smartphone will be required to use the car sharing service (e.g. locate and unlock the vehicles)

I am concerned about not being able to smoke in the car share vehicle

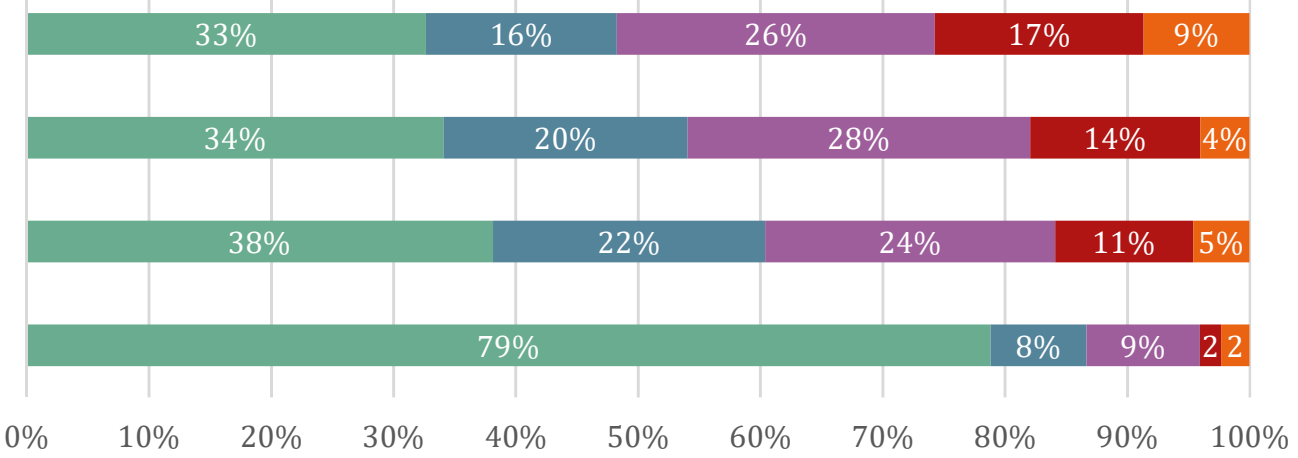
— Strongly disagree
Somewhat disagree
- Neither agree nor disagree
Somewhat agree
- Strongly agree

Figure 7.34. The survey respondents' level of agreement with a range of statements regarding concerns with car sharing (N=346) 
The survey respondents were asked an open-ended question about whether they had any other concerns with using car sharing. This not only enabled comparison with the quantitative answers above but also raised concerns not already captured by the closed-ended questions.

Figure 7.35 shows the concerns raised in answer to this question, divided into nine thematic groups. Each thematic group will be discussed below with illustrative quotes.
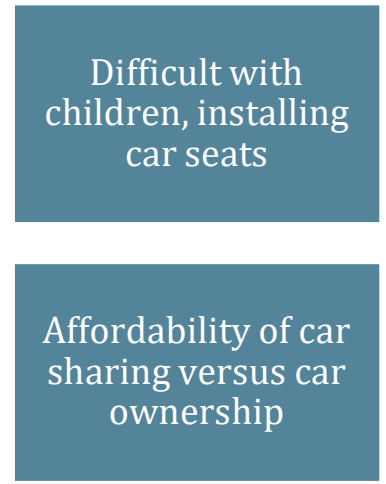

Sharing with other people, cleanliness of the vehicles
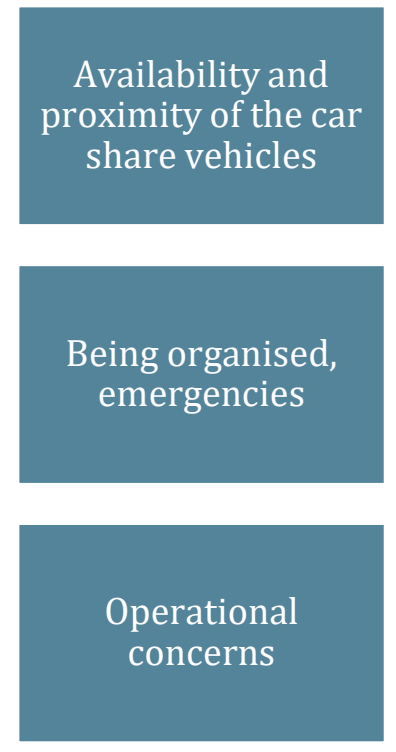

Safety, maintenance and types of vehicles available
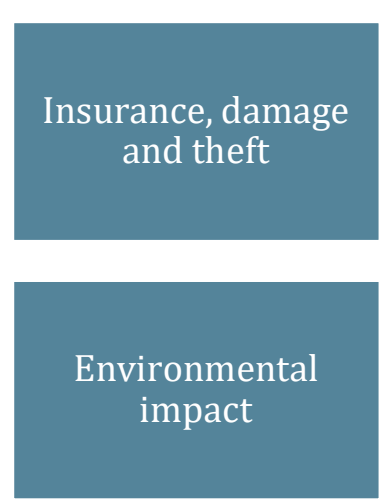

Figure 7.35. Concerns with using car sharing 


\section{Difficult with children, installing car seats}

The most frequent concern raised by the respondents was that car sharing would be difficult with children, especially getting the children and car seats to the car share vehicle, and having to install car seats for each use (Box 7.21). This concern was not addressed in the statements discussed in the previous sub-section, and clearly for parents who answered the survey this was a paramount concern.

"Pain in the ass if you have to haul car seats for kids around"

"I have a toddler and use car seats. They are a NIGHTMARE to install."

"I have two small children with [sic] require car seats. The car would need to fit the car seats and be parked very near my house to make it practical."

Box 7.21. Difficult with children, installing car seats

\section{Availability and proximity of the car share vehicles}

The next major concern raised by the survey respondents was the availability and proximity of the car share vehicles. In particular, whether the car share vehicles will be available when and where the respondents want to use them (Box 7.22).

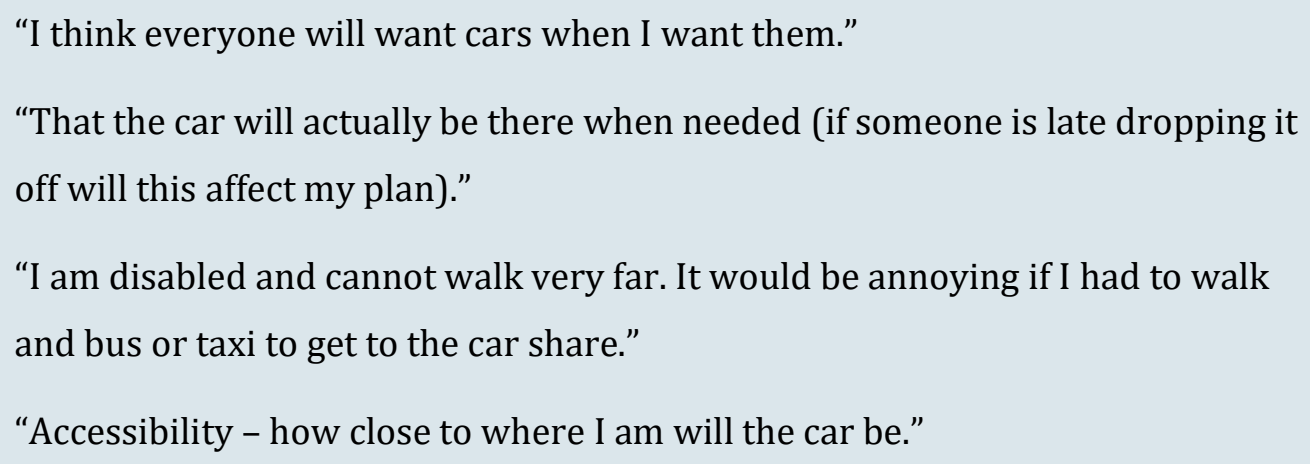

Box 7.22. Availability and proximity of the car share vehicles 


\section{Safety, maintenance and types of vehicles available}

Several respondents expressed concern about the safety features of the car share vehicle, the maintenance of the car share vehicles, and what types of vehicles would be available (Box 7.23).

"Maintenance of the vehicles. The vehicles would be in use far more than a regular car. This would mean there would be significantly more wear on parts." "My concern [is] with make \& model... were models/makes recognised for their safety records."

"Type of cars available for sharing (e.g. vans, 7-seater etc.)"

Box 7.23. Safety, maintenance and types of vehicles available

\section{Affordability of car sharing versus car ownership}

Several survey respondents noted that affordability was a concern, and that they would only use car sharing if it was cheaper than car ownership (Box 7.24).

"When I own a car I do not plan on using it often - therefore car sharing may be more expensive. If I'm only putting $\$ 20-40$ petrol into my car a week, $\$ 10-20$ an hour for car sharing is expensive."

"It often seems to cost as much to borrow a car share car as it does to hire a car for an entire day."

Box 7.24. Affordability of car sharing versus car ownership 


\section{Being organised, emergencies}

Several respondents were concerned that car sharing would require them to be more organised with their travel plans, and would not work as well as owning a car for emergencies (Box 7.25).

"Will car sharing prevent spontaneity/works well with schedule but not a planning person/things don't always go to plan."

"I have a car \& use $2 \mathrm{x}$ a week. I want it there for emergencies e.g. for child or pet. I prefer to use public transport but this isn't always available. Car is there as a back-up... for safety I prefer not to borrow."

"Relying on car sharing is a great concept but unpredictable and [un] expected day to day events happen where parents of children are concerned (pick up from play dates, going to doctors [sic] urgently with child vomiting/bleeding etc.... a forgotten ingredient for dinner...) It's the everyday unexpected inconveniences that make this concept not so great for me."

Box 7.25. Being organised, emergencies

\section{Insurance, damage and theft}

Several respondents were concerned by issues such as insurance, and what happens if the car is stolen, breaks down or is damaged (Box 7.26).

"Perhaps security of car use; if it was stolen etc.?"

"Would it include breakdown cover?"

Box 7.26. Insurance, damage and theft 


\section{Sharing with other people, cleanliness of the vehicle}

A few respondents stated that they are concerned about the cleanliness of the vehicle, in particular people smoking in the vehicle. Some respondents indicated concern with the types of people who they would be sharing the vehicles with (Box 7.27).

"I would really HATE to use a car that someone had smoked in. In fact if it couldn't be guaranteed that no one would smoke in the car, I wouldn't use it." "Whether other people have used drugs or cigarettes in the car. Some people are gross!"

Box 7.27. Sharing with other people, cleanliness of the vehicles

\section{Operational concerns}

Several respondents had concerns about different aspects of how car sharing operates (Box 7.28). While these concerns were quite diverse, they have been grouped together for discussion. These concerns include: how the booking system works, whether the cars will have enough petrol/charge when they are picked up, whether car sharing requires cell phones to be in range to unlock the vehicles, the types of car share parks available (i.e. not parallel parks), having to return the vehicles at fixed times, and not being able to drop the vehicle at a different location to where it was picked-up.

"I would be concerned about the amount of petrol left in the car/the amount it was charged (if electric) when I'm about to use it."

"I would also be potentially concerned about parking the shared car at the pickup/dropoff point if the access was tricky or you had to back it in/parallel park on a busy inner-city street."

"Having to return a shared car to its original pickup location is a significant problem for me. If I could pick up the car near my starting location, and drop it off near my destination, then I would be much more likely to use a car-share service." 


\section{Environmental impact}

Interestingly, some respondents raised concerns that car sharing would not reduce the number of cars on the road, and would discourage people from using public transport, resulting in negative impacts on the environment (Box 7.29).

"It would discourage people further from using public transport and hence would be worse for the environment."

Box 7.29. Environmental impact

\section{Survey results (open-ended question 2)}

To help understand how the concerns discussed above might be overcome, the survey respondents were also asked what, if anything, would encourage them to use car sharing. The responses from this open-ended question are also divided into thematic groups (Figure 7.36) and discussed below with illustrative quotes.
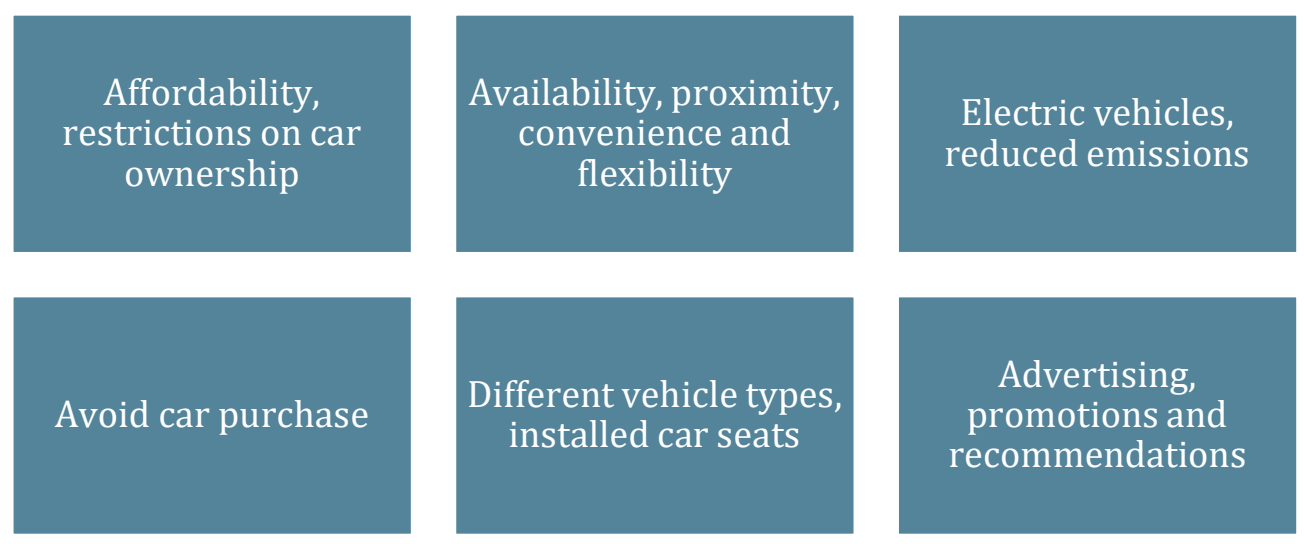

Cost calculator

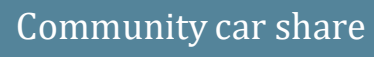

Figure 7.36. Encouragements for using car sharing 


\section{Affordability and restrictions on car ownership}

The most frequent response to the question was affordability, in particular, car sharing being cheaper than owning a car (Box 7.30). The answers differed as to how much cheaper car sharing had to be than car ownership, anywhere from 50 percent cheaper to close to the cost of having a private vehicle. Some respondents would only use car share if it cost less than owning a car for the same amount of use (i.e. every day), or if it were cheaper than using a taxi service.

"If costs were lower than, or close to owning/using my own [car]."

"If it was cheaper than car ownership for everyday use."

"Affordable (\$10-20 an hour is ok)"

"Affordability for drivers under 25, as hiring a car can be very expensive for young adults."

"A range of pricing options. Not having to spend a lot to join up. Free trial?"

\section{Box 7.30. Affordability}

Several respondents said restrictions on car ownership or parking constraints would encourage them to use car sharing (Box 7.31). This included increases to the cost of buying a car or registering a car, a carbon tax, higher parking fees and increased fuel costs. In other words, more unaffordable car ownership could push some respondents towards car sharing.

"If the govt [government] increased the cost of private vehicle registration."

"Restrictions on driving and parking in the city for non-shared vehicles."

"If owning private vehicles was made more difficult through various measures e.g. increasing parking costs, fewer parking places, increased fuel costs, carbon tax on cars. I would sell my car and use car sharing."

"Cost (environmental and financial) of owning own car becomes too great."

"If it became too expensive to own and run a private car - eg petrol got to $\$ 3$ litre." 


\section{Availability, proximity, convenience and flexibility}

Popular responses also included if the car share vehicles were readily available and nearby, and if the service was convenient (Box 7.32). Convenience included being able to book, unlock and pay for the vehicles easily.

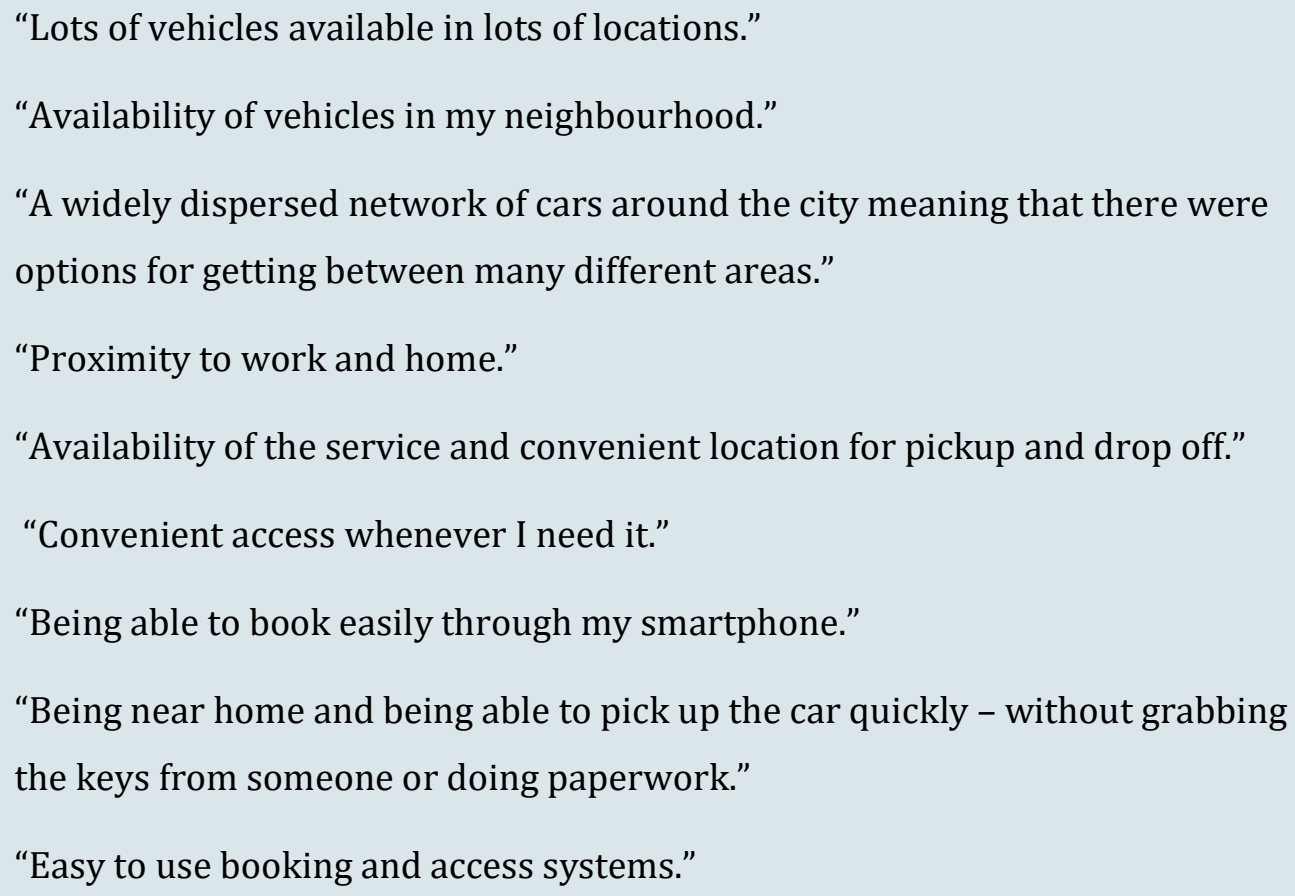

\section{Box 7.32. Availability, proximity and convenience}

In addition to availability, proximity and convenience, several respondents indicated flexibility would encourage them to use the service (Box 7.33). For example, if they could pick up the vehicle spontaneously, and return it when they were ready rather than by a set time, this would encourage them to use car sharing. Several respondents also said point-to-point (or A to B) car sharing would encourage them to use the service.

"They need to be flexible - if a meeting runs late I'm not going to want to be slapped with late fees, nor do I want to lose my booking."

"Allowing drop-offs at a different location to pickup... and allowing ad-hoc usage charged by the minute rather than always requiring a booking." 
Many of the respondents suggested they would be encouraged to use car sharing if the service used electric vehicles, or resulted in reduced emissions (Box 7.34).

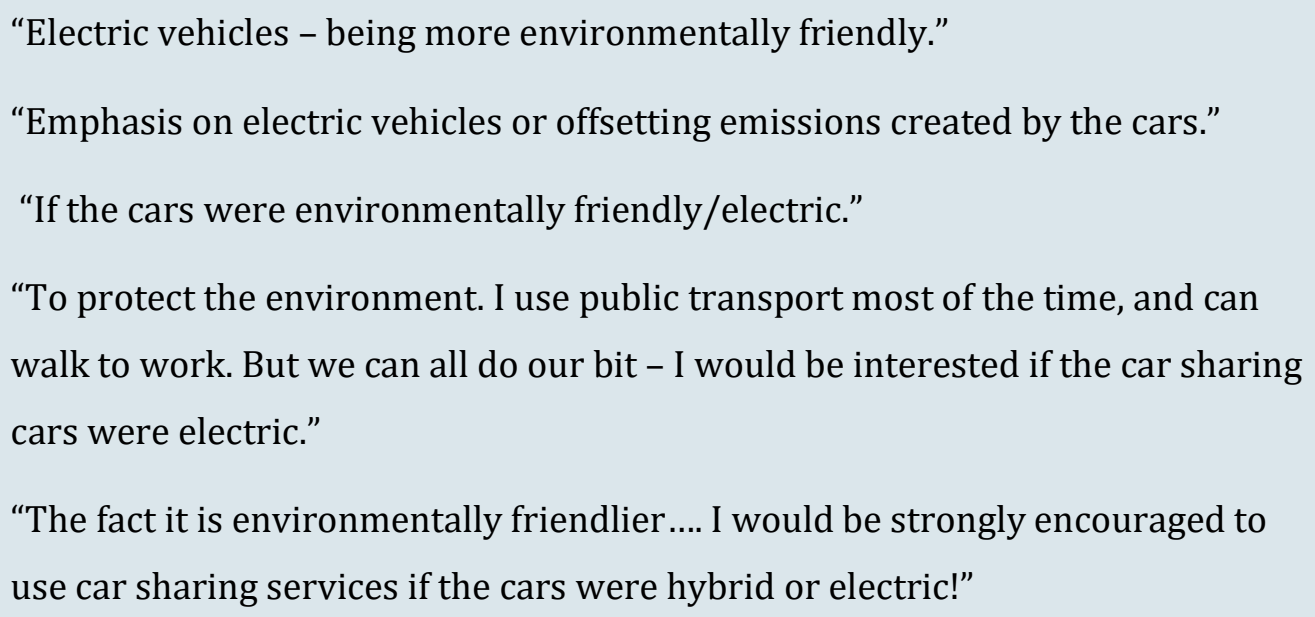

Box 7.34. Electric vehicles, reduced emissions

\section{Avoid car purchase}

Several respondents suggested that they would be encouraged to use car sharing if it meant they would avoid having to purchase a new car, particularly if their current car broke down beyond repair (Box 7.35).

"Not having to own a car, but having access to a car for grocery shopping and occasional day trips/holidays."

"My car dying on me, and then realising that I was close to a car sharing pick up point."

"If my car needed replacing, I may be tempted to look at car sharing."

"If our current car died, I'd look at car sharing." 


\section{Different vehicle types, installed car seats}

Several respondents suggested that a range of vehicle types would encourage them to use car share. And a number of respondents also said installed car seats (Box 7.36).

"If there were cars I would not normally drive or have access to whether it be size or just make and model."

"Variety of vehicle sizes - I'm not fussed on how the car looks, but it would be good if there were little cars for running errands around the city (especially in Wellington's narrow streets!), and larger ones for grocery shopping/moving house/picking up furniture etc. Perhaps availability of bike racks on some of the cars?"

"Child seats pre-install or easily installed."

Box 7.36. Different vehicle types, installed car seats

\section{Advertising, promotions and recommendations}

Several respondents suggested that they would be more likely to use the service if it was widely advertised, or offered some sort of promotion i.e. 30-day trial. A number of the respondents also mentioned having good, accessible information about the service, and recommendations (Box 7.37).

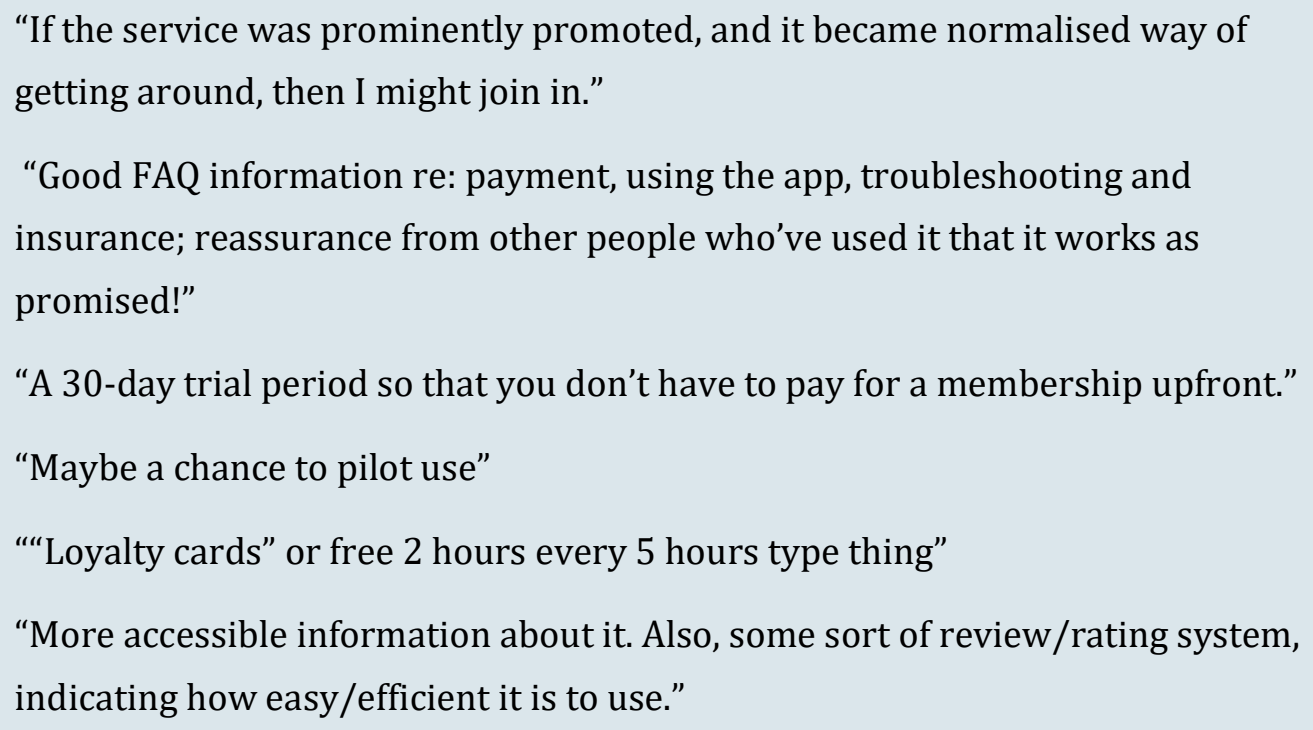




\section{Cost calculator}

As discussed above, cost is a significant concern and affordability would encourage many of the respondents to use car sharing. Several respondents suggested that if car share were cheaper than ownership they would use the service. A few respondents would like to see a cost-benefit analysis, or the ability to use a cost calculator, to work out if the service would be cheaper for them (Box 7.38).

"Provision of some calculator tools to help analyse the cost/benefit of sharing relative to car ownership for my personal situation."

"A cost/benefit study showing car sharing a better option to private car ownership for people driving less than $5000 \mathrm{~km}$ per year."

Box 7.38. Cost calculator

\section{Community car share}

Several respondents also mentioned their desire to use an informal or communitybased car share (Box 7.39).

"Ability to create informal car sharing clubs that can use an effective booking system."

"Would prefer a model where my local community shared an electric car so easy to access."

Box 7.39. Community car share 


\subsubsection{What do stakeholders see as key barriers facing car sharing in Wellington, and how might these barriers be overcome?}

Interview results

Internationally, car share provision has faced a range of barriers before becoming successful. To understand if car sharing in Wellington faces similar barriers, the interview participants were asked what they see as the main barriers facing car sharing in the city, and how these barriers might be overcome. They were also asked whether there is anything distinct about the New Zealand and Wellington contexts that could work against or in favour of car sharing. These barriers have been divided into four thematic groups (Figure 7.37). Each of these thematic groups is explained in this section, and participant quotes are used to illustrate the themes discussed.
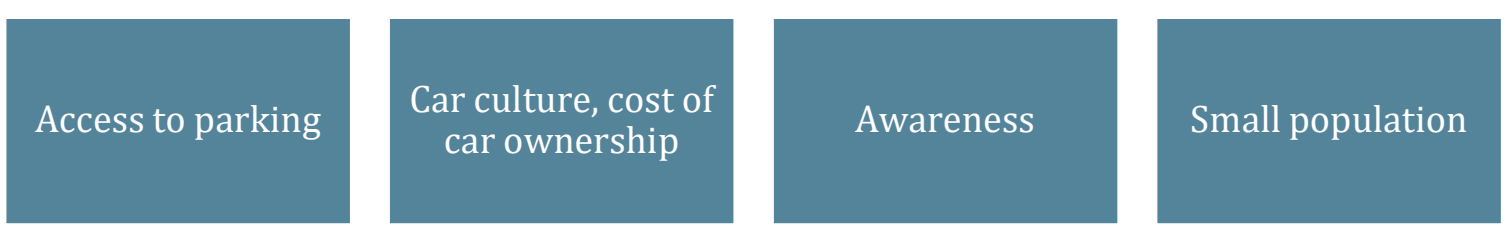

Figure 7.37. The main barriers facing car sharing in Wellington

\section{Access to parking}

Most of the stakeholders identified access to parking as one of the main barriers facing car sharing (Box 7.40). For the car share providers, access to on-street parking is critical for their companies to succeed. The Mevo representative spoke about how car sharing could not work without access to public parking, and that the finances would not stack up if they were to pay market rates for that parking. The WCC officers spoke about how careful they have to be with allocating public space to a commercial business. A traffic resolution process has to be undertaken for each park, and the council has to decide whether the benefits of supporting car share outweigh the loss of revenue from those car parks.

In many ways for Wellington this barrier has already been overcome. WCC has already committed 100 car parks, over 3 years, across the city for car share and EVs in the Low Carbon Capital Plan. All the car share providers were positive about this new policy, and believed it to be a good start, especially considering what the car 
share companies can offer right now. Several participants suggested that in future more car parks will need to be allocated, especially for a free-floating car share model which requires more parks to be available than car share vehicles. There were also concerns that the policy's requirement to prove demand before any allocation of parks might prevent the companies from getting quickly to the scale necessary for a successful car share scheme.

In terms of overcoming the parking barrier, the officers from WCC discussed how important it is that any businesses who see themselves as potentially affected are brought on board with car sharing. In that way car share providers could help themselves by speaking with local businesses. The other way officers from WCC said they could help car share providers, is by allowing them to indicate where they would like to put their cars, where they see their growth happening, and giving them advice on viable parts of the city.

"It has to be premium spots, where people are tripping over it. That's why we have to be bold and brave, we're actually going to free up premium spots, it could be outside the library, it could be down Wakefield St, on The Terrace, all these kinds of high profile areas, where people, at crossings, where they can actually see that there is a really brightly signposted area there for car share." WCC councillor

"I think having on-street parking in locations which are highly visible and desirable. But that park is public space, and we have to be very careful when we allow commercial businesses to take over public space, that we're doing it for the right reasons. And we've got that balance between public good and commercial benefit right..."

"We have to prove the public good of having car share in Wellington, how it adds to the vibrancy of Wellington, how it reduces congestion, how it's a service that actually is being provided to the public, even if there's a business on the other side of it, that's making money off it..."

"It's smart for car share providers to get out and talk to the businesses around that area, and tell them what they're doing, and make sure as much as possible, they can get them on board or make them feel comfortable" WCC officer 1 


\section{Car culture, cost of car ownership}

Several participants identified that another key barrier to car sharing is New Zealand's car culture and the cost of car ownership (Box 7.41). Several participants suggested that it will be difficult to convince many New Zealanders to give up car ownership in favour of sharing. Cars are also relatively cheap to buy and run in New Zealand, and people often do not understand or ignore the actual cost of car ownership (for example, factoring into the cost of car ownership, the vehicle's depreciation, insurance, registration, warrant of fitness, petrol etc.). If the true cost of car ownership is not considered then car sharing can appear expensive in comparison. In terms of overcoming these barriers, several participants discussed how local and central government policy could influence the cost of car ownership and remove incentives for driving (such as free parking).

"It does cost money to own a car, to run it, to insure it and all those kinds of things. But it's very low barriers to get one, you can get a very cheap car for no money... that's a very hard one for a car share operator to compete with." EECA official

"I think we've got a strong addiction to our cars, as a nation. I think we've got a long way to go, in terms of the kind of attitudes about the car that you see in other countries." GWRC officer 1

"We're a car-centric culture and breaking that is not easy. And for years, right across the country, we just plan cities around cars..."

"I certainly think, given the low rates of car ownership in Wellington, and the high rates of low car-user owners, we think there is definitely a market for it here." WCC officer 1

Box 7.41. Car culture, cost of car ownership 
Several participants identified lack of awareness of car sharing, and understanding about how car sharing works, as a key barrier (Box 7.42). Local governments could help overcome this barrier by helping the car share providers advertise their service.

"I think a lot of it is also about education, people don't necessarily know how these things work, if they haven't been overseas and seen how they work over there." GWRC officer 1

“Anything to get more people aware of the benefits because it changes people's transport habits in a positive way for the environment, for public health, and that's good for the New Zealand taxpayer." YourDrive representative

\section{Box 7.42. Awareness}

\section{Small population}

Most of the participants spoke about Wellington's small population and how that makes it difficult to provide services like car sharing. Several participants spoke about whether car share providers can get the scale necessary to be successful in Wellington (Box 7.43). Several participants spoke about the importance of investment, and how it can help the providers grow more quickly and get to scale. In addition, the representative from Mevo spoke about how New Zealand's small population means that it is not a market priority for global car share operators, giving local operators an opportunity in the space.

"The challenge will be for any of these schemes, can they get 50 - 100 more vehicles, to really provide a value proposition for people. Once they do that I think that'll show whether they're successful or not." EECA official 


\subsection{Summary}

The stakeholders interviewed for this research identified a range of benefits of car sharing in Wellington. Car sharing was seen to have potential to reduce congestion, demand for parking and GHG emissions. It can encourage the uptake of public transport, walking and cycling and offers public health benefits. Car sharing can save individuals and businesses money, and improve their transport choices by giving them an alternative to car ownership. Car sharing can also be an important tool for talking about sustainability and can help shift New Zealand away from a car-centric culture.

There are several survey results which are key to identifying the potential users of car sharing in Wellington. The variables 'household type', 'access to a car', 'car ownership' and 'car use' all had statistically significant associations with the survey respondents' interest in car sharing. Multinomial regression modelling found that 'car use' was the best predictor of interest in car sharing. The survey respondents who used their car one day or less a week were the most likely to be 'very interested' in car sharing. The interview participants also identified who they think will use car sharing in Wellington. They suggested that inner city residents and businesses are the key market for car sharing. Car sharing is also attractive to young people and empty-nesters, rather than families who use their vehicles frequently. Car sharing might be adopted by families who are trying to avoid purchasing a second vehicle. Car sharing might also appeal to the environmentally conscious, who are looking for a more sustainable alternative to car ownership. In addition, interview participants suggested that car share users may tend to be "smart" or have a "millennial mind-set."

The survey also had results relevant to whether car sharing can support people who live in central Wellington. A statistically significant association was found between the survey respondents' places of residence and their interest in car sharing. The respondents who lived closer to the central city were more likely to be interested in the service. A statistically significant association was also found between the survey respondents' access to parking at work or study, and their interest in car sharing. The respondents who had no access to parking at their place of work or study were more likely to be very interested in car sharing. The survey respondents who found 
parking convenient at their place of residence were less likely to be interested in car sharing. The interview results highlighted that car sharing works better in higherdensity areas because car ownership is more expensive and less convenient there, residents already have good access to amenities and more transport choices, and parking is more constrained. Density is also important for building a car share network, as it enables a network of vehicles to be located within the range of many users.

The survey results are also key for examining whether car sharing can offer an alternative to car ownership, and whether it is complementary to public transport, walking and cycling. There was a statistically significant association between the survey respondents' main mode of travel to work or study, grocery shopping and leisure activities, and their interest in car sharing. The respondents who travel for the most part by active or public transport are far more likely to be very interested in car sharing than those who travel by motor vehicle. For the respondents who are interested in car sharing, it is considered more convenient than owning a car, it would improve their transport choices and is considered an environmentally friendly alternative to car ownership. From the perspectives of the interview participants, public transport, walking and cycling support car sharing by enabling people to not require a car all the time. Car sharing was seen as filling a gap in the transport network by providing an alternative to car ownership. It can also encourage the uptake of public transport, walking and cycling but at the same time it competes with them.

Car sharing and modern technologies are closely connected. There were statistically significant positive correlations between the survey respondents' interest in car sharing and being more likely to use the service if it incorporated EVs and smartphone technology. In other words, the survey respondents most interested in car sharing would be incentivised by the use of modern technologies. The respondents not at all interested in car sharing were more likely to be discouraged by the inclusion of modern technologies. The interview participants spoke about how EVs can raise the profile of car sharing, and inevitably car sharing will adopt EV technology as it becomes more viable. However, the benefits of car sharing stand on their own, and currently EVs are an added risk/complication. Modern technology is 
also critical for making car sharing easy and convenient, and can improve the safety features of the car share vehicles.

In terms of concerns with car sharing, most of the participants agreed that they would be concerned with the availability of the car share vehicles, how much car sharing costs, having to pick-up/return the vehicles at set times, the proximity of the vehicles, cleanliness of the vehicles, and insurance. In addition, the survey respondents also raised concerns about installing car seats in the car share vehicles, the safety and maintenance of the vehicles, sharing with other people, a range of operational concerns, and car sharing having a negative environmental impact due to encouraging people to drive. Many of the respondents highlighted that if car sharing was more affordable than car ownership, or if there were more restrictions on car ownership, they would be encouraged to use the service. Many of the respondents also suggested they would be encouraged to use the service if it had good availability and proximity, as well as being convenient and flexible. The use of EVs and the potential of car sharing to reduce emissions was also another significant motivation.

The interview participants identified a range of barriers facing car sharing in Wellington. The key barrier identified by most of the stakeholders was access to public parking, seen as critical for the success of car sharing. WCC has to prove the public good in allocating public parks to a commercial business. The stakeholders suggested that, for the most part, this barrier has already been overcome by the WCC Low Carbon Capital Plan. Several participants identified New Zealand's car culture as a major barrier facing car sharing, with people often ignoring the full costs of car ownership. Many people have not yet heard of car sharing, making awareness another key issue. This is an area where local government can support car share providers by helping them to advertise their service. Many of the participants spoke about the difficulty of developing car sharing in Wellington because of its small population, which can make it difficult to finance car sharing and build it to a successful scale.

The next chapter will compare the quantitative and qualitative results from this chapter with each other and the literature review to further address and reflect on the research questions. 


\section{Chapter 8 Discussion and conclusion}

This chapter discusses the main quantitative and qualitative results of this study, as well as evidence from the literature review, to answer and reflect on each of the research questions. This is followed by a discussion of the strengths and limitations of this project, as well as avenues for further research. The conclusion summarises the main contributions of this research to the literature.

\subsection{Research question 1}

The first central research question of this study asks 'What are the potential benefits of car sharing in Wellington? In particular, how could car sharing support compact living and sustainable transport patterns in Wellington?' This section answers each of the five sub-questions that were developed to assist in answering this question.

\subsubsection{What do stakeholders see as the main benefits of car sharing?}

The stakeholders interviewed for this research identified an array of benefits of car sharing in Wellington. For the most part, these benefits align with those identified in the international literature.

Most of the interviewees discussed car sharing's potential to reduce congestion, or take cars off the road in Wellington. There is compelling evidence from overseas that car sharing does reduce car ownership and VKT (Shaheen \& Cohen, 2007, 2013). For example, research undertaken in Australia found that one car share vehicle can replace seven to ten privately owned vehicles (Shaheen \& Cohen, 2013). By reducing car ownership and VKT, car sharing can help lower congestion and demand for parking in Wellington. By reducing demand for parking, car sharing could free up valuable space for development in the city. It is worth highlighting that car sharing could also be an important tool for dissuading currently carless households in Wellington from acquiring a car (Martin \& Shaheen, 2011a; Martin et al., 2010).

Several stakeholders also spoke about how car sharing can reduce GHG emissions in Wellington. International evidence suggests that car sharing does have a net impact on reducing GHG emissions (Martin \& Shaheen, 2010). However, it is worth noting that car sharing can either increase or decrease a household's emissions, depending on their car use before and after joining car sharing (Martin \& Shaheen, 2010). The 
use of hybrid and electric vehicles in car sharing fleets has the potential to improve the emission outlook of car sharing significantly (Shaheen \& Chan, 2015; Shaheen \& Cohen, 2013). In 2015, a total of 80.8 percent of electricity generation in New Zealand came from renewable resources (Ministry of Business, Innovation and Employment, 2016). This means that the use of EVs can significantly reduce the GHG emission profile of car share companies in New Zealand.

Several participants suggested that car sharing can encourage the uptake of public transport, walking and cycling in Wellington. Martin and Shaheen (2011b) found that in North America, public transport usage remained the same as a result of car sharing, with the increased usage by some car share members offset by the decreased usage of other members. In contrast, that study found that there was an overall increase in the modal share of walking and cycling (Martin \& Shaheen, 2011b). For Wellington, initially car sharing may absorb significant numbers of carless households, who will gain a new mobility option and therefore may decrease their mode share of public transport. However, it is expected that this will be offset by the users who increase public transport use, while replacing car ownership with car sharing. In contrast, walking and cycling rates are likely to increase in Wellington because of car sharing. In the future, if car sharing becomes more widespread in Wellington, it may attract more car dependent households. This may improve car sharing's ability to facilitate increases in alternative transport modes.

Some of the interviewees also suggested that car sharing could result in a range of public health benefits for Wellington. Reducing VKT can result in lower car-related emissions, which can help lower rates of mortality and morbidity from respiratory disease (Kent, 2014). Reducing GHG emissions can help mitigate the impacts of climate change and related health impacts, such as vulnerability to natural disasters (Kent, 2014). Further, increased physical activity from the uptake of walking and cycling reduces the risk of mortality and morbidity from obesity (Kelly et al., 2014; Kent, 2014). Interestingly, the representative from Meridian Energy also spoke about car sharing's potential to improve health and safety through providing modern vehicles with the latest safety features. No literature was found specifically discussing this benefit of car sharing, and it could be an area of useful future research. 
Several participants highlighted the financial savings for individuals and businesses who adopt car sharing in lieu of owning a private vehicle, particularly one likely to be used infrequently. This is supported by international evidence, which suggests that car sharing is a cost-effective alternative to owning a vehicle driven fewer than approximately 10,000 kilometres per year (Barth \& Shaheen, 2002; Litman, 2000). In addition, several stakeholders spoke about car sharing's ability to improve people's transport choices in Wellington, giving them greater mobility. This is supported by Kent and Dowling (2013), who argue that car sharing fills the space left by the limited carrying capacity, timetables, inflexibility and costs associated with other modes. Surprisingly, a point not raised explicitly by the stakeholders, is that car sharing also has the potential to improve equity. Litman (2000) suggests that car sharing can increase equity by improving the mobility choices of people who are disadvantaged in their transport choices. For example, in Wellington car sharing could improve equity by offering households who cannot afford to own a car or who spend a significant proportion of their income on a car they seldom need, an alternative to car ownership.

Another benefit not explicitly identified by the stakeholders is car sharing's potential to help introduce new technologies to the public, encouraging their uptake. For example, the incorporation of EVs into a car share fleet can raise awareness of the technology and enable car share members to gain experience driving them (Litman, 2000; Wappelhorst et al., 2016). This benefit has been identified by central government, which has enabled car sharing schemes to apply for funding through the Low Emission Vehicle Contestable Fund. This fund supports projects which encourage the uptake of EVs in New Zealand (Energy Efficiency and Conservation Authority, 2017). As discussed previously, Mevo, a Wellington car share provider, was recently awarded funding through this initiative (Mevo, 2017a).

Several stakeholders discussed the ability of car sharing to help change New Zealand's car-centric culture. They noted that the service has the potential to shift attitudes towards car ownership because it enables access to a car without the need to own one. Further, car sharing can be a useful tool for promoting sustainability because it has clear interrelated economic, social and environmental benefits. In the international literature, very little has been written explicitly about 
how car sharing can combat car culture. Kent and Dowling (2013) have noted car sharing's potential to 'puncture' automobility. They suggest that the dominance of private vehicle use is being challenged by non-private but still car-based forms of mobility, such as car sharing, and maintain that car sharing is a less problematic, more sustainable mode of mobility in comparison to the private car. It can also challenge private car ownership by tapping into many of the same practices and meanings of private car ownership (Kent \& Dowling, 2013). It is evident that car sharing could play an important part in challenging the dominance of private car ownership in New Zealand and the transition towards sustainable transport patterns. However, this is an area of research that requires further exploration.

\subsubsection{Who is interested in using car sharing?}

The survey and interview results indicate the characteristics of the individuals who are the most interested in car sharing in Wellington. Importantly, these people appear to have similar characteristics to the members of international car share organisations.

The survey found that the respondents who lived in apartments, in higher-density neighbourhoods in Wellington, are more likely to be very interested in car sharing than those who live in standalone houses in lower-density areas. This was not a statistically significant finding but it does support the views of the stakeholders, who identified inner-city residents and businesses as a key market for car sharing in Wellington. Internationally, car share users tend to live in central neighbourhoods (Le Vine et al., 2014; Loose, 2010; Martin \& Shaheen, 2010). The survey also found that a higher percentage of the respondents in the younger age brackets were very interested in car sharing, compared to those in the older age brackets in Wellington. This was not a statistically significant finding but it also aligns with the interview results. The stakeholders suggested that it is mostly young people who will be interested in car sharing in Wellington. Internationally, it is young people that predominantly use car sharing services (Le Vine et al., 2014; Loose, 2010; Martin \& Shaheen, 2010).

The survey found that household type had a statistically significant association with the survey respondents' interest in car sharing. The survey found that household 
types which have children living at home were the most likely to be not at all interested in car sharing. This corroborates the interview results, with most of the stakeholders indicating that families would not be interested in car sharing in Wellington because they use their vehicles too frequently. However, several interviewees suggested that car share might appeal to families who wish to avoid owning a second vehicle. Internationally, round-trip car sharing is popular with households made up of single people living alone, and couples without children living at home (Le Vine et al., 2014; Loose, 2010; Martin \& Shaheen, 2010).

A strong finding of this study relates to car ownership, access and use. The survey respondents' interest in car sharing was statistically significantly associated with how often they had access to a car and whether they owned a car. The respondents who rarely had access to a car were the highest percentage to be very interested in car sharing. The survey respondents who did not own a car were far more likely to be very interested in car sharing than those who did own one or more vehicles. These findings are supported by the interview results, with several participants suggesting that car sharing is attractive to people who would like to use a car occasionally but for whom owning a car it too expensive or inconvenient. It is worth noting that Wellington has the highest percentage of households with no access to a vehicle in New Zealand, at 11.7 percent (Statistics New Zealand, 2013). This suggests that there is a significant proportion of carless households in Wellington who might be interested in car sharing. Internationally, car sharing is popular with carless or single-car households (Le Vine et al., 2014; Loose, 2010; Martin \& Shaheen, 2010). The survey respondents' interest in car sharing was statistically significantly associated with how often they used a car. The respondents who used a car one day or less a week were the most likely to be very interested in car sharing. Conversely, the group who were the most likely to be not at all interested in car sharing used their car every day of the week. In addition, multinomial regression analysis compared a range of variables, including socio-demographic, dwelling and neighbourhood characteristics, car ownership and car use with the survey respondents' interest in car sharing. The regression found that car use was the best predictor of the survey respondents' interest in car sharing. Internationally, car sharing is popular with people who need a car infrequently, relying instead on non- 
car forms of transport, such as public transport, walking and cycling (Le Vine et al., 2014; Loose, 2010; Martin \& Shaheen, 2010).

In addition to the survey findings, several stakeholders also suggested that car sharing might appeal to environmentally conscious people, who are looking for a more sustainable alternative to car ownership. And two of the car share providers suggested that car share users may also tend to be "smart" or have a "millennial mind-set." These results are only suggestive but do align with research undertaken by Burkhardt and Millard-Ball who found that car share users tend to have high levels of concern about environmental issues, and consider themselves to be innovators (2006).

Car sharing is still in the early stages of development in Wellington. Therefore, the characteristics discussed above most likely pertain to initial adopters of car sharing. As car sharing gains popularity it may appeal to a wider range of people.

\subsubsection{How important is high population density for car sharing? And how can car sharing support people who live in the central city?}

The survey and interview results suggest that high density is important for car sharing to succeed in Wellington, and it can support people living in the central city.

The survey found a statistically significant association between the survey respondents' interest in car sharing and the type of access to parking they have at their place of work or study. The survey found that the respondents with no access to parking were the most likely to be very interested in car sharing. The survey also found that the respondents who have convenient parking at their place of residence were less likely to be interested in car sharing. These results suggest that people with limited access to parking in Wellington are more likely to be interested in car sharing than those who have convenient access to parking. This is supported by the interview results, with several stakeholders suggesting that parking constraints encourage the uptake of car sharing. There is often more parking pressure in higherdensity areas, supporting the argument that high density is important for car sharing. International evidence also shows that successful car sharing neighbourhoods often have limited parking available for private vehicles, making car sharing more attractive (Millard-Ball et al., 2005). 
Previous discussion showed that the survey respondents who lived in apartments in higher-density neighbourhoods were more likely to be very interested in car sharing than those who live in standalone houses in low-density areas. In addition, the survey found that there was a statistically significant association between the survey respondents' interest in car sharing, and the distance they lived from central Wellington. The respondents who lived the closest to central Wellington were the most likely to be very interested in car sharing. This suggests that car sharing is more attractive to people living in central Wellington. Several stakeholders saw car sharing as attractive in the central city because higher-densities make car ownership more expensive and inconvenient. This suggests that the service can support people living in the central city by providing them with another transport choice and an alternative to car ownership.

Several stakeholders also suggested that high density is important for car sharing because it facilitates building a car share network. The higher the population density, the larger the customer base within walking distance of each car share location. It is also important that car share providers have access to both commercial and residential customers, which is more likely in a higher-density area. This is supported by the international evidence which shows that car sharing generally works best in higher-density urban areas, with a mix of commercial and residential users (Le Vine et al., 2014; Millard-Ball et al., 2005). Several stakeholders suggested that Wellington's relatively dense CBD will make it easier to build a network of car share vehicles. Wellington's naturally compact central city has a population-weighted density of 100 people per hectare in some places (Nunns, 2014). The city's density is projected to keep growing, suggesting that car sharing will become increasingly viable in Wellington over time.

In addition, several stakeholders suggested that high density is important for car sharing because it means that there is a greater availability of alternative modes, such as public transport, walking and cycling. These provide the supporting network required for car sharing to succeed. The importance of public transport, walking and cycling for car sharing is discussed in more detail in the next section of this chapter. 
Car sharing might under some circumstances work in lower-density areas of Wellington. Round-trip car share companies may financially struggle to operate in lower-density areas due to fewer potential customers. However, this provides an opportunity to community-based car share schemes and peer-to-peer operations which are less reliant on customer numbers due to lower upfront costs (Hampshire \& Gaites, 2011). Internationally, car sharing has worked outside higher-density urban locations, such as at university campuses and in small towns (Millard-Ball et al., 2005). In these cases, car sharing is often characterised by a high level of member involvement and community programmes operated by volunteers (Millard-Ball et al., 2005). Overall, high density is important for car sharing to succeed, and it can support people living in Wellington's city centre. However, while high density is important, it does not preclude car sharing from working in lower-density areas given enough community support.

\subsubsection{Does car sharing offer an alternative to private vehicle ownership, and is it complementary to public transport, walking and cycling?}

The survey and interview results indicate that car sharing does provide an alternative to private car ownership in Wellington. Car sharing can also complement public transport, walking and cycling in Wellington; however, this relationship is not always straightforward.

As discussed previously, the survey respondents who used a car one day or less a week were the most likely to be very interested in car sharing. The survey also found that the respondents most interested in car sharing tended to agree that car sharing would be more convenient than owning a vehicle and a more environmentally friendly alternative to car ownership. In addition, they also agreed that car sharing would improve their transport choices and give them greater access to amenities. These findings suggest that car sharing does offer an alternative to car ownership in Wellington, especially for people who want access to a car occasionally but consider car ownership too inconvenient or harmful for the environment. For these individuals, car sharing could also improve their transport choices. This is supported by the interview results, with several stakeholders suggesting that car sharing fills an important gap in the transport system. Driving is sometimes the best mode for a journey, and taxi or traditional car rental are not always suitable. This is supported 
by international literature which argues that car sharing is an important component of a wider transport network (Britton, 1999; Litman, 2000; Nawangpalupi \& Demirbilek, 2008).

The survey results suggest that car sharing can complement public transport, walking and cycling in Wellington. The survey found statistically significant associations between the survey respondents' interest in car sharing and their main mode of transport to work or study, grocery shopping and regular leisure activities. The respondents who mainly travel by public or active transport are more likely to be interested in car sharing in comparison to those who mostly travel by car. This indicates that car sharing could act as a substitute for car ownership for people who only need to drive occasionally as most of the time other modes meet their travel needs. The interview results support these findings, with several stakeholders suggesting that public transport, walking and cycling are important for car share because they enable people to not own a car. Internationally, car share members tend to be relatively heavy users of non-car forms of transport (Le Vine et al., 2014; Millard-Ball et al., 2005). Wellington's already high rates of public transport usage and walking in New Zealand may help to support car share schemes (Statistics New Zealand, 2013).

However, the interview results indicate that the relationship between car sharing and public transport, walking and cycling is not necessarily straightforward. Several interviewees suggested that car sharing can compete with public transport, walking and cycling. The high use of these modes makes the gap for car sharing quite small in Wellington as people are already reasonably mobile. This idea is supported to some extent by Martin and Shaheen's (2011b) study which showed that car share members can decrease their public transport use after adopting car share, as previously they did not have access to a vehicle. However, as discussed previously, this is offset by the members who use public transport more because of car sharing. Overall, car sharing does offer an alternative to car ownership, and the relationship between car sharing and public transport, walking and cycling is complementary. However, this relationship can be complex: the modes complement each other whilst at the same time compete. 


\subsubsection{How important are modern technologies for car sharing?}

The survey and interview results suggest that modern technologies could have a significant role in supporting car sharing in Wellington. Modern technologies include the latest EV technology, and operational technologies such as automated booking services, billing and vehicle access.

As discussed previously, car sharing can help introduce modern technologies to the public, encouraging their uptake. Internationally, car share organisations tend to adopt modern technologies. As of 2015, EVs were included in car sharing schemes in over half the countries where car sharing operates (Shaheen \& Chan, 2015). Internationally, car share providers have also adopted innovative technologies to run their networks and improve the convenience of their services (Shaheen \& Cohen, 2013). Increasingly, modern technologies appear to be playing a central role in New Zealand's car share operations. New Zealand's four car share companies have all adopted some level of modern technology. For example, Mevo's car share fleet comprises plug-in hybrid electric vehicles; Cityhop have recently included a fully electric vehicle into their fleet; Mevo, Cityhop and Roam provide smartphone or smartcard access to their vehicles; and all the companies have online booking.

The survey results suggest that the car share companies in Wellington are moving in the right direction for attracting more customers. There were statistically significant positive correlations between the survey respondents' interest in car sharing and being more likely to use the service if it incorporated EVs and smartphone technology. In other words, the survey respondents most interested in car sharing would be incentivised by modern technologies. The respondents who are not at all interested in car sharing are more likely to be discouraged by the inclusion of modern technologies. In addition, the respondents most concerned about the impact of car ownership on the environment were more likely to use car sharing if the service used EVs. This is important because environmental concern is a significant driver for people to join car sharing. The next section will discuss what encourages people to use car sharing in more detail.

Most of the stakeholders believed that that EVs will inevitably be adopted by all car share companies as the technology improves and costs fall. However, many of the 
interviewees expressed reservations about using EV technology now, as it could be an added risk/complication which could detract from the service. In addition, car sharing has a range of compelling benefits on its own, without including EVs in car sharing fleets. Most of the interviewees considered modern technologies, such as online booking, to be central for managing car sharing networks, and for making the service convenient and improving the safety features of car share vehicles. Overall, it was clear that from the perspectives of the stakeholders, modern technologies will play an increasingly important role in the success of car sharing in Wellington.

\subsection{Research question 2}

The second central research question of this study asks 'What are the main barriers facing car sharing in Wellington? And how might these barriers be overcome?' Two sub-questions were developed to assist in answering this question. This section answers each of these sub-questions by discussing the survey and interview results with reference to the literature review.

\subsubsection{What concerns do Wellington residents have about using car sharing? And what would encourage them to use car sharing?}

The survey results suggest that people have a range of concerns with using car sharing in Wellington, and for the most part car sharing is driven by practicality, cost and environmental concern.

Most of the survey respondents agreed that they were concerned with the availability of the car share vehicles and with the affordability of car sharing. The majority of the respondents also agreed that they were concerned with having to pick-up/return the car share vehicles at set times, the proximity of the vehicles to where they live, the cleanliness of the vehicles, and how the vehicles are insured. In addition, respondents raised concerns about installing child car seats in the car share vehicles, the safety and maintenance of the vehicles, sharing with other people, a range of operational concerns, and car sharing having a negative environmental impact if it encourages people to drive. There is very little international research on concerns people have with car sharing. However, the available research suggests that the concerns found in this study are not dissimilar to those found overseas. For example, Nawangpalupi and Demirbilek (2008) found 
that availability was the main issue that users had with car sharing in Sydney, Australia. In Beijing, China, the main apprehension about using car sharing was responsibility in the case of car share vehicle theft or accident, and the car share vehicle safety features (Shaheen \& Martin, 2010).

Many of the survey respondents highlighted that if car sharing was more affordable than car ownership, or if there were more restrictions on car ownership, they would be encouraged to use the service. Many of the respondents also suggested they would be encouraged to use the service if it had good availability and proximity, as well as being convenient and flexible. The use of EVs and the potential of car sharing to reduce emissions was also another main motivation. These findings are supported by Nawangpalupi and Demirbilek's (2008) study, which found that car share users in Sydney were mainly motivated by practicality, the cost effectiveness of car sharing, and environmental concern. The authors suggest that car sharing can attract users by overcoming many of the inconveniences of private car ownership. For example, with designated car parking spaces for car share vehicles, car sharing could attract people who have limited access to parking for private vehicles (Nawangpalupi \& Demirbilek, 2008). Similarly, in Beijing parking is one of the main challenges for car drivers, and guaranteed parking spaces for car sharing vehicles would be a considerable benefit of using the service (Shaheen \& Martin, 2010).

Overall, the survey results reflect a range of concerns people have with using car sharing. Many of these concerns can be overcome by offering an affordable, cost effective, convenient and environmentally friendly alternative to car ownership. Car sharing can benefit from its ability to overcome many of the inconveniences of car ownership, including having designated car parks for car share vehicles.

\subsubsection{What do stakeholders see as key barriers facing car sharing in Wellington,} and how might these barriers be overcome?

The interview participants identified a range of barriers facing car sharing in Wellington. The key barrier identified by most of the stakeholders was access to public parking, which is critical for the success of car sharing. However, the stakeholders suggested that, for the most part, this barrier has already been overcome in Wellington through the WCC Low Carbon Capital Plan. The international literature made it clear that providing free or reduced cost public car 
parks is important for supporting the growth of car sharing (Le Vine et al., 2014; Shaheen \& Cohen, 2013). The provision of parking in Wellington may become more of a barrier in the future as car share companies grow and require more parking spaces. Future research providing more empirical evidence of the public benefits of car sharing in Wellington could help address this barrier.

Many of the participants spoke about the difficulty of developing car sharing in Wellington because of its small population, which can make it difficult to finance car sharing and build it to a successful scale. Research undertaken in New Zealand found that lack of funding was a key barrier facing transport innovators in the country, including car share schemes (Hyde, 2015; Walton et al., 2016). The overseas literature also identified financing car sharing as a key barrier, especially for new entrants in the market (Barth \& Shaheen, 2002; Bleischwitz et al., 2009; Enoch \& Taylor, 2006; Litman, 2000). Relatively few car sharing schemes are completely selfsupported from user fees, and depend on financial assistance from government and private investors (Barth \& Shaheen, 2002; Shaheen et al., 2004). Public funding has included start-up grants, guaranteed use by government agencies and subsidised access to public parking. The Low Emission Vehicle Contestable Fund has provided one avenue for funding for car share providers in New Zealand. However, this fund is geared towards projects which encourage the uptake of EVs. Car share providers could be supported by funding that is specifically aimed at their services, and which acknowledge the range of public good benefits that car sharing offers regardless of whether they include EVs in their vehicle fleets.

Further barriers identified by the stakeholders included lack of awareness of car sharing schemes, and New Zealand's cultural attachment to private vehicle ownership. New Zealand research on transport innovators in the country has also found that these were both barriers (Hyde, 2015; Walton et al., 2016). Awareness is an area where local government could potentially support car share providers by underlining to the public the social, economic and environmental benefits of car sharing. In terms of influencing New Zealand's car culture, several participants suggested local and central governments could increase the cost of car ownership to reflect its full social costs, and remove incentives for driving, such as free parking. As discussed previously, a potential benefit of car sharing is its ability to combat car 
culture itself by providing an alternative to car ownership. Wellington has lower rates of car ownership and car use in comparison with the rest of New Zealand. This suggests that there may be less of a car culture in Wellington, and therefore this may be less of a barrier compared to the rest of New Zealand. The impact of New Zealand's car culture on car sharing, and car sharing's ability to help the country transition towards more sustainable transport patterns is an area for further exploration.

\subsection{Strengths, limitations and future research}

This study has begun to fill a large gap in the literature by focusing on car sharing in the New Zealand context. Accordingly, this thesis has explored a wide range of issues relating to car sharing, including both the perceived benefits of car sharing and the barriers facing the service in Wellington. This has resulted in a breadth of findings on car sharing issues, and laid the foundation for future research in this area. Further research would be useful to investigate each of the areas covered in this thesis in more depth.

The decision to focus solely on Wellington was influenced by the current and prospective car sharing situation in New Zealand. Car sharing looks set to expand considerably in Wellington over the next year with the support of both local and central government. Therefore, Wellington could benefit from research undertaken on car sharing in the city. Focusing solely on car sharing in the Wellington context was suited to a Master's thesis due to resource and time constraints. Future research could compare car sharing in New Zealand's major centres to establish how car sharing differs by context.

Car sharing in Wellington is still in the early stages of development, with only a few car share vehicles currently available in the city. Therefore, instead of focusing on current car share users, it was decided that more could be gained from surveying the wider population about their travel behaviour and perceptions on car sharing. This resulted in a reasonably large survey sample size $(n=356)$. It is unlikely that a similar sample size could have been achieved if the survey was restricted to current car share users in Wellington. In addition, surveying the wider Wellington population provided a richer picture of prospects for car sharing - by enabling a 
more complete analysis of the groups who are very interested in car sharing as well as those that are opposed to using the service. In the future, as car sharing grows in Wellington, it would be valuable to research current car share users. For example, gaining a picture of how car share members change their travel behaviour before and after joining car sharing, and the resulting impact on GHG emissions, would be useful.

The methodology chapter briefly outlined the limitations with the method of data collection in this study. An online survey was chosen because it is a fast and economical way of reaching a large population; however, it can limit participants to those who have internet access and basic computer literacy. The snowball recruitment method of encouraging people to forward the survey link on to their contacts resulted in a reasonably large sample size of 356 people. This provides strength to the results and conclusions drawn. However, this method also resulted in participants being self-selected, which resulted in biases towards certain demographic groups. In terms of the interviews, good coverage and saturation was achieved for both the car share providers and policy experts. However, further interviews could have taken place with businesses which use car sharing, to gain a wider set of insights on the research problem. This is a gap not only in New Zealand but also in the international literature; there is very little known about businesses which use car sharing. Further research in this field could, for example, shed some light on the benefit that car sharing has in terms of health and safety, by providing businesses with safer vehicles than they would use otherwise.

This study has highlighted that New Zealand's car culture is a significant barrier facing car sharing in this country. However, car sharing can also potentially play an important part in challenging the dominance of private car ownership in New Zealand and supporting the transition towards more sustainable transport patterns. Further research could explore this relationship in more depth. 


\subsection{Conclusion}

Sprawling urban development and high levels of car dependency in New Zealand's main urban areas has resulted in a range of adverse impacts for the country, including increased GHG emissions and air pollution. Compact urban development, alongside a sustainable transport system, can increase economic productivity, improve public health and wellbeing, increase social equity, increase energy efficiency, and reduce GHG emissions and air pollution. Car sharing is a transport innovation which can support compact living and sustainable transport patterns by offering a potential alternative to private vehicle ownership. There is a growing body of international literature on car sharing; however, very little has been written about car sharing in the New Zealand context. This thesis contributes to the literature in several ways by exploring car sharing in Wellington.

This thesis has identified a range of benefits that car sharing can offer Wellington, which for the most part align with the benefits found overseas. Perhaps most importantly, car sharing can reduce car ownership and usage, which in turn can help decrease congestion, demand for parking and GHG emissions in Wellington. Car sharing can also facilitate the uptake of alternative transport modes, expand the transport choices available to Wellington's residents, and improve the access of transport disadvantaged households. In addition, car sharing can result in a range of public health benefits, save individuals and businesses money, and encourage public uptake of modern technologies. Car sharing can also be an important tool for talking about sustainability because of its social, economic and environmental benefits, and has the potential to moderate New Zealand's car culture. This is a benefit identified by this study which is not widely discussed in the literature, and is particularly relevant to New Zealand. By changing attitudes towards car ownership, car sharing could help with Wellington's transition away from private car dependency towards sustainable transport patterns.

This research has provided evidence that the people most interested in using car sharing in Wellington have similar characteristics to car share members overseas. This includes younger people, apartment dwellers, households without children, and people who use a car occasionally but do not necessarily own one. This thesis has shown that car sharing can support people living in central Wellington by offering 
them a convenient alternative to car ownership which can improve their transport choices. Some journeys are best done by car, and taxi or car rental are not always suitable. Car sharing fills a significant gap in the transport network. This thesis has highlighted that car sharing is complementary to alternative modes of transport even though they are also competing. Car sharing acts as a substitute for car ownership for people who only need to drive occasionally, as most of the time alternative modes meet their travel needs.

This study underlines that modern technologies and car sharing are closely connected. It has shown that the people most interested in car sharing are likely to be incentivised by the inclusion of EVs into car share fleets, and the use of smartphone technology for locating and booking car share vehicles. The benefits of car sharing stand on their own without the inclusion of EVs. However, as EV technology improves and costs fall, EVs will increasingly be adopted into car share fleets. Modern operational technologies, such as automated booking, are critical for making car sharing convenient and for operating the car share network. It is apparent that modern technologies will play an important role in the success of car sharing in Wellington.

This study has provided insight into the barriers that car sharing faces in Wellington, and how these barriers might be overcome. The survey respondents expressed a range of concerns about car sharing, such as the availability of car share vehicles and the cost of car sharing. In general, car share members are driven by practicality, cost and environmental concern. Car sharing can benefit from its ability to overcome many of the inconveniences and costs of private ownership, by having designated parking spaces for car share vehicles. For providers, access to parking is critical, and financial assistance can help the businesses grow and eventually become selfsupporting. Further barriers include lack of public awareness of car sharing and New Zealand's car culture. Local and central government can help car share companies through providing access to low-cost or free public parking and financial assistance in line with car sharing's demonstrated public good benefits. Further, government can support car sharing by ensuring the cost of private car ownership reflects its full social costs and by removing incentives for driving. 
Car sharing offers an array of social, economic and environmental benefits. It can support compact living and sustainable transport patterns in Wellington. To become widespread in Wellington, car share providers have to overcome a range of barriers, especially relating to parking access and finance. Due to the public good benefits that car sharing can offer, there is an argument for local and central government to support car share providers, particularly in the early stages of their development. Significant progress has already been made to remove barriers facing car sharing in Wellington but more support for car sharing could allow Wellington to take full advantage of its benefits. 


\section{References}

Auckland Transport. (2015a). Auckland Transport parking strategy. Auckland Transport. Retrieved from https://at.govt.nz/media/1119147/AucklandTransport-Parking-Strategy-May-2015.pdf

Auckland Transport. (2015b, March 8). Auckland Transport wants to share our roads. Retrieved 30 May 2016, from https://at.govt.nz/about-us/newsevents/auckland-transport-wants-to-share-our-roads

Baptista, P., Melo, S., \& Rolim, C. (2014). Energy, environmental and mobility impacts of car-sharing systems. Empirical results from Lisbon, Portugal. Procedia Social and Behavioral Sciences, 111, 28-37.

Barth, M., \& Shaheen, S. (2002). Shared-use vehicle systems: Framework for classifying carsharing, station cars, and combined approaches. Transportation Research Record: Journal of the Transportation Research Board, 1791, 105112.

Bleischwitz, R., Bahn-Walkowiak, B., Irrek, W., Schepelmann, P., Schmidt-Bleek, F., Giljum, S., ... Pratt, N. (2009). Eco-innovation-putting the EU on the path to a resource and energy efficient economy. Wuppertal Spezial, Wuppertal Institut für Klima, Umwelt und Energie. Retrieved from http://www.econstor.eu/handle/10419/59278

Braun, V., \& Clarke, V. (2006). Using thematic analysis in psychology. Qualitative Research in Psychology, 3(2), 77-101.

Britton, E. (1999). Carsharing 2000 - a hammer for sustainable development. The Journal of World Transport Policy \& Practice, 5(3). Retrieved from http://www.eco-logica.co.uk/pdf/wtpp05.3.pdf

Burkhardt, J., \& Millard-Ball, A. (2006). Who is attracted to carsharing? Transportation Research Record: Journal of the Transportation Research Board, (1986), 98-105.

Cairns, S., \& Harmer, C. (2012). The emission impacts of car clubs in London. Transport Research Laboratory. Retrieved from https://trid.trb.org/view.aspx?id=1136673

Christchurch City Council. (2016, March). Car share policy. Retrieved 31 May 2016, from https://www.ccc.govt.nz/the-council/plans-strategies-policies-andbylaws/policies/transport-policies/car-share-policy

Cityhop. (2017). About Cityhop. Retrieved 10 June 2017, from http://www.cityhop.co.nz/about-cityhop/

Creswell, J. W. (2014a). A concise introduction to mixed methods research. Thousand Oaks, California: SAGE Publications. 
Creswell, J. W. (2014b). Research design: qualitative, quantitative, and mixed method approaches (4th Edition). Thousand Oaks, California: Sage Publications.

Creswell, J. W., \& Clark, V. L. P. (2011). Designing and conducting mixed methods research (2nd Edition). Thousand Oaks, California: SAGE Publications.

Devlin, C. (2015, July 16). Wellington car-sharing platform Roam aims to unlock worldwise car ownership. Stuff. Retrieved from http://www.stuff.co.nz/business/industries/70289746/wellingtoncarsharing-platform-roam-aims-to-unlock-worldwide-car-ownership

Dowling, R., \& Kent, J. L. (2015). Practice and public-private partnerships in sustainable transport governance: The case of car sharing in Sydney, Australia. Transport Policy, 40, 58-64.

Early, L., Howden-Chapman, P., \& Russell, M. (Eds.). (2015). Drivers of urban change. Wellington: Steele Roberts Aotearoa.

Edmunds, S. (2016, October 29). Making money from your unused car. Retrieved 12 June 2017, from http://www.stuff.co.nz/business/money/85871767/making-money-fromyour-unused-car

Energy Efficiency and Conservation Authority. (2017). Low emission vehicles contestable fund. Retrieved 15 June 2017, from https://www.eeca.govt.nz/funding-and-support/electric-vehiclesprogramme/

Enoch, M. P., \& Taylor, J. (2006). A worldwide review of support mechanisms for car clubs. Transport Policy, 13(5), 434-443.

Firnkorn, J., \& Müller, M. (2011). What will be the environmental effects of new freefloating car-sharing systems? The case of car2go in Ulm. Ecological Economics, 70(8), 1519-1528.

Floater, G., Rode, P., Robert, A., Kennedy, C., Hoornweg, D., Slavcheva, R., \& Godfrey, N. (2014). Cities and the New Climate Economy: the transformative role of global urban growth. Retrieved from http://lsecities.net/publications/reports/the-new-climate-economyreport/?/

Fowler, F. J. (2014). Survey research methods (5th ed.). SAGE Publications.

Fricker, R. D. (2011). Sampling methods for web and e-mail surveys. In The SAGE Handbook of Online Research Methods (pp. 195-216). SAGE Publications.

Greater Wellington Regional Council. (2016). Fare zones - Metlink. Retrieved 5 June 2017, from https://www.metlink.org.nz/tickets-and-fares/fare-zones/ 
Guest, G., Bunce, A., \& Johnson, L. (2006). How many interviews are enough?: An experiment with data saturation and variability. Field Methods, 18(1), 59-82. https://doi.org/10.1177/1525822X05279903

Hampshire, R., \& Gaites, C. (2011). Peer-to-peer carsharing: Market analysis and potential growth. Transportation Research Record: Journal of the Transportation Research Board, 2217, 119-126.

Hyde, A. (2015, June). Transport in New Zealand: A call for sustainable transitions. University of Otago, Dunedin, New Zealand.

IPCC. (2014). Climate Change 2014: Mitigation of Climate Change - Chapter 12 Human Settlements, Infrastructure and Spatial Planning. Potsdam: IPCC - Working Group III. Retrieved from http://pure.iiasa.ac.at/11114/

Kamargianni, M., Li, W., Matyas, M., \& Schäfer, A. (2016). A critical review of new mobility services for urban transport. Transportation Research Procedia, 14, 3294-3303.

Katzev, R. (2003). Car sharing: A new approach to urban transportation problems. Analyses of Social Issues and Public Policy, 3(1), 65-86.

Kelly, P., Kahlmeier, S., Götschi, T., Orsini, N., Richards, J., Roberts, N., ... Foster, C. (2014). Systematic review and meta-analysis of reduction in all-cause mortality from walking and cycling and shape of dose response relationship. International Journal of Behavioral Nutrition and Physical Activity; London, 11. Retrieved from https://search-proquestcom.helicon.vuw.ac.nz/docview/1635675409/abstract/A0747E06FFB24996 $\mathrm{PQ} / 1$

Kent, J. L. (2014). Carsharing as active transport: What are the potential health benefits? Journal of Transport \& Health, 1(1), 54-62.

Kent, J. L., \& Dowling, R. (2013). Puncturing automobility? Carsharing practices. Journal of Transport Geography, 32, 86-92.

Kim, J., Rasouli, S., \& Timmermans, H. (2017). Satisfaction and uncertainty in carsharing decisions: An integration of hybrid choice and random regret-based models. Transportation Research Part A: Policy and Practice, 95, 13-33. https://doi.org/10.1016/j.tra.2016.11.005

Kim, K. (2015). Can carsharing meet the mobility needs for the low-income neighborhoods? Lessons from carsharing usage patterns in New York City. Transportation Research Part A: Policy and Practice, 77, 249-260. https://doi.org/10.1016/j.tra.2015.04.020

Le Vine, S., Zolfaghari, A., \& Polak, J. (2014). Carsharing: Evolution, challenges and opportunities. Retrieved from http://www.carsharing.org/research/ICL/SAG_Report_Car_Sharing.pdf 
Litman, T. (1999). Carsharing benefits to consumers and society. World Transport Policy \& Practice, 5(3). Retrieved from https://trid.trb.org/view.aspx?id=1162177

Litman, T. (2000). Evaluating carsharing benefits. Transportation Research Record: Journal of the Transportation Research Board, (1702), 31-35.

Litman, T. (2002). Evaluating transportation equity. World Transport Policy \& Practice, 8(2), 50-65.

Litman, T. (2017). Smart congestion relief: comprehensive evaluation of traffic congestion costs and congestion reduction strategies. Victoria Transport Policy Institute. Retrieved from http://www.vtpi.org/cong_relief.pdf

Loose, W. (2010). The state of European car-sharing. Project Momo Final Report D, 2. Retrieved from http://carsharing.de/images/stories/pdf_dateien/wp2_report_englisch_fina 1_2.pdf

MacManus, R. (2017, May 28). Transport as a service: are we there yet? Retrieved 11 June 2017, from https://www.newsroom.co.nz/2017/05/28/30812?slug=here-in-my-car

Martin, E., \& Shaheen, S. (2010). Greenhouse gas emission impacts of carsharing in North America. Mineta Transportation Institute, San Jose State University. Retrieved from http://tsrc.berkeley.edu/sites/default/files/Greenhouse\%20Gas\%20Emissio n\%20Impacts\%20of\%20Carsharing\%20in\%20North\%20America\%20\%28fi nal\%20report\%29.pdf

Martin, E., \& Shaheen, S. (2011a). The impact of carsharing on household vehicle ownership. ACCESS Magazine, 1(38). Retrieved from http://escholarship.org/uc/item/7w58646d.pdf

Martin, E., \& Shaheen, S. (2011b). The impact of carsharing on public transit and non-motorized travel: An exploration of North American carsharing survey data. Energies, 4(12), 2094-2114.

Martin, E., Shaheen, S., \& Lidicker, J. (2010). Impact of carsharing on household vehicle holdings: Results from North American shared-use vehicle survey. Transportation Research Record: Journal of the Transportation Research Board, 2143, 150-158.

Maude, S. (2016, March 20). Electric car scheme fizzles out. Retrieved 31 May 2016, from http://www.stuff.co.nz/motoring/news/77739363/electric-carscheme-fizzles-out

Mercury Energy. (2017, May 24). Auckland car-sharing goes electric. Retrieved 12 June 2017, from 
http://www.scoop.co.nz/stories/AK1705/S00585/auckland-car-sharinggoes-electric.htm

Mevo. (2017a, January 19). Low emission vehicles contestable fund. Retrieved 12 June 2017, from /press/index.html

Mevo. (2017b, May 9). Mevo car share on track for 50+ EV fleet in Wellington.

Retrieved 12 June 2017, from

http://www.scoop.co.nz/stories/BU201705/S00316.htm

Millard-Ball, A., Murray, G., Ter Schure, J., Fox, C., \& Burkhardt, J. (2005). Car-sharing: where and how it succeeds (Transit cooperative research program No. 108). Washington, DC: Transportation Research Board of the National Academies.

Ministry for the Environment. (2017). New Zealand's Greenhouse Gas Inventory 19902015. Ministry for the Environment. Retrieved from http://www.mfe.govt.nz/sites/default/files/media/Climate\%20Change/FIN AL\%20GHG\%20inventory\%20-\%2025\%20May.pdf

Ministry of Business, Innovation and Employment. (2016). Energy in New Zealand 2016. Ministry of Business, Innovation and Employment. Retrieved from http://www.mbie.govt.nz/info-services/sectors-industries/energy/energydata-modelling/publications/energy-in-new-zealand/energy-in-nz-2016.pdf

Ministry of Transport. (2015a). Annual fleet statistics 2015. Ministry of Transport.

Retrieved from http://www.transport.govt.nz/assets/Uploads/Research/Documents/Fleetreports/The-NZ-Vehicle-Fleet-2015-final.pdf

Ministry of Transport. (2015b). Comparing travel modes: New Zealand household travel survey 2011 - 2014. Ministry of Transport. Retrieved from http://www.transport.govt.nz/assets/Uploads/Research/Documents/Comp aring-travel-modes-2015.pdf

Ministry of Transport. (2017). Electric vehicles. Retrieved 15 June 2017, from http://www.transport.govt.nz/ourwork/climatechange/electric-vehicles/

Nawangpalupi, C., \& Demirbilek, O. (2008). Investigation on the drivers and the barriers for travel behaviour changes and the analysis of the impact: A case study of car sharing in Australia. The International Journal of Environmental, Cultural, Economic and Social Sustainability, 4(4), 1.

Nijland, H., \& van Meerkerk, J. (2017). Mobility and environmental impacts of car sharing in the Netherlands. Environmental Innovation and Societal Transitions, 23, 84-91. https://doi.org/10.1016/j.eist.2017.02.001

Nunns, P. (2014). Population-weighted densities in New Zealand and Australian cities: A new comparative dataset. Auckland: MRCagney Pty Ltd. Retrieved from http://www.greaterauckland.org.nz/wp-content/uploads/2014/09/Nunns2014-NZ-Aus-population-weighted-density-small.pdf 
OECD. (2013). Road traffic, vehicles and networks. In Environment at a Glance 2013: OECD Indicators. Paris: OECD Publishing.

Rabbitt, N., \& Ghosh, B. (2016). Economic and environmental impacts of organised Car Sharing Services: A case study of Ireland. Research in Transportation Economics, 57, 3-12.

Racioppi, F., Dora, C., \& Rutter, H. (2005). Urban settings and opportunities for healthy lifestyles: rediscovering walking and cycling and understanding their health benefits. Built Environment (1978-), 31(4), 302-314.

Rode, P., Floater, G., Thomopoulos, N., Docherty, J., Schwinger, P., Mahendra, A., \& Fang, W. (2014). Accessibility in cities: transport and urban form. Retrieved from http://eprints.lse.ac.uk/60477/

Shaheen, S., \& Chan, N. (2015). Evolution of e-mobility in carsharing business models. In D. Beeton \& G. Meyer (Eds.), Electric Vehicle Business Models (pp. 169-178). Springer International Publishing. Retrieved from http://link.springer.com/chapter/10.1007/978-3-319-12244-1_10

Shaheen, S., Chan, N. D., \& Micheaux, H. (2015). One-way carsharing's evolution and operator perspectives from the Americas. Transportation, 42(3), 519-536.

Shaheen, S., \& Cohen, A. (2007). Growth in worldwide carsharing: An international comparison. Transportation Research Record: Journal of the Transportation Research Board, (1992), 81-89.

Shaheen, S., \& Cohen, A. (2013). Carsharing and personal vehicle services: Worldwide market developments and emerging trends. International Journal of Sustainable Transportation, 7(1), 5-34.

Shaheen, S., \& Cohen, A. (2014). Innovative mobility carsharing outlook: Fall 2014 (No. Volume 3, Issue 2). Transportation Sustainability Research Center, University of California, Berkeley.

Shaheen, S., \& Cohen, A. (2016). Innovative mobility carsharing outlook: Winter 2016. Transportation Sustainability Research Center, UC Berkeley. Retrieved from http://innovativemobility.org/wpcontent/uploads/2016/02/Innovative-Mobility-Industry-Outlook_World2016-Final.pdf

Shaheen, S., Mallery, M., \& Kingsley, K. (2012). Personal vehicle sharing services in North America. Research in Transportation Business \& Management, 3, 71-81.

Shaheen, S., \& Martin, E. (2010). Demand for carsharing systems in Beijing, China: An exploratory study. International Journal of Sustainable Transportation, 4(1), 41-55.

Shaheen, S., Schwartz, A., \& Wipyewski, K. (2004). Policy considerations for carsharing and station cars: Monitoring growth, trends, and overall impacts. 
Transportation Research Record: Journal of the Transportation Research Board, (1887), 128-136.

Statistics New Zealand. (2013). NZStat. 2013 Census. Retrieved 4 June 2017, from http://nzdotstat.stats.govt.nz/wbos/Index.aspx

Steininger, K., Vogl, C., \& Zettl, R. (1996). Car-sharing organizations: The size of the market segment and revealed change in mobility behavior. Transport Policy, $3(4), 177-185$.

Stillwater, T., Mokhtarian, P. L., \& Shaheen, S. (2008). Carsharing and the built environment: A GIS-based study of one U.S. operator. Institute of Transportation Studies. Retrieved from http://escholarship.org/uc/item/2wj7q6cm

Sue, V. M., \& Ritter, L. A. (2012). Conducting online surveys (2nd ed.). SAGE Publications.

The New Climate Economy. (2014). Better growth better climate: the new climate economy report. Washington, DC: The New Climate Economy. Retrieved from https://www.unilever.com/Images/better-growth-better-climate-newclimate-economy-global-report-september-2014_tcm244-425167_en.pdf

Walton, S., Hyde, A., \& Patel, V. (2016). Entrepreneurial actors in transport systems. An energy cultures perspective. Dunedin, New Zealand: Centre for Sustainability, University of Otago. Retrieved from https://otago.ourarchive.ac.nz/handle/10523/7135

Wappelhorst, S., Dobrzinski, J., Graff, A., Steiner, J., \& Hinkeldein, D. (2016). Flexible carsharing-Potential for the diffusion of electric mobility. In Markets and Policy Measures in the Evolution of Electric Mobility (pp. 67-84). Springer. Retrieved from http://link.springer.com/chapter/10.1007/978-3-31924229-3_5

Wellington City Council. (2016a). Car share policy 2016. Wellington City Council. Retrieved from http://wellington.govt.nz/ /media/your-council/planspolicies-and-bylaws/files/car-share-j001370.pdf?la=en

Wellington City Council. (2016b). Low carbon capital: A climate change action plan for Wellington 2016-2018. Wellington City Council. Retrieved from http://wellington.govt.nz/ /media/services/environment-andwaste/environment/files/low-carbon-capital-plan-2016-2018.pdf?la=en

Wellington City Council. (2017, May 5). Wellington leading the way with commitment to car sharing. Retrieved 12 June 2017, from http://wellington.govt.nz/your-council/news/2017/05/car-sharing

YourDrive. (2016). YourDrive: The Way Forward. Retrieved 30 May 2016, from https://yourdrive.co.nz/ 

MEMORANDUM

\begin{tabular}{l|l}
\hline TO & Lucia Sobiecki \\
\hline COPY TO & AJProf Ralph Chapman \\
\hline FROM & AProf Susan Corbett, Convener, Human Ethics Committee \\
\hline
\end{tabular}

\begin{tabular}{l|l}
\hline DATE & 9 November 2016
\end{tabular}

\begin{tabular}{l|l}
\hline PAGES & 1 \\
\hline
\end{tabular}

\begin{tabular}{l|l}
\hline SUBJECT & Ethics Approval: $\mathbf{2 3 6 1 3}$
\end{tabular}

Car sharing in Wellington. Exploring the role car sharing could play

in promoting higher-density living and low-carbon transport

patterns in Wellington, and determining the barriers facing car sharing in Wellington and how they might be overcome.

Thank you for your application for ethical approval, which has now been considered by the Standing Committee of the Human Ethics Committee.

Your application has been approved from the above date and this approval continues until 30 June 2017 . If your data collection is not completed by this date you should apply to the Human Ethics Committee for an extension to this approval.

Best wishes with the research.

Kind regards

Susan Corbett

Convener, Victoria University Human Ethics Committee 


\section{TE WHARE WĀNANGA O TE ŨPOKO O TE IKA A MĀUI}

Online survey - car sharing in Wellington

Participant consent

Thank you for your interest in this research project. Please read the following information before deciding whether to take part in the survey.

Who am I?

My name is Lucia Sobiecki and I am a Masters student in the Environmental Studies programme at Victoria University of Wellington. This survey is being conducted as part of my thesis.

\section{What is the aim of this project?}

This study will explore the role car sharing could play in promoting higher-density living and low-carbon transport patterns in Wellington, as well as determine the barriers facing car sharing in Wellington and how they might be overcome. This research project has been approved by the Victoria University of Wellington Human Ethics Committee (approval 23613)

\section{How can you help?}

If you agree to take part, you will fill out a 10 to 15-minute survey that consists of demographic questions, questions about how you travel, your access to vehicles and parking, your perceptions of car ownership and driving, and questions about car sharing. You are not required to answer every question if you do not wish to. You may withdraw your participation at any time while taking the survey; however once you submit your survey it will be impossible to withdraw.

\section{What will happen to the information you give?}

All of the information you provide is anonymous and confidential. Access to the collected data will be restricted to me, and will be stored in a password-protected file for up to two years, after which it will be erased.

\section{What will the project produce?}

The data will be reported in my Master's thesis, which will be submitted for marking to the School of Geography, Environment and Earth Sciences, Victoria University of Wellington. A copy of this thesis will be publicly available through the Victoria University of Wellington library. The information may also feature in academic, industry or local government publications and/or be presented at academic or professional conferences.

\section{If you have any questions or problems, who can you contact?}

If you have any questions regarding this study, please email me at lucia.sobiecki@vuw.ac.nz,or you can email my supervisor Associate Professor Ralph Chapman at ralph.chapman@vuw.ac.nz.

\section{Human Ethics Committee Information}

If you have any concerns about the ethical conduct of this research, you may contact the Victoria University HEC Convener: Associate Professor Susan Corbett. Email susan.corbett@vuw.ac.nz or telephone +64 44635480.

Many thanks,

Lucia Sobiecki 
I I confirm that I am 18 years of age or older, and have read and understood the information provided and wish to continue with the survey.

Note: Questions will be viewed by respondents according to their answers. Therefore, not every question will be viewed by all participants.

Introduction

It should take you approximately 10 to 15 minutes to complete this survey, which is divided into three sections:

- Section one includes a range of demographic questions

- Section two includes questions about how you travel, your access to vehicles and parking, and your perceptions of car ownership and driving

- Section three includes questions about car sharing

Thank you for taking the time to complete this survey.

Section 1. demographic questions

Please remember that your responses are confidential and anonymous.

Q1. Do you live in the Wellington Region?

$\square \quad$ Yes

No

If no is selected, the participant is directed to the end of the survey.

Q2. Where do you live? (This is in order to estimate your distance to the CBD and local amenities, as well as the walkability of your location and links to public transport and cycling facilities).

Street:

Suburb:

Q3. Which of the following best describes your living situation?

$\square \quad$ Single living alone

$\square$ Single with children living at home

$\square \quad$ Couple without children living at home

$\square$ Couple with children living at home

․ Flat/group living together

Q4. How would you describe your place of residence?

$\square \quad$ High rise apartment (more than 4 levels)

ㄴ Low rise apartment (4 or fewer levels)

$\square$ Town house

Standalone house

Q5. How would you describe your neighbourhood?

Primarily standalone houses

$\square \quad$ Mix of standalone houses and apartments/town houses

$\square \quad$ Primarily apartments/town houses 
Q6. Which best describes your employment situation? Please select all that apply.

Full time paid employment - 20 hours or more per week

․ Part time paid employment - less than 20 hours per week

․ Full time tertiary student

口 Part time tertiary student

․ Not in paid employment

口 Other

Q7. Please indicate your annual level of income before tax:
$\square$ \$0
$\$ 1-\$ 25,000$
口 $\$ 25,001-\$ 50,000$
ㅁ $\$ 50,001-\$ 100,000$
ㅁ $\$ 100,001+$

Q8. Please indicate your gender:
口 Male
․ Female
Other

Q9. Please indicate your age:
a $18-24$
ㅁ 25-34
ㅁ $35-44$
45-54
$55-64$
․ $65+$

Q10. Please indicate your highest level of education:

No qualification

口 High school qualification

ㅁ Tertiary degree

․ Tertiary other 
Section 2. Transport patterns, access to vehicles and parking, perceptions of car ownership and driving

Transport patterns

Q11. Do you have a car driver's licence?

$\square \quad$ No licence

ㄴ Learners licence

․ Restricted licence

$\square \quad$ Full licence

Q12. Do you regularly commute for either work or study?

$\square \quad$ Yes

$\square \quad$ No

If no, the participant is directed to question 14.

Q13. What is the main mode of transport that you usually use to travel to either work or study?

$\square$ Driver in a car

Passenger in a car

ㅁ Public transport (bus, train, ferry)

․ Motorcycle or scooter

Bicycle

Walk

Taxi

ㅁ Other, please specify:

Q14. What is the main mode of transport that you usually use to travel to do your grocery/food shopping?
Driver in a car
ㅁ Passenger in a car
․ Public transport (bus, train, ferry)
- Motorcycle or scooter
Bicycle
口 Walk
Taxi
$\square \quad$ Other, please specify:

Q15. What is the main mode of transport that you usually use to travel to regular recreational/leisure activities? (E.g. weekly sports, visiting friends/family)
Driver in a car
口 Passenger in a car
Public transport (bus, train, ferry)
口 Motorcycle or scooter
- Bicycle
口 Walk
Taxi
ㅁ Other, please specify: 
Vehicle access and purchase plans

Q16. How often do you have access to a car for travel around the Wellington region?

$\square \quad$ All of the time

․ Most of the time

ㅁ Mainly in the evenings or weekends

Rarely

$\square \quad$ Never

Q17. What vehicles do you have access to for travel around the Wellington region? Please select all that apply.
No vehicles
․ 1 car
2 cars or more
․ A scooter/motorcycle
$\square \quad$ A bicycle
$\square \quad$ Other, please specify:

Q18. Do you own one or more cars?

$\square \quad$ Yes

$\square \quad$ No

If yes, the participant is directed to question 20.

Q19. What are the main reasons for you not owning your own car? Please select all that apply.

ㅁ I have access to someone else's car (e.g. friend, family member or flatmate's car)

$\square$ I have a bicycle/scooter/motorbike

$\square \quad$ The cost of owning a car

$\square$ The inconvenience of owning a car (e.g. parking is difficult)

$\square \quad$ No need to own a car (e.g. I walk or catch public transport everywhere)

$\square$ Environmental concerns

口 Health reasons

$\square \quad$ I do not have a driver's licence

$\square \quad$ Other, please specify:

Q20. On average, how often do you use a car?

$\square \quad$ Every day of the week

ㅁ 2-6 days of the week

$\square \quad$ One day or less a week

Q21. Do you plan to purchase a car within the next 12 months?

$\square \quad$ Yes

№

If no, the participant is directed to question 23 . 
Q22. What will be the main use of this car?

․ Commuting to work or study

Grocery/food shopping

$\square \quad$ Regular recreational/leisure activities (e.g. weekly sports, visiting friends/family)

Occasional recreational/leisure activities (e.g. daytrips)

$\square \quad$ Holiday travel

$\square$ Other, please specify:

Access to parking

Q23. Do you have access to car parking at your place of residence?

$\square \quad$ Free off-street parking

ㅁ Free on-street parking

$\square \quad$ Paid off-street parking

$\square \quad$ Paid on-street parking

No access to parking

Q24. Do you have access to car parking at your place of work or study?

$\square \quad$ Free off-street parking

$\square \quad$ Free on-street parking

- Paid off-street parking

ㅁ Paid on-street parking

No access to parking

Q25. Please indicate to what extent you agree or disagree with each of these statements:

\begin{tabular}{|l|l|l|l|l|l|l|}
\hline & $\begin{array}{c}\text { Strongly } \\
\text { agree }\end{array}$ & Agree & $\begin{array}{c}\text { Neither } \\
\text { agree } \\
\text { nor } \\
\text { disagree }\end{array}$ & Disagree & $\begin{array}{c}\text { Strongly } \\
\text { disagree }\end{array}$ & N/A \\
\hline $\begin{array}{l}\text { There is always a conveniently } \\
\text { located car park available at my } \\
\text { place of residence }\end{array}$ & 1 & 2 & 3 & 4 & 5 & 6 \\
\hline $\begin{array}{l}\text { There is always a conveniently } \\
\text { located car park available at my } \\
\text { place of work or study }\end{array}$ & 1 & 2 & 3 & 4 & 5 & 6 \\
\hline $\begin{array}{l}\text { Parking is expensive at my } \\
\text { place of residence }\end{array}$ & 1 & 2 & 3 & 4 & 5 & \\
\hline $\begin{array}{l}\text { Parking is expensive at my } \\
\text { place of work or study }\end{array}$ & 1 & 2 & 3 & 4 & 5 & 6 \\
\hline
\end{tabular}


Perception of car ownership and driving

Q26. Please indicate to what extent you agree or disagree with each of these statements:

\begin{tabular}{|c|c|c|c|c|c|}
\hline & $\begin{array}{l}\text { Strongly } \\
\text { agree }\end{array}$ & Agree & $\begin{array}{l}\text { Neither } \\
\text { agree } \\
\text { nor } \\
\text { disagree }\end{array}$ & Disagree & $\begin{array}{l}\text { Strongly } \\
\text { disagree }\end{array}$ \\
\hline $\begin{array}{l}\text { It is important for me to own my own } \\
\text { vehicle }\end{array}$ & 1 & 2 & 3 & 4 & 5 \\
\hline $\begin{array}{l}\text { It is important for me to have access to a } \\
\text { vehicle but I do not need to own it }\end{array}$ & 1 & 2 & 3 & 4 & 5 \\
\hline $\begin{array}{l}\text { It is important for me to have access to a } \\
\text { vehicle all of the time }\end{array}$ & 1 & 2 & 3 & 4 & 5 \\
\hline $\begin{array}{l}\text { It is important for me to have access to a } \\
\text { vehicle some of the time }\end{array}$ & 1 & 2 & 3 & 4 & 5 \\
\hline $\begin{array}{l}\text { I prefer driving as opposed to public } \\
\text { transport, walking or cycling }\end{array}$ & 1 & 2 & 3 & 4 & 5 \\
\hline $\begin{array}{l}\text { I only drive when I have to, most of the time } \\
\text { I prefer to take public transport, walk or } \\
\text { cycle }\end{array}$ & 1 & 2 & 3 & 4 & 5 \\
\hline $\begin{array}{l}\text { I do not have an alternative to driving (e.g. } \\
\text { public transport is too far away; I have to } \\
\text { travel with heavy work equipment) }\end{array}$ & 1 & 2 & 3 & 4 & 5 \\
\hline $\begin{array}{l}\text { It is very important to me what } \\
\text { make/model of vehicle I drive }\end{array}$ & 1 & 2 & 3 & 4 & 5 \\
\hline $\begin{array}{l}\text { I am concerned with the negative impacts } \\
\text { car ownership has on the environment }\end{array}$ & 1 & 2 & 3 & 4 & 5 \\
\hline
\end{tabular}

Section 3. Car sharing

Car sharing description

Car sharing is a type of car rental service. It is not a taxi or Uber service, as you drive the vehicle yourself. It is different from carpooling or ridesharing, which refer to the shared use of privately owned vehicles for a particular journey.

In general, car sharing has the following characteristics:

- a member can book a vehicle by the hour (in advance, or when you need it)

- it has an hourly rate, such as \$10-20 per hour, which covers the cost of fuel, maintenance and insurance, plus a membership fee

vehicles are located in convenient locations around the city, such as the CBD and transit hubs

- vehicles can be booked via a mobile app or online, and are unlocked with phone or smart card technologies

- car sharing is either 'round-trip' (return the vehicle to the place it was picked up) or 'point-to-point' (pick up a vehicle in one location and return it to a different location).

Car sharing schemes are generally operated by a business which provides the fleet of vehicles. An alternative car sharing scheme is peer-to-peer car sharing in which individuals choose to make their personal vehicles available for others in exchange for payment. 


\section{Familiarity with car sharing}

Q27. Have you heard of car sharing before today?

$\square \quad$ Yes

$\square \quad$ No

If no is selected, the participant is directed to question 33 .

Q28. How did you hear about car sharing?

․ Commercial means (e.g. advertising via social media, newspaper, radio etc.)

口 Non-commercial (e.g. newspaper article, blog, word of mouth etc.)

Q29. Have you used car sharing before?

$\square \quad$ Yes

No

If no is selected, the participant is directed to question 33.

Q30. Where have you used car sharing?

ㅁ In New Zealand

$\square \quad$ Overseas

\section{If overseas is selected, the participant is directed to question 33 .}

Q31. Do you currently use car sharing services in New Zealand?

$\square \quad$ Yes

No

Q32. What is the main reason you used or are using car sharing?

Cost

ㅁ Convenience

Environmental concerns

ㅁ Other, please specify:

Perceptions of car sharing

Q33. Car share vehicles can generally be rented by the hour or for the day. If you were to use car sharing services, which of the following types of trips do you think you would do via car sharing? Please select all that apply.

ㅁ Commuting to work or study

Food shopping

$\square \quad$ Regular recreational/leisure activities (e.g. weekly sports game, visiting friends/family)

$\square \quad$ Occasional recreational/leisure activities (e.g. daytrips)

․ Holiday travel

$\square \quad$ Other, please specify: 
Q34. Car share vehicles are generally located in a number of convenient locations around the city, such as CBD and transit hubs. How far do you think you would be happy to walk from your place of residence, work or study to the car share vehicle pick up/return point?

․ Less than a 2 or 3-minute walk

$\square \quad$ Less than a 5-minute walk

5 to 10 -minute walk

ㅁ 10 to 15 -minute walk

ㅁ 15 to 20 -minute walk

․ More than a 20-minute walk

Q35. Please indicate to what extent you agree or disagree with each of these statements:

\begin{tabular}{|c|c|c|c|c|c|}
\hline & $\begin{array}{l}\text { Strongly } \\
\text { agree }\end{array}$ & Agree & $\begin{array}{l}\text { Neither } \\
\text { agree } \\
\text { nor } \\
\text { disagree }\end{array}$ & Disagree & $\begin{array}{l}\text { Strongly } \\
\text { disagree }\end{array}$ \\
\hline $\begin{array}{l}\text { Car sharing would be more convenient than } \\
\text { owning my own car or buying a car }\end{array}$ & 1 & 2 & 3 & 4 & 5 \\
\hline $\begin{array}{l}\text { Car sharing would be more convenient than } \\
\text { owning a second car or buying a second car }\end{array}$ & 1 & 2 & 3 & 4 & 5 \\
\hline $\begin{array}{l}\text { Car sharing would improve my transport } \\
\text { options, giving me greater accessibility to } \\
\text { amenities }\end{array}$ & 1 & 2 & 3 & 4 & 5 \\
\hline $\begin{array}{l}\text { Car sharing would be more affordable than } \\
\text { owning my own car or buying a car }\end{array}$ & 1 & 2 & 3 & 4 & 5 \\
\hline $\begin{array}{l}\text { Car sharing would be more affordable than } \\
\text { owning a second car or buying a second car }\end{array}$ & 1 & 2 & 3 & 4 & 5 \\
\hline $\begin{array}{l}\text { Car sharing would work well for occasional } \\
\text { activities (but not commuting) }\end{array}$ & 1 & 2 & 3 & 4 & 5 \\
\hline $\begin{array}{l}\text { If car sharing used high-end vehicles, I } \\
\text { would be more likely to use the service }\end{array}$ & 1 & 2 & 3 & 4 & 5 \\
\hline $\begin{array}{l}\text { If car sharing used electric vehicles, I would } \\
\text { be more likely to use the service }\end{array}$ & 1 & 2 & 3 & 4 & 5 \\
\hline $\begin{array}{l}\text { If car sharing used smartphone technology } \\
\text { for locating and booking vehicles, I would } \\
\text { be more likely to use the service }\end{array}$ & 1 & 2 & 3 & 4 & 5 \\
\hline $\begin{array}{l}\text { If it were easier to walk, cycle or use public } \\
\text { transport for the majority of my travel, I } \\
\text { would be more likely to use car sharing for } \\
\text { occasional trips instead of owning my own car } \\
\text { or buying a car }\end{array}$ & 1 & 2 & 3 & 4 & 5 \\
\hline $\begin{array}{l}\text { Car sharing would be a more } \\
\text { environmentally friendly alternative to car } \\
\text { ownership }\end{array}$ & 1 & 2 & 3 & 4 & 5 \\
\hline
\end{tabular}


Q36. Please indicate to what extent you agree or disagree with each of these statements:

\begin{tabular}{|c|c|c|c|c|c|}
\hline & $\begin{array}{l}\text { Strongly } \\
\text { agree }\end{array}$ & Agree & $\begin{array}{l}\text { Neither } \\
\text { agree } \\
\text { nor } \\
\text { disagree }\end{array}$ & Disagree & $\begin{array}{l}\text { Strongly } \\
\text { disagree }\end{array}$ \\
\hline $\begin{array}{l}\text { I am concerned about the cleanliness of the } \\
\text { car share vehicle (e.g. it may not be clean } \\
\text { when I pick it up) }\end{array}$ & 1 & 2 & 3 & 4 & 5 \\
\hline $\begin{array}{l}\text { I am concerned about how much car } \\
\text { sharing costs (e.g. the hourly rate and } \\
\text { membership fee) }\end{array}$ & 1 & 2 & 3 & 4 & 5 \\
\hline $\begin{array}{l}\text { I am concerned about the availability of the } \\
\text { car share vehicle (when I want to use it) }\end{array}$ & 1 & 2 & 3 & 4 & 5 \\
\hline $\begin{array}{l}\text { I am concerned about having to pick up and } \\
\text { return the car share vehicle at set times }\end{array}$ & 1 & 2 & 3 & 4 & 5 \\
\hline $\begin{array}{l}\text { I am concerned about not being able to take } \\
\text { pets in the car share vehicle }\end{array}$ & 1 & 2 & 3 & 4 & 5 \\
\hline $\begin{array}{l}\text { I am concerned about not being able to } \\
\text { smoke in the car share vehicle }\end{array}$ & 1 & 2 & 3 & 4 & 5 \\
\hline $\begin{array}{l}\text { I am concerned about the selection of cars } \\
\text { available (e.g. } 4 \text { or } 6 \text { seater, electric or } \\
\text { hybrid, standard or high-end vehicle) }\end{array}$ & 1 & 2 & 3 & 4 & 5 \\
\hline $\begin{array}{l}\text { I am concerned about the distance between } \\
\text { my place of residence, work or study and } \\
\text { the pick-up point for the car share vehicles }\end{array}$ & 1 & 2 & 3 & 4 & 5 \\
\hline $\begin{array}{l}\text { I am concerned about insurance (e.g. in } \\
\text { case the car is damaged) }\end{array}$ & 1 & 2 & 3 & 4 & 5 \\
\hline $\begin{array}{l}\text { I am concerned about having to use } \\
\text { smartphone technology to use the car } \\
\text { sharing service (e.g. book and locate the } \\
\text { vehicles) }\end{array}$ & 1 & 2 & 3 & 4 & 5 \\
\hline
\end{tabular}

Q37. Are there any other concerns you have about car sharing? Please specify:

Q38. How interested are you in using car sharing?

\begin{tabular}{|c|c|c|c|c|}
\hline $\begin{array}{c}\text { Very } \\
\text { interested }\end{array}$ & & Maybe & & $\begin{array}{c}\text { Not at all } \\
\text { interested }\end{array}$ \\
\hline 1 & 2 & 3 & 4 & 5 \\
\hline
\end{tabular}

Q39. What, if anything, would encourage you to use car sharing services? Please specify:

Q40. Do you have any other comments regarding car sharing? 
End of survey

Thank you for taking the time to complete this survey. Your answers and opinions are highly valued.

It would be very helpful for my research if you could please share this survey with any of your friends, family, colleagues or acquaintances, who live in the Wellington Region and are 18 years of age or older. Please feel free to copy and paste the below description and link to the survey:

Hello! My name is Lucia Sobiecki, and I am a Masters student at Victoria University of Wellington. As part of my Master's thesis, I am conducting a survey on car sharing in Wellington. If you live in the Wellington Region, and are 18 years of age or older, please help my research by filling in this 10 to 15 minute survey: http://vuw.qualtrics.com/SE/?SID=SV 2u9jFBIl5aXauBT. Your interest in this research project is very much appreciated.

If you manage a business based in Wellington, it would greatly add to my research if I could speak to you briefly about car sharing in relation to your business. If you are willing to answer some questions, please email me atlucia.sobiecki@vuw.ac.nz.

Many thanks

Lucia Sobiecki

\section{Do you have any questions or problems regarding this survey?}

If you have any questions regarding this study, please email me at lucia.sobiecki@vuw.ac.nz, or you can email my supervisor Associate Professor Ralph Chapman at ralph.chapman@vuw.ac.nz.

\section{Human Ethics Committee Information}

If you have any concerns about the ethical conduct of this research, you may contact the Victoria University Human Ethics Committee Convener: Associate Professor Susan Corbett. Email susan.corbett@vuw.ac.nz or telephone +6444635480 . 


\section{Information sheet}

\section{ags \\ Master's Thesis: Car Sharing in Wellington \\ INFORMATION SHEET FOR PARTICIPANTS}

Thank you for your interest in this project. Please read this information before deciding whether to take part. If you decide to participate, thank you. If you decide not to take part, thank you for considering my request.

\section{Who am I?}

My name is Lucia Sobiecki and I am a Masters student in the Environmental Studies programme at Victoria University of Wellington. This research will form part of my thesis.

\section{What is the aim of the project?}

My thesis will explore the role car sharing could play in supporting higher-density living and low-carbon transport patterns in Wellington, as well as determine the barriers facing car sharing in Wellington and how they might be overcome. This research project has been approved by the Victoria University of Wellington Human Ethics Committee (approval 23613).

\section{How can you help?}

If you agree to take part, I will ask you a range of questions about car sharing in Wellington. This includes questions about the main benefits of car sharing, the barriers car sharing faces in Wellington, and the relationship between car sharing and compact urban form, public transport, walking and cycling. The interview will take place at a time and location that is convenient for you, and will take no longer than an hour. I will record the interview and write it up later. You will have the opportunity to read over and comment an a transcript or summary of your interview to ensure your thoughts have been correctly presented before they are used in analysis. You can stop the interview at any time, without giving a reason. You can withdraw from the study by contacting me at any point before $28^{\text {th }}$ February 2017. If you withdraw, the information you provide will be destroyed or returned to you.

\section{What will happen to the information you give?}

You will not be named in the final report but your organisation will be identified (provided you have the authority to agree to this on behalf of your organisation).

Only my supervisor and I will read the notes or transcript of the interview. The interview transcripts, summaries and any recordings will be kept securely and destroyed 2 years after the research is completed or returned to you.

\section{What will the project produce?}

The data collected will be reported in my Master's thesis, which will be submitted for marking to the School of Geography, Environment and Earth Sciences, Victoria University of Wellington. A copy of this thesis will be publicly available through the Victoria University of Wellington library. The information may also feature 
in academic, industry or local government publications and/or be presented at academic or professional conferences.

If you accept this invitation, what are your rights as a research participant?

You do not have to accept this invitation if you do not wish to. If you do decide to participate, you have the right to:

- choose not to answer any question

- ask for the recording device to be turned off at any time during the interview

- withdraw from the study before $28^{\text {th }}$ February 2017

- ask any questions about the study at any time

- receive a copy of the transcript of your interview

- receive a summary of your interview

- read over and comment on a transcript or summary of your interview

- receive a copy of the final report

If you have any questions or problems, who can you contact?

If you have any questions regarding this study, please email me at lucia.sobiecki@vuw.ac.nz, or you can email my supervisor Associate Professor Ralph Chapman at ralph.chapman@vuw.ac.nz.

\section{Human Ethics Committee Information}

If you have any concerns about the ethical conduct of this research, you may contact the Victoria University HEC Convener: Associate Professor Susan Corbett. Email susan.corbett@vuw.ac.nz or telephone +64 4463 5480 


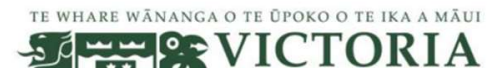 ST \\ Master's Thesis: Car Sharing in Wellington \\ CONSENT TO INTERVIEW}

This consent form will be held for 2 years.

Researcher: Lucia Sobiecki, School of Geography, Environment and Earth Sciences, Victoria University of Wellington

- I have read the Information Sheet and the project has been explained to me. My questions have been answered to my satisfaction. I understand that I can ask further questions at any time.

- I agree to take part in an audio-recorded interview.

I understand that:

- I may withdraw from this study at any point before $28^{\text {th }}$ February 2017 without giving any reason, and any information that I have provided will be returned to me or destroyed.

- The information I have provided will be destroyed 2 years after the research is finished.

- Any information I provide will be kept confidential to the researcher and the supervisor. I understand that the results will be used for a Master's report and a summary of the results may be used in academic reports and/or presented at conferences.

- I consent to information or opinions which I have given being attributed to my organisation in any reports on this research:

- I would like a copy of the transcript of my interview:

Yes $\square \quad$ No $\square$

Yes $\square \quad$ No $\square$

- I would like a summary of my interview:

Yes $\square \quad$ No $\square$

- I would like to receive a copy of the final report and have added my email address below.

Yes $\square \quad$ No $\square$

Signature of participant:

Name of participant:

Date:

Contact details: 
TE WHARE WĀNANGA O TE ŨPOKO O TE IKA A MĀU S⿹

Master's Thesis: Car Sharing in Wellington

INTERVIEW GUIDE

Date:

Researcher: Lucia Sobiecki, Victoria University of Wellington

Interviewee:

1. Introduction

Discuss and sign the Information Sheet for Participants and Consent to Interview Form.

2. Car sharing in Wellington

- How are you involved with car sharing in Wellington?

- What do you see as the main benefits of developing car sharing in Wellington?

- Who do you think will use car sharing in Wellington and why?

- What do you see as the main barriers facing car sharing in Wellington? From a business/policy/individual perspective.

- How do you think these barriers might be overcome?

- How important are public transport, walking and cycling infrastructure for the success of car sharing?

- How important is compact/dense city form for the success of car sharing?

- How important is the use of hybrid/electric vehicles for the success of car sharing?

- How important is the use of modern technologies for the success of car sharing?

- What is different/distinct about the New Zealand/Wellington context, compared with overseas?

3. Conclusion

Discuss any further thoughts and other potential interviewees. Thanks for participation. 


\section{Appendix D Thematic maps}

\section{Figure C.1. Thematic map of the interview results}

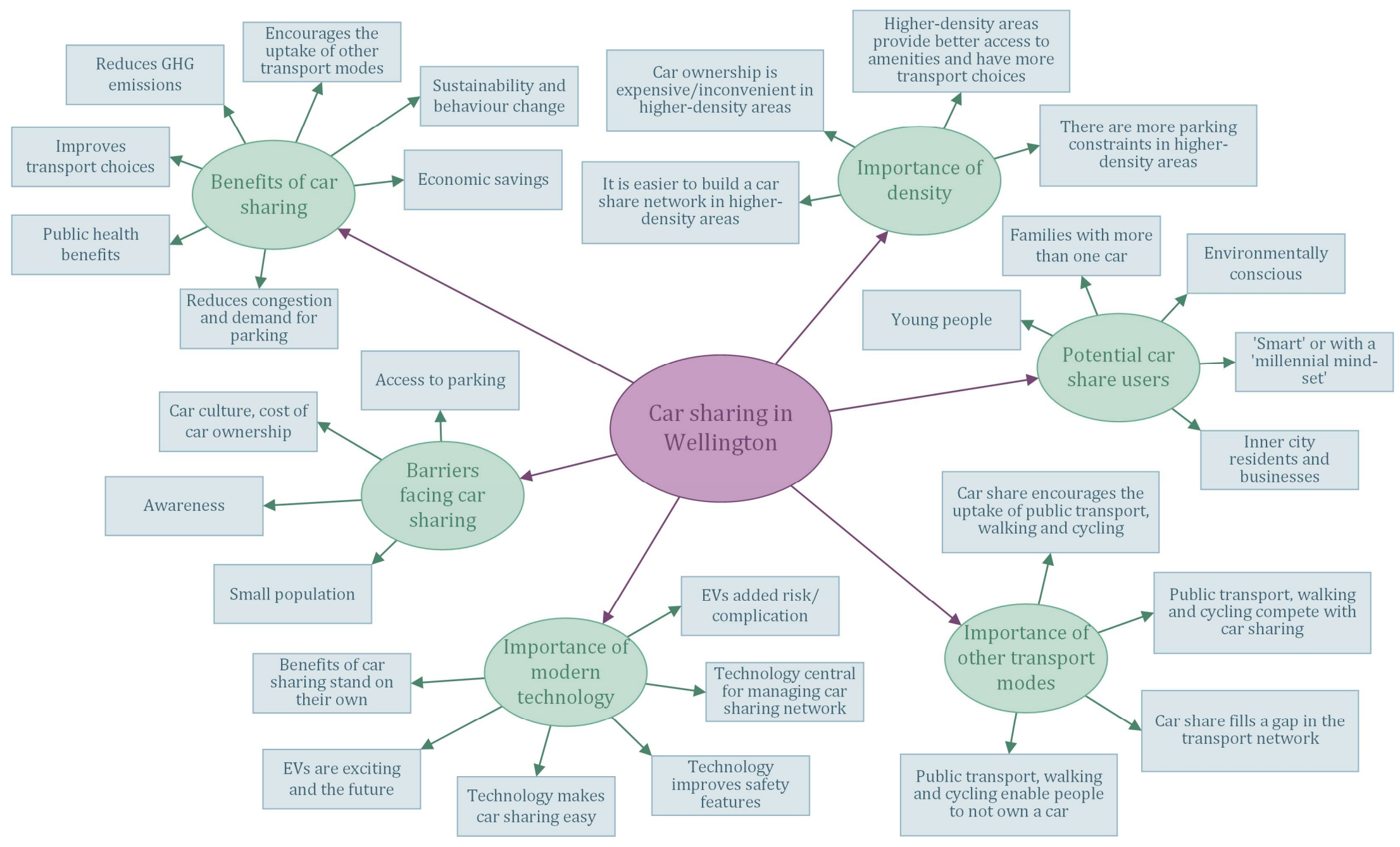


Figure C.2. Thematic map of the results from the open-ended survey questions

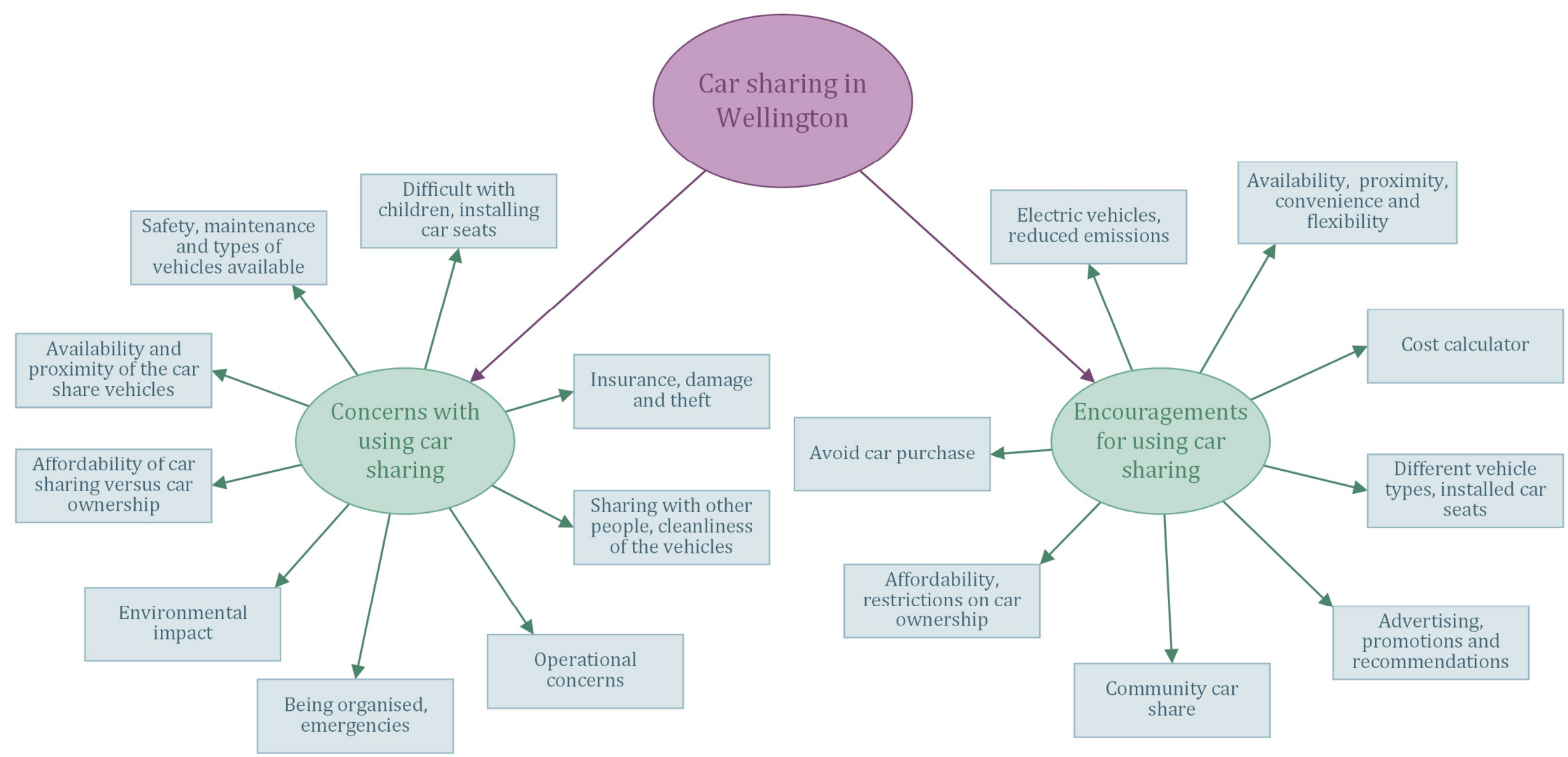


Multinomial regression works better if there are no significant multicollinearity issues. Multicollinearity occurs when two or more independent variables are highly correlated with each other. The following tables present the Tolerance and VIF (Variance Inflation Factor) values for the data. Tolerance values less than 0.1 which equates to a VIF value of 10 or greater - indicates a collinearity problem. The 'offending' variables in the data are highlighted in Table E.2. These variables were removed from the analysis one at a time until no collinearity issues could be identified. Table E.2 shows that there are no longer any collinearity issues after the removal of location, highest qualification and access to a car. It is likely that car use was highly correlated with access to a car, and so the removal of the latter resolved the collinearity issue with car use and it could be kept in the analysis. 
Table E.1. Multicollinearity including all variables

\begin{tabular}{|c|c|c|c|}
\hline Coefficients & & \multicolumn{2}{|c|}{ Collinearity Statistics } \\
\hline \multirow{5}{*}{ Location } & Wellington & 0.083 & 12.061 \\
\hline & Porirua & 0.277 & 3.607 \\
\hline & Lower Hutt & 0.115 & 8.720 \\
\hline & Upper Hutt & 0.392 & 2.549 \\
\hline & Kapiti Coast & 0.375 & 2.665 \\
\hline \multirow{4}{*}{$\begin{array}{l}\text { Household } \\
\text { type }\end{array}$} & Couple with children living at home & 0.278 & 3.600 \\
\hline & Couple without children living at home & 0.420 & 2.381 \\
\hline & Single living alone & 0.541 & 1.849 \\
\hline & Single with children living at home & 0.722 & 1.384 \\
\hline \multirow{3}{*}{ Dwelling type } & High rise apartment & 0.451 & 2.216 \\
\hline & Low rise apartment & 0.594 & 1.685 \\
\hline & Town house & 0.680 & 1.470 \\
\hline \multirow[b]{2}{*}{$\begin{array}{l}\text { Neighbourhood } \\
\text { density }\end{array}$} & Primarily apartments/town houses & 0.393 & 2.541 \\
\hline & $\begin{array}{l}\text { Mix of standalone houses and apartments/town } \\
\text { houses }\end{array}$ & 0.641 & 1.560 \\
\hline \multirow{3}{*}{ Employment } & Paid employment - 20 hours or more per week & 0.176 & 5.678 \\
\hline & Full time tertiary student & 0.263 & 3.803 \\
\hline & Other & 0.381 & 2.621 \\
\hline \multirow{3}{*}{$\begin{array}{l}\text { Personal } \\
\text { income }\end{array}$} & $\$ 0-\$ 25,000$ & 0.291 & 3.439 \\
\hline & $\$ 25,001-\$ 50,000$ & 0.437 & 2.291 \\
\hline & $\$ 50,001-\$ 100,000$ & 0.446 & 2.242 \\
\hline Gender & Gender & 0.810 & 1.235 \\
\hline \multirow{5}{*}{ Age group } & $18-24$ & 0.190 & 5.262 \\
\hline & $25-34$ & 0.122 & 8.166 \\
\hline & $35-44$ & 0.154 & 6.492 \\
\hline & $45-54$ & 0.159 & 6.271 \\
\hline & $55-64$ & 0.281 & 3.559 \\
\hline \multirow{3}{*}{$\begin{array}{l}\text { Highest } \\
\text { qualification }\end{array}$} & High school qualification & 0.092 & 10.861 \\
\hline & Tertiary other & 0.056 & 17.929 \\
\hline & Tertiary degree & 0.041 & 24.536 \\
\hline \multirow{4}{*}{ Access to a car } & All of the time & 0.042 & 23.728 \\
\hline & Most of the time & 0.078 & 12.818 \\
\hline & Mainly in the evenings or weekends & 0.135 & 7.405 \\
\hline & Rarely & 0.139 & 7.187 \\
\hline Car ownership & Car ownership & 0.347 & 2.880 \\
\hline \multirow{3}{*}{ Car use } & Every day of the week & 0.077 & 12.934 \\
\hline & 2-6 days of the week & 0.073 & 13.616 \\
\hline & One day or less a week & 0.128 & 7.831 \\
\hline
\end{tabular}

Table E.2. Multicollinearity without location, highest qualification and access to a car 


\begin{tabular}{|c|c|c|c|}
\hline \multirow[t]{2}{*}{ Coefficients } & & \multicolumn{2}{|c|}{ Collinearity Statistics } \\
\hline & & Tolerance & VIF \\
\hline \multirow{4}{*}{$\begin{array}{l}\text { Household } \\
\text { type }\end{array}$} & Couple with children living at home & 0.292 & 3.423 \\
\hline & Couple without children living at home & 0.450 & 2.222 \\
\hline & Single living alone & 0.576 & 1.737 \\
\hline & Single with children living at home & 0.745 & 1.342 \\
\hline \multirow{3}{*}{ Dwelling type } & High rise apartment & 0.461 & 2.171 \\
\hline & Low rise apartment & 0.621 & 1.611 \\
\hline & Town house & 0.716 & 1.397 \\
\hline \multirow[b]{2}{*}{$\begin{array}{l}\text { Neighbourhood } \\
\text { density }\end{array}$} & Primarily apartments/town houses & 0.414 & 2.415 \\
\hline & $\begin{array}{l}\text { Mix of standalone houses and apartments/town } \\
\text { houses }\end{array}$ & 0.683 & 1.464 \\
\hline \multirow{3}{*}{ Employment } & Paid employment - 20 hours or more per week & 0.186 & 5.389 \\
\hline & Full time tertiary student & 0.280 & 3.575 \\
\hline & Other & 0.398 & 2.512 \\
\hline \multirow{3}{*}{$\begin{array}{l}\text { Personal } \\
\text { income }\end{array}$} & $\$ 0-\$ 25,000$ & 0.312 & 3.203 \\
\hline & $\$ 25,001-\$ 50,000$ & 0.473 & 2.114 \\
\hline & $\$ 50,001-\$ 100,000$ & 0.457 & 2.186 \\
\hline Gender & Gender & 0.874 & 1.145 \\
\hline \multirow{5}{*}{ Age group } & $18-24$ & 0.200 & 4.993 \\
\hline & $25-34$ & 0.130 & 7.701 \\
\hline & $35-44$ & 0.162 & 6.161 \\
\hline & $45-54$ & 0.170 & 5.889 \\
\hline & $55-64$ & 0.293 & 3.410 \\
\hline Car ownership & Car ownership & 0.506 & 1.976 \\
\hline \multirow{3}{*}{ Car use } & Every day of the week & 0.152 & 6.582 \\
\hline & 2-6 days of the week & 0.152 & 6.600 \\
\hline & One day or less a week & 0.241 & 4.147 \\
\hline
\end{tabular}




\section{Parameter estimates}

Table E. 3 shows the contribution of the variables to the model and their statistical significance. As there were three categories of the dependent variable, there are two sets of logistic regression coefficients. The first set of coefficients are found in the 'very interested' row, and represent the comparison of 'very interested' category to the reference category 'not at all interested'. The second set of coefficients are found in the 'somewhat interested' row, and represent the comparison of 'somewhat interested' with the reference category 'not at all interested'. The highlighted lines below show the variables that added significantly to the model/prediction. 
Table E.3. Parameter Estimates

\begin{tabular}{|c|c|c|c|c|c|c|c|c|c|}
\hline \multirow{2}{*}{\multicolumn{2}{|c|}{$\begin{array}{l}\text { Interest in car sharing } \\
\text { (reference category: Not at all interested) }\end{array}$}} & \multirow{3}{*}{\begin{tabular}{|c|} 
B \\
-3.051 \\
\end{tabular}} & \multirow{3}{*}{\begin{tabular}{|c|} 
Std. \\
Error
\end{tabular}} & \multirow{3}{*}{\begin{tabular}{|l} 
Wald \\
2.821 \\
\end{tabular}} & \multirow{3}{*}{$\begin{array}{r}\text { df } \\
1 \\
\end{array}$} & \multirow{3}{*}{$\begin{array}{l}\text { Sig. } \\
0.093\end{array}$} & \multirow{3}{*}{$\operatorname{Exp}(B)$} & \multicolumn{2}{|c|}{ 95\% C.I. for $\operatorname{Exp}(B)$} \\
\hline & & & & & & & & \multirow{2}{*}{$\begin{array}{l}\text { Lower } \\
\text { Bound }\end{array}$} & \multirow{2}{*}{$\begin{array}{l}\text { Upper } \\
\text { Bound }\end{array}$} \\
\hline \multirow{5}{*}{ 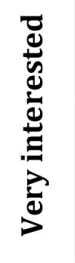 } & Intercept & & & & & & & & \\
\hline & \multicolumn{9}{|c|}{ Household type (reference category: Flat/group living together) } \\
\hline & Couple with children living at home & -0.990 & 0.738 & 1.800 & 1 & 0.180 & 0.372 & 0.087 & 1.578 \\
\hline & Couple without children living at home & 0.032 & 0.603 & 0.003 & 1 & 0.957 & 1.033 & 0.317 & 3.367 \\
\hline & Single living alone & 0.217 & 0.901 & 0.058 & 1 & 0.810 & 1.243 & 0.212 & 7.271 \\
\hline & Single with children living at home & 0.427 & 1.251 & 0.116 & 1 & 0.733 & 1.532 & 0.132 & 17.804 \\
\hline & \multicolumn{9}{|c|}{ Dwelling type (reference category: Standalone house) } \\
\hline & High rise apartment & -0.276 & 1.448 & 0.036 & 1 & 0.849 & 0.759 & 0.044 & 12.971 \\
\hline & Low rise apartment & 0.507 & 1.031 & 0.242 & 1 & 0.623 & 1.661 & 0.220 & 12.539 \\
\hline & Town house & -0.680 & 0.692 & 0.965 & 1 & 0.326 & 0.507 & 0.130 & 1.968 \\
\hline & \multicolumn{9}{|c|}{ Neighbourhood density (reference category: Primarily standalone houses) } \\
\hline & Primarily apartments/town houses & -0.612 & 1.202 & 0.259 & 1 & 0.611 & 0.542 & 0.051 & 5.717 \\
\hline & $\begin{array}{l}\text { Mix of standalone houses and } \\
\text { apartments/town houses }\end{array}$ & 0.344 & 0.552 & 0.389 & 1 & 0.533 & 1.411 & 0.478 & 4.162 \\
\hline & \multicolumn{9}{|c|}{ Employment (reference category: Not in paid employment / Retired) } \\
\hline & $\begin{array}{l}\text { Paid employment - } 20 \text { hours or more per } \\
\text { week }\end{array}$ & 1.665 & 1.364 & 1.491 & 1 & 0.222 & 5.285 & 0.365 & 76.509 \\
\hline & Full time tertiary student & 0.740 & 1.580 & 0.220 & 1 & 0.639 & 2.097 & 0.095 & 46.395 \\
\hline & Other & 3.425 & 1.547 & 4.903 & 1 & 0.027 & 30.711 & 1.482 & 636.451 \\
\hline & \multicolumn{9}{|c|}{ Personal income (reference category: $\$ 100,001+$ ) } \\
\hline & $\$ 0-\$ 25,000$ & 0.932 & 1.000 & 0.868 & 1 & 0.352 & 2.538 & 0.357 & 18.025 \\
\hline & $\$ 25,001-\$ 50,000$ & 0.725 & 0.708 & 1.050 & 1 & 0.305 & 2.066 & 0.516 & 8.272 \\
\hline & $\$ 5 \overline{0}, 0001-\$ 1100,0000$ & 0.974 & 0.580 & 2.822 & 1 & 0.093 & 2.647 & 0.850 & 8.243 \\
\hline & \multicolumn{9}{|l|}{ Gender (reference category: Male) } \\
\hline & Female & -0.086 & 0.422 & 0.041 & 1 & 0.839 & 0.918 & 0.401 & 2.100 \\
\hline & \multicolumn{9}{|l|}{ Age group (reference category: $65+$ ) } \\
\hline & $18-24$ & 0.846 & 1.612 & 0.276 & 1 & 0.599 & 2.331 & 0.099 & 54.871 \\
\hline & $25-34$ & 0.626 & 1.442 & 0.189 & 1 & 0.664 & 1.871 & 0.111 & 31.608 \\
\hline & $35-44$ & 1.157 & 1.432 & 0.652 & 1 & 0.419 & 3.179 & 0.192 & 52.645 \\
\hline & $45-54$ & 0.645 & 1.461 & 0.195 & 1 & 0.659 & 1.906 & 0.109 & 33.408 \\
\hline & $55-64$ & 0.924 & 1.401 & 0.435 & 1 & 0.509 & 2.520 & 0.162 & 39.234 \\
\hline & \multicolumn{9}{|l|}{ Car ownership (reference category: No) } \\
\hline & Yes & -0.796 & 0.664 & 1.438 & 1 & 0.230 & 0.451 & 0.123 & 1.657 \\
\hline & \multicolumn{9}{|l|}{ Car use (reference category: Never) } \\
\hline & Every day of the week & -0.693 & 0.979 & 0.501 & 1 & 0.479 & 0.500 & 0.073 & 3.410 \\
\hline & 2-6 days of the week & 1.066 & 0.915 & 1.357 & 1 & 0.244 & 2.903 & 0.483 & 17.451 \\
\hline & One day or less a week & 1.918 & 0.857 & 5.013 & 1 & 0.025 & 6.805 & 1.270 & 36.468 \\
\hline
\end{tabular}




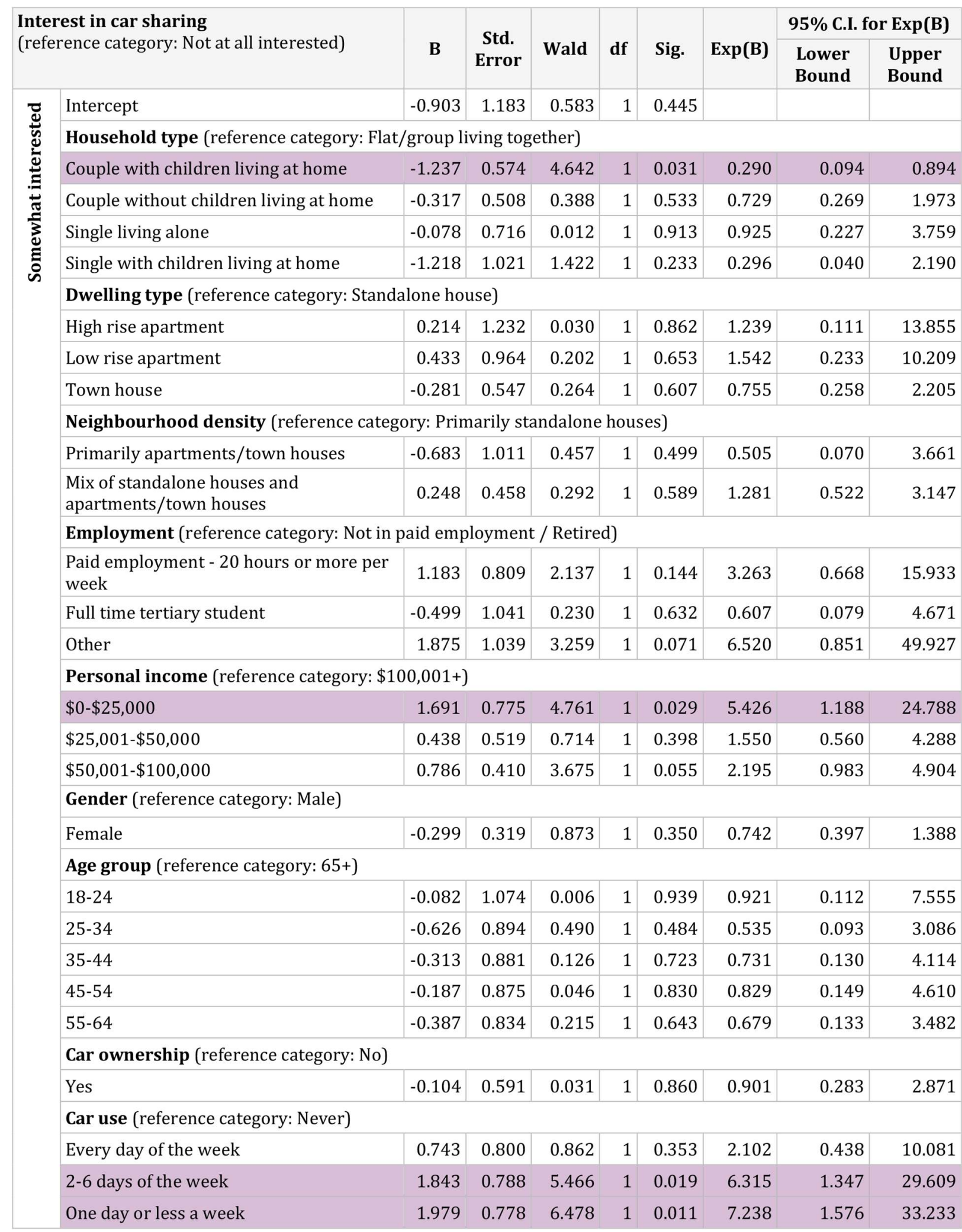


Appendix F Full Metlink fare zone map

Figure F.1. Full Metlink fare zone map, adapted from Greater Wellington Regional Council (2016)

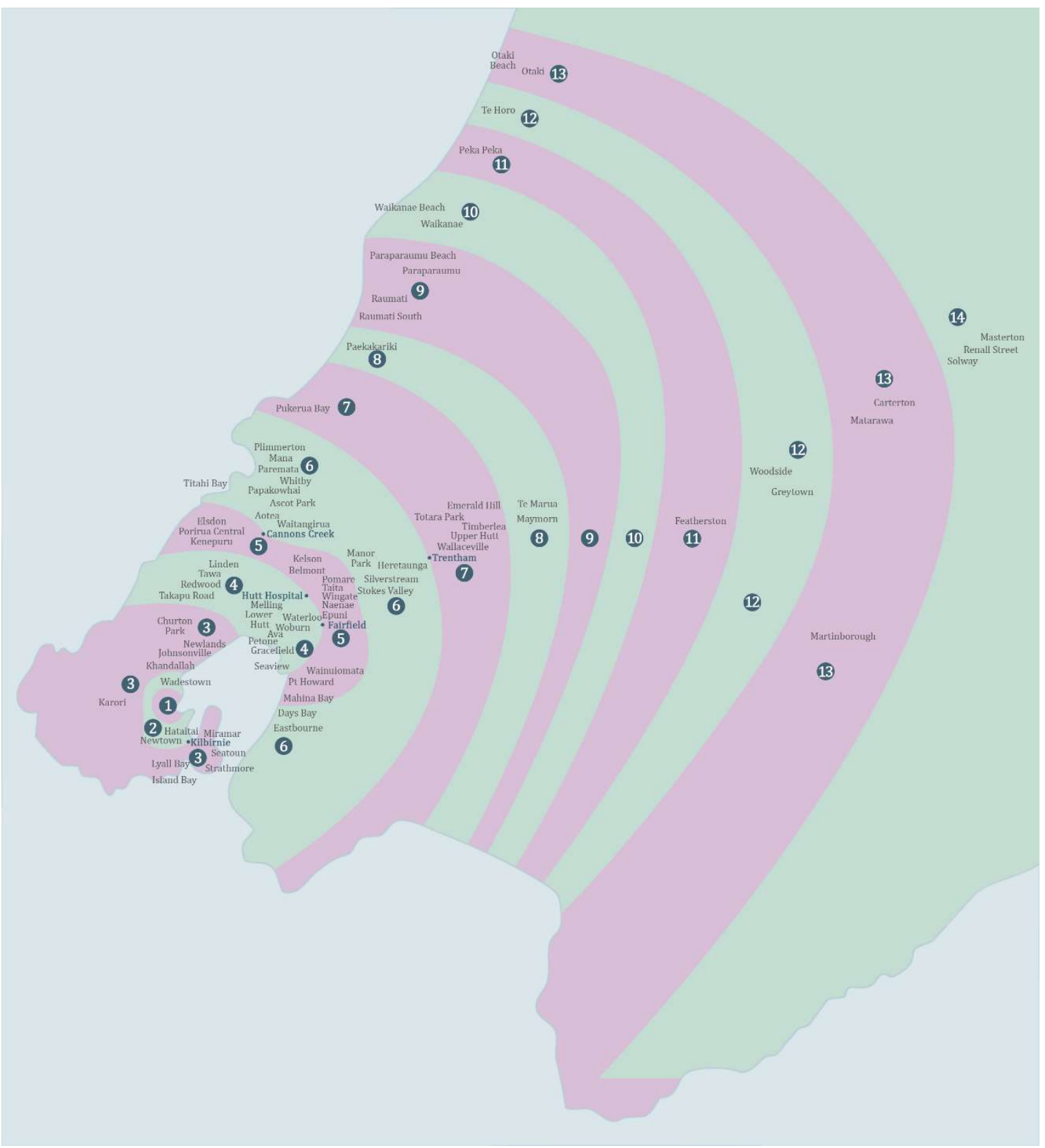

